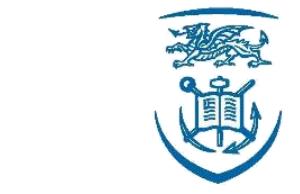

Swansea University

Prifysgol Abertawe

\title{
Renewable Energy from Solar, Biomass and Biofuels Resources
}

\section{Saham Faryd Ibarhiam}

Thesis submitted to Swansea University in fulfilment of the requirements for the Degree of Doctor of Philosophy

September 2020

Copyright: The author, Saham F. Ibarhiam, 2021. 


\section{SUMMARY}

In the current study, the waste stones and rachis obtained from Barhee and Medjool dates palm trees were characterized on a laboratory scale and their potential as biomass feedstock were investigated. The proximate, ultimate, structure/composition and thermo-gravimetric analysis experiments were conducted to characterize the selected biomass materials. The results showed that the Medjool and Barhee stones are a promising biomass feedstock as they have high volatile and fixed carbon contents with low ash content. Moreover, they have high carbon and nitrogen contents with a very high cellulose contents reaching up to $66 \%$ in the case of Barhee stones. The thermogravimetric analysis showed that the decomposition of Barhee and Medjool stones can be completed below $420{ }^{\circ} \mathrm{C}$; while it can be completed below $360{ }^{\circ} \mathrm{C}$ for Barhee and Medjool rachis under thermo-gravimetric pyrolysis analysis. Based on the TGA results obtained, slow pyrolysis experiments for the stones and rachis feedstock materials were conducted. Among the four slow pyrolysis trials, maximum yield for bio-oil of 21.54\% was achieved when Barhee rachis was used, while Medjool rachis produced the least value. Characterization and analysis of the bio-oil extracted from the pyrolysis experiments showed the superiority of the bio-oil from Barhee stone as it has the highest heating value. The gas chromatography mass spectrometry analysis showed that phenol, furfural and benzoic acid are the main components of the bio-oil obtained from the date palm rachis samples while d-allose, furfural, 5-methyl 2furancarboxaldehyde, and dodecanoic acid are the main components of the bio-oil extracted from the date palm stones. The opportunities of exploitation of renewable energy with solar, biomass and biofuels resources in the Middle East, are also reviewed in detail in this work. The techno-economic analysis for the concentrating solar power plants installed in the Middle East showed promising potential from the economic and technical point of view. 


\section{DECLARATION AND STATEMENTS}

\section{DECLARATION}

This work has not previously been accepted in substance for any degree and is not being concurrently submitted in candidature for any degree.

Signed

(candidate)

Date ..3.0/1.9.1.20.20

\section{STATEMENT 1}

This thesis is the result of my own work and investigation, except where otherwise stated. Where correction services have been used, the extent and nature of the correction is clearly marked in a footnote(s).

Other sources have been acknowledged by giving explicit references. A bibliography is appended.

Signed (candidate)

Date 3... 1.9 .1 .2 .0 .20

\section{STATEMENT 2}

I hereby give consent for my thesis, if accepted, to be available for photocopying and for inter-library loan, and for the title and summary to be made available to outside organisations.

Signed (candidate)

Date $30 / 91.2020$

NB: Candidates on whose behalf a bar on access has been approved by the University (see Note 7), should use the following version of Statement 2.

I hereby give consent for my thesis, if accepted, to be available for photocopying and for inter-library loans after expiry of a bar on access approved by the Swansea University.

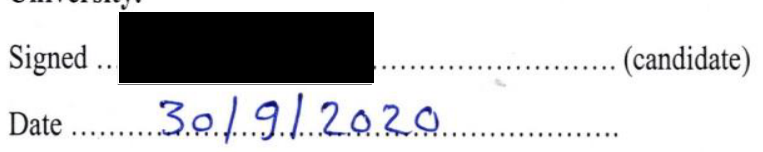




\section{ACKNOWLEDGEMENTS}

I would like to express my ultimate gratitude and special appreciation to my supervisor Dr. James Titiloye for his continuous inspirational guidance, motivation, encouragement and for giving suggestions and showing the right direction throughout the entire period of my study.

I would also like to thank Dr. Geraint Sullivan, Dr. Peter Douglas and Dr. Katherine Hopper for their help.

I sincerely appreciate Mr. Ian Matthews and all technicians and engineers for their help in the chemical lab.

I truly thank Tabuk University and Saudi Arabia cultural Bureau in the UK for their support and continuous help to pursuit my academic degree.

I would also like to express my appreciation to my parents for giving me support that I needed to achieve my goals and unlimited encouragement and their endless love throughout my study. Also, a great appreciation to my sisters, brothers and family.

My thanks and appreciation also go to my friends for their motivation and support during this work. 


\section{TABLE OF CONTENTS}

SUMMARY

DECLARATION AND STATEMENTS Error! Bookmark not defined.

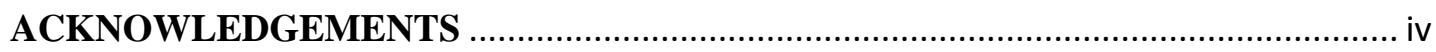

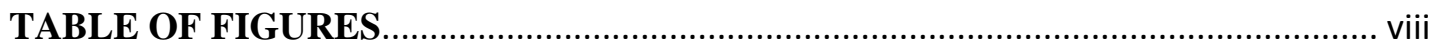

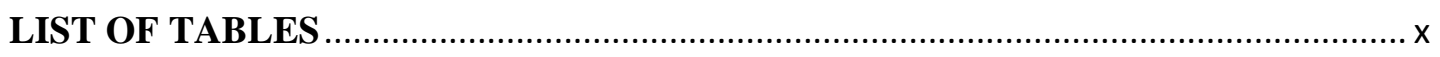

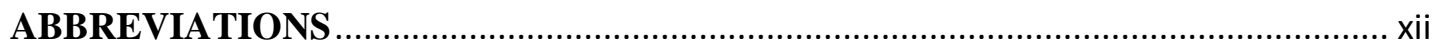

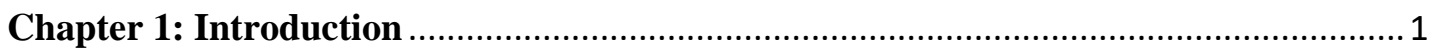

1.1 Agricultural residues in Saudi Arabia and Middle East ................................. 1

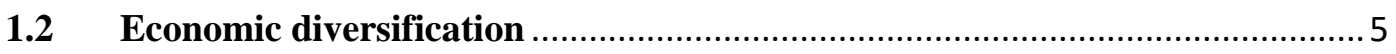

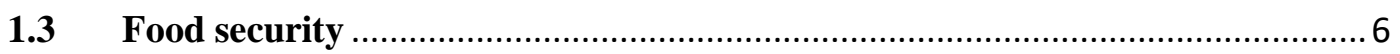

1.4 Biomass conversion techniques (biological and thermal) ................................ 7

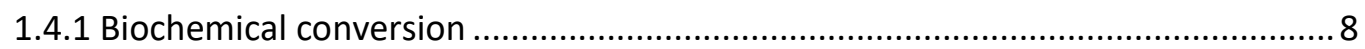

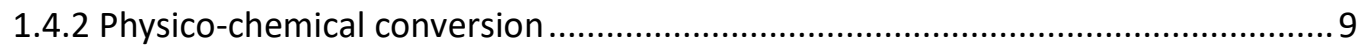

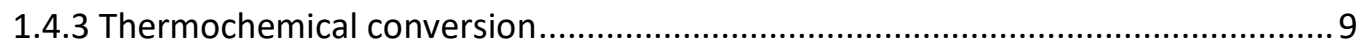

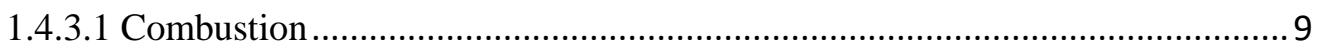

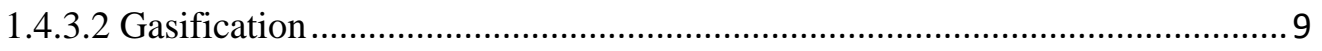

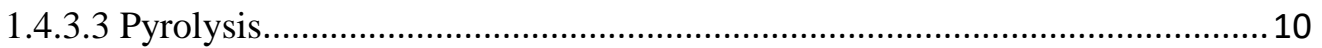

1.5 Feedstock: Date Palm Wastes (Varieties and Selection) …............................. 11

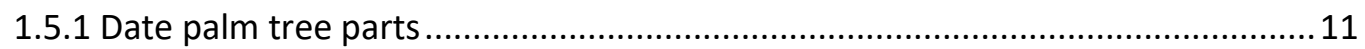

1.5.2 The products, by-products and residues of date palm tree ................................ 15

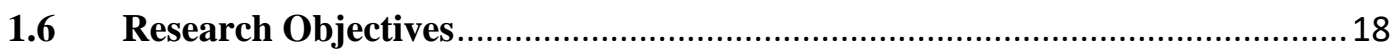

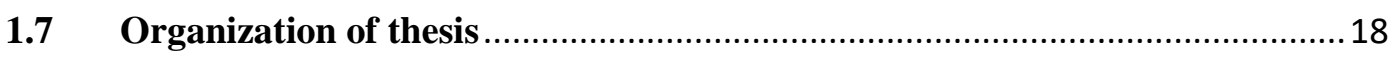

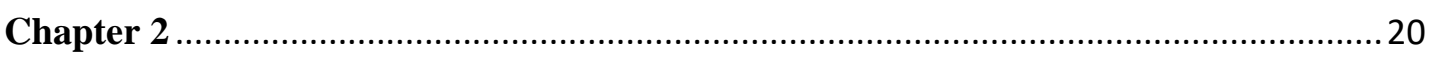

Literature Review on Biomass and Pyrolysis of Biomass .............................................. 20

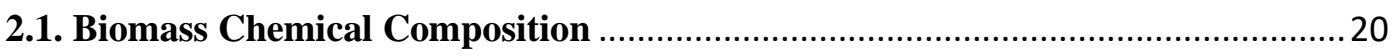

2.2. Introduction to pyrolysis process of biomass …….................................................. 25

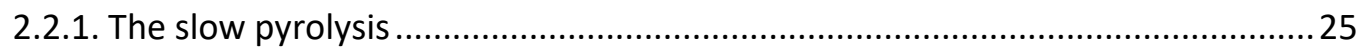

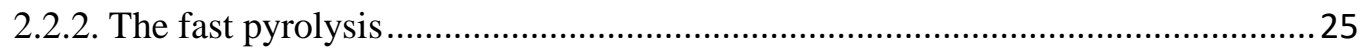

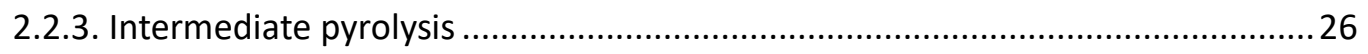

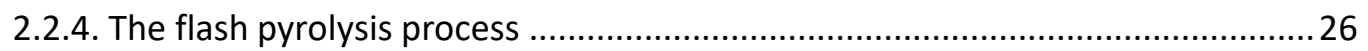

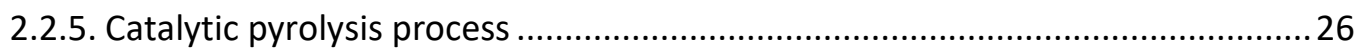


2.2.6. Comparison between the slow and fast pyrolysis .............................................28

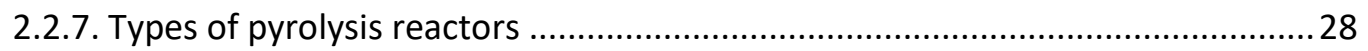

2.2.8. The effect of temperature and heating rate on the pyrolysis yield...................... 30

2.3. Biomass feedstock and Pyrolysis review ............................................................. 30

2.3.1. Review of the pyrolysis of different biomass materials....................................... 31

2.3.2. Literature review on biofuel production from date palm wastes ........................ 34

2.3.2.1. The products of the date palm waste pyrolysis ............................................ 40

2.3.2.1.1. Characterization of the pyrolysis bio-oil................................................. 40

2.3.2.1.2. Characterization of the bio-char........................................................ 42

2.3.2.1.3. The composition of non-condensable gases (syngas) ............................ 44

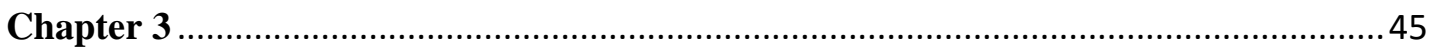

Thermochemical characterisation of biomass and bio-oil............................................. 45

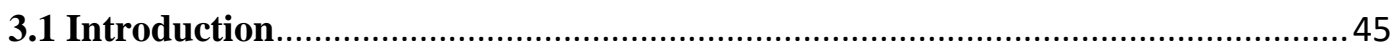

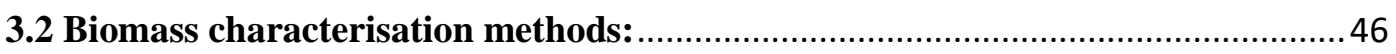

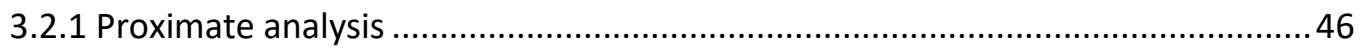

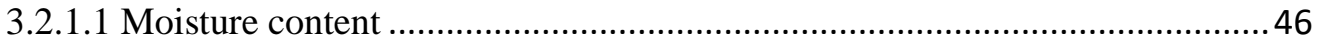

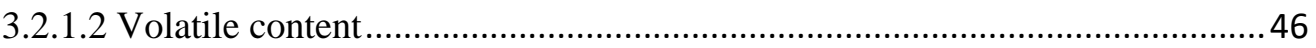

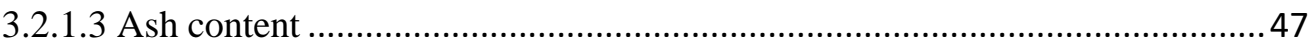

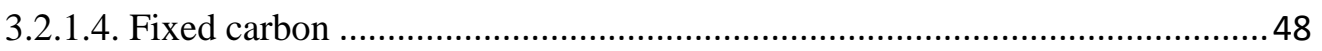

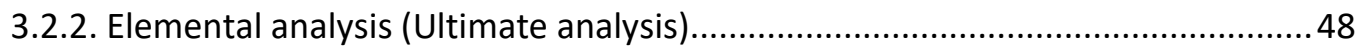

3.2.3. Structure/Composition Analysis .................................................................. 48

3.2.3.1. The Compositional Pelican Method............................................................... 48

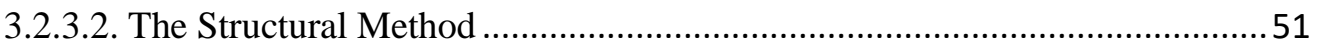

3.2.3.3. Structural Analysis - Klason Lignin Determination (small scale method) ...52

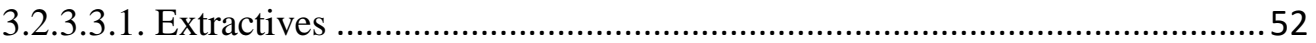

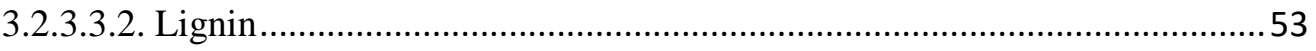

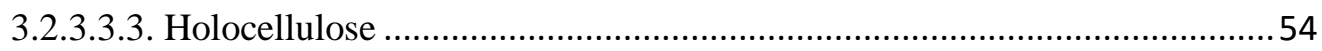

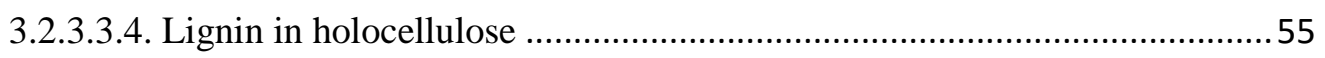

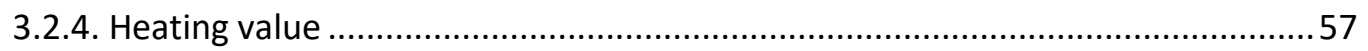

3.2.4.1. The Theoretical Calculation of HHV ……............................................... 57

3.2.4.2. The Experimental Calculation of HHV (Bomb calorimeter C200M/2/006

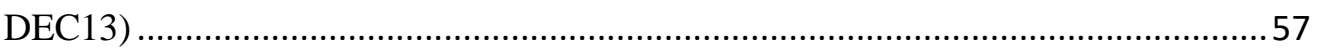

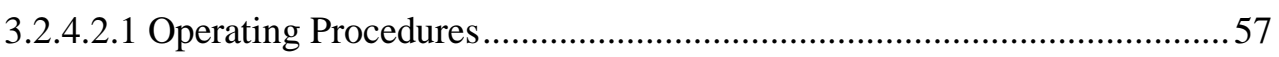

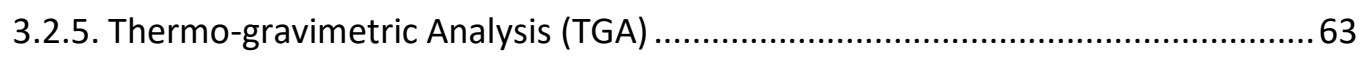

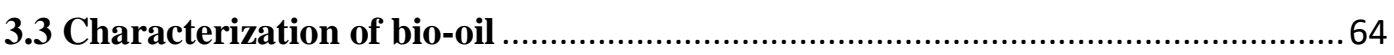




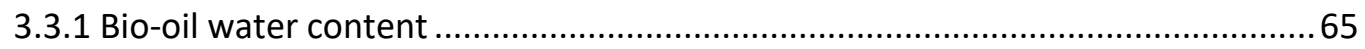

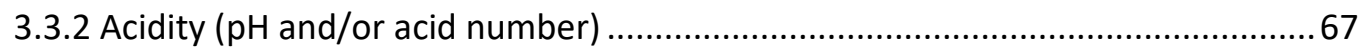

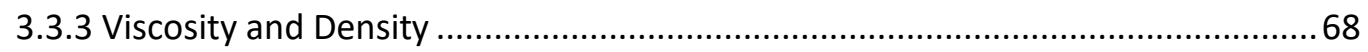

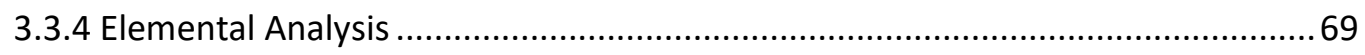

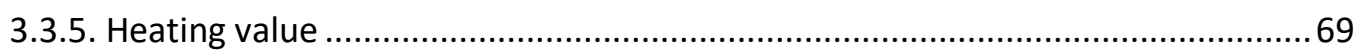

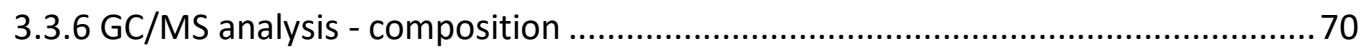

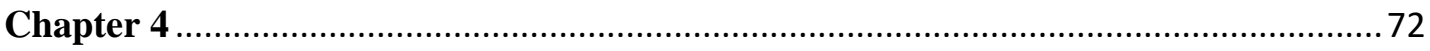

Thermochemical characterisation of Date palm fruit wastes ........................................ 72

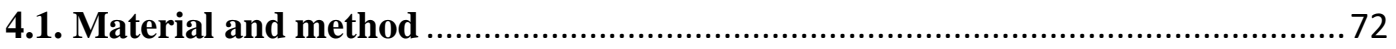

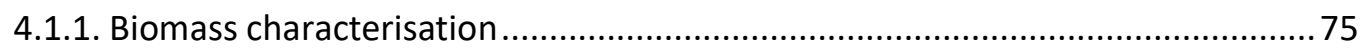

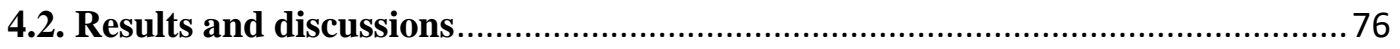

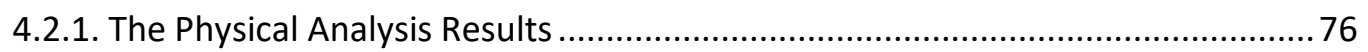

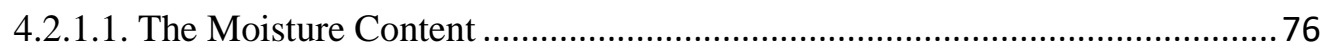

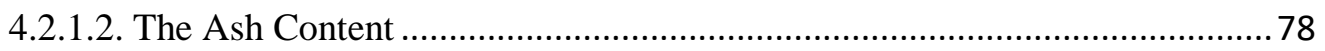

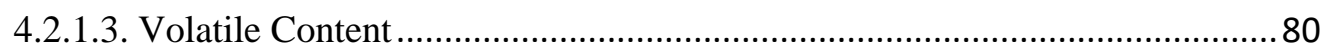

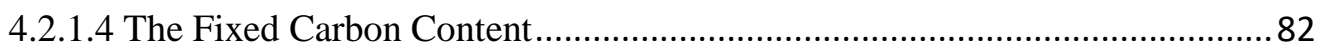

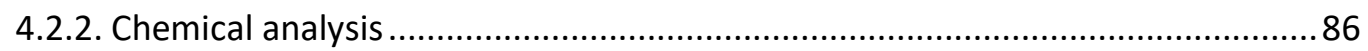

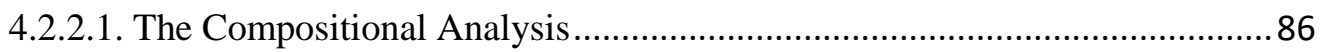

4.2.2.2. The Klason Measurement Results ............................................................... 88

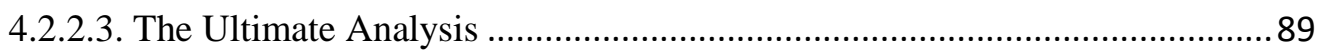

4.2.2.4. Comparisons of HHV Obtained via Various Routes .....................................91

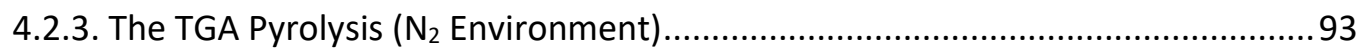

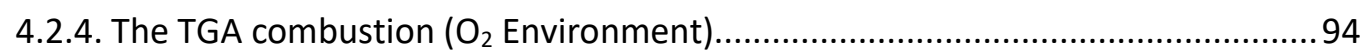

4.2.5. The TGA and DTG Analysis (Overall Comparison)......................................... 96

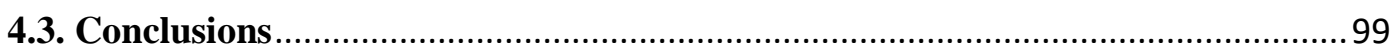

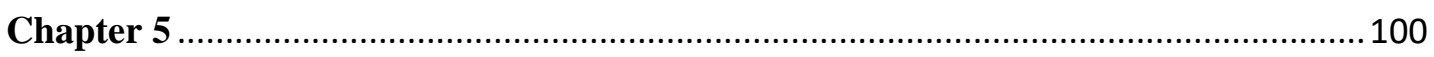

Slow pyrolysis studies of Date Palm Fruit Wastes ........................................................100

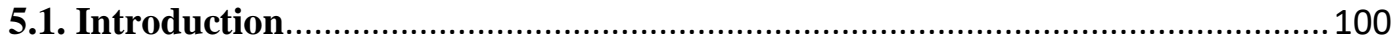

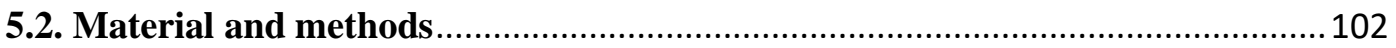

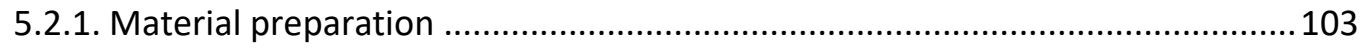

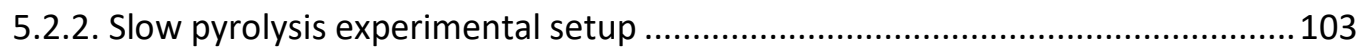

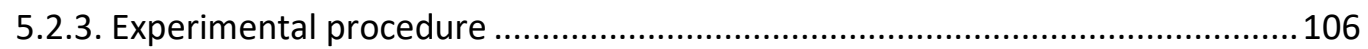

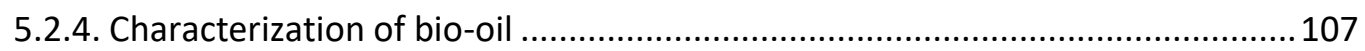

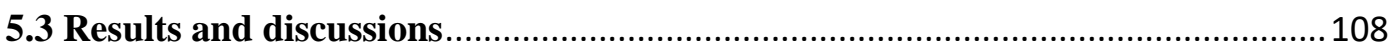


Techno-economic Analysis of hybrid solar-biomass energy in the Middle East.

6.1 Availability and current status of hybrid solar-biomass development in the Middle East

6.2 Review on Solar thermal Energy plants

6.3 Review on Biomass energy plant

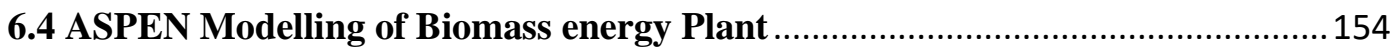

6.4.1 Aspen plus modeling of biomass pyrolysis energy plant ..................................154

6.5 Simulation of date palm wastes slow pyrolysis using Aspen Plus ........................158

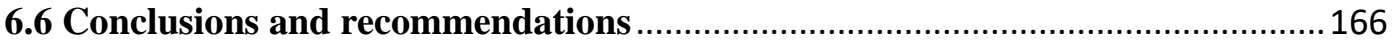

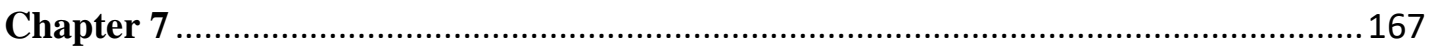

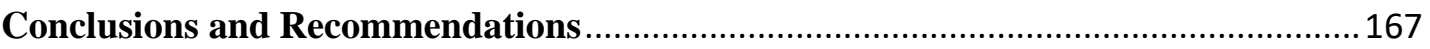

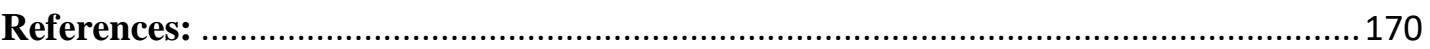

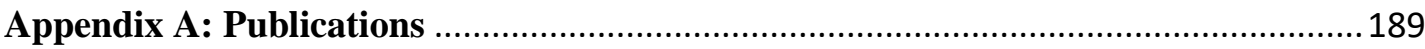

\section{TABLE OF FIGURES}

Fig. 1. 1. The most produced agriculture commodities of KSA in 2018 [5] ...............................2

Fig. 1. 2. The top 10 producers of dates (production in 2018) [5] . .............................................3

Fig. 1. 3. Biomass conversion processes [2] ...................................................................8

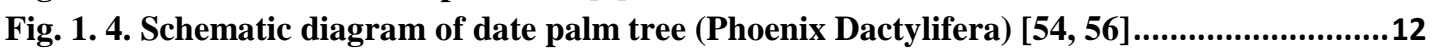

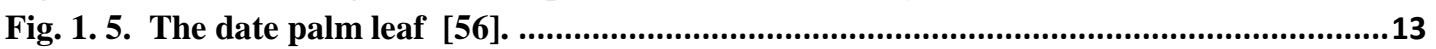

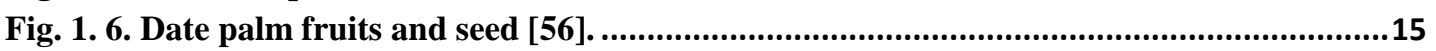

Fig. 1. 7. The products and residues of the date palm tree...................................................17

Fig. 2. 1. The structure of cellulose, hemicellulose and lignin [73]...........................................21

Fig. 2. 2. The several categories of pyrolysis processes [99] ................................................27

Fig. 2. 3. Types of pyrolysis reactors, (a) stirred tank reactor, (b) fixed bed reactor, (c) fluidized bed reactor, (d) conical spouted bed reactor $($ CSBR), (e) screw or rotary reactor [126]. ...29

Fig. 3. 1. An illustration of the NDF determination of the rachis (left) and stone (right) samples.

Fig. 3. 2. An illustration of the ADL determination of the stone (left) and rachis (right) samples 
Fig. 3. 3. An illustration of the Ash content determination of the stone (left) and rachis (right) samples.

Fig. 3. 4. An illustration of the Soxhlet extractor utilised in the experiment. ............................51

Fig. 3. 5. (a) Alkali extractives sample, (b) Alkali extractives sample $+72 \%$ sulphuric acid after

2 hours and, (c) Alkali extractives sample $+72 \%$ sulphuric acid after dry .....................53

Fig. 3. 6. The holocellulose wash with acetone. ...................................................................55

Fig. 3. 7. (a) Holocellulose sample and $72 \%$ sulfuric acid, (b) Lignin in holocellulose at $20{ }^{\circ} \mathrm{C}$, (c)

Lignin in holocellulose after dry, (d) a-cellulose sample and $17.5 \% \mathrm{NaOH}$, (e) A-cellulose

sample at $20{ }^{\circ} \mathrm{C}$ and, (f) a-cellulose sample after dry..................................................56

Fig. 3. 8. The various parts of the Bomb Calorimeter...........................................................58

Fig. 3. 9. The pellet press used to prepare the solid samples...................................................59

Fig. 3. 10. The crucible holder used in the experiment. .......................................................61

Fig. 3. 11. The procedure of set up the water jacket for the experiment. ................................62

Fig. 3. 12. The 870 Volumetric Karl Fischer Titrator. ...........................................................65

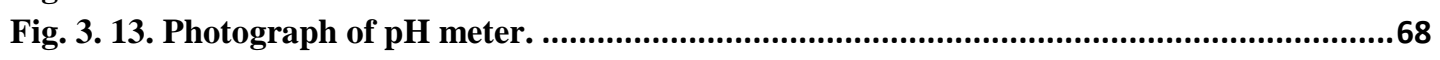

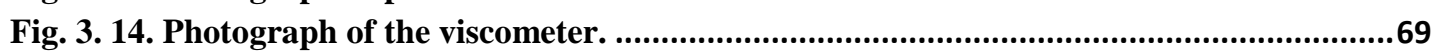

Fig. 3. 15. Clarus 680 GC connected to Clarus 600 T MS......................................................70

Fig. 3. 16. Bio-oil samples prepared for the GC-MS analysis. ................................................71

Fig. 4. 1. The Medjool tree and fruit (left) and the Barhee tree and fruit (right).....................72

Fig. 4. 2. The ground samples of the Medjool (left) and Barhee (right) Rachis and stones.........74

Fig. 4. 3. (a) Comparison between moisture contents of Barhee and Medjool stones, (b) comparison between moisture contents of Barhee and Medjool rachis.

Fig. 4. 4. (a) Comparison between ash contents of Barhee and Medjool stones, (b) comparison between ash contents of Barhee and Medjool rachis.

Fig. 4. 5. (a) The volatile content in Barhee and Medjool stone samples, (b) volatile content in Barhee and Medjool rachis samples.

Fig. 4. 6. (a) The fixed carbon content in Barhee and Medjool stones samples, (b) The fixed carbon content in Barhee and Medjool rachis samples.

Fig. 4. 7. The compositional analysis of the Medjool and Barhee stone samples. .......................87

Fig.4. 8. The compositional analysis of the Medjool and Barhee rachis samples. ......................87

Fig. 4. 9. The results obtained from Klason method for the Barhee and Medjool stones and

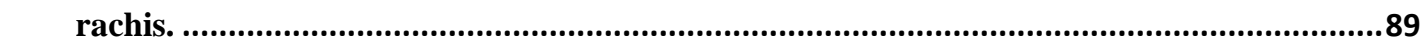

Fig. 4. 10. The TGA Pyrolysis curves for the Barhee and Medjool Rachis.................................93

Fig. 4. 11. The TGA Pyrolysis curves for the Barhee and Medjool Stone. ..................................94

Fig. 4. 12. The TGA Combustion curves for the Barhee and Medjool Rachis.............................95

Fig. 4. 13. The TGA pyrolysis curves for the Barhee and Medjool stone. ..................................95

Fig. 4. 14.The TGA Pyrolysis (a) and Combustion (b) curves for all Barhee and Medjool Rachis and stones.

Fig. 4. 15. The DTG Pyrolysis (a) and Combustion (b) curves for the Barhee and Medjool rachis and stones.

Fig. 5. 1. Stone and Rachis samples

Fig. 5. 2. Photograph of the slow pyrolysis experiment setup (a), Schematic diagram of the slow pyrolysis experiment setup (b).

Fig. 5. 3. The bio-oil and char collected from the slow pyrolysis of Barhee and Medjool rachis and stone.

Fig. 5. 4. GC-MS of Barhee rachis bio-oil. ....................................................................121

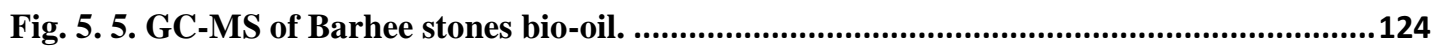

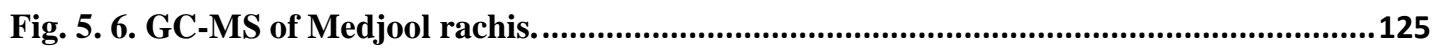

Fig. 5. 7. GC-MS of Medjool stone bio-oil...................................................................128 
Fig. 6. 1. The solar thermal power plant $[232,233]$.

Fig. 6. 2. A schematic diagram of the different parts of the solar thermal power plant including

the different strategies of solar field and power cycle [232]. .......................................136

Fig. 6. 3. 10 MW ST plant located at Seville, Spain [234] ..................................................138

Fig. 6. 4. Hybrid CSP-Wind power plant diagram [252]. .................................................146

Fig. 6. 5. Flow chart of the computational algorithm of the CSP on SAM software [249]. .......149

Fig. 6. 6. Schematic of the BIG/GT plant $[258]$............................................................... 151

Fig. 6. 7. Schematic of the EFGT/CC plant [258].......................................................... 152

Fig. 6. 8. Multi-step reactions kinetics of biomass pyrolysis [268] .......................................155

Fig. 6. 9. Aspen plus flow sheet of the biomass fast pyrolysis for electric power generation [267].

Fig. 6. 10. Photograph from Aspen plus simulation for components setup. .............................159

Fig. 6. 11. Photograph from Aspen simulation for biomass specifications. ..............................159

Fig. 6. 12. Photograph from Aspen simulation for nitrogen specifications...............................160

Fig. 6. 13 (a) Photograph from Aspen simulation for the proximate analysis of Medjool stones,

(b) Photograph from Aspen simulation for the ultimate analysis of Medjool stones. .......160

Fig. 6. 14. Photograph from Aspen for the simulation flow sheet..........................................161

Fig. 6. 15. Photograph from Aspen simulation for chemical reactions in R-batch reactor.......162

Fig. 6. 16. Photograph from Aspen simulation for the pyrolysis yields. ...................................164

Fig. 6. 17. Photograph from Aspen for the pyrolysis products components............................165

\section{LIST OF TABLES}

Table 1. 1. The estimated amounts of waste in KSA. 2

Table 1. 2. The amount of agriculture residues burned in the ME [5]. ..................................4

Table 2. 1. Comparison between the chemical composition of several date palm wastes and other biomass materials.

Table 2. 2. The biomass materials recently studied for biofuel production by pyrolysis process 33

Table 2. 3. Elemental composition of date palm wastes (weight basis) ........................................35

Table 2. 4. The pyrolysis product obtained from different date palm wastes in wet basis..........39

Table 2. 5. Ultimate analysis of the bio-oil obtained from the pyrolysis of date palm wastes compared with other agricultural wastes.

Table 2. 6. The elemental analysis of the bio-char obtained from different palm tree parts on wet basis.

Table 2. 7. The chemical composition of syngas obtained from the pyrolysis of several date palm wastes.

Table 3. 1. An overall comparison between the TGA pyrolysis and combustion.

Table 4. 1.The general distinguishing characteristics of the Barhee and Medjool tree and fruit

Table 4. 2. The moisture contents of Medjool and Barhee stones and rachis.............................76

Table 4. 3. Ash contents of Medjool and Barhee stones and rachis. ...........................................78

Table 4. 4. Volatile contents of Medjool and Barhee stones and rachis.....................................80

Table 4. 5. Fixed carbon content in Barhee and Medjool stones and rachis..............................82 
Table 4. 6. An overall average comparison for all samples examined in the current study for the stones and rachis.

Table 4. 7. The physical analysis results $(60$ mesh size) compared to literature studies..............85

Table 4. 8. Compositional analysis results of Barhee and Medjool stones and rachis ................86

Table 4. 9. The results obtained from Klason method for the Barhee and Medjool rachis and stones.

Table 4. 10. The results of the ultimate analysis obtained from the current work alongside literature studies. .90

Table 4. 11. The theoretical and practical values of HHV obtained from various sources.

Table 5. 1. The yield of slow pyrolysis of Barhee and Medjool date palm stone and rachis compared with similar results in the literature.

Table 5. 2. Physical and chemical properties of bio-oil.

Table 5. 3. The water content of the bio-oil produced from Barhee and Medjool stone and rachis

Table 5. 4. The ultimate analysis of the bio-oil extracted from slow pyrolysis of Barhee and Medjool date palm stones and rachis compared with similar results in the literature. ....115

Table 5. 5. GC-MS of Barhee rachis bio-oil. .120

Table 5. 6. GC-MS of Barhee stones bio-oil. ......................................................................122

Table 5. 7. Medjool Rachis chemical composition............................................................125

Table 5. 8. Chemical composition of Medjool stones. ..........................................................127

Table 6. 1. The data of Tamanrasset, Bechar, Ghardia and Alger sites [241]........................140

Table 6. 2. The LCOE of different configurations [244] ......................................................142

Table 6. 3. The design parameters of the molten salt and DSG ST plants [251]. .....................145

Table 6. 4. The CSP plants based on PTC and ST. ........................................................147

Table 6. 5. The pyrolysis yields.............................................................................................164

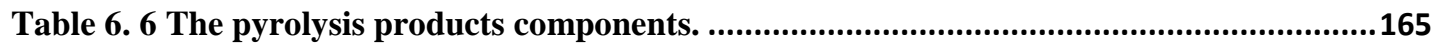




\section{ABBREVIATIONS}

ADF

ADL

CSP

C.C

DP

DPG

DPL

DPR

DPW

DTG

DSG

EES

EFB

EFGT/CC

FBS

FC

GC-MS

GCV

GT

H.E.

HHV

HPGT

HRSG

HTF

LCOE

LFR

NDF

NREL

PTC

$\mathrm{S}_{\mathrm{i}}$

SAM
Determination of the acid detergent fibre

Acid detergent lignin

Concentrating solar power

Combustion chamber

Degree of polymerization

Date palm Glaich

Date palm leaflets

Date palm rachis

Date palm waste

Derivative thermo-gravimetric graph

Direct steam generation

Engineering equation solver software

Empty fruit bunches

externally fired gas turbine combined cycle

Fuel backup system

Fixed carbon

Gas chromatography- mass spectroscopy

Gross calorific value

Gas turbine

Heat exchanger

Higher heating value

High-pressure gas turbine

Heat recovery steam generator

Heat transfer fluid

Levelized cost of electricity

Linear Fresnel reflector

Neutral detergent fibre

National renewable energy laboratory

Parabolic trough collector

Sample number (i)

System advisor model software 
ST

STP

TES

TGA

$\mathrm{VM}$

WC
Solar tower

The solar thermal power

Thermal energy storage

Thermo-gravimetric analysis

Volatile matter

Water content 


\section{Chapter 1: Introduction}

\subsection{Agricultural residues in Saudi Arabia and Middle East}

The Kingdom of Saudi Arabia (KSA) spreads over an area of 2.15 million $\mathrm{km}^{2}$ which is considered the largest country in the Middle East [1]. It is located between $16^{\circ} 20$ $16^{\circ} 22^{\prime}$ and $32^{\circ} 14^{\prime}$ North Latitudes and $34^{\circ} 29^{\prime}$ and $55^{\circ} 40^{\prime}$ East Longitudes [2-4]. The KSA is considered one of the most arid countries of the Arabian Peninsula, and presents restricted agricultural growth as it has large desert land, scarce water resources, high temperatures and low rainfall [1]. This desert climatic nature matches the growing of date palm (Phoenix dactylifera L.), where the KSA total production of dates in 2018 was 1,302,859 tons, harvested from more than 25 million palm trees, distributed in 116,125 hectare [5]. Date palm is an important element of the flora in all Arab countries and plays a significant role in economic, social, and cultural life in the region. A massive quantity of waste results annually from the seasonal pruning of the date palm trees. Where, the annual residues from palm trees in KSA are estimated to be one million tons [6]. These residues include leaves, fruit stalk pruning, and date stones.

The fruits, cereals, wheat, grains, barley, vegetables, watermelon, and potatoes are also of great production in the KSA as they reported as the most produced agriculture commodities of KSA in 2018 as shown in Fig. 1. 1. The KSA has also 977,000 hectares of forest area where $254,000 \mathrm{~m}^{3}$ of round wood were produced in 2011. Most of this production of wood was used in industry of paper and paper board [7].

In addition to date palm residues, the wheat straw residues is also of great amount in KSA. Limited amount of these residues was used as raw materials for wood industries [8]. While, the majority of wheat residues was burned which reached 38,607 tons during 2018 [5]. The total agriculture wastes in KSA are estimated to be 3.5 Million tons which is considered $19.7 \%$ as reported in Table 1.1 [9].

The possibilities of energy production from these agriculture waste in KSA were also investigated but still at experimental scales [10]. While, most of these residues were burnt as in most of developing countries. Accordingly, the KSA government has launched a new policy of vision 2030 with an objective to seek 
sustainable solutions for the waste management to minimize the waste-disposal issues and generate economic benefits [11-13]. The conversion of agriculture wastes to biofuel is considered one of the best solutions from the economic benefits point of view.

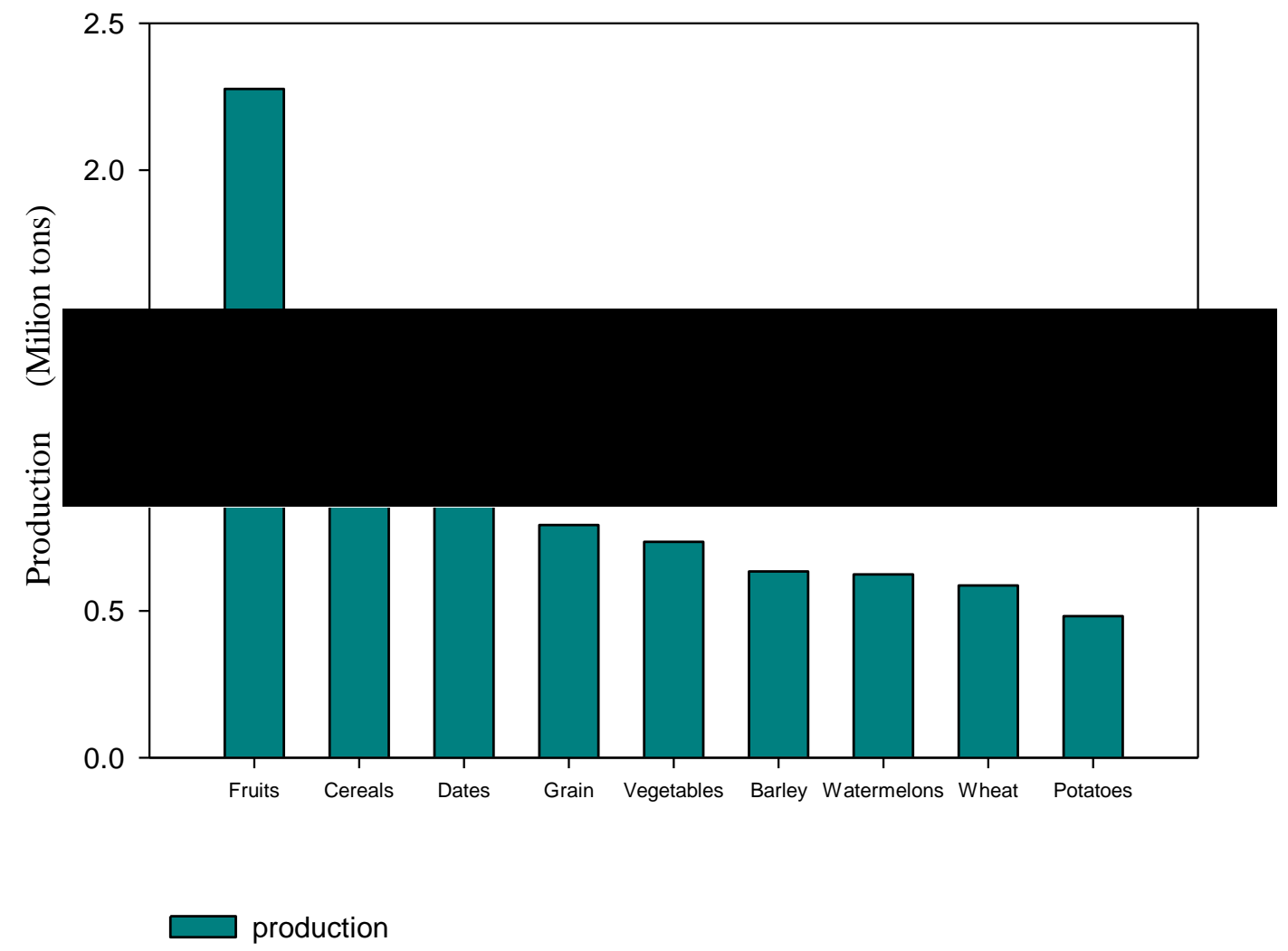

Fig. 1. 1. The most produced agriculture commodities of KSA in 2018 [5].

Table 1. 1. The estimated amounts of waste in KSA.

\begin{tabular}{ll}
\hline The waste source & The estimated amount (Million tons) \\
\hline Municipal solid waste & 10.5 \\
Agricultural residues & 3.5 \\
Forestry residues & 0.5 \\
Agro-industrial residues & 0.8 \\
Sewage & 2.5 \\
Total waste & 17.8
\end{tabular}


Egypt, Turkey and Iran are in the top of the Middle East (ME) in the agriculture production of rice, wheat, maize, coarse grain, vegetable and fruits. [5]. These three countries are ranked within the top twenty in the production of vegetables and fruits around the world.

Moreover, Egypt, KSA, and Iran are respectively considered the top three countries of the world in the production of date palm. The largest production of dates is in Egypt, where its production has increased from 1,006,710 tons in 2000 to 1,562,171 tons in 2018. While, the production of KSA and Iran in 2018 were 1,302,859 and 1,204,158 tons, respectively. Iraq, Oman and United Arab of Emirates (UAE) are also mentioned in the top ten producer in the world with production of 614584, 368808, and 345119 tons in 2018 as shown in Fig. 1. 2 [5].

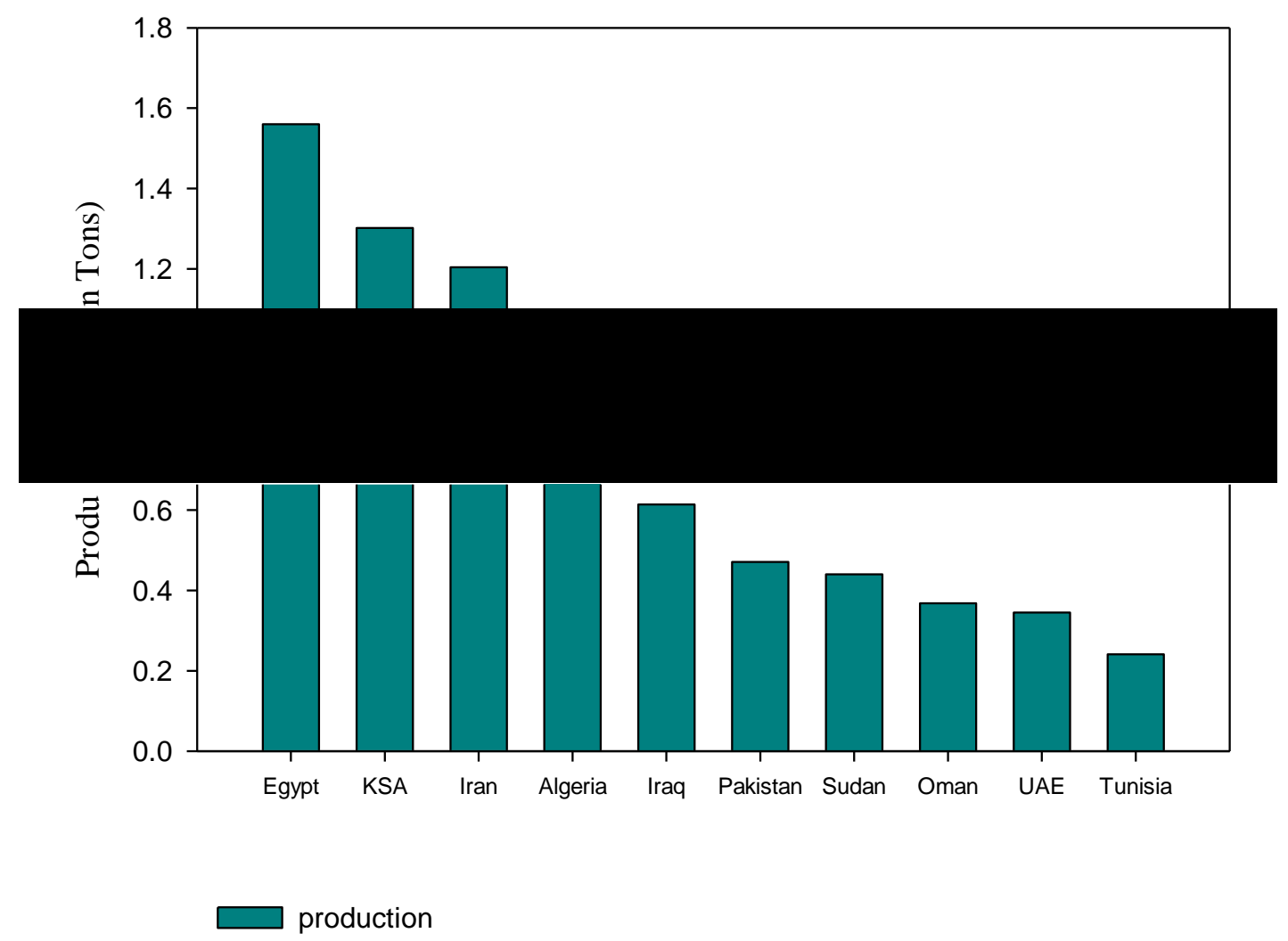

Fig. 1. 2. The top 10 producers of dates (production in 2018) [5]. 
This massive production of dates, rice, wheat, maize, sugar cane and wood in the ME results in huge amounts of agriculture wastes where it reaches 3 million tons/year in Egypt only [14]. Some of these wastes such as the residues of wheat are disposed by simple process of converting to animals feeds. While, most of the other residues are burned as reported in Table 1.2 [5].

Among the agriculture residues, the disposal of rice residues causes an environmental problem especially in Egypt and Iran, where it is mostly burned causing the known black cloud. Table 1.2 shows the huge amount of rice residues burned in Egypt and Iran [5]. The problem of the disposal of rice residues (rice husk and straw) is mainly due to the difficulties of converting it to animals feeds compared with wheat residues in addition to the farmers believe in its benefits for the land when it is burned.

Table 1.2. The amount of agriculture residues burned in the ME [5].

\begin{tabular}{llllllll}
\hline \multirow{2}{*}{$\begin{array}{l}\text { Agriculture } \\
\text { Residues }\end{array}$} & \multicolumn{7}{l}{ Amount of burned residues (dry matter) in tons } \\
\cline { 2 - 8 } & Egypt & Turkey & Iran & KSA & Iraq & Oman & UAE \\
\hline Rice & 377249 & 60228 & 314360 & - & 29856 & - & - \\
Wheat & 537122 & 3064909 & 2680000 & 38607 & 419012 & 372 & 10 \\
Maize & 920601 & 637726 & 174033 & 2471 & 52012 & 1021 & 241 \\
Sugar cane & 88013 & - & 60875 & - & 228 & 33 & - \\
\hline
\end{tabular}

Many solutions were introduced in the ME for the disposal of rice residue such as converting it to fuel by gasification [15-17], utilization of rice husk in mud bricks manufactures [18].

In addition to the problem of rice residues, the date palm residues caused also a great problem in the ME especially in the area of the Arab gulf countries especially in KSA, Iraq and United Arab of Emirates. Great research efforts have been made in the ME to convert the date palm residues to fuel by gasification [19], and pyrolysis $[20,21]$ process. Nevertheless, the outputs of these research still in the laboratory scale and were not implemented in the large scale so far. So, the disposal of date palm residues is of great interest in the current study. 


\subsection{Economic diversification}

The KSA is particularly endowed with natural resources and cheap energy sources. These constitute important sources of competitive advantage in the various economies. The KSA has about $25 \%$ of the world proven oil reserves and produces about $12 \%$ of total world oil output. It also ranks fifth in possession of world natural gas reserves[22]. The King Arabia Saudi economy depends not only on crude oil and natural gas production, petrochemical industry and religious tourism, but also the agricultural, poultry and fish production are of great interest [22].

Agriculture in KSA has improved dramatically over the past decades under the plan of the government to reduce the heavy dependence on oil where revenues make up around $90-95 \%$ of total KSA export earnings [22]. Although deserts cover a large part of its area, there are many areas that represent a climate and fertile land for agriculture. The government has contributed to this process by converting large areas of the desert into agricultural fields, through the implementation of major irrigation projects, and land reclamation.

Today, agriculture in Saudi Arabia focuses on self-sufficiency, as well as exporting wheat, dates, dairy products, eggs, fish, poultry, fruits, vegetables, and flowers to markets all over the world. The Ministry of Environment, Water and Agriculture is primarily responsible for agricultural policies in the country, and the government provides interest-free loans to farmers for the long term.

The private sector also plays an important role in the agricultures investment, as its contribution in 2016 amounted to $\$ 14.4$ billion in cultivation of approximately 700 thousand hectares. Saudi Arabia achieved self-sufficiency and a production surplus of $110 \%-120 \%$ in several crops such as potatoes, eggplant, cucumber, okra, eggs and fresh milk alongside dates, which Saudi Arabia ranks second in world production as previously mentioned.

Foreign direct investment is considered one of the major tools in the KSA effort towards economy diversification and hence its ability to counteract adverse cyclical movements in oil prices and smooth out fluctuations in its income stream. Historically, foreign direct investment in the KSA contributed to oil explorations and 
refining. It also contributed to the development of Infrastructure and the Banking industry.

\subsection{Food security}

The issue of food and its provision to meet the needs of the population in the KSA occupies priority among the objectives of the economic policy of the Kingdom. The Kingdom follows many policies to provide safe food for people through increased domestic production, raise the efficiency of resources, intensification of agricultural investment. In addition, the policy aims to support and provide food for the population of the Kingdom, at local rates, to suit all categories of community residents.

In the Middle East, especially Saudi Arabia, food security is of great concern for policy makers. In desert countries the food commodities are mostly imported as their local production is not enough to meet the domestic needs and KSA is not exception as most of the cereals and red meat are imported.

Introduction of recent agricultural expertise, feasible credit scheme, free land distribution and effective extension programs improved the yield of cereals, fruits, vegetables and animal related products. These effective programs not only enabled the KSA to fulfil the domestic needs but made it capable to export the surplus.

Considering the current situation of existing water resources the government decided to back down in its policy and that the agriculture production based on unjust use of non-renewable natural water resources is not a feasible practice [23]. This reduction is noticeable in some crops that consumes huge water such as wheat where the KSA production was reduced from 2,775,678 tons in 2004 to 586,413 tons in 2018 [5], while it expanded in crops of less water consumption such as date palm where its production increases from 941,293 tons in 2004 to 1,302,859 tons in 2018 [5].

Based on the current situation of scarce water resources, it is expected that all of its domestic needs will be imported by 2050 , if the government has not vision and good plan to provide a renewable water resources and increase land reclamation. Many potential technologies may be used to save land and water such as promotion of traditional crops, hydroponics and greenhouse farming, seawater harvesting, investing in bio-salinity research and rainwater harvesting [24]. 


\subsection{Biomass conversion techniques (biological and thermal)}

The biomass refers to the organic material which can be converted into energy. Biofuel is a type of energy derived from biomass such as plants, agricultural, animal, domestic and industrial wastes.

Based on the type of biomass, the production of biofuels can be classified into three generations [25].

First generation biofuels are produced from the storage plants, containing mainly sugars, starch and oil. Biofuel can be obtained from these resources through relatively cheap and rapid techniques (microbial fermentation of carbohydrates and trans esterification of oils) [26].

The second generation biofuel using the waste from agro food industries, especially sugar industry (sugar beet pulp and sugarcane bagasse). The utilization of these products to produce biofuel not only keep the first purpose of the feedstock in the human food sector, but also disposal from the waste of these industries.

The third generation relies on the algal biomass. Certain species of microalgae have a very high oil content that acts as the starting compound for the fuel synthesis [27]. Microalgae show a rapid growth rate and a high production capacity of lipids. They also do not compete with food or feed production since they can be grown on non-arable lands or in saline water. These advantages make the third generation biofuels a complementary way of energy production to the second generation rather than a competing technology.

Biomass is converted into biofuels through thermochemical, physico-chemical or biochemical processes [28] as in schematic diagram illustrated in Fig. 1. 3. 


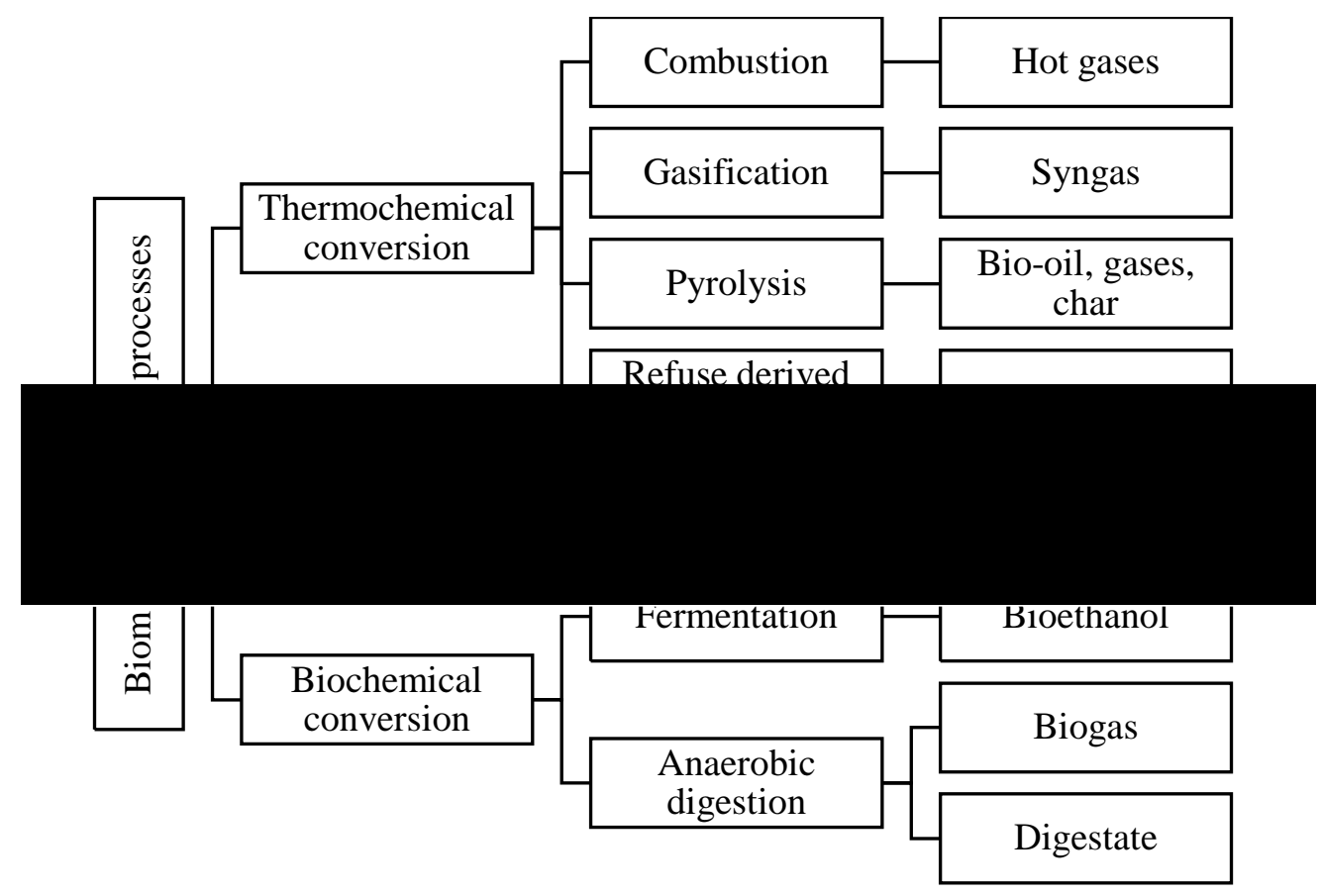

Fig. 1. 3. Biomass conversion processes [2].

\subsubsection{Biochemical conversion}

The fermentation and anaerobic digestion are the biochemical processes used to produce bioethanol and biogas, respectively. Bioethanol is produced by fermentation of sugar sources such as wheat, molasses, corn, and beets [29]. This includes biomass pre-treatment followed by fermentation of the sugars to ethanol then separation and purification to produce pure ethanol [30]. This process is also used to transform biomass into any type of petrochemical product compounds, such as olefins and aromatics.

Biogas is produced by anaerobic digestion by organic substances, and it is usually associated with methane, carbon dioxide and sulphuric components. Biogas production includes 3 processes; first, fermentation that involves hydrolysis and acid genesis, acetone genesis and methane genesis. In this process, alongside with the hydrolysis the biomass substance is transformed into tinier molecules which is transformed into dissolvable acids by acidogenese [31]. After that, changing the produced materials in the first step into acetic acid, hydrogen and carbon dioxide. The final process is conclusion to metanogenese process, producing methane gas by 
anaerobic bacteria. The only disadvantage of biogas as a source of energy is that methane is more poisonous than carbon dioxide itself, however, it was found that the households with biogas plants had half the emissions of households without biogas plants [32].

\subsubsection{Physico-chemical conversion}

Physico-chemical technologies use chemical agents to convert biomass to energy, typically in the form of liquid fuels. Trans-esterification is the most common physicchemical conversion technology used to produce biodiesel [2].

\subsubsection{Thermochemical conversion}

In thermochemical processes, heat energy is required to treat and convert the biomass into biofuel. The thermochemical processes include combustion, gasification and pyrolysis.

\subsubsection{Combustion}

Combustion is the direct burning of biomass in the air for the purpose of heating and power generation. It is the simplest way used by the human science that knew fire. The emission of NO is the main problem associated with the combustion of Biomass. Recently, an experimental study has been carried out by Shah et al. [33] using the oxy fuel combustion technique to reduce the nitrogen emissions from the combustion of rice husk, maize stalk, wheat straw and groundnut hull. They concluded that oxygen played key role in achieving satisfactory reduction in NOx emissions. The techniques used to reduce NO emission from biomass combustion were also studied by Gong et al. [34] and Dong et al.[35].

\subsubsection{Gasification}

Gasification is a process that converts biomass based carbonaceous materials into carbon monoxide, carbon dioxide and hydrogen known as syngas. The syngas can be processed to produce different types of gaseous biofuels and liquids. Gasification is achieved by heating the biomass material to high temperatures (more than $700{ }^{\circ} \mathrm{C}$ ), 
without combustion, but with a controlled amount of oxygen and/or steam. Many studies have been conducted in the ME using gasification conversion of different agricultural wastes such as rice residues [15-17], date stone [36, 37].

\subsubsection{Pyrolysis}

Pyrolysis process is also achieved by applying thermal energy in the absence of oxygen to produce bio-oil, non-condensable gases and a solid char residue [38]. It produces also heavy fuel oil for heat and power applications. Pyrolysis can convert over $60 \%$ of the biomass into liquid bio-oil [39]. Pyrolysis requires moderate temperature in the range of $400-600{ }^{\circ} \mathrm{C}$ to depolymerize biomass to a mixture of oxygenates (or 'bio-oil') that are liquid at room temperature [40].

Among thermochemical processes for biofuel production, the pyrolysis is the most attractive process because it is based on well-established methodologies and produces a range of compounds that might be integrated into existing petroleum infrastructure [41-46].

The bio-oil produced from the pyrolysis is a potential substitute for petroleum to generate heat and power [47]. Bio-oil can substitute heavy fuel oil, light fuel oil and natural gas in most of power generation devices including boilers, gas turbines and other heating equipment. However, bio-oil is a dark-brown, acidic $(\mathrm{pH} \mathrm{2-3)}$ and thermally unstable product that contains a high proportion of water and oxygenated compounds [48]. Pyrolysis oil shows various environmental advantages; bio-oils are $\mathrm{CO}_{2} / \mathrm{GHG}$ neutral, and can therefore generate credits of $\mathrm{CO}_{2}$ with no $\mathrm{SO}_{\mathrm{x}}$ emissions [47]. Besides, $\mathrm{NO}_{\mathrm{x}}$ emissions generated by bio-oils have been quantified as $50 \%$ lower than those of diesel oil in gas turbines $[49,50]$.

Techno-economic comparison between thermochemical and biochemical production of biofuels is performed by Anex et al. [51]. They found that pyrolysis not only has the lowest capital cost but also has the lowest operating cost. While, gasification and biochemical process showed the highest capital and operating cost, respectively. Moreover, the ethanol production using thermochemical process lead to lower greenhouse gases emission than the biochemical conversion process [52]. On one hand, the thermochemical process consumes less process chemicals, and on the other hand, it has higher amount carbon efficiency, meaning that a higher amount of 
carbon remains in the products and less $\mathrm{CO}_{2}$ is emitted than during the biochemical process.

Based on the latter advantages associated with the pyrolysis process, it is selected in this work for biofuel production.

\subsection{Feedstock: Date Palm Wastes (Varieties and Selection)}

"The date palm (Phoenix dactylifera L.) is an angiosperm monocotyledonous plant that belongs to the family Arecaceae (syn. Palmaceae) that includes 200 genera" [53]. Date palm is considered one of the main fruits crop in arid and semiarid regions, specially, in the arid regions of western Asia and North Africa. The palm tree is well adapted to desert environments that are characterized by high temperatures and water shortage due to scarcity of rainfall [53].

Date palm is a diploid plant, enduring, and monocotyledonous. The source of its name comes from its fruit "phoenix" in Greek which means "purple" or "red" and "dactylifera" means the finger shape of the date fruit. It is also dioecious, which means it is divided into female and male trees, but both embraced in a solid fibrous cover that protects the flowers from sun and heat during the early stages of its growth [54]. The date palm tree may reach an age of over 100 years and average mature tree is about $20 \mathrm{~m}$ tall [55].

\subsubsection{Date palm tree parts}

The various parts of the palm tree are shown in Fig. 1. 4. The main parts of the date palm are; roots, trunk, leaves, and fruits. Each part of the palm tree has its own characteristics and functions as will be discussed in this section. 


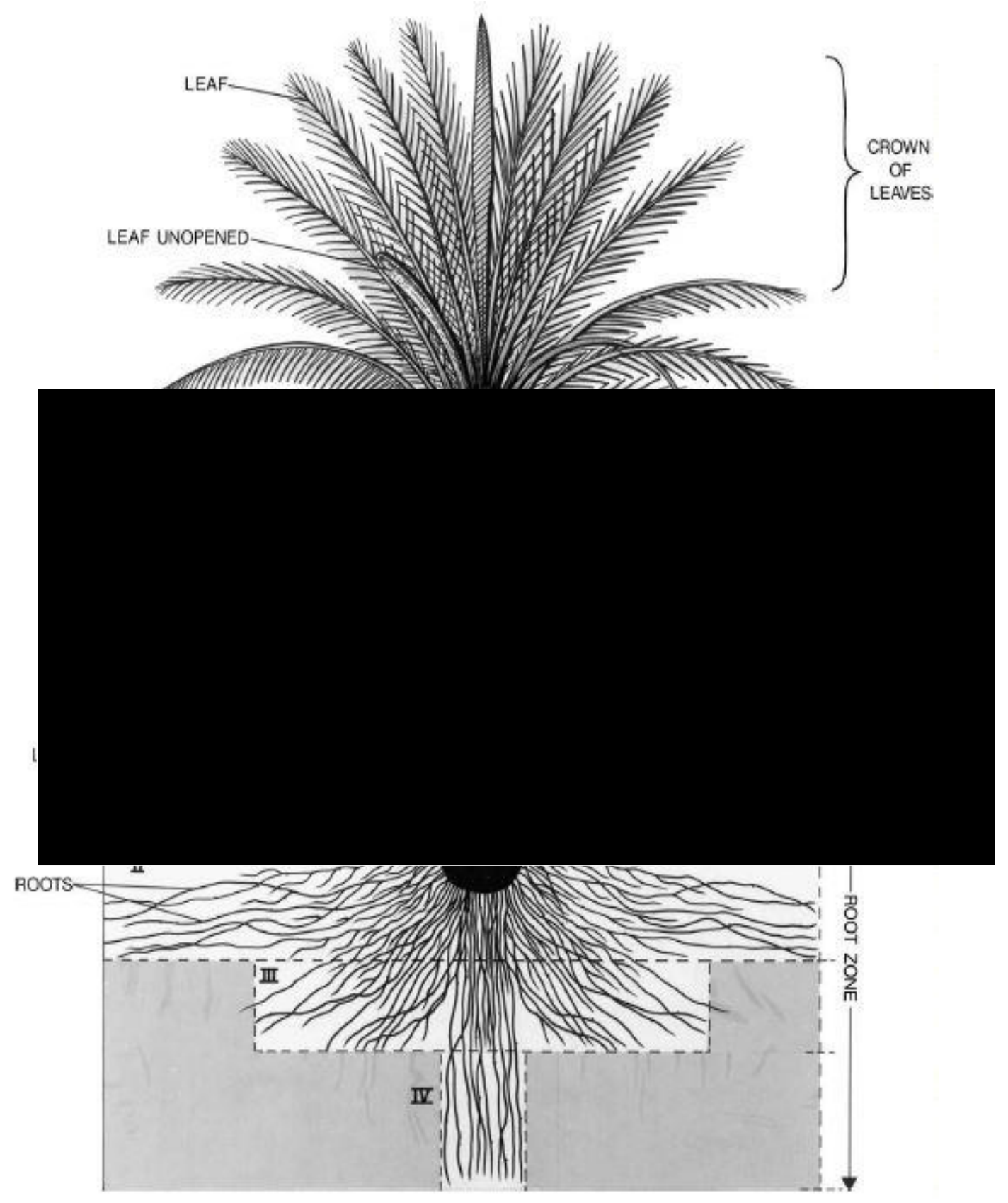

Fig. 1. 4. Schematic diagram of date palm tree (Phoenix Dactylifera) $[54,56]$

The roots of the date palm is fibrous with secondary roots branched from the primary roots which directly extend from the seeds. They extended $25 \mathrm{~m}$ far from the tree and $6 \mathrm{~m}$ deep. Date palm roots can resist wet soil for months, but if it continues for longer period, it becomes toxic for the roots and will affect the fruit production.

The trunk is also known as stem or stipe. It has a cylinder shape and brown color and fully lignified [56] with average tall of $25 \mathrm{~m} \mathrm{[55].} \mathrm{Also,} \mathrm{it} \mathrm{has} \mathrm{no} \mathrm{branches}$ and covered by remaining dry palms. Date palm tree has a rough trunk because of its 
fibrous composition, and fibrous bonds established together forming a matrix of cellular tissue which is lignified by the exterior side of the trunk.

The leaf of date palm consists of frond midrib, rachis, spins, and leaflets as illustrated in Fig. 1. 5. It is 3-6 m long and usually lasts for 3-7 years.

The rachis is considered the main axis of the leaf and many leaflets extend from its two sides. The rachis and leaflet are considered the main parts of the leaf as they represent 53.4 and $46 \%$ of the whole date palm tree on a dry weight basis, respectively. The adult date palm tree has 100-125 green leaves and 10-26 new leaves annually grow. The date palm leaves has 3 levels; the external leaves which are green and photosynthesis-effective and outline $50 \%$ of the leaves, the central leaves which are fast growing and green and outline 10\%, and the inside leaves which are inside the palm and not yet green, nor yet photosynthesis-active and these outline $40 \%$ of the leaves.

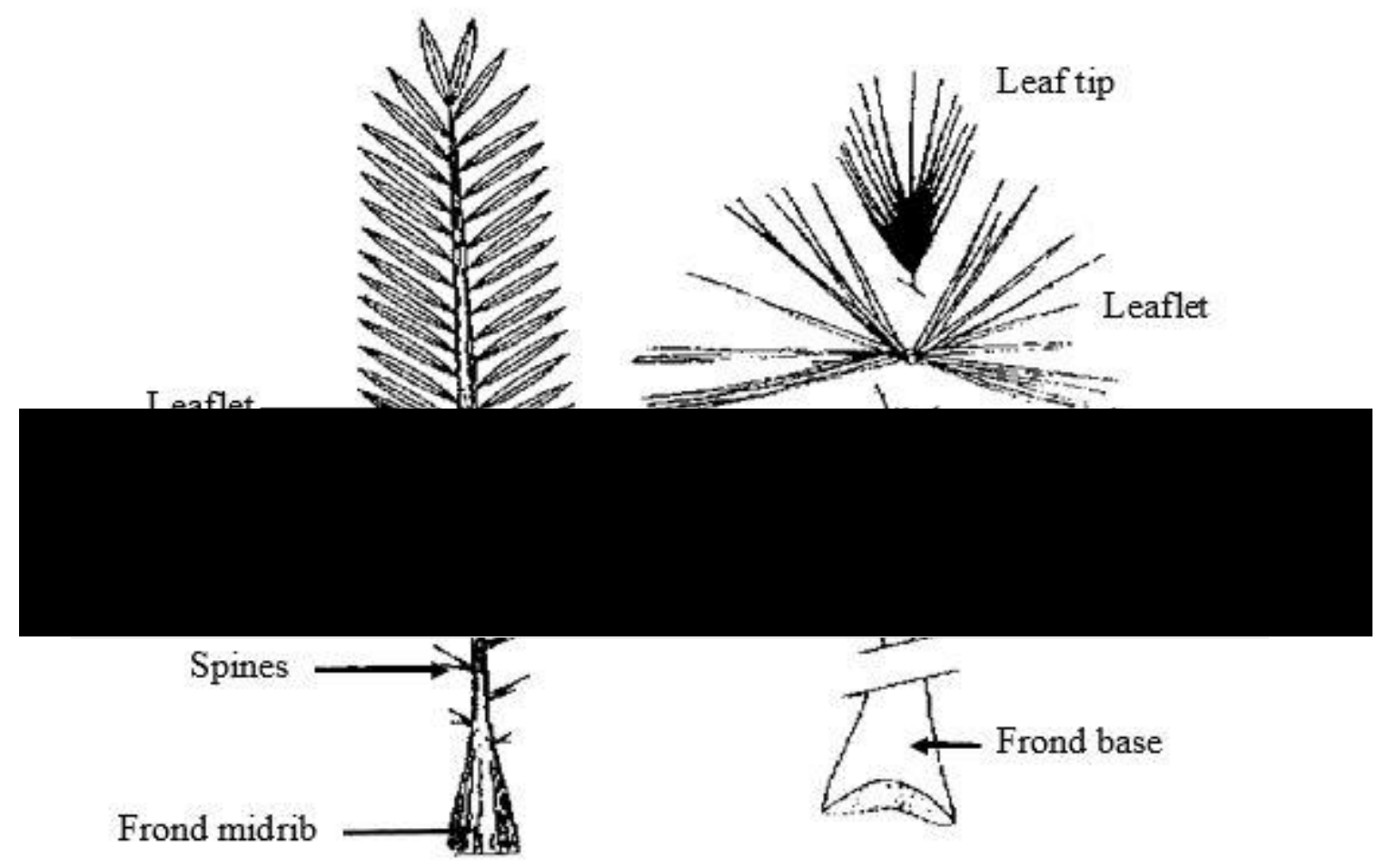

Fig. 1. 5. The date palm leaf [56]. 
The fruits of date palm, called dates, have many characteristics variety according to the environmental and agricultural conditions in each country. For example, Iraq produces 400 types of date palm fruits as described by Zaid [56]. Accordingly, date palm fruits life cycle has different stages: Kimri, Khalaal, Rutab, and mature Tamr [57]. Through these stages، the amount of water in the fruit lowered from $85 \%$ at the early Kimri stage to $20 \%$ at Tamr stage. The date fruit usually weighs between 2-60 g, and has a length of $18-110 \mathrm{~mm}$, width of 8-32 mm. It contains $32 \%$ glucose and $30 \%$ fructose, while the water-insoluble fibers of its flesh made of $49.9 \%$ lignin and $20.9 \%$ polysaccharides [57]. The color of the fruit depends on its stage, and there are many stages from yellow to black, and the taste varies accordingly as well as its texture [56].

The date palm stone or seed usually weighs around 0.5-4 g, and its length normally around 12-36 $\mathrm{mm}$ and has width of 3-6 mm. It has an oblong shape, ventral groove and a tiny embryo inside consist of tough endosperm made of cellulose [56]. The parts of the date palm fruit are displayed in Fig. 1. 6. 


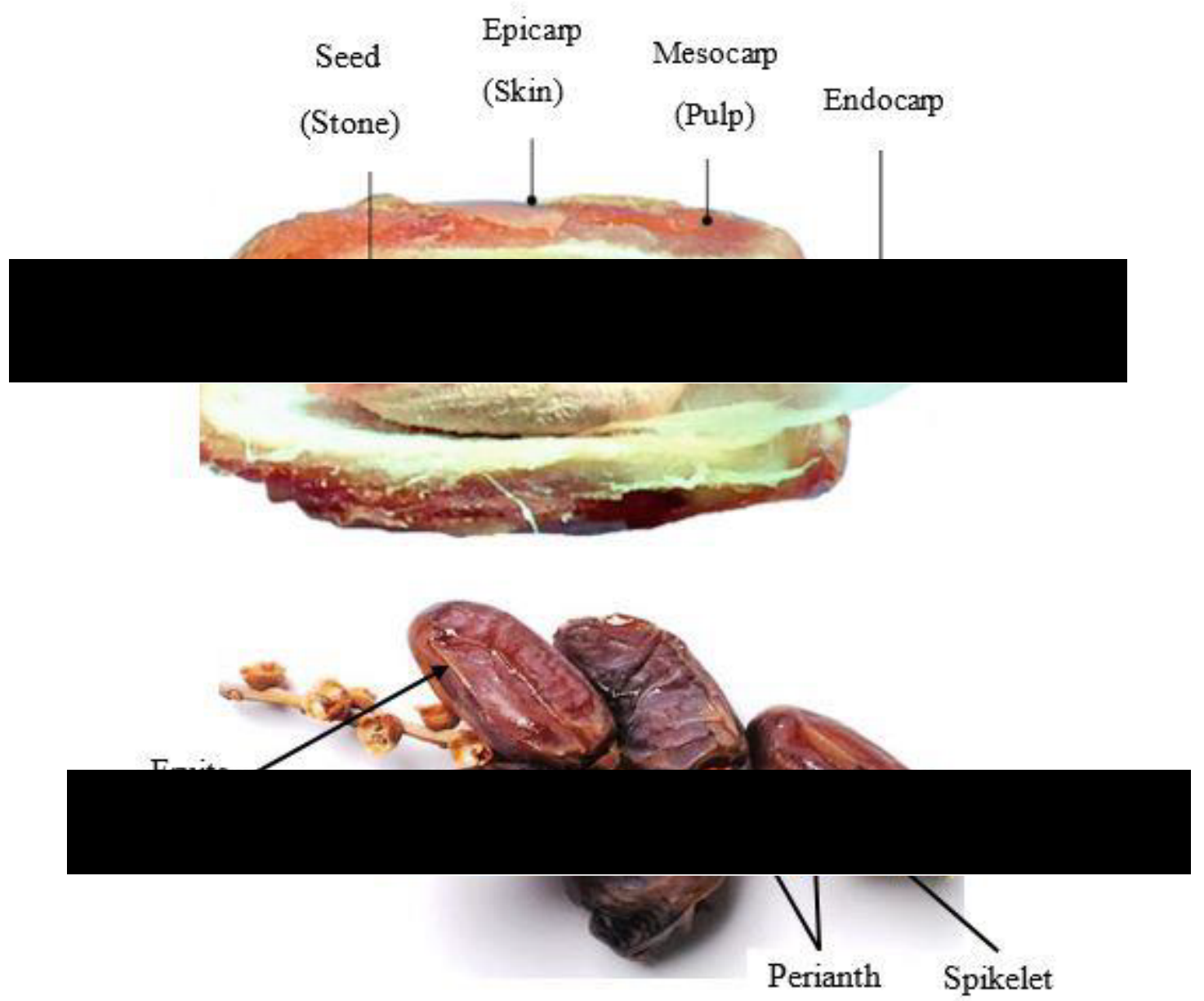

Fig. 1. 6. Date palm fruits and seed [56].

\subsubsection{The products, by-products and residues of date palm tree}

Besides the direct consumption of date, the industry of date manufacture a variety of date products such as date paste, syrup, honey, jam and vinegar. The dates are also fermented to produce wine, alcohol, and organic acids [58].

The by-product of date, is being used in the preparation of foodstuffs such as marmalades, concentrated beverages, chocolates, ice cream, confectioneries, sweets, snacks, bakery products and healthy foods. It is produced as an incidental by-product when bagged humid dates are heaped for several months, during which some syrup oozes out by the force of its own weight [58]. 
The huge number of date palm trees in the ME, specifically in Egypt, KSA, Iran, Iraq, and UAE, produces large amounts of agricultural residues such as leaves, fruit stalk pruning, date stones. In addition, the trunk becomes available upon natural or accidental death of the palm or by forced removal when the plantations are renewed. The majority of the date palm residues are the leaves (frond, rachis, and leaflets) resulting from yearly pruning as every palm tree produce 22 leaves as residues per year. In addition, the date stones represent about $10 \%$ of the date produced weight [59]. The date palm tree products, by-products and residues are summarized in Fig. 1. 7.

In addition to the date palm agriculture wastes, the industrial by-products of date palm produces also a great quantity of wastes. Most of these wastes are burned in farms causing a great danger on the environment [58]. Some of these residues like rachis, leaflets, and frond are used as raw material in many handcrafts to make several products like chairs, baskets, ropes, and building structures [60]. So, the disposal of these residues does not cause any urgent problems in most of ME countries. On the contrary, the date palm stones have not a widespread economical use so far. It is just used as animal feeds for cattle, sheep, camel and poultry [61].

Date palm residues are also an attractive source of biomass energy since they are renewable, and abundantly available. The thermal behavior of date palm residues; rachis, leaflets, trunk, date stone and fruit stalk pruning, was studied by El may et al. [55] in order to evaluate their usefulness for energy production. They concluded that among the different date palm residues, the high energy density of date stone makes it the most attractive material for energy recovery. The date palm frond, rachis and stones are also of great interest for biofuel production [58].

Based on the previous conclusion and the data mentioned above, the date palm stone and rachis collected from Barhee and Medjool date palm tree are selected in this study in order to evaluate their usefulness for energy production.

Date stones contain $27.34 \%$ (wt.) lignin, $20.63 \%$ (wt.) cellulose and $13.49 \%$ (wt.) hemicellulose [62]. While in the case of rachis, the cellulose is the majority with $44 \%$ and lower amount lignin content (14 wt.\%) is observed [63]. 


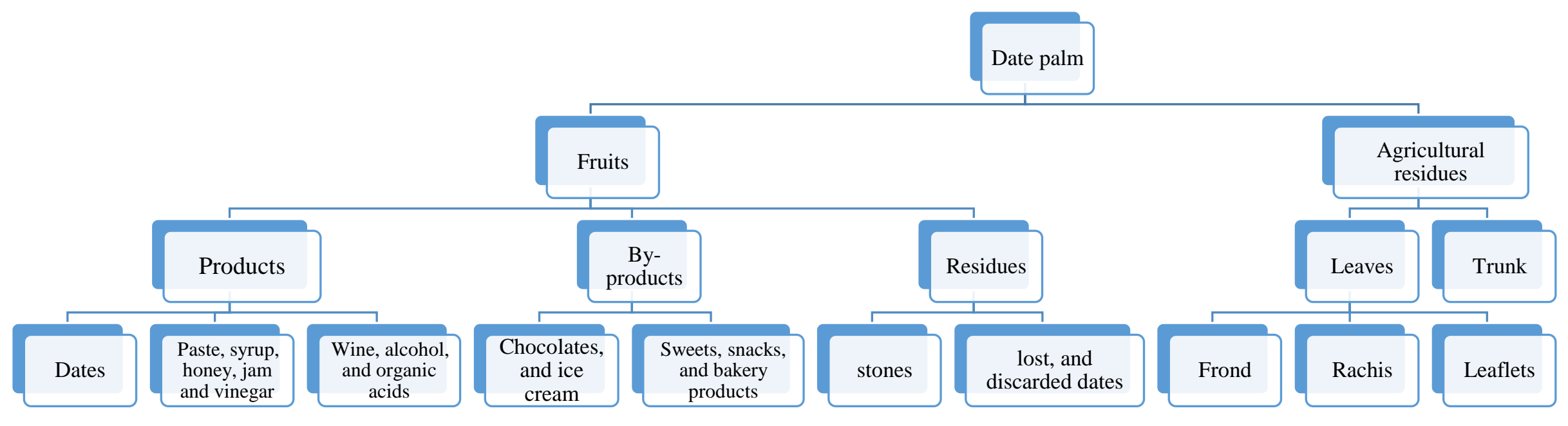

Fig. 1. 7. The products and residues of the date palm tree. 


\subsection{Research Objectives}

Presenting an economic solution to disposal of the huge amount of date palm wastes particularly in KSA on one hand and producing biofuel on the other hand is considered the main objective of this work. Among the date palm wastes the potential of Barhee date palm stones (BDPS) and rachis (BDPR) and Medjool date palm stones (MDPS) and rachis (MDPR) for biofuel production are investigated.

In order to achieve this goal, many specific objectives to be achieved includes:

- Characterization of date palm residues, rachis and stones performing slow pyrolysis experiments of the selected biomass residue.

- Characterization of the bio-oil products extracted from the slow pyrolysis experiment.

- Investigate the opportunities of installation of the hybrid solar-biomass energy in the Middle East.

- To provide data to those concerned with the investment in agricultural waste recycle using simple technology for biofuel production.

\subsection{Organization of thesis}

Literature review on biomass and pyrolysis of biomass is introduced in Chapter 2. This review focuses on the biomass chemical composition; cellulose, hemicellulose, lignin, extractives, and ash. The different type of pyrolysis processes; slow, intermediate and fast are of great interest in this review. The Barhee and Medjool date palm residues especially rachis and stone as feedstock to pyrolysis process are also reviewed in details. The pyrolysis products; bio-oil, char, and non-condensable gases are also reviewed.

In Chapter 3, the biomass characterisation methods are presented. The basis of proximate analysis, where the content of moisture, volatile, ash, fixed Carbon are obtained, are discussed. The elemental analysis (ultimate analysis), ash composition, inorganic element, compositional analysis, heating value and thermo-gravimetric analysis (TGA) are discussed in detail in this chapter. The characterisation method for bio-oil and char are also explored. 
The thermochemical characterisation experiments of date palm wastes are given in Chapter 4. The results obtained from these experiments are discussed and compared with similar results found in the literature.

Chapter 5 is dedicated to present the slow pyrolysis experiment of the selected date palm residues. The experimental setup, procedures are illustrated in the first section of this chapter followed by the discussion of the obtained results. The bio-oil characterisation results and discussion are also presented in detail and compared with literature data.

Techno-economic analysis of the hybrid solar-biomass energy in the Middle East is introduced in Chapter 6. The availability and current status of hybrid solarbiomass development in Middle East is reported. Review on Solar thermal Energy plants and biomass energy plants are also introduced in this chapter. Modelling of biomass energy plant is also presented in this chapter.

The conclusions and recommendations are introduced in Chapter 7 followed by references section. 


\section{Chapter 2}

\section{Literature Review on Biomass and Pyrolysis of Biomass}

\subsection{Biomass Chemical Composition}

Biomass is composed of all organic materials that comes from plants including algae, trees and crops as well as organic wastes. Biomass is the plant material derived from the reaction between $\mathrm{CO}_{2}$ in the air, water and sunlight, via photosynthesis, to produce carbohydrates that form the building blocks of biomass. When these bonds between adjacent carbon, hydrogen and oxygen molecules are broken by digestion, combustion, or decomposition, these substances release their stored chemical energy [64].

All biomass materials are composed of cellulose, hemicellulose, lignin, extractives, and ash [64-66]. Cellulose, hemicellulose, and lignin are considered the essential resources in thermochemical processes (pyrolysis and gasification). As cellulose comprises $30-50 \%$ of most harvestable biomass materials, it is considered the most abundant organic material on earth [64]. Cellulose is a glucose polymer, consisting of linear chains of $(1,4)$-D-glucopyranose units, in which the units are linked 1-4 in the b-configuration, with an average molecular weight of around 100,000 [64].

The chemical formula of cellulose is often denoted as $\left(\mathrm{C}_{6} \mathrm{H}_{10} \mathrm{O}_{5}\right)_{\mathrm{n}}$, where $\mathrm{n}$ is the degree of polymerization (DP) $[67,68]$. The average DP for woody fibre is at least $9000-10,000$ and possibly as high as 15,000 [69]. The glycosidic bonds linking the glucose units in cellulose are not strong and tend to cleave under acid or hightemperature conditions. Therefore, the cellulose structure degrades sharply during the initial stages of fast pyrolysis with the reduction of DP due to the cleavage of glycosidic bonds. Cleavage of b-1, 4 glycosidic bonds contributes largely to the formation of furans and levoglucosan [95].

The degradation of cellulose takes place at temperatures around $350^{\circ} \mathrm{C}$ [70]. During the pyrolysis process, the polymer chains are broken into smaller polymers and then into smaller gas species.

In contrast to cellulose, hemicellulose is composed of short chain heteropolysaccharides and presents an amorphous and branched structure. Although 
the shape of the polysaccharide chain is similar to that of cellulose, the degree of polymerization of hemicellulose is only approximately 200 [71]. The monosaccharide units constituting hemicellulose include mainly hexoses (glucose, mannose, and galactose) and pentoses (xylose and arabinose), as well as some other low-content saccharides (rhamnose and fructose). In addition, there are some uronic acids (4-Omethyl-d-glucuronic acid, d-glucuronic acid, and d-galacturonic acid) and acetyl groups in the hemicellulose structure.

Lignin has an aromatic matrix that adds strength and rigidity to the cell walls. Lignin consists of three primary monomers as shown in Fig. 2. 1. The molecular weight of lignin is about 15,000 and it degrades at temperatures around $390^{\circ} \mathrm{C}$ [72]. The structure of cellulose, hemicellulose and lignin are displayed in Fig. 2.1.

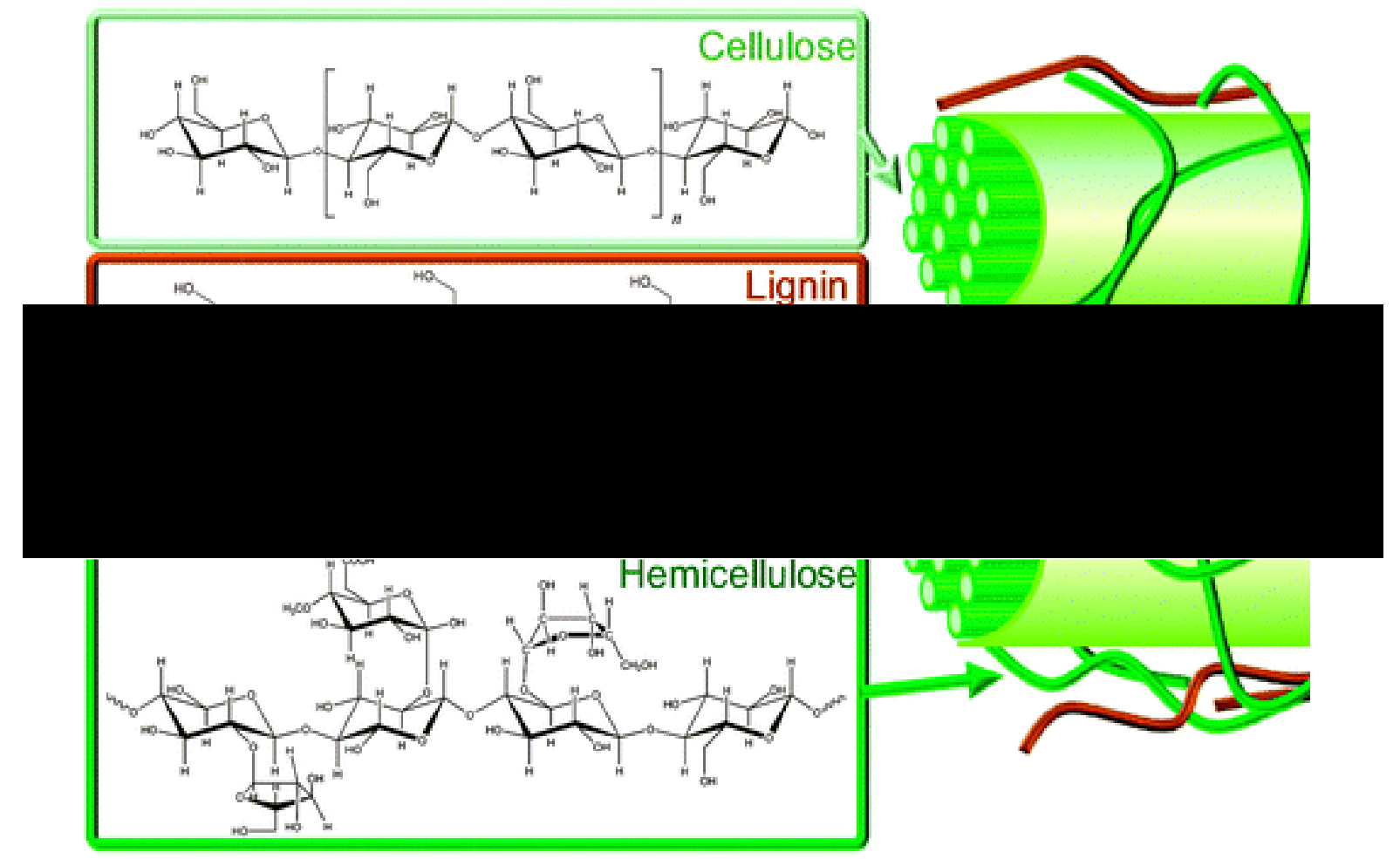

Fig. 2. 1. The structure of cellulose, hemicellulose and lignin [73].

In addition to the three major components, there are small amounts of extractives in biomass. They do not constitute cell walls or cell layers but are nonstructural components. Extractives can be extracted by non-polar solvents (such as toluene and hexane) or polar solvents (such as water, methylene chloride and alcohol).The extractives in lignocellulosic biomass mainly include waxes, fats, resins, tannins, sugars, starches, and pigments [68]. 
Many studies have been conducted to specify the chemical composition of different biomass materials such as rice [74, 75], and date palm wastes [63, 76-79].

The chemical composition of date palm rachis, leaflets, leaf sheath and tree surface fibre (fibrillum) was studied by Saadaoui et al. [77]. They used ADF/NDF method of Van Soest and Wine [80, 81] to determine the percentage of cellulose, hemicelluloses and lignin in the studied date palm residues. Among all studied samples, their results reveal that the fibrillum has the highest amounts of cellulose and lignin $50.6 \%$ and $31.9 \%$, respectively. While it has the lowest amount of hemicellulose of $8.1 \%$. The leaflets, rachis and leaf sheath have low contents of lignin ranging from $11.6 \%$ to $18.2 \%$, while, they have high contents of cellulose reached $29.7,39.8$ and $34 \%$, respectively. The date palm rachis has the highest content of hemicellulose of $31.4 \%$ followed by the $28.9 \%$ for the leaf sheath. They also found that the highest ash content of $12.3 \%$ is found in leaf sheath while its lowest content of $6.8 \%$ is found in fibrillum. These results are close to those reported by Bensidhom et al. [82] for several date palm wastes as clearly seen in Table 2.1 .

The chemical composition of date palm leaflets was also studied by Hamza et al. [78]. They found that the cellulose, hemicellulose, lignin contents of date palm leaflets are 39.23, 28.41 and 20.05\%, respectively, compared with 43.27, 33.15 and 27.86 for date palm stip. Similar values were reported in the literature where the leaflets has 33.5 and $34.9 \%$ of cellulose as reported by Bendahou et al. [63] and Bensidhom et al. [82], respectively; while it has $19.84 \%$ of hemicellulose and $14.03 \%$ of lignin [82]. While, rachis has $39.8-45 \%$ of cellulose [63, 76, 77, 82], 33\% of hemicellulose and $12.5 \%$ of lignin [82]. On the contrary, high content of hemicellulose in rachis reaches $74.8 \%$ was reported by Kiari et al. [76].

The cellulose, hemicellulose, lignin and ash contents in the date stones were determined by Hamid and Ismail [62]. They found that the cellulose, hemicellulose and lignin contents of date palm stones are 20.6, 13.5 and $27.3 \%$, respectively. While Bouchelta et al. [83] found that the date palm seed composition is $42 \%$ of cellulose, $18 \%$ of hemicellulose, and $11 \%$ of lignin. The chemical composition of date palm stone and a mixture of date palm waste excluding date stone was also reported by Bharath [84]. Their results indicated that the contents of date stone is comprised $65 \%$ cellulose, $15 \%$ hemicellulose and 5-10\% lignin; whereas, the contents of the date palm wastes mixture were $30 \%$ cellulose, $35 \%$ hemicellulose and 10-20\% lignin. 
For the purpose of comparison, the chemical composition of date palm wastes and other biomass materials are summarized in Table 2.1. The tabulated results reveal that the percentage of cellulose content is the highest in most of date palm wastes $[20,77$, 78, 82-85] and other feedstock reported in the literature as seen in Table 2.1 [86-92]. Where the cellulose content in date stones varies from 20.6 to $65 \%$ compared to 39.8 to $45 \%$ in the case of date palm rachis. These differences in the cellulose content for the same date palm waste such as stone not only backs to the different places where the waste is collected from but also due to the differences in apparatus accuracy used in measurements from laboratory to other. Nevertheless, most of these studies assure that the highest content in all feedstock is the cellulose and the lowest content is ash. While the content of hemicellulose or lignin is ranked the second after cellulose according to the type of biomass. It is also assured that the hemicellulose is ranked the second in date palm rachis $[77,82]$ and leaflets $[77,78,82,85]$. From the results illustrated in Table 2.1, the highest cellulose content of $65 \%$ is found in date palm stone [84], followed by pistachio shell (53.98\%) [89], date palm Fibrillum (50.6\%) [77], leaflets (47.14\%) [85] and rachis (45\%) [76]. The date stones also has hemicellulose ranging from 13.5 to $30.2 \%$ and lignin from 5 to $37.03 \%$. 
Table 2. 1. Comparison between the chemical composition of several date palm wastes and other biomass materials.

\begin{tabular}{|c|c|c|c|c|c|c|}
\hline Biomass material & $\begin{array}{l}\text { Cellulose } \\
(\%)\end{array}$ & $\begin{array}{l}\text { Hemicellulose } \\
(\%)\end{array}$ & $\begin{array}{l}\text { Lignin } \\
(\%)\end{array}$ & $\begin{array}{l}\text { Ash } \\
(\%)\end{array}$ & Extractives & Ref. \\
\hline \multirow[t]{5}{*}{ Date palm stone } & 43.88 & 17.67 & 16.33 & 1.47 & 8.2 & {$[20]^{\mathrm{a}}$} \\
\hline & 20.6 & 13.5 & 27.3 & 2.05 & - & {$[62]^{\mathrm{a}}$} \\
\hline & 42 & 18 & 11 & 4 & - & {$[83]^{b}$} \\
\hline & 65 & 15 & $5-10$ & 5.29 & - & {$[84]^{\mathrm{a}}$} \\
\hline & 32.77 & 30.2 & 37.03 & 1.4 & 31.54 & {$[85]^{\mathrm{a}}$} \\
\hline \multirow[t]{4}{*}{ Date palm rachis } & 40.4 & 33.08 & 12.49 & 5.5 & - & {$[82]^{\mathrm{a}}$} \\
\hline & 39.8 & 31.4 & 14 & 9.2 & 19.3 & {$[77]^{\mathrm{a}}$} \\
\hline & 45 & 74.8 & 27.2 & 5 & 40.2 & {$[76]^{\mathrm{a}}$} \\
\hline & 44 & - & 14 & 2.5 & - & {$[63]^{\mathrm{a}}$} \\
\hline \multirow[t]{5}{*}{ Date palm leaflets } & 34.87 & 19.84 & 14.03 & 11.58 & - & {$[82]^{\mathrm{a}}$} \\
\hline & 29.7 & 23.3 & 11.6 & 9.2 & 40.8 & {$[77]^{\mathrm{a}}$} \\
\hline & 39.23 & 28.41 & 20.05 & - & 21.82 & {$[78]^{\mathrm{a}}$} \\
\hline & 33.5 & - & 27 & 6.5 & - & {$[63]^{\mathrm{a}}$} \\
\hline & 47.14 & 16.13 & 37.73 & 15.2 & 32.86 & {$[85]^{\mathrm{a}}$} \\
\hline Date palm empty Fruit & 38.44 & 24.65 & 25.08 & 4.2 & - & {$[82]^{\mathrm{a}}$} \\
\hline Bunches & 44.4 & 24.3 & 31.3 & 1.78 & 13.42 & {$[85]^{\mathrm{a}}$} \\
\hline Date palm fruit stalk & 43.05 & 27.48 & 29.47 & 1.8 & 9.75 & {$[85]^{\mathrm{a}}$} \\
\hline Date Palm glaich & 22.22 & 20.24 & 16.01 & 2.4 & - & {$[82]^{\mathrm{a}}$} \\
\hline Date palm leaf sheath & 34 & 28.9 & 18.2 & 12.3 & 21.2 & \\
\hline Date palm Fibrillum & 50.6 & 8.1 & 31.9 & 6.8 & 16.3 & {$[77]^{\mathrm{a}}$} \\
\hline Date palm frond midrib & 45.16 & 28.16 & 26.68 & 3.56 & 17.45 & \\
\hline Date palm Frond Base & 43.05 & 31.34 & 25.61 & 9.81 & 24.9 & {$[85]^{\mathrm{a}}$} \\
\hline Date palm trunk & 39.37 & 30.31 & 30.32 & 3.86 & 25.15 & \\
\hline Date palm mixture wastes & 30 & 35 & $10-20$ & 7.54 & - & {$[84]^{\mathrm{a}}$} \\
\hline Rice husk & 41.52 & 14.04 & 33.67 & 14.83 & 10.77 & {$[86]^{\mathrm{a}}$} \\
\hline Wheat straw & 45.1 & 30.2 & 17.3 & 5.1 & 1.2 & {$[87]^{b}$} \\
\hline Cardoon & 47.8 & 22.8 & 10.3 & 4.8 & - & {$[88]^{\mathrm{a}}$} \\
\hline Pistachio shell & 53.98 & 20.1 & 25.25 & 0.09 & 0.67 & {$[89]^{\mathrm{a}}$} \\
\hline Peach stones & 46 & 14 & 33 & 1.1 & 7 & {$[93]^{\mathrm{a}}$} \\
\hline Apricot kernel shells & 29.57 & 17.01 & 47.97 & 0.95 & - & {$[91]^{\mathrm{a}}$} \\
\hline Cherry stones & 32.06 & 28.59 & 29.08 & 1.16 & 8.7 & {$[90]^{\mathrm{a}}$} \\
\hline Mahua seed & 32.4 & 7.9 & 29 & 2 & 31 & {$[92]^{\mathrm{a}}$} \\
\hline
\end{tabular}




\subsection{Introduction to pyrolysis process of biomass}

Recently, the conversion of the biomass to biofuel has been of great interest around the world. The ease of handling, storage and transportation are the key attractive points of bio-oil. Hence, the biomass pyrolysis process is commonly used, in order to maximize the percentage of the produced bio-oil. Pyrolysis is a thermal decomposition of the biomass occurring prior to combustion in the absence of oxygen [94, 95]. Depending on the process conditions the pyrolysis process can be classified into several categories as shown in Fig. 2. 2. Among the several categories of pyrolysis processes, the slow, fast, flash and catalytic pyrolysis are considered the most investigated processes in the literature.

\subsubsection{The slow pyrolysis}

The slow pyrolysis is the first category where slow heating rate $\left(<60{ }^{\circ} \mathrm{C} / \mathrm{min}\right)$, temperatures less than $500{ }^{\circ} \mathrm{C}$ and long pyrolysis time from 5 to 60 minutes are required [96-99]. The slow pyrolysis is usually conducted to produce bio-char which reaches $35 \%$ [98], as the low heating rate with longer residence time further promotes the formation of solid products. Nevertheless, in some types of biomass, such as date palm stones, the bio-oil yield of slow pyrolysis reached 52.67-66.5\% [20, 84]. Furthermore, slow pyrolysis can handle a wider range of biomass particle size from 5 to $50 \mathrm{~mm}[100,101]$. The slow heating rate and the low temperature gives the slow pyrolysis little superiority in terms of the ease of handling; despite its low yield of biooil compared with other pyrolysis processes.

\subsubsection{The fast pyrolysis}

The fast pyrolysis has four essential features [95, 99, 102-104]: (1) high heating rate of $100-1000{ }^{\circ} \mathrm{C} / \mathrm{s}$ is used, (2) a high pyrolysis temperature $\left(500-1250{ }^{\circ} \mathrm{C}\right)(3)$ short pyrolysis times is used (0.5-10 s) [100, 105], and (4) pyrolysis vapour is rapidly cooled to maximize the bio-oil (vapour residence less than $2 \mathrm{~s}$ ). To accommodate such processing temperature and time, this requires a finely grinded biomass (particle size less than $1 \mathrm{~mm}$ ) to ensure effective heating $[100,106]$. The majority of fast pyrolysis yield is the bio-oil which reaches $60-75 \%$ of the total yield based on the type of biomass [96]. In order to maximize the yield of bio-oil, a low temperature, high heating rate, and short gas residence time should be implemented; while a high 
temperature, relatively low heating rate and long vapour residence time are preferred to maximize the yield of fuel gas [107-110].

\subsubsection{Intermediate pyrolysis}

The intermediate pyrolysis is carried out between the operating conditions of slow and fast pyrolysis [152]. The moderate pyrolysis occurred at temperatures around $500{ }^{\circ} \mathrm{C}$, pyrolysis time from 30 to $1500 \mathrm{~s}$, and vapour residence time from 2 to $10 \mathrm{~s}$ [95, 111]. Through this process, the liquid remains as the largest product fraction (40-60\%), followed by non-condensable bio-syngas $(20-30 \%)$ then solid products $(15-25 \%)$ [112].The bio-oil obtained from intermediate pyrolysis shows low viscosity and tar concentration, so it can be directly used in boilers and engines [113, 114].

\subsubsection{The flash pyrolysis process}

In the flash pyrolysis, the biomass of particle size of $0.2 \mathrm{~mm}$ or less is exposed to high temperature (around $1000{ }^{\circ} \mathrm{C}$ ) for less than $1 \mathrm{~s}$, at a very high heating rate (more than $\left.1000{ }^{\circ} \mathrm{C} / \mathrm{s}\right)[96,104]$. The main product of the flash pyrolysis is the bio-oil and syngas $[104,115]$.

\subsubsection{Catalytic pyrolysis process}

Catalytic pyrolysis has attracted considerable attention due to its removal of condensable hydrocarbons (tar cracking) [116] and the production of higher quality bio-oil $[86,117]$. The effects of different catalysts on improving the pyrolysis bio-oil are reviewed by Bhoi et al. [104]. They concluded that the catalysts play significant role to limit the formation of undesired products and to improve hydrocarbon compounds in bio-oil during the pyrolysis of biomass. In order to improve the pyrolysis process as well as the characteristics of the products many catalysts were used such as acid type, base-type, metal-type, zeolite-type, carbon-type or mixture of different materials as [100, 118-120]. 


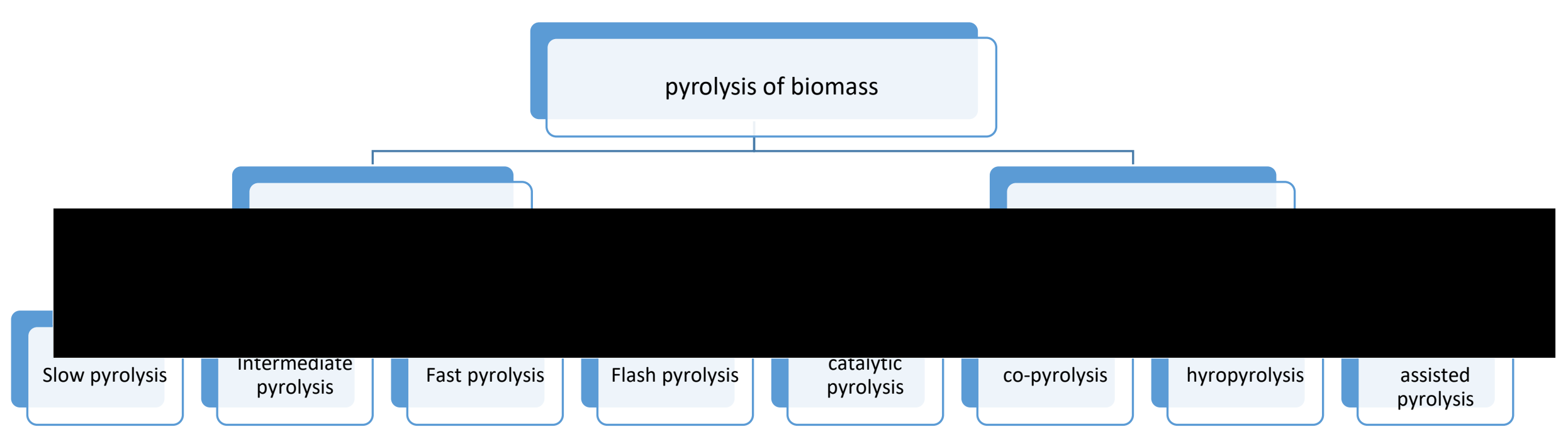

Fig. 2. 2. The several categories of pyrolysis processes [99]. 


\subsubsection{Comparison between the slow and fast pyrolysis}

In order to recognize the superiority of a certain pyrolysis process, comparison between the slow and fast pyrolysis is conducted in this part. This comparison based on experimental studies conducted to compare between the two processes, so, a meaningful comparison is obtained.

Comparison between slow and fast pyrolysis of rice straw has been experimentally conducted by Nam et al. [121]. They used three types of reactor; bench-scale auger and batch reactors for slow pyrolysis and fluidized bed reactor for fast pyrolysis. They found that the highest bio-oil yield of $43 \%$ was obtained from the fluidized bed reactor (fast pyrolysis), while the maximum bio-char yield of $48 \%$ was obtained from the batch reactor (slow pyrolysis).

Comparison between slow and fast pyrolysis of willow was also investigated by Greenhalf et al. [122]. A laboratory scale fluidized bed reactor was used to achieve the fast pyrolysis at $500{ }^{\circ} \mathrm{C}$; whereas, slow pyrolysis experiment was carried out in a batch reactor at $500{ }^{\circ} \mathrm{C}$. They found that the heating rate and pyrolysis temperature have a significant influence on the chemical content of decomposition products. The bio-oil produced from fast and slow pyrolysis was compared using GC-MS. It is found that high yields of acetic acid and methyl acetate from fast pyrolysis, and significant yields of phenol and 2,6-dimethoxyphenol as well. While, high yields of methyl acetate, 3-hydroxy-2-butane, furfural and cyclopentenes are noticed in the slow pyrolysis.

Based on the results previously presented, the selection of the type of pyrolysis depends on which kind of pyrolysis product is required; where fast pyrolysis is used in the case of bio-oil demand, while the slow pyrolysis gives higher production of char [121]. The chemical composition of the bio-oil is also of great interest in this selection as discussed by Greenhalf et al. [122].

\subsubsection{Types of pyrolysis reactors}

The main types of pyrolysis reactors are shown in Fig. 2. 3. Stirred reactors are based on an autoclave-type type configuration where feedstock are fed discontinuously whereas the inert gas required for the pyrolysis and products flows continuously. 
The fixed bed reactor is very simple in construction. At the laboratory scale of the process, the main part of it consists of a quartz tube; it can also be made of stainless steel for industrial scale with a capacity reaches 16 and 4 ton/day. The pyrolysis process can be carried out in the presence or absence of an inert gas.

The fluidized bed pyrolysis, in contrast to fixed bed pyrolysis, is a continuous process and is therefore very popular, particularly in commercial plants. An initially stationary fixed bed of solid particles, located in the bottom part of the reactor, is brought into a fluidized state by the carrier gas, supplied through a distributor located below the sieve bottom: the bed particles are kept in suspension at fluidization velocities between 0.5 and $3.0 \mathrm{~m} / \mathrm{s}$. The construction of the sieve bottom, consisting of numerous nozzles or openings for their proper dimensions according to the rate of inert gas flow, should be enabled to create a bubbling fluidized surface. The space above the bubbling fluidized bed surface, most often with a larger diameter than the bed, is called the freeboard.

The conical spouted bed reactor (CSBR) produces a higher liquid yields obtained compared to other reactors technologies. This results gives a convenience of working with a CSBR reactor as the main pyrolysis goal is to optimize the liquid product yield. These results are due to the interesting features of CSBRs: (i) simple design that does not require a gas distributor [123, 124], (ii) low pressure drop [124, 125], (iii) versatility to be used with particles of different geometries and densities.

A pilot plants using a screw/rotary reactor were established at Japanese Kobe Steel (Japan), ENEA Research Center (Italy) and the University of Kassel (Germany) [52].

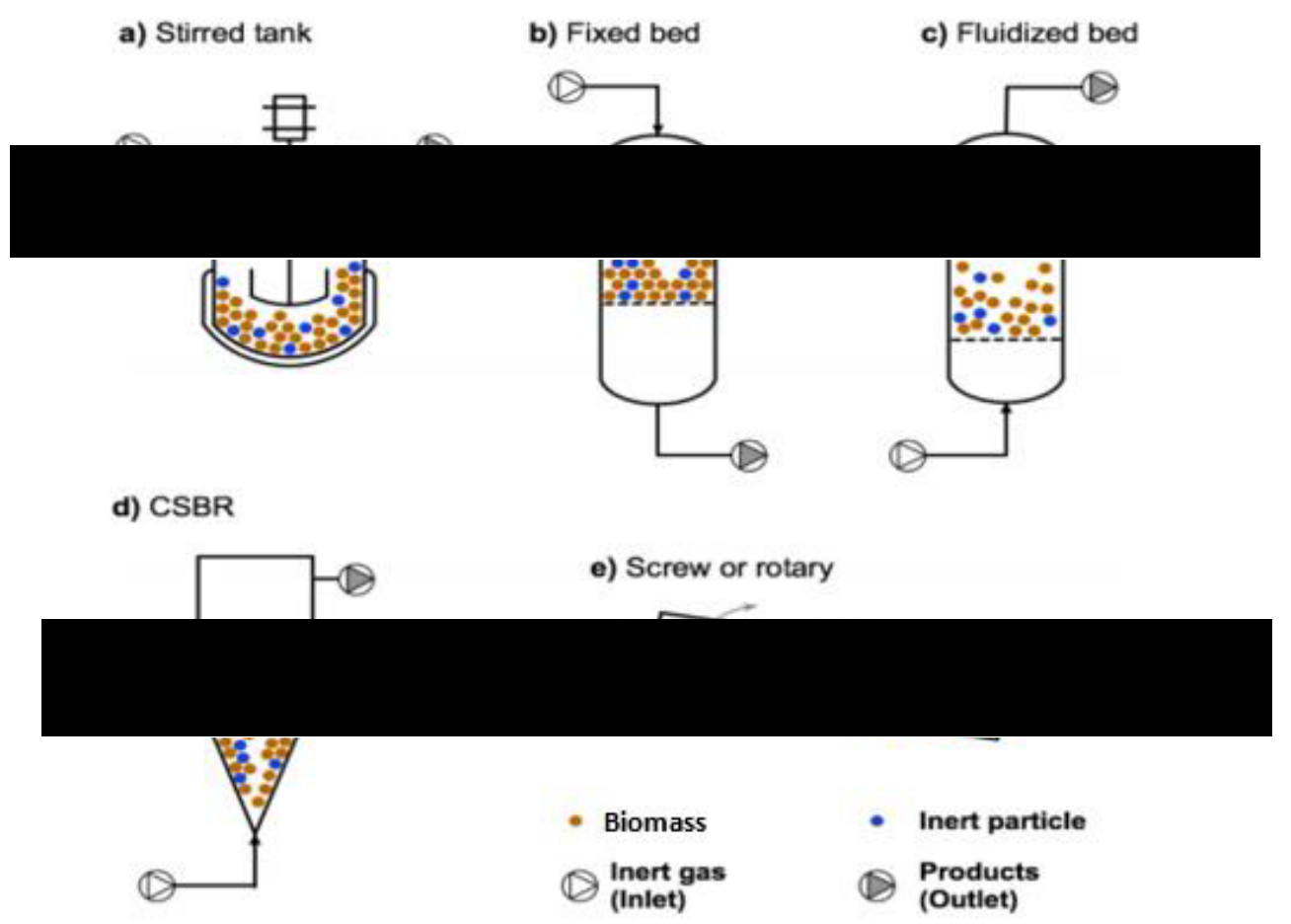

Fig. 2. 3. Types of pyrolysis reactors, (a) stirred tank reactor, (b) fixed bed reactor, (c) fluidized bed reactor, (d) conical spouted bed reactor (CSBR), (e) screw or rotary reactor [126]. 


\subsubsection{The effect of temperature and heating rate on the pyrolysis yield}

The slow pyrolysis of the pine wood in batch reactor was studied by Williams and Besler [127]. They investigated the effect of changing temperature from $300-720{ }^{\circ} \mathrm{C}$ and the heating rate from 5 to $80{ }^{\circ} \mathrm{C} / \mathrm{min}$ on the slow pyrolysis yield. They found that as the pyrolysis temperature is increased as the percentage of produced char decreased; while the bio-oil and non-condensable gases increased. Whereas the effect of heating rate on the pyrolysis yield is insignificant. Similar results of the slow pyrolysis of eastern giant fennel in fixed bed reactor were obtained by Aysu and Kucuk [128]. The relation between the temperature on one side and the bio-oil and non-condensable gases from the other side is also confirmed by Stummann et al. [129] and Varma et al. [130] when they studied the Beech and sawdust wood pyrolysis in fluidized bed and semi batch reactor, respectively.

The effect of temperature $\left(450-600{ }^{\circ} \mathrm{C}\right)$ on the yield of fast pyrolysis of switch grass and different parts of cottonwood was investigated by Daniel et al. [131]. They found that the maximum quantity of bio-oil of $39.8 \%$ is obtained from cottonwood secondary stem at $450{ }^{\circ} \mathrm{C}$ whereas the maximum bio-oil yields for cottonwood main stem (38.4\%), cottonwood branch (35.6\%), and switch grass (34\%) are found at 500 ${ }^{\circ} \mathrm{C}, 450{ }^{\circ} \mathrm{C}$, and $450{ }^{\circ} \mathrm{C}$, respectively. these results are confirmed in several studies, where the maximum yields of bio-oil obtained from the pyrolysis of apricot kernel shells [91], pistachio[89], castor seeds [132], tamarind seed [133] and safflower seeds [134] are obtained at 500, 500, 550, 400, and $600{ }^{\circ} \mathrm{C}$, respectively, when they studied the influence of the temperature on the pyrolysis products.

Based on these results, it is concluded that the maximum pyrolysis yield of the bio-oil is achieved at certain temperature according to the type of the biomass material [89, 91, 131-137]. While, the non-condensable gases production increases when the pyrolysis temperature is increased [127-129].

\subsection{Biomass feedstock and Pyrolysis review}

This section is divided to two parts; review of all biomass materials used for biofuel production via the pyrolysis process is introduced in the first part. While the second part is specified to review the date palm residues used as biomass for pyrolysis process. 


\subsubsection{Review of the pyrolysis of different biomass materials}

In this section, the recent studies on the pyrolysis process of different biomass materials are reviewed. The review focuses on the type of the pyrolysis and reactor and operating temperature as well. The pyrolysis product (bio-oil, char and noncondensable gases) are also of great interest in this section.

Rice, wheat and sugar cane residues are present in large quantities in the Middle East as mentioned in the previous chapter of this study. So, they take a lot of consideration in this review.

Commercial-scale downdraft circulating fluidized-bed fast pyrolysis system with a feeding capacity of $3 \mathrm{t} / \mathrm{h}$ was studied by Cai et al. [138] for biofuel production from rice husk. The system was continuously operated at $550{ }^{\circ} \mathrm{C}$ for $80.42 \mathrm{~h}$. The biooil properties such as water content, density, viscosity, $\mathrm{pH}$, specific heat, solid and ash contents were also analyzed. They found that all the tested properties of the bio-oil meet the pyrolysis liquid biofuels standards, except for the water content of the biooil, which is considered slight high. Their energy balance analysis showed that the potential recovered energy of the three main products is 8.0, 2.1 and 5.3 MJ/kg for bio-oil, char and non-condensable gas, respectively.

The biofuel production from the rice husk was also experimentally studied by Wang and Jan [139] using laboratory fluidized bed fast pyrolysis system. They found that the maximum bio-oil yield of $34.4 \%$ can be achieved at $450{ }^{\circ} \mathrm{C}$.

The fast pyrolysis of rice husk using fixed bed reactor was also studied by $\mathrm{Hu}$ et al. [140] and Gautam and Chaurasia [141]. The results obtained from these studies are summarized in Table 2.2.

The slow pyrolysis of rice husk using fixed bed reactor was studied by Vieira et al. [142]. They studied the effect of changing the heating rate heating rate $(5,10$ and $\left.20{ }^{\circ} \mathrm{C} / \mathrm{min}\right)$, temperature $\left(300,400\right.$, and $\left.500{ }^{\circ} \mathrm{C}\right)$ and residence time $(3600,5400$ and $7200 \mathrm{~s}$ ) on the slow pyrolysis yield. They found that the temperature is the most significant parameter for the slow pyrolysis process to produce bio-char of good thermal characteristics.

Slow pyrolysis of wheat straw in fixed bed reactor is investigated by Farooq et al. [143]. Considerable bio-oil yields are obtained from the wheat straw pyrolysis compared with that obtained from the slow pyrolysis of the biomass materials as obviously seen in Table 2.2. 
Many studies have been conducted for biofuel production from the sugar cane residues by using slow [144-146] and fast pyrolysis [147, 148] process. The results showed that high bio-oil yield of $43 \%$ is obtained from the pyrolysis of sugar cane bagasse in fixed bed reactor [144].

Gutiérrez et al. [88] used pyrolysis process to obtain bio-oil from cardoon. They concluded that high yield of bio-oil reaches $38.91 \%$ can be achieved by the pyrolysis of cardoon.

Slow pyrolysis of various materials were also studied such as bamboo subfamily [149], crambe seeds [150], cypress [151], vegetable waste and pine cones [152], walnut shells [136], live and dead vegetation native to the southern United State of America [153].

The various biomass materials recently studied for biofuel production using pyrolysis processes are summarized in Table 2. 2 . 
Table 2. 2. The biomass materials recently studied for biofuel production by pyrolysis process

\begin{tabular}{|c|c|c|c|c|c|c|}
\hline \multirow[t]{2}{*}{ Biomass material } & \multirow[t]{2}{*}{ Type of pyrolysis/ reactor } & \multirow{2}{*}{$\begin{array}{l}\text { Operating } \\
\text { temperature }\left({ }^{\circ} \mathrm{C}\right)\end{array}$} & \multicolumn{3}{|l|}{ Pyrolysis yield (\%) } & \multirow[t]{2}{*}{ Ref. } \\
\hline & & & Bio-oil & Char & Gases & \\
\hline \multirow{5}{*}{ Rice husk } & $\begin{array}{l}\text { Fast pyrolysis/downdraft circulating fluidized bed } \\
\text { reactor }\end{array}$ & 550 & 53.2 & 30 & 16.8 & [138] \\
\hline & Fast pyrolysis/Fluidized bed & 450 & 40 & 27 & 33 & [139] \\
\hline & Fast pyrolysis/Fixed bed reactor & 550 & 40.26 & 34.39 & & [140] \\
\hline & Fast pyrolysis/Fixed bed reactor & $450-650$ & $42\left(\right.$ at $\left.550^{\circ} \mathrm{C}\right)$ & 40 & 18 & [141] \\
\hline & Slow pyrolysis/Fixed bed reactor & $300-500$ & $39.84\left(\right.$ at $\left.400^{\circ} \mathrm{C}\right)$ & 37.51 & 9.81 & [142] \\
\hline \multirow{3}{*}{ Rice straw } & Slow pyrolysis/ auger reactor & & 25.7 & 44.9 & 13.2 & \\
\hline & Slow pyrolysis/batch reactor & 500 & 31.3 & 47.7 & 11.5 & [121] \\
\hline & Fast pyrolysis/Fluidized bed reactor & & 43.4 & 26.8 & 23 & \\
\hline Wheat straw & Slow pyrolysis/ fixed bed reactor & 500 & 35 & 32 & 33 & [143] \\
\hline Sugar cane bagasse & Slow pyrolysis/fixed bed reactor & $300-550$ & 43 (at $420^{\circ} \mathrm{C}$ ) & 32.6 & 24.4 & [144] \\
\hline Sugar cane straw & Fast pyrolysis/fluidized bed reactor & $470-600$ & $35.5\left(\right.$ at $470{ }^{\circ} \mathrm{C}$ ) & 48.2 & 16.3 & [147] \\
\hline Giant fennel & Slow pyrolysis/fixed bed reactor & $300-600$ & $45.02\left(\right.$ at $500^{\circ} \mathrm{C}$ ) & 26.15 & 28.83 & [128] \\
\hline walnut shells & Slow pyrolysis/fixed bed reactor & $300-600$ & $42\left(\right.$ at $\left.500^{\circ} \mathrm{C}\right)$ & 32 & 26 & [136] \\
\hline Grape seeds & Slow pyrolysis/fixed bed reactor & 550 & 38.8 & 33.4 & 23.9 & [154] \\
\hline Wood sawdust & Semi batch reactor & $350-650$ & $44.16\left(\right.$ at $500^{\circ} \mathrm{C}$ ) & 30 & 25.84 & [130] \\
\hline Beech wood & Catalytic hydro-pyrolysis/fluidized bed reactor & $365-511$ & 22.5 at $\left(511^{\circ} \mathrm{C}\right)$ & 67.5 & 10 & [129] \\
\hline Waste cooking oil & Laboratory scale fixed-bed reactor & $550-800$ & 80 (at $800{ }^{\circ} \mathrm{C}$ ) & 0 & 20 & [155] \\
\hline
\end{tabular}




\subsubsection{Literature review on biofuel production from date palm wastes}

The potential of date palm residues conversion to biofuel were studied by many researchers in the Middle East and North Africa, where the date palm trees are abundantly available. The proximate, ultimate, and thermo-gravimetric analyses are considered the primary step in any approach to biofuel production from any biomass material. This step is very important to determine the physical and chemical properties of the biomass and its elemental composition. Based on these analyses the utilization potential of any feedstock as biomass for bio-fuel production can be identified.

Nasser et al. [85] used the proximate, ultimate, and thermo-gravimetric techniques to chemically analyze the different parts of date palm. Samples from different parts of date palm were collected and experimentally studied, namely date stone, leaflets, trunk, frond base and midrib, coir, fruit stem, and fruit empty bunches. The ultimate analysis showed that high carbon and hydrogen contents are found in the date stone compared with other parts of date palm as illustrated in Table 2.3. Based on their obtained results, they recommended date palm stones and palm coir for biofuel production using the pyrolysis process. Among the different date palm residues, the date palm stone is also recommended by El may et al. [55] for biofuel production. The proximate, and ultimate analysis were used by many researchers in the Middle East in order to chemically analyze the different parts of date palm wastes such as stones [20, 156], rachis[21, 82, 156], leaflets[21, 82, 156], empty fruit bunches [21, 82], Glaich [82], and fronds [157]. The results obtained from these studies are summarized in Table 2.3.

From the results tabulated in Table 2.3, the highest carbon content of (45.3$51.2 \%)$ was found in date palm stone $[20,55,85,156]$.

Pyrolysis kinetics of date palm wastes (stones, leaflets and rachis) are studied by Sait et al. [156] using thermo-gravimetric analysis technique. They concluded that the date palm stones and leaflets showed almost similar pyrolysis characteristics. 
Table 2. 3. Elemental composition of date palm wastes (weight basis)

\begin{tabular}{|c|c|c|c|c|c|c|}
\hline Biomass material & C \% & Н \% & $\mathbf{N} \%$ & S \% & $0 \%^{a}$ & Ref. \\
\hline \multirow[t]{4}{*}{ Date palm stone } & 48.43 & 6.44 & 0.67 & - & 42.2 & [20] \\
\hline & 47.14 & 6.63 & 0.9 & - & 45.33 & [85] \\
\hline & 51.2 & 6.4 & 0.73 & $<0.2$ & 40.9 & [55] \\
\hline & 45.3 & 5.6 & 1 & 0.8 & 47.2 & [156] \\
\hline \multirow[t]{4}{*}{ Date palm rachis } & 39.95 & 7.19 & 0.158 & - & 52.7 & [82] \\
\hline & 39.8 & 5.7 & 0.19 & 0.26 & 43 & [55] \\
\hline & 36.1 & 5.2 & 0.7 & 0.7 & 57.2 & [156] \\
\hline & 42.67 & 5.83 & 0.58 & 0.15 & 50.78 & [21] \\
\hline \multirow[t]{5}{*}{ Date Palm Leaflets } & 43.14 & 7.49 & 0.196 & - & 52.71 & [82] \\
\hline & 46.5 & 5.69 & 0.66 & - & 47.15 & [85] \\
\hline & 40.8 & 6 & 0.63 & 0.21 & 35.2 & [55] \\
\hline & 49.4 & 5.8 & 1.2 & 1.3 & 42.3 & [156] \\
\hline & 40.76 & 5.55 & 1.32 & 0.24 & 52.14 & [21] \\
\hline \multirow[t]{2}{*}{ Date Palm trunk } & 44.46 & 5.75 & 0.55 & - & 49.24 & [85] \\
\hline & 42.76 & 5.8 & 0.21 & 0.12 & 45.5 & [55] \\
\hline \multirow[t]{2}{*}{ Date Palm fruit stalk pruning } & 44.47 & 5.97 & 0.32 & - & 49.24 & [85] \\
\hline & 42.7 & 5.8 & $<0.3$ & $<0.2$ & 40.9 & [55] \\
\hline \multirow{3}{*}{ Date palm Empty Fruit Bunches } & 43.49 & 7.51 & 0.188 & - & 52.73 & {$[82]$} \\
\hline & 45.58 & 6.03 & 0.26 & - & 48.13 & [85] \\
\hline & 44.07 & 5.97 & 0.74 & 0.18 & 49.05 & [21] \\
\hline \multirow[t]{2}{*}{ Date palm frond base } & 40.48 & 5.63 & 0.28 & - & 53.61 & [85] \\
\hline & $36.3-38.9$ & $5.4-5.7$ & $0.28-0.47$ & $0.33-0.66$ & $54.4-57.6$ & [157] \\
\hline Date palm frond midrib & 45.65 & 5.95 & 0.27 & - & 48.13 & [85] \\
\hline Date Palm Glaich & 43.65 & 7.59 & 0.158 & - & 52.74 & [82] \\
\hline
\end{tabular}


The slow pyrolysis of palm date stones in a laboratory scale semi-batch fixed bed reactor was investigated by Fadhil et al. [20]. They used the Perkin $240 \mathrm{C}$ Elemental Analyzer to determine the date stones carbon, hydrogen and nitrogen contents. The cellulose, hemicellulose and lignin contents were also determined according to the procedure described by the national renewable energy laboratory (NREL) [158]. The influence of the pyrolysis temperature, time and date stones size on the bio-oil yield was also studied. They found that the maximum bio-oil yield of $52.67 \%$ is obtained when the temperature and time of the pyrolysis process are $500{ }^{\circ} \mathrm{C}$ and $60 \mathrm{~min}$, respectively, when date stone size of $0.25 \mathrm{~mm}$ is used as shown in Table 2.4. The proximate and ultimate analysis were performed to obtain the physical and chemical properties of the bio-oil. Furthermore, they also used adsorption column chromatography to determine the chemical composition of the obtained bio-oil. They found that the chemical composition of the bio-oil produced from the pyrolysis of date stones showed the potential of date stones is an important source of alternative fuel and chemicals as well.

Recently, slow pyrolysis of date palm stones and date palm mixture wastes in a bench-scale fluidized bed reactor was studied by Bharath et al. [84]. In order to optimize the production of pyrolysis bio-oil, they studied the effects of varying the different experimental parameters such as the pyrolysis time (10-60 $\mathrm{min})$, temperature (300-600 $\left.{ }^{\circ} \mathrm{C}\right)$, fluidizing gas flow rate $(5-30 \mathrm{~mL} / \mathrm{min})$, and biomass loading (50-350 g). The elemental analysis of the used date palm waste (DPW) and the obtained biooil were also conducted. In addition, the chemical composition of the bio-oil were also found using the GC-MS analysis. Their results showed that a high quantity of bio-oil is produced from the pyrolysis of date stone and date palm mixture wastes at $500{ }^{\circ} \mathrm{C}$ for $30 \mathrm{~min}$ with a feedstock loading of $200 \mathrm{~g}$ and fluidizing gas flow rate of $10 \mathrm{~mL} / \mathrm{min}$.

Slow Pyrolysis of DPW in a fixed-bed reactor was studied by Bensidhom et al. [82]. The DPW includes date palm rachis (DPR), date palm leaflets (DPL), empty fruit bunches (EFB) and date palm Glaich (DPG). The moisture, volatile matter, ash and fixed carbon contents of the DPWs were firstly determined. The celluloses, hemicelluloses and lignin were also measured. The pyrolysis of the different DPW samples were conducted in fixed bed reactor at final temperature of $500{ }^{\circ} \mathrm{C}$, with heating rate of $15^{\circ} \mathrm{C} / \mathrm{min}$. The elemental analysis of bio-oil and char obtained from each DPW was also determined. They also presented the composition of the syngas 
obtained from each DPW. They concluded that the maximum bio-oil is obtained from the pyrolysis of date palm empty fruits bunches which reaches $25.99 \%$ followed by rachis which produces bio-oil of $25.9 \%$ as illustrated in Table 2.4.

The fast pyrolysis of several date palm wastes such as leaflets, rachis (leaf stem), empty fruit bunches and mixture of DPW was performed by Makkawi et al. [21]. The fast pyrolysis was performed in a bubbling fluidized bed reactor at $525{ }^{\circ} \mathrm{C}$. The proximate and ultimate analysis of different used DPW as well as their produced bio-oil were conducted. The chemical composition of the bio-oil was also determined using GC-MS analysis. They found that the pyrolysis yield consists of $38.75 \%$ biooil, $37.23 \%$ bio-char and $24.02 \%$ non-condensable gas. The GC-MS analysis showed that the bio-oil consisted of at least 140 detectable compounds, where d-Allose (monosaccharide), phenols, catechol and apocynin are the main components.

In order to recognise the effect of the pyrolysis temperature on the produced bio-char, a slow pyrolysis of date palm rachis was conducted at two temperatures (700 and $900{ }^{\circ} \mathrm{C}$ ) by Poulose et al. [159]. The elemental analysis showed that the carbon content of bio-char has increased from $66.7 \%$ to $69.38 \%$ as the pyrolysis temperature is increased from $700{ }^{\circ} \mathrm{C}$ to $900{ }^{\circ} \mathrm{C}$, while the hydrogen and oxygen contents decreased from $1.01 \%$ to $0.65 \%$ and from $8.05 \%$ to $5.35 \%$, respectively.

An optimized model of fast pyrolysis was developed by Mabrouki et al. [160] for the production of bio-fuels from date palm rachis, olive stones, vine stems and almond shells. Simulation tests were performed at different temperatures ranging from 450 to $650{ }^{\circ} \mathrm{C}$, and residence times ranging from 0.1 to $10 \mathrm{~s}$. The optimal temperature and residence time that give the maximum yield of bio-oil are found $575{ }^{\circ} \mathrm{C}$ and 0.25 $\mathrm{s}$, respectively. They found also that the highest yield of bio-oil is obtained from the date palm rachis flowed by vine stem.

In order to maximize the bio-oil yield from the slow pyrolysis of date palm shell, an helical screw fluidized bed reactor was designed and installed by Qureshi et al. [161]. Their experiments were performed with heating rate of $10{ }^{\circ} \mathrm{C} / \mathrm{min}$ to reach $500{ }^{\circ} \mathrm{C}$ without using any inert gases. They found that the bio-oil yield is increased from 38.4 to $51.6 \mathrm{wt}$ \% when the helical screw rotation is increased from 0 to $50-\mathrm{rpm}$. The elemental analysis of the bio-oil and char were also performed. Moreover, the chemical composition of the produce bio-oil was also determined.

The production of bio-char from slow pyrolysis of date palm fronds was investigated by Jouiad et al. [162]. The proximate analysis showed that the bio-char 
produced from the fronds of date palm has fixed carbon $45 \%$, volatile $43.2 \%$ and ash $7.1 \%$; while the elemental analysis showed high carbon content of $60.9 \%$.

A pyrolysis of date palm waste heated by parabolic trough solar collector was designed and simulated by Giwa et al. [163] for bio-char production. The economic and environmental sustainability implications were also evaluated. Their proposed system not only shows sustainable opportunities for bio-char production but also reduces the life cycle emissions and costs. 
Table 2. 4. The pyrolysis product obtained from different date palm wastes in wet basis.

\begin{tabular}{|c|c|c|c|c|c|c|}
\hline Ref. & Pyrolysis mode/type of reactor & $\begin{array}{l}\text { Temperature }\left({ }^{\circ} \mathrm{C}\right) \text {, } \\
\text { heating rate } \\
\left({ }^{\circ} \mathrm{C} / \mathrm{min}\right)\end{array}$ & Date palm wastes & Bio-oil (\%) & Char $(\%)$ & $\begin{array}{l}\text { Gases } \\
(\%)\end{array}$ \\
\hline [20] & $\begin{array}{l}\text { Slow/laboratory scale fixed bed } \\
\text { reactor }\end{array}$ & $350-600,20$ & Date palm stone & $52.67\left(\max\right.$. at $\left.500^{\circ} \mathrm{C}\right)$ & 22.33 & 25 \\
\hline [84] & Slow pyrolysis/ fluidized bed reactor & $300-600,20$ & & $66.5\left(\max\right.$. at $500{ }^{\circ} \mathrm{C}$ ) & 27.3 & 6.2 \\
\hline \multirow[t]{4}{*}{ [82] } & Slow/fixed bed & 500,15 & Date palm rachis & 25.9 & 35 & 39.1 \\
\hline & & & Date Palm Leaflets & 17.03 & 36.66 & 46.31 \\
\hline & & & Empty Fruit Bunches & 25.99 & 33.33 & 40.68 \\
\hline & & & Date Palm Glaich & 25 & 31.63 & 43.37 \\
\hline \multirow[t]{2}{*}{ [161] } & $\begin{array}{l}\text { Slow/helical screw fluidized bed } \\
\text { reactor without rotation }\end{array}$ & 500,10 & Palm shell & 38.4 & 35.5 & 26.1 \\
\hline & $\begin{array}{l}\text { Slow/helical screw fluidized bed } \\
\text { reactor with rotation } 50 \mathrm{rpm}\end{array}$ & 500,10 & Palm shell & 51.6 & 26.6 & 21.8 \\
\hline [164] & Slow /fixed bed & $550 / 10$ & Date palm frond & 49 & 26 & 25 \\
\hline [21] & $\begin{array}{l}\text { Fast/bubbling } \\
\text { fluidized bed }\end{array}$ & $525 /-$ & $\begin{array}{l}\text { Mixture of date palm } \\
\text { wastes }\end{array}$ & 38.75 & 37.23 & 24.02 \\
\hline
\end{tabular}


Among the several date palm wastes displayed in Table 2.4, the maximum bio-oil yield of $66.5 \%$ is obtained from date palm stone by slow pyrolysis recently conducted by Bharath et al. [84] using fluidized bed reactor at $500{ }^{\circ} \mathrm{C}$ and heating rate $20{ }^{\circ} \mathrm{C} / \mathrm{min}$. The bio-oil production from the slow pyrolysis of date palm stone, performed by Fadhil et al. [20] in a fixed bed reactor at $500{ }^{\circ} \mathrm{C}$ with heating rate $20{ }^{\circ} \mathrm{C} / \mathrm{min}$, comes in the second rank with $52.67 \%$. The slow pyrolysis of palm shell in fluidized bed reactor at 500 with heating rate $10{ }^{\circ} \mathrm{C} / \mathrm{min}$ is also of high amount $51.6 \%$, followed by the slow pyrolysis of the palm frond in a fixed bed reactor at $550{ }^{\circ} \mathrm{C}$ with heating rate $10{ }^{\circ} \mathrm{C} / \mathrm{min}$. While the first top four process of char production are the fast pyrolysis of date palm mixture wastes including rachis [21], slow pyrolysis of leaflets [82], palm shell [161], and rachis [82] using fixed bed reactor.

Finally, the results of Table 2.4 shows that the selection of specific date palm waste as well as the pyrolysis type for biofuel production depends on the biofuel type that required to be optimized. So, in order to optimize the bio-oil yield based on the results of Table 2.4, it is recommended to use slow pyrolysis of date palm stone in fluidized bed or fixed bed reactor, at temperature of $500{ }^{\circ} \mathrm{C}$ and heating rate of 20 ${ }^{\circ} \mathrm{C} / \mathrm{min}$. While the slow pyrolysis of leaflets, rachis and palm shell in fixed bed reactor is recommended for bio-char production.

\subsubsection{The products of the date palm waste pyrolysis}

The characterization of the pyrolysis products obtained from the date palm wastes (bio-oil, char and gas) is studied by many researchers in the Middle East and north of Africa $[20,21,82]$. The characterization of the bio-oil and bio-char includes the proximate and ultimate analysis in order to determine the physical and chemical properties in addition to its elemental composition. While the GC-MS analysis is used to obtain the chemical composition of bio-oil. The syngas composition is also measured using a gas analyzer. In the following section the characterization of bio-oil, char and non-condensable gases specifically obtained from the date palm wastes pyrolysis are reviewed.

\subsection{Characterization of the pyrolysis bio-oil}

In order to consider the bio-oil for any application, it is very important to know the composition, physical and chemical properties of the bio-oil extracted from the 
pyrolysis process. Table 2.5 displays the elemental analysis of the bio-oil obtained from several date palm wastes. The date palm stone shows high carbon content of $73.56 \%$ compared with other date palm wastes. It is similar to other plant seeds especially rapeseed and linseed as clearly seen in Table 2.5 .

The chemical composition of the bio-oil obtained from the pyrolysis of several DPW such as date palm stones [84], palm frond [164], palm shell [161] and date palm mixture wastes [84] are summarized in Table 2.5.

Table 2. 5. Ultimate analysis of the bio-oil obtained from the pyrolysis of date palm wastes compared with other agricultural wastes.

\begin{tabular}{|c|c|c|c|c|c|c|}
\hline Biomass material & $\mathrm{C} \%$ & Н \% & $\mathbf{N} \%$ & S \% & $0 \%^{a}$ & $\begin{array}{c}\text { HHV } \\
(\mathbf{M J} / \mathbf{k g})\end{array}$ \\
\hline Date palm stone [20] & 73.56 & 10.50 & 1.26 & - & 14.68 & 37.38 \\
\hline Date palm rachis [82] & 60.43 & 8.02 & 0.012 & - & 31.45 & 24.21 \\
\hline Date Palm Leaflets [82] & 51.5 & 7.68 & 0.046 & - & 40.78 & 21.46 \\
\hline $\begin{array}{c}\text { Empty Fruit Bunches } \\
{[82]}\end{array}$ & 57.45 & 8.07 & 0.037 & - & 34.45 & 23.4 \\
\hline Date Palm Glaich [82] & 58.7 & 8.25 & 0.025 & - & 32.97 & 23.89 \\
\hline Palm shell [161] & $65-77$ & 12 & $6.6-9.5$ & 0.92 & $0.4-14.9$ & $37-43.7$ \\
\hline $\begin{array}{l}\text { Mixture of date palm } \\
\text { wastes [21] }\end{array}$ & 49.63 & 7.35 & 1.09 & 0.1 & 41.84 & 20.88 \\
\hline Rice husk [86] & 23.38 & 10.39 & 0.51 & $<0.1$ & 65.63 & 28.71 \\
\hline Rapeseed [165] & 73.1 & 11.5 & 4.7 & 0 & 10.7 & - \\
\hline Linseed [166] & 75.42 & 10.26 & 1.5 & 0 & 13.8 & - \\
\hline Pistachio shell [89] & 67.44 & 7.82 & 0.42 & - & 24.32 & - \\
\hline Apricot shell [91] & 64.45 & 8.24 & 0.18 & - & 26.5 & 27.19 \\
\hline Mahua seed [92] & 69.23 & 9.12 & 2.53 & - & 18.14 & 39.02 \\
\hline Pomegranate seeds [167] & 64.26 & 8.21 & 2.06 & - & 25.43 & 34.67 \\
\hline
\end{tabular}




\subsection{Characterization of the bio-char}

Rarely studies on the characterization of the bio-char obtained from the pyrolysis of FPW were found in the literature. The elemental analysis of the bio char obtained from the date palm rachis, leaflets, empty fruit bunches and glaich by pyrolysis at $500{ }^{\circ} \mathrm{C}$ and $15^{\circ} \mathrm{C} / \mathrm{min}$ are summarized in Table 2.6. It is obviously seen in this table that the carbon content is found in the range of 52.70-62.68 \% for all DPW except glaich, where high carbon content is found $(73.68 \%)$. The bio-char hydrogen content is found in the range 3.21-6.62 \%, nitrogen content varied from 0.13 to $0.21 \%$, and oxygen content was $22.30-34.12 \%$, except for leaflets sample which had $40.54 \%$ of oxygen content. The carbon, hydrogen and oxygen contents are close to those of bio-char samples obtained from grape seeds using fixed bed reactor at final temperature $500{ }^{\circ} \mathrm{C}$ [168] and bio-char samples obtained from cherry seed and cherry seed shell [169]. 
Table 2. 6. The elemental analysis of the bio-char obtained from different palm tree parts on wet basis.

\begin{tabular}{|c|c|c|c|c|c|c|c|c|}
\hline Ref. & $\begin{array}{c}\text { Type of pyrolysis, temperature, and } \\
\text { heating rate }\end{array}$ & Biomass material & $\mathrm{C} \%$ & H \% & $\mathbf{N} \%$ & $\mathbf{S} \%$ & $0 \%$ & $\begin{array}{c}\text { HHV } \\
\text { (MJ/kg) }\end{array}$ \\
\hline \multirow[t]{4}{*}[82]{} & Slow pyrolysis in fixed bed reactor, $500^{\circ} \mathrm{C}$, & Date palm rachis & 62.68 & 4.32 & 0.129 & - & 32.87 & 22.36 \\
\hline & & Date Palm Leaflets & 52.7 & 6.62 & 0.135 & - & 40.54 & 21.09 \\
\hline & & Empty Fruit Bunches & 62.47 & 3.21 & 0.206 & - & 34.12 & 21.56 \\
\hline & & Date Palm Glaich & 73.68 & 3.86 & 0.61 & - & 22.3 & 25.16 \\
\hline \multirow[t]{2}{*}[159]{} & Slow pyrolysis, $700^{\circ} \mathrm{C}$ & & 66.7 & 1.01 & - & - & 8.05 & - \\
\hline & Slow pyrolysis, $900^{\circ} \mathrm{C}$ & Date palm rachis & 69.38 & 0.65 & - & - & 5.35 & - \\
\hline [162] & Slow pyrolysis, $400{ }^{\circ} \mathrm{C}, 5^{\circ} \mathrm{C} / \mathrm{min}$ & Date palm fronds & 60.9 & 2.5 & 1.2 & 2.2 & 25.6 & - \\
\hline \multirow[t]{2}{*}{ [161] } & $\begin{array}{l}\text { Slow/helical screw fluidized bed reactor } \\
\text { without rotation, } 500{ }^{\circ} \mathrm{C}, 10^{\circ} \mathrm{C} / \mathrm{min}\end{array}$ & & 60.12 & 9.21 & 0.42 & 0.92 & 29.33 & 31.3 \\
\hline & $\begin{array}{l}\text { Slow/helical screw fluidized bed reactor with } \\
\text { rotation } 50 \mathrm{rpm}, 500{ }^{\circ} \mathrm{C}, 10^{\circ} \mathrm{C} / \mathrm{min}\end{array}$ & Date palm shell & 57.45 & 9.62 & 0.28 & 0.67 & 31.98 & 27.5 \\
\hline
\end{tabular}




\subsection{The composition of non-condensable gases (syngas)}

Rarely studies have reported the composition of non-condensable gases obtained from the pyrolysis of date palm wastes. The composition of syngas obtained from the slow pyrolysis of date palm rachis, leaflets, empty fruit bunches and glaich are determined by Bensidhom et al. [82] using a gas analyzer. The main component of the syngas is $\mathrm{CO}$ which constitutes $31.8-57.95 \%$ as clearly seen in Table 2.7. The maximum amount of CO of $57.95 \%$ is obtained from rachis, followed by empty fruit bunches which reaches $55.15 \%$. A considerable amount of $\mathrm{H}_{2}(12.76 \%)$ and $\mathrm{CH}_{4}(6.7 \%)$ are obtained from date palm empty fruit bunches.

Table 2. 7. The chemical composition of syngas obtained from the pyrolysis of several date palm wastes.

\begin{tabular}{|c|c|c|c|c|c|c|}
\hline Ref. & Biomass material & $\begin{array}{l}\mathrm{CO} \\
\text { (wt.\%) }\end{array}$ & $\begin{array}{l}\mathrm{CO}_{2} \\
(\mathrm{wt} . \%)\end{array}$ & $\begin{array}{l}\mathrm{CH}_{4} \\
(\mathrm{wt} . \%)\end{array}$ & $\begin{array}{l}\mathrm{C}_{\mathrm{n}} \mathrm{H}_{\mathrm{m}} \\
(\mathrm{wt} . \%)\end{array}$ & $\begin{array}{l}\mathrm{H}_{2} \\
\text { (wt.\%) }\end{array}$ \\
\hline \multirow[t]{4}{*}[82]{} & Date palm rachis & 57.95 & 0.55 & 2.61 & 0.52 & 0.71 \\
\hline & Date palm leaflets & 50.03 & 0.33 & 3.27 & 0.52 & 1.90 \\
\hline & $\begin{array}{l}\text { Date palm empty fruit } \\
\text { bunches }\end{array}$ & 55.15 & 0.41 & 6.70 & 0.70 & 12.76 \\
\hline & Date palm glaich & 31.80 & 0.34 & 3.60 & 0.53 & 1.96 \\
\hline
\end{tabular}

From the results reviewed in this chapter, and based on the abundant of date palm trees in the Middle East, date palm wastes especially date stones and rachis are useful as source of biofuel production using the pyrolysis process. 


\section{Chapter 3}

\section{Thermochemical characterisation of biomass and bio-oil}

\subsection{Introduction}

Several factors affect the fuel properties obtained from biomass materials. Lignin and higher extractives contents contribute to a high heating value [170,171], while ash content in the biomass is considered as an undesirable material for fuel production [171-175]. The

density and heating value of the raw material are also very important factors affecting the overall fuel production [171, 176-178].

The chemical energy of a solid fuel is stored in the forms of volatiles and fixed carbon [64]. The volatile matter content (VM) is the portion driven off as a vapour or gas by heating the biomass to $950^{\circ} \mathrm{C}$, while the remaining portion is known as fixed carbon (FC), excluding the ash and moisture contents. The measurement of VM, FC, ash and water contents (WC) is known as a proximate analysis which is considered an excellent method to predict the heating values of a biomass [179-182].

The elemental analysis (ultimate analysis) is used to determine the elemental mass fraction of carbon, hydrogen, nitrogen, sulphur and oxygen $(\mathrm{C}, \mathrm{H}, \mathrm{N}, \mathrm{S}$ and $\mathrm{O})$ in the biomass, bio-oil, and bio-char. High oxygen content in the feedstock promotes the formation of oxygenated compounds in the bio-oil which have a negative impact on the bio-oil stability and limit its application as a transportation fuel [21]. High sulphur content is also unwanted, as it increases the corrosion and undesirable gas emissions [21].

Thermo-gravimetric analysis (TGA) was used to recognise the thermochemical conversion kinetics of several biomasses such as date seed [156, 183], wheat straw [87], peanut shell, corncob and pine needle [173].

Unlike the conventional crude oil derived from fossil fuels (such as petroleum and coal oil), the chemical composition of bio-oil from fast pyrolysis of biomass is highly complex and contains a vast array of chemical compounds and a water fraction. Bio-oil is generally known to be thermally unstable and has high tendency to polymerize when exposed to air $[102,184]$. So, The GC/MS analysis is also of great important, where it specify the chemical composition of the produced bio-oil. 
In this study, the thermochemical characterisation of date palm stones and rachis obtained from two types of palm trees, Barhee and Medjool is experimentally studied. This chapter describe in detail the analysis methods used for characterization of the biomass feedstock and the product bio-oil from pyrolysis.

\subsection{Biomass characterisation methods:}

\subsubsection{Proximate analysis}

The proximate analysis is used to determine the physical characteristics of biomass. Using this method, the moisture content, volatile matter, ash, fixed carbon, total solid, calorific value and decomposition temperature of the biomass sample can be obtained.

\subsubsection{Moisture content}

The moisture content $(M C)$ is defined as the amount of water present in the sample which significantly changes when exposed to air [185]. In the current work, the moisture content was determined according to the ASTM E1757-01. Where the biomass is dried at $105^{\circ} \mathrm{C}$ for 3 to 72 hours the percentage of remaining solids can be calculated as follow:

$$
\begin{gathered}
m_{s, 105} \%=\frac{m_{f}-m_{c}}{m_{i}-m_{c}} \times 100 \\
M C \%=\left(100-m_{s, 105} \%\right) .
\end{gathered}
$$

Where:

$m_{s, 105}, m_{c}, m_{i}$, and $m_{f}$, are the mass percent of total solids based on $105^{\circ} \mathrm{C}$, the mass of the dried container, initial mass of the container and biomass and the final mass of the container and the biomass at $105^{\circ} \mathrm{C}$.

\subsubsection{Volatile content}

The volatile content is the amount of gaseous products released (excluding moisture) when the sample is exposed to high temperatures. Furnace of maximum temperature 1100 ${ }^{\circ} \mathrm{C}$ was used in this test, where the sample is placed in a crucible at temperature $900^{\circ} \mathrm{C}$ for 7 minutes. Afterwards, the crucible and the sample were removed from the furnace and the weight of the crucible and sample was measured. The difference in weight loss before and after heating cycle inside the furnace is representative of the amount of the volatile compounds [186]. Firstly, the weight loss percentage is given by: 


$$
\text { Weight loss, } \%=\frac{\mathrm{A}-\mathrm{B}}{\mathrm{A}} \times 100 .
$$

Where A and B are the weight of sample before and after heating, respectively.

The volatile matter is then calculated by:

$$
\text { Volatile matter }(V M), \%=C-D \text {. }
$$

Where $\mathrm{C}$ is the weight loss percentage; while $\mathrm{D}$ is the moisture content percentage.

\subsubsection{Ash content}

The ash is the residual inorganic mass that remains after the combustion of the biomass at a given temperature $[186,187]$. The ash content is measured after the moisture content test according to the ASTM E 1755-01 standard. This test involves heating up the sample at temperatures around $575 \pm 25^{\circ} \mathrm{C}$ for 3 hours. The remaining mass represents the weight of ash. The moisture-free solid in the biomass sample can be calculated based on the value of $m_{s, 105}$ calculateted using Eq. (3.1):

$$
m_{s}=\left(m_{i}-m_{c}\right) \times m_{s, 105} .
$$

Where:

$m_{s}$ : is the mass of moisture-free solids in the biomass sample, $m_{i}$ : is the initial mass of the prepared sample and the container, $m_{c}$ : is the mass of the container, $m_{s, 105}$ : is the mass percent of total solids based on $105^{\circ} \mathrm{C}$ mass.

Afterwards, the percentage of ash can be calculated using the following equation:

$$
a s h \%=\frac{m_{a s h}-m_{c}}{m_{s}} \times 100 .
$$

Where:

$\%$ ash: is the mass percentage of ash based on $105^{\circ} \mathrm{C}$ oven-dried mass of the sample, $m_{\text {ash }}:$ is the mass of ash and container, $m_{s}$ : is the mass of the moisture-free solids in the prepared sample. 


\subsubsection{Fixed carbon}

The fixed carbon is defined as the amount of carbon left in the sample after the sample has been heated to thermally decompose. The fixed carbon can be calculated as follow [188]:

$$
F C \%=100-(M C \%+V M \%+a s h \%)
$$

\subsubsection{Elemental analysis (Ultimate analysis)}

The ultimate analysis provides information about the elemental components such as carbon, hydrogen, nitrogen, oxygen and sulphur contents [187, 189]. This analysis can be carried out by passing the biomass sample through a reduction furnace where the sample is separated in a chromatographic column using helium as the carrier gas. The device contains a thermal conductivity detector that specifies the concentration of the individual elements in the sample [190]. In fact, the equipment that carry out this analysis is not available in the laboratory, so, the samples were sent to MEDAC LTD (analytical and chemical consultancy services) to carry out the ultimate analysis. Where carbon, hydrogen and nitrogen were provided, while the oxygen content was calculated from the difference.

\subsubsection{Structure/Composition Analysis}

\subsubsection{The Compositional Pelican Method}

The compositional or the pelican method determines the neutral detergent fibre (NDF). Where a powdered biomass sample of $0.5-1 \mathrm{~g}$ was placed in a crucible in which $100 \mathrm{ml}$ of a neutral detergent solution and $0.5 \mathrm{~g}$ of sodium sulphite were previously added at room temperature. The sample was then heated to $400{ }^{\circ} \mathrm{C}$ then it is refluxed for 60 minutes from the onset of boiling. The mixture is then filtered and washed with water and acetone and the crucible was dried at $105^{\circ} \mathrm{C}$ for 8 hours as shown in Fig. 3. 1. The remaining mass shown in Fig 3.1 represents the NDF. The percentage of NDF was calculated according to Soest et al. [191] as follows:

$$
\operatorname{NDF}(\%)=\frac{(\text { Weight of crucible }+N D F)-\text { Weight of crucible }}{\text { Weight of sample }} \times 100 .
$$



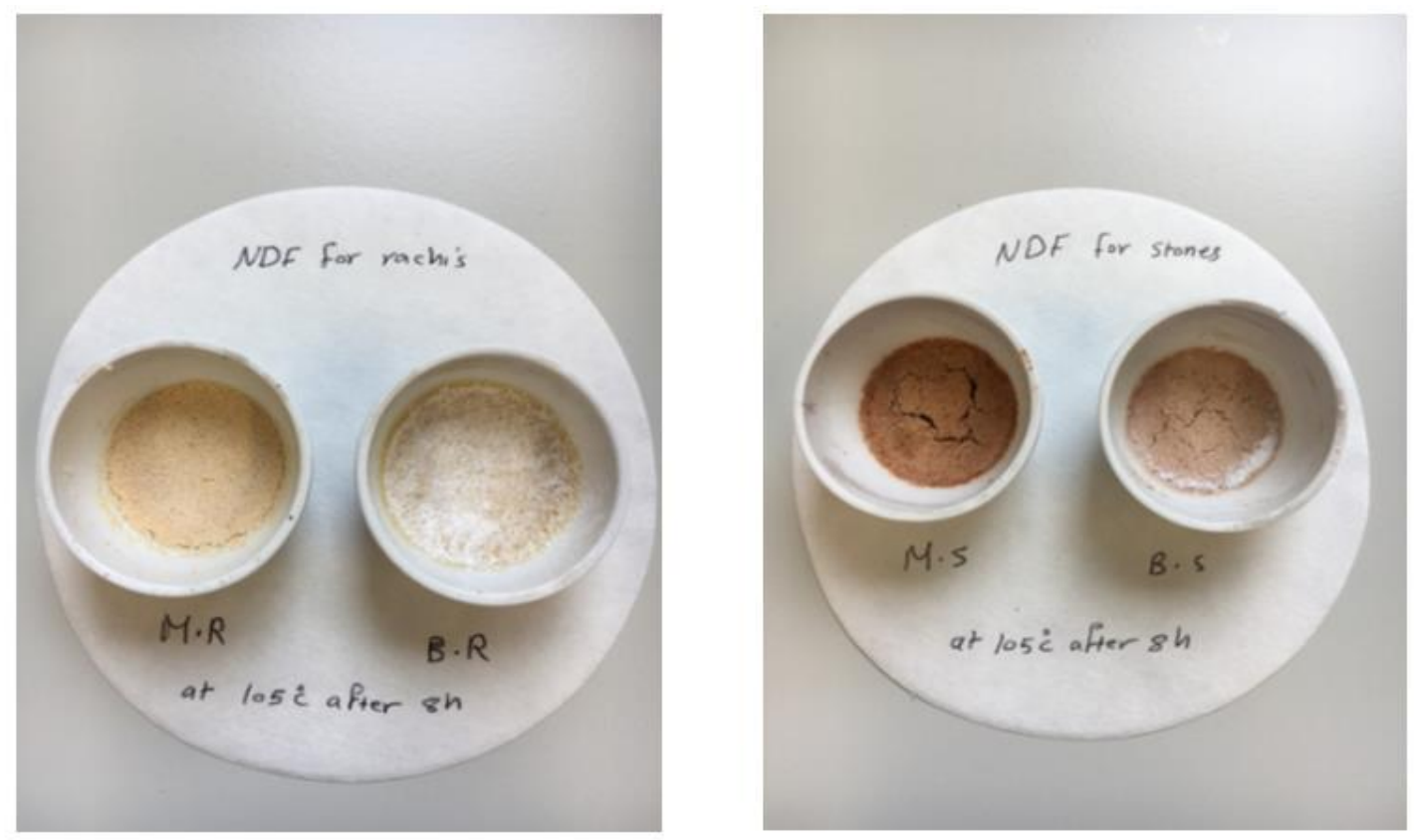

Fig. 3. 1. An illustration of the NDF determination of the rachis (left) and stone (right) samples.

On the other hand, the determination of the acid detergent fibre (ADF) has been carried out using a similar process used for the NDF, the only difference is an acid detergent has been used in place of the neutral detergent solution. The percentage of ADF was obtained as [191]:

$$
A D F(\%)=\frac{(\text { Weight of crucible }+A D F)-\text { Weight of crucible }}{\text { Weight of sample }} \times 100 \text {. }
$$

In order to calculate the acid detergent lignin (ADL), the ADF has been prepared in a crucible by adding $72 \%$ of $\mathrm{H}_{2} \mathrm{SO}_{4}$ which was allowed to be mixed at a constant stirring rate for 3 hours. The mixture was then washed twice with water and dried in hot air oven at $100{ }^{\circ} \mathrm{C}$ for 8 hours while the weight loss was recorded. An illustration of the ADL samples prepared in the current study are shown in Fig. 3. 2. The ash was also determined by keeping the crucible in a muffle furnace at $500{ }^{\circ} \mathrm{C}$ for 7 minutes while recording the weight loss of the sample as seen in Fig. 3.3. 

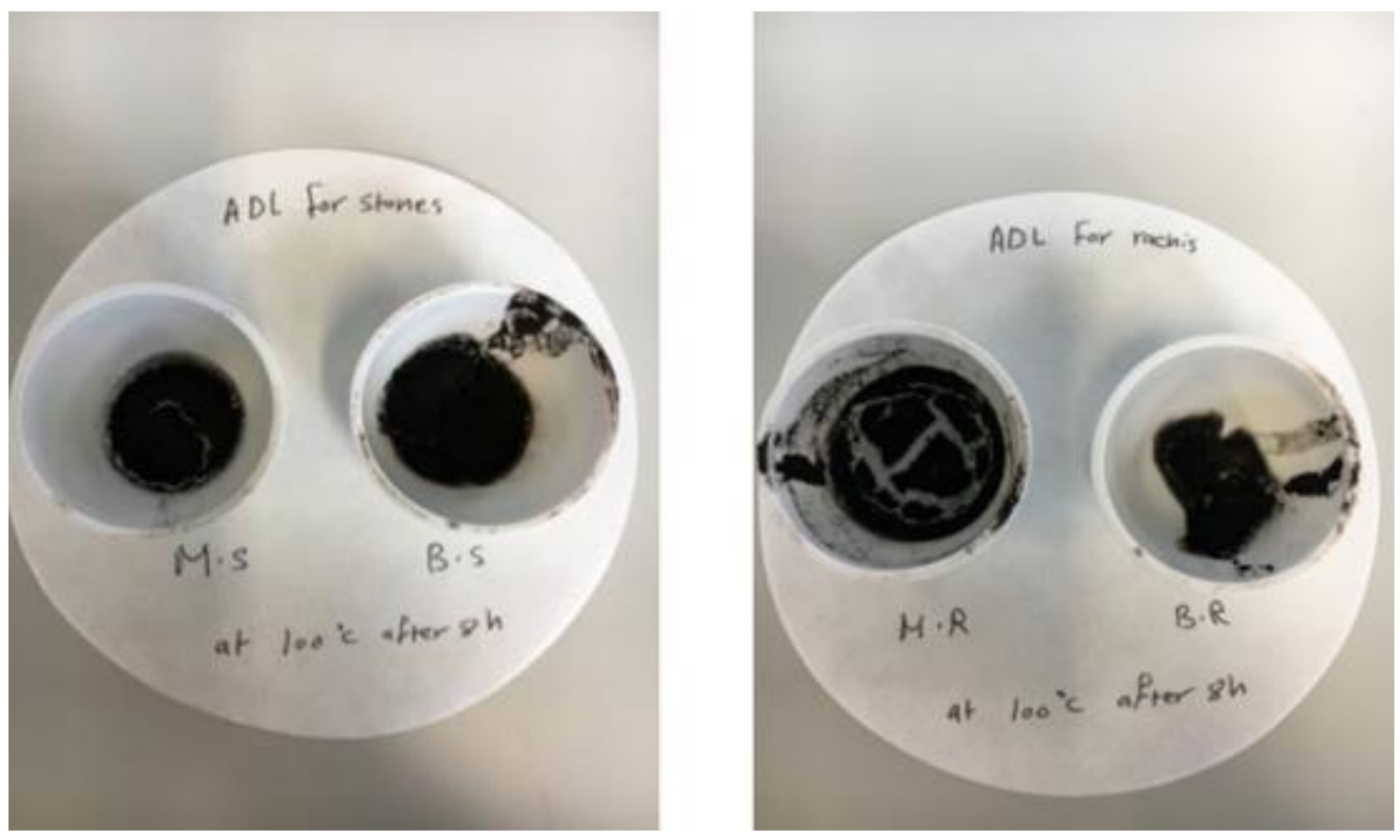

Fig. 3. 2. An illustration of the ADL determination of the stone (left) and rachis (right) samples
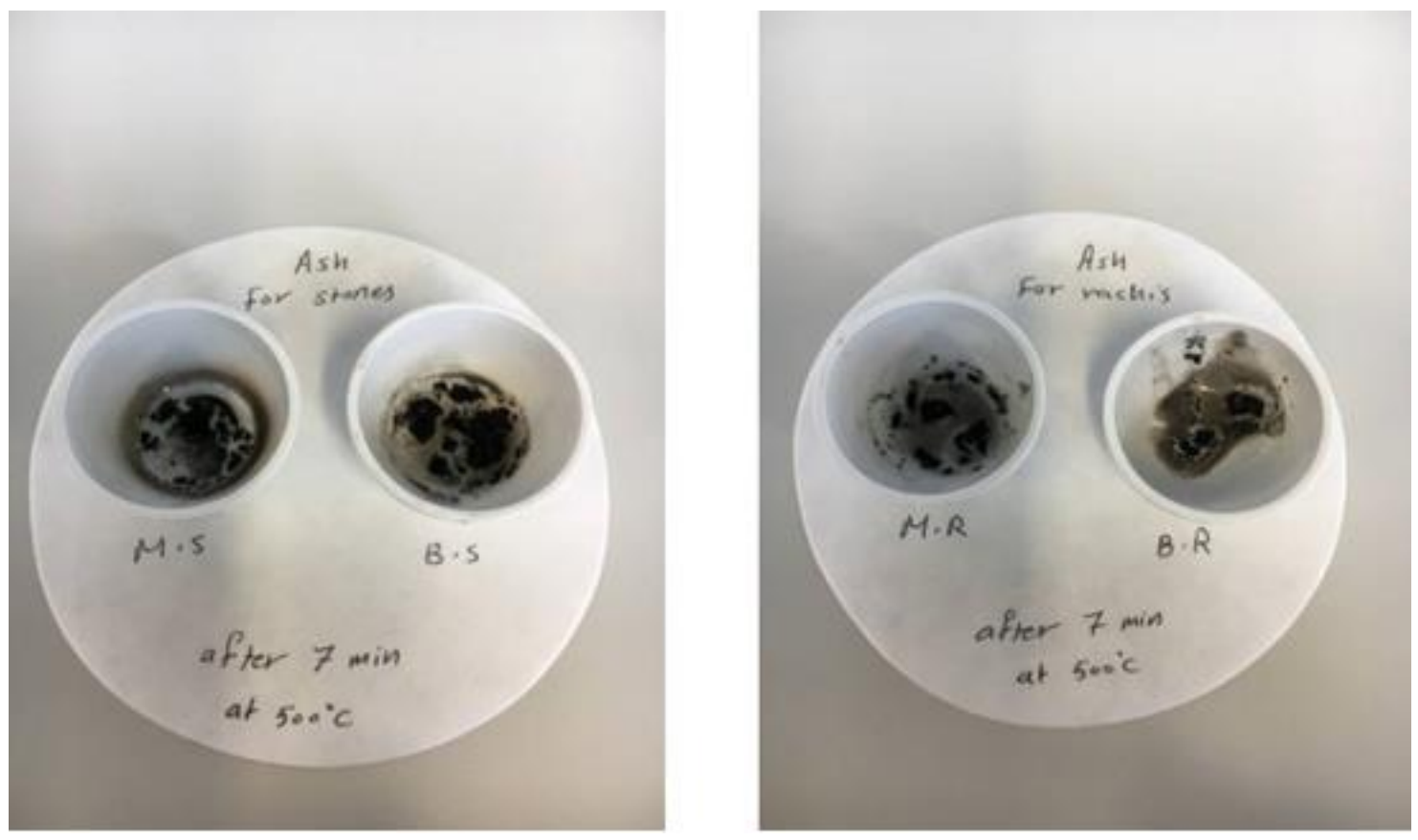

Fig. 3. 3. An illustration of the Ash content determination of the stone (left) and rachis (right) samples. 
The percentage of cellulose, hemicellulose and lignin were determined as follows [191]:

Hemicellulose $(\%)=N D F(\%)-\% A D F(\%)$.

Cellulose $(\%)=\frac{(\text { Weight of } A D F+\text { Crucible })-(\text { Weight of crucible }+ \text { Lignin })}{\text { Weight of sample }} \times 100$.

$$
\operatorname{Lignin}(\%)=\frac{(\text { Weight of crucible }+ \text { Lignin })-(\text { Weight of crucible }+ \text { Ash })}{\text { Weight of sample }} \times 100 \text {. }
$$

\subsubsection{The Structural Method}

The Soxhlet extraction method was conducted to determine the amount of cellulose، hemicellulose and lignin. The Soxhlet extractor is shown in Fig. 3. 4.
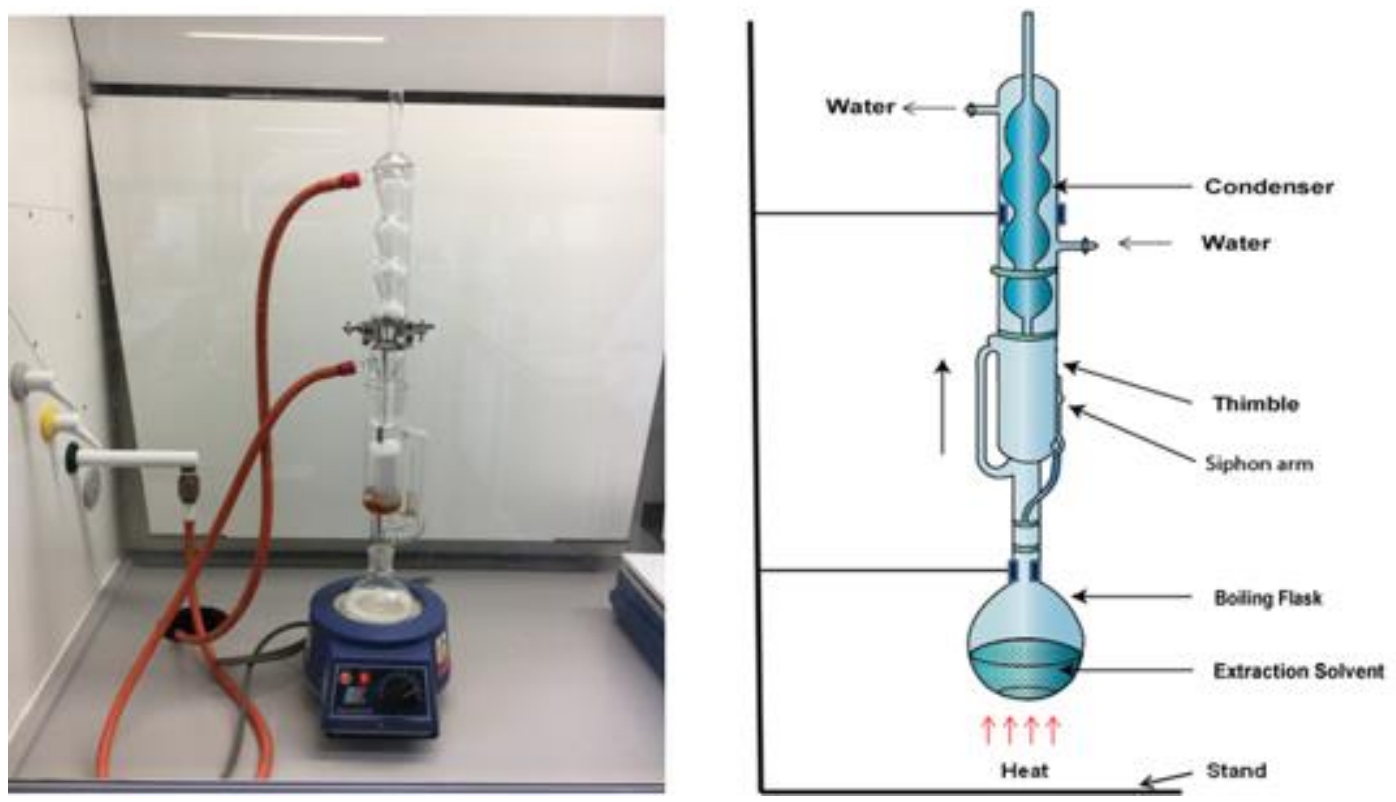

Fig. 3. 4. An illustration of the Soxhlet extractor utilised in the experiment.

The current analysis was carried out according to a standard method described by Ona et al [192]. In this method, biomass samples were extracted with a mixture of $95 \%$ ethanol and toluene (1: 2 by volume) for 6 hours followed by $95 \%$ ethanol for 4 hours and distilled 
water for 4 hours by a Soxhlet extractor. The extractives contents were then calculated from the weight loss. Lignin contents were determined as Klason lignin or acid-insoluble lignin, which is the residue after hydrolysis with $72 \%$ sulphuric acid. Holocellulose samples were prepared by delignification using acid chlorite method where sodium chlorite $(\mathrm{NaCI})$ was used for the reaction in acetate buffer $(\mathrm{pH} 3.5)$. Hemicellulose was removed by alkali extraction method in which $17.5 \% \mathrm{NaOH}$ solution was applied.

\subsubsection{Structural Analysis - Klason Lignin Determination (small scale method)}

\subsection{Extractives}

In this part of the experiment, ethanol-benzene and hot water have been used as the solvents. This set of solvents are normally used to extract waxes, fats, resins and wood gum where the hot water removes the tannins, gums, sugars and the colour-producing chemicals. On the other hand, the ASTM standard E1690-08/95 has been used for the extractive measurements of the biomass [193]. The test procedure of the current method involves the followings (Fig. 3. 5):

1. The thimbles were weighed alongside the cover without the sample. The thimbles were weighed by adding 2-3 g of sample.

2. The thimbles were dried in a vacuum furnace at temperatures not exceeding $45^{\circ} \mathrm{C}$ for about 24 hours (or till the weight becomes stable, i.e. constant).

3. The thimbles were then dried down to room temperature in a desiccator for an hour then weighed.

4. The thimbles were then kept in the Soxhlet extraction unit.

5. At this stage, $200 \mathrm{ml}$ of ethanol-toluene mixture were placed in a $500 \mathrm{ml}$ round bottom flask alongside several boiling chips to prevent bumping.

6. The extraction process is then commenced with well-ventilated chemical fume hood for about 2 hours while keeping the liquid boiling. The siphoning from the extractor should not be less than 4 times/hour.

7. The thimbles were then removed from the extractor so that they drain the excess solvent. 
8. The sample was then washed using ethanol and dried in a vacuum furnace overnight at temperature of $45^{\circ} \mathrm{C}$ for about 24 hours.

9. The dried sample was then removed and cooled down in a desiccator for an hour.

10. The sample was then weighed and at this stage the sample is called an 'extractivefree sample'.
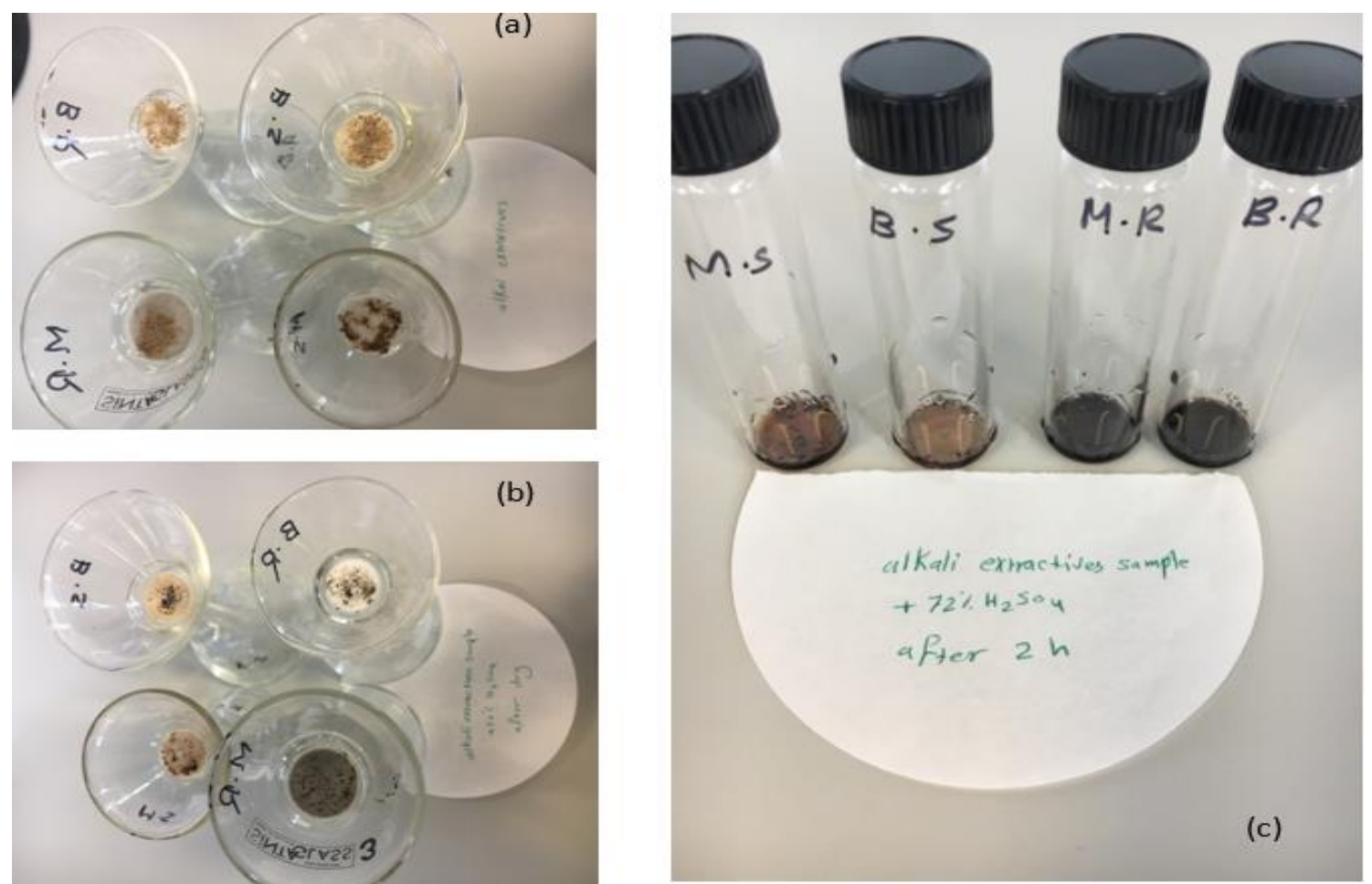

Fig. 3. 5. (a) Alkali extractives sample, (b) Alkali extractives sample $+72 \%$ sulphuric acid after 2 hours and, (c) Alkali extractives sample $+72 \%$ sulphuric acid after dry.

\subsection{Lignin}

The process for measuring the lignin content was as follows [192]:

1. About $15 \mathrm{mg}$ of the extractive-free samples was weighed and placed in a $2 \mathrm{ml}$ Eppendorf tube.

2. Around $0.75 \mathrm{ml}$ of $0.1 \mathrm{M}$ Sodium Hydroxide was added and boiled for an hour with occasional mixing on a heating block with a dry bath incubator. 
3. The sample was then filtered with a pre-weighted glass filtering crucible $(2 \mathrm{ml}$, medium porosity). The sample was then washed with $4.5 \mathrm{ml}$ of hot distilled water, $0.75 \mathrm{ml}$ of $10 \%$ Acetic Acid and $4.5 \mathrm{ml}$ of hot distilled water.

4. The sample was dried under high vacuum and then the residue was weighed to determine the Alkali extractives (Fig. 3. 5).

5. Around $10 \mathrm{mg}$ of the Alkali-extracted sample was weighed and placed in a $25 \mathrm{ml}$ flask.

6. The flask was then soaked in a $20{ }^{\circ} \mathrm{C}$ water bath while adding $0.2 \mathrm{ml}$ of $72 \%$ sulphuric acid.

7. The sample was then smashed occasionally during reaction using a disposable transfer pipette. Then, after 2 hours, $10 \mathrm{ml}$ of distilled water and reflux was added.

8. After 2 hours of treatment, the sample should be filtered using a pre-weighed glass filtering crucible $(0.8 \mathrm{ml}$, fine porosity) and then washed with distilled water 3 times.

9. The sample should be dried under vacuum and the residue has to be weighed in order to calculate the lignin content.

\subsection{Holocellulose}

The procedure to measure the amount of holocellulose was as follows (Fig. 3. 6):

1. A new sample of the extractive-free sample has to be withdrawn so that about 90 mg was left in the same glass filtering crucible as that used for extraction.

2. The sample was then washed using Acetone and dried under high vacuum.

3. The crucible leg was plugged with a septum and the joint was wrapped using labosealing tape (3M, St. Paul, MN).

4. The crucible was then soaked in a $70{ }^{\circ} \mathrm{C}$ water bath while adding $1.4 \mathrm{ml}$ of $0.2 \mathrm{M}$ sodium acetate ( $\mathrm{pH} 3.2)$.

5. About 0.1-0.2 $\mathrm{ml}$ of sodium chlorite was added and stirred with a small glass rod.

6. After $30 \mathrm{~min}$, the process in point (5) has to be repeated.

7. After $45 \mathrm{~min}$, the spetum was removed and placed in an ice cold distilled water while soaking the glass crucible for $5 \mathrm{~min}$. 
8. The sample was then squeezed and washed with ice-cold $1 \%$ acetic acid 3 times and then with ice-cold acetone twice.

9. The sample was then dried under high vacuum and the residue was weighed.

10. The holocellulose was then determined after measuring the lignin content in the holocellulose.

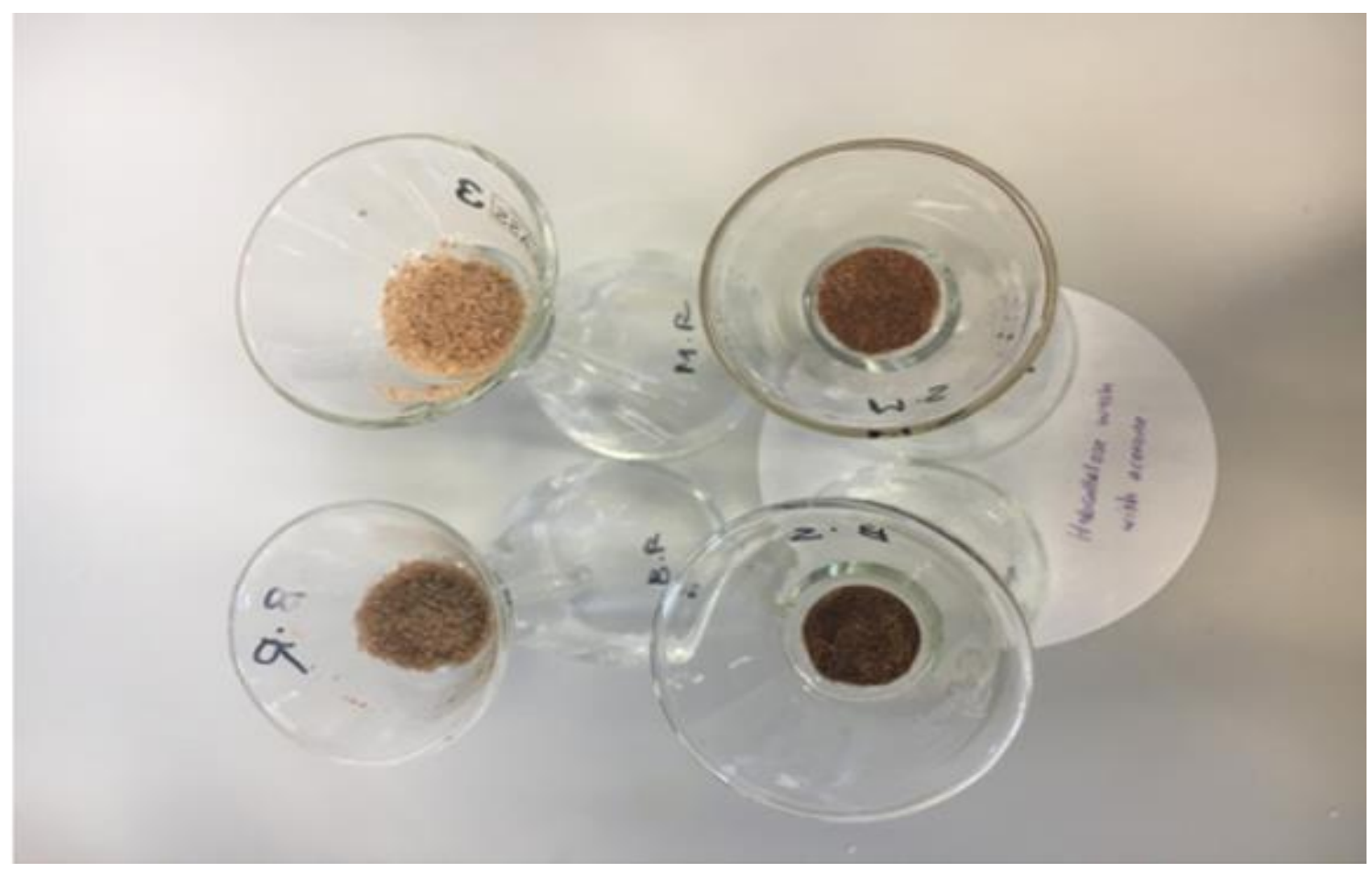

Fig. 3. 6. The holocellulose wash with acetone.

\subsection{Lignin in holocellulose}

The process used to determine the amount of lignin in holocellulose was as follows (Fig. 3. 7):

1. A $10 \mathrm{mg}$ sample of the holocellulose was weighed then the steps from point (5) to (9) used to determine holocellulose were followed.

2. For the $\alpha$-cellulose, the process was as follows:

a. A sample of around 19 to $21 \mathrm{mg}$ holocellulose was withdrawn from the glass filtering crucible that was sued for the holocellulose preparation. 
b. The sample was washed with acetone and then dried under high vacuum and weighed.

c. The crucible was plugged with septum and then the joint was wrapped with labo-sealing tape.

d. The crucible was then soaked in a $20{ }^{\circ} \mathrm{C}$ water bath while adding $0.2 \mathrm{ml}$ of $17.5 \%$ sodium hydroxide and then stirred.

e. After $5 \mathrm{~min}$, an amount of $0.4 \mathrm{ml}$ of $17.5 \%$ sodium hydroxide was then added.

f. After $40 \mathrm{~min}$, an amount of $0.4 \mathrm{ml}$ of distilled water was then added while removing the septum.

g. The sample was then squeezed and washed with distilled water 3 times.

h. An amount of $0.3 \mathrm{ml}$ of $12 \%$ acetic acid was then added and held for $5 \mathrm{~min}$.

i. The sample was then washed with distilled water 3 times and then dried under high vacuum.

j. The residue was then weighed to calculate the $\alpha$-cellulose content.
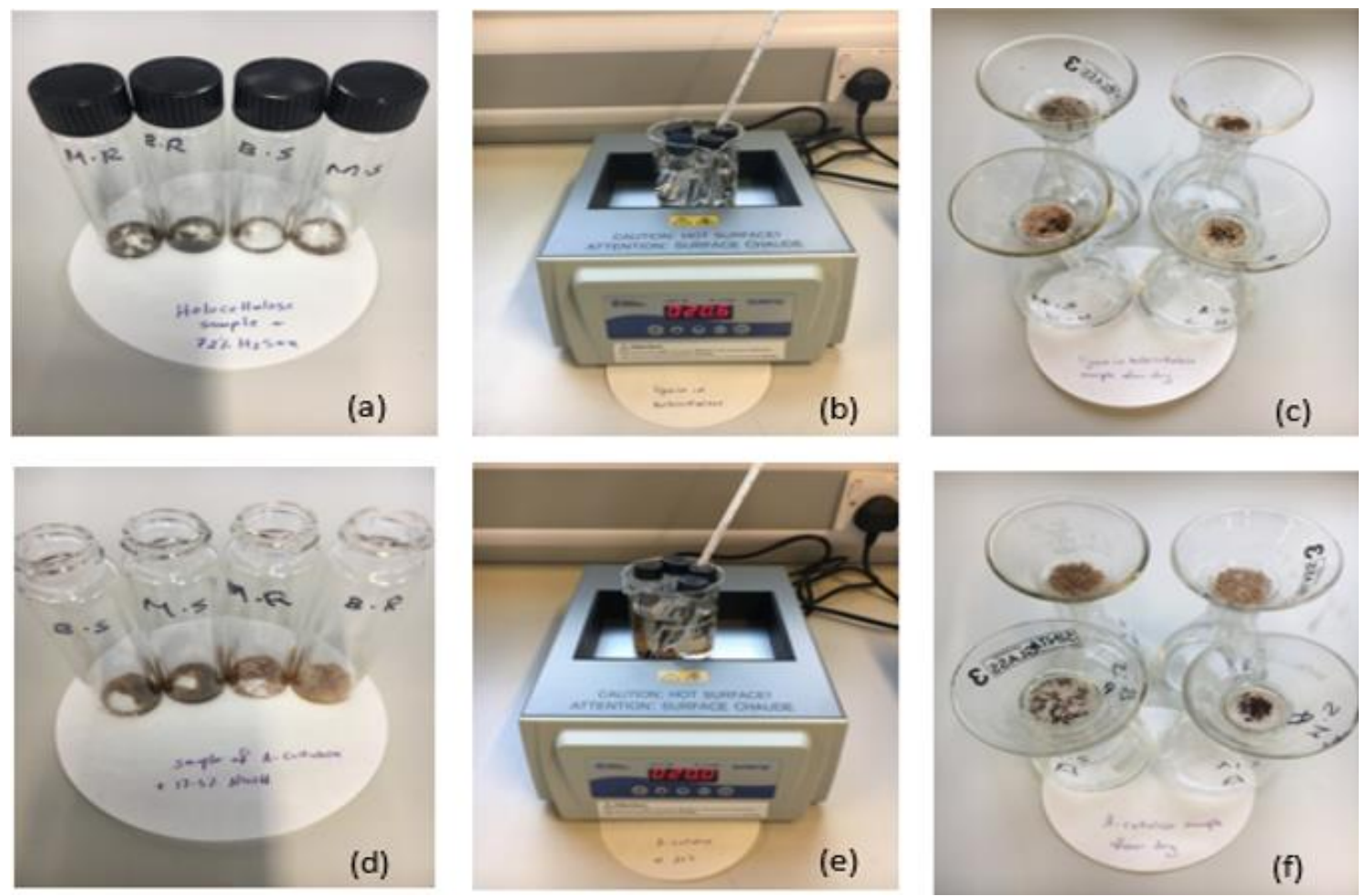

Fig. 3. 7. (a) Holocellulose sample and $72 \%$ sulfuric acid, (b) Lignin in holocellulose at $20{ }^{\circ} \mathrm{C}$, (c) Lignin in holocellulose after dry, (d) a-cellulose sample and $17.5 \% \mathrm{NaOH}$, (e) A-cellulose sample at $20^{\circ} \mathrm{C}$ and, (f) a-cellulose sample after dry. 


\subsubsection{Heating value}

\subsubsection{The Theoretical Calculation of HHV}

The value of the higher heating value (HHV) was determined using the HHV equation given by Singh et al. [188] and Demirbas [194]:

$\mathrm{HHV}=(33.5 \times \mathrm{C} \%+142.3 \times \mathrm{H} \%-15.4 \times \mathrm{O} \%-14.5 \times \mathrm{N} \%) \times 10^{-2}$

This analysis will be used in order to calculate the amount of energy available in each unit of the biomass.

\subsubsection{The Experimental Calculation of HHV (Bomb calorimeter C200M/2/006} DEC13)

A bomb calorimeter will measure the amount of heat generated when combustion matter is burnt. It is a sealed combustion chamber that is pre-filled with a known mass of fuel and sufficient pure oxygen to ensure complete combustion.

\subsection{Operating Procedures}

\section{Charge weight calculation}

Before operating the bomb, it is necessary to ensure that the product of the sample weight and the potential calorific value do not exceed the $7000 \mathrm{cal}$ (29300 J) allowable maximum. The gross calorific value assumes that the water of combustion is entirely condensed and that the heat contained in the water vapour is recovered. If the sample for example is diesel then the typical gross calorific value (GCV) is $44,800 \mathrm{~kJ} / \mathrm{kg}$ ( or $\mathrm{GCV}=44.8 \mathrm{~kJ} / \mathrm{g}$ ).

If the allowable maximum energy release for the calorimeter is $29300 \mathrm{~J}$, then the allowable maximum charge $\left(\mathrm{m}_{\mathrm{f}}\right)$ of the diesel would be:

$$
\begin{gathered}
m_{f}=\frac{G C V}{M a x Q} \\
m_{f}=\frac{29300 \mathrm{~J}}{44.8 \mathrm{~kJ} / \mathrm{g}} \\
=0.650 \mathrm{~g}
\end{gathered}
$$


As the density of fuels can vary, it is recommended that the fuel sample is weighed into the sample crucible using an accurate balance.

\section{The Main Components of the Bomb Calorimeter:}

The main parts of the Bomb Calorimeter are shown in Fig. 3. 8. These parts were used to carry out the experiment as will be discussed later.

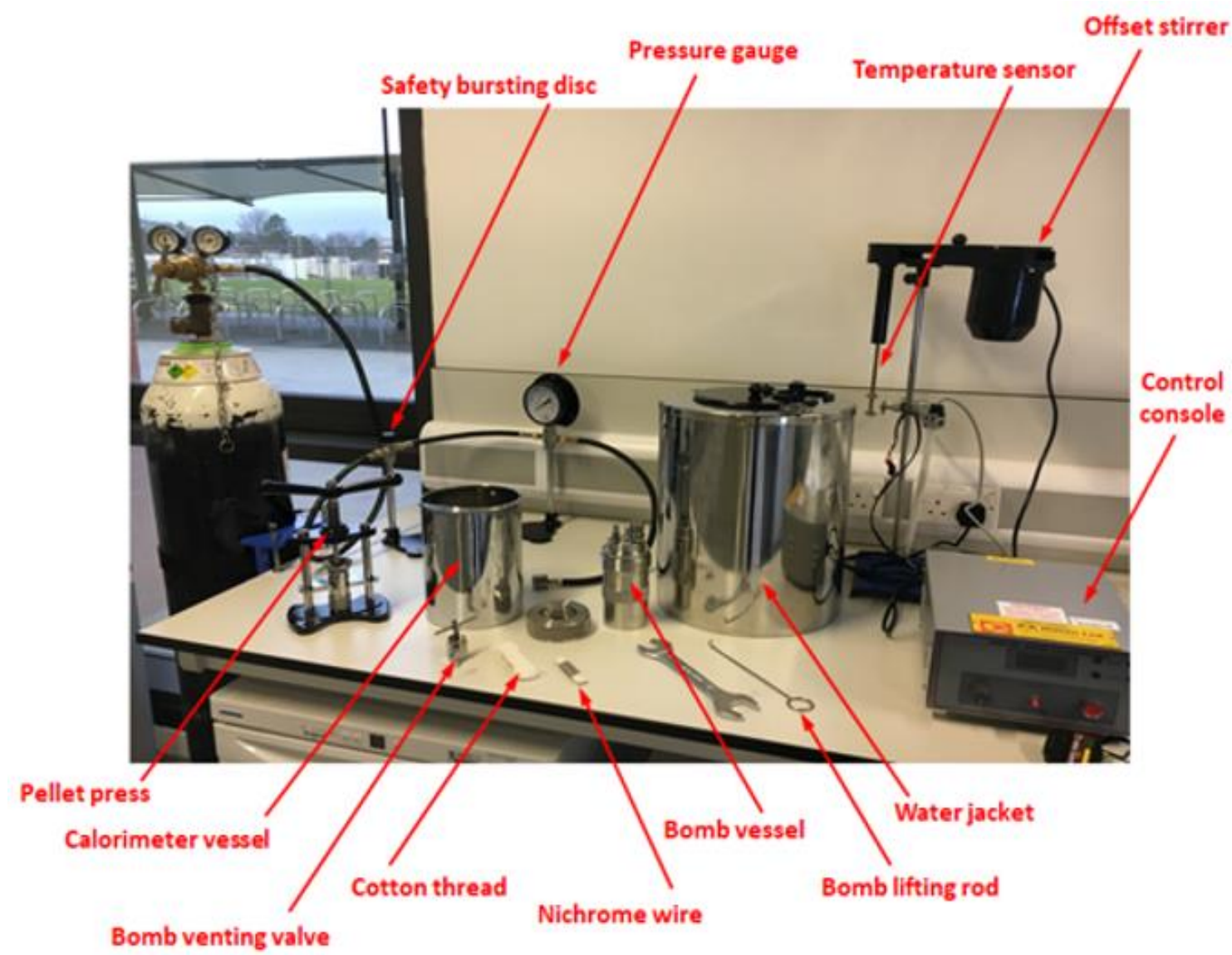

Fig. 3. 8. The various parts of the Bomb Calorimeter.

\section{Preparing the samples (solids)}

The following steps were followed to prepare the solid samples (Fig. 3. 9):

1. An electronic scale, was used to weigh approximately $1.0 \mathrm{~g}$ of the biomass sample $\left(m_{f}\right)$.

2. The powder sample was placed into the pellet press. 
3. The screw was used to press the completed pellet out of the cylinder.

4. Finally, the pellet was re-weighed to ensure that it is not over the maximum weight calculated in the charge weight calculation.

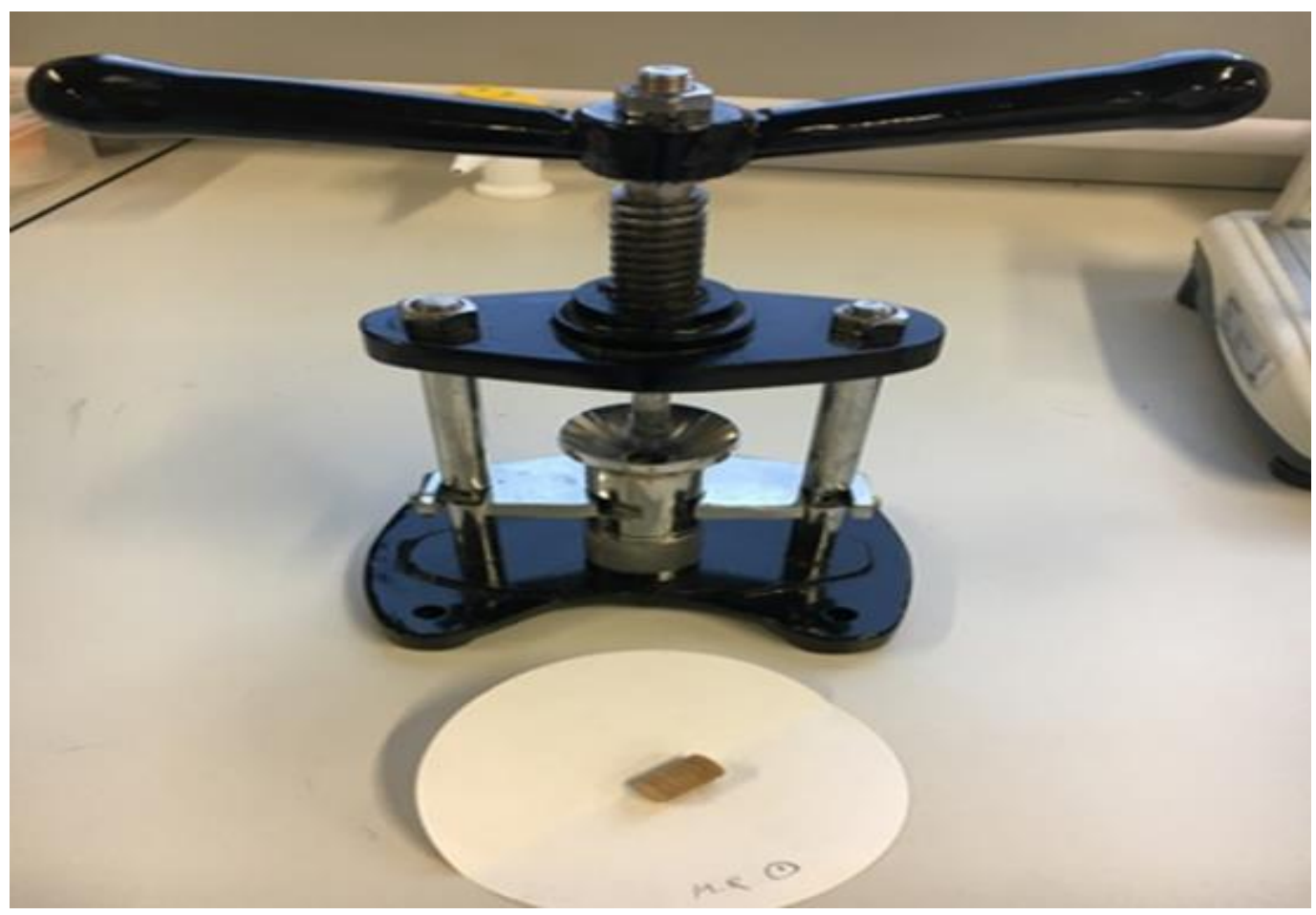

Fig. 3. 9. The pellet press used to prepare the solid samples.

\section{Preparing the sample (liquid)}

The following steps were followed to prepare the liquid samples:

1. It was ensured that the crucible was thoroughly dried. Then, the crucible was weighed with and without the sample.

2. It is necessary to use some form of dropper or syringe in order to drop the fuel into the crucible.

3. The liquid sample in the crucible was weighed by an accurate balance. If too much fuel is added then it is possible to extract some using the wick of cotton or tissue. 


\section{Preparing the Bomb Vessel (solid and liquid samples)}

It is important to ensure that the bomb vessel and crucible are clean from inside. Then the following steps have to be followed:

1. A length of approximately $60 \mathrm{~mm}$ of the Nichrome wire was cut and weighed using a suitable balance (the recorded weight is sampled $m_{w}$ ).

2. The bomb electrodes have two slots to accept the wire. The ends of the wire was slide into the slots and winded around the electrodes. The two rings was slide down to lock the wire and to get a good electrical contact.

3. A length of approximately $100 \mathrm{~mm}$ of the cotton thread was cut and weighed using a sensitive balance (the recorded weight is sampled $m_{c}$ ). Next, the cotton thread was tied in the center of the wire leaving 2 long tails. If the sample is a solid cylinder, it is important to ensure that the ends of the cotton make contact with the sample while ensuring that the ends of the thread dip into the liquid sample.

4. The crucible loaded by sample was placed in the crucible holder ring below the prepared Nichrome wire fuse (Fig. 3. 10).

5. The top section of the bomb was place inside the base and the clamping ring was screwed down onto the top of the bomb firmly by hand. This is best achieved by holding the bomb vessel firmly on a bench so that the sample is not disturbed inside the crucible.

6. The top section of the bomb was carefully placed inside the base and it is important to ensure that the $\mathrm{O}$ ring seal is in good condition.

7. The bomb vessel has as $\mathrm{O}$ ring that must be fitted before the connection is made to the hose.

8. The bomb must be charged with pure oxygen bottle regularly.

9. For disconnecting the bomb vessel from the oxygen supply, firstly the bottle main valve was closed then the bomb pressure regulator knob fully turned anti clockwise and carefully loosen one of the hoses connected to the safety bursting disc. At the same time the pressure gauge was noticed until reach zero. 
10. After ensuring that the bomb has been fired and that the experiment is complete, or if it has been noticed that the bomb pressure is too high (above 25 bar), it can be reduced safely using the bomb venting valve by screwing in the $\mathrm{T}$ handle which will press onto the Schrader valve and release the pressure inside the bomb.

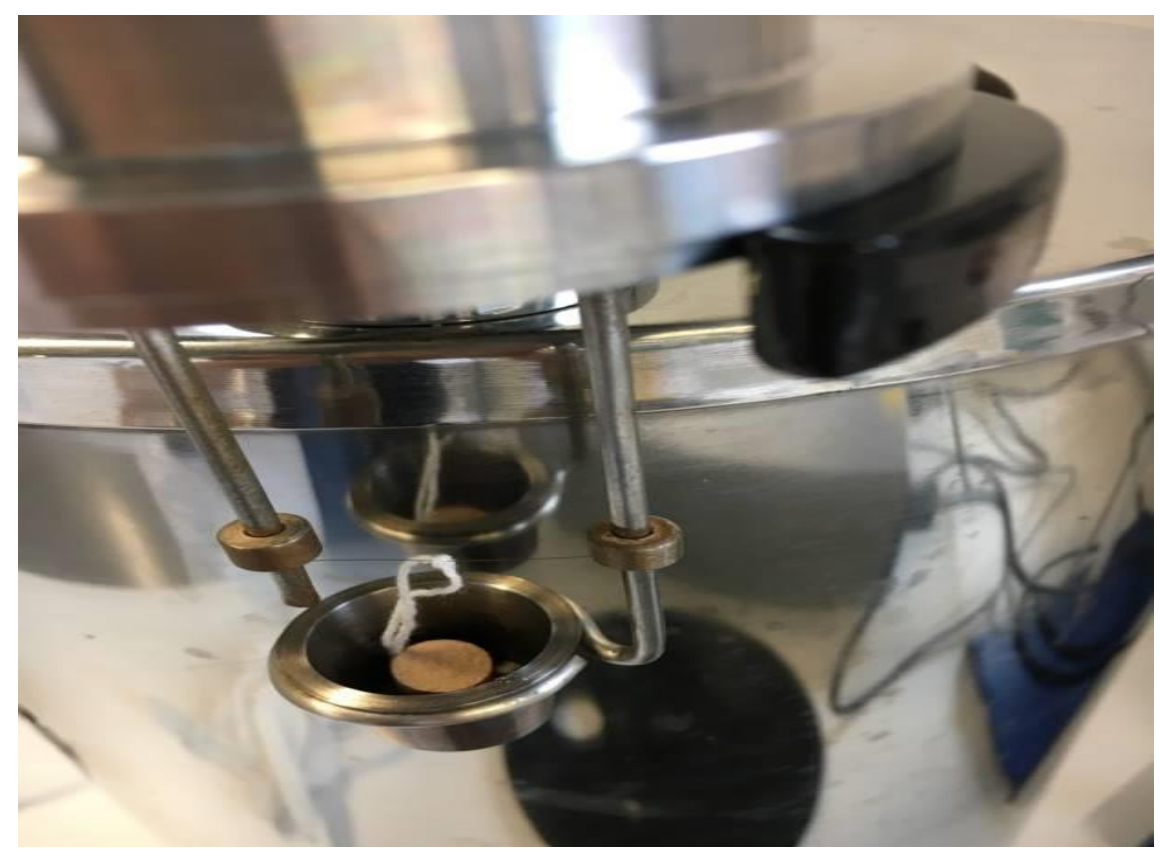

Fig. 3. 10. The crucible holder used in the experiment.

\section{Conducting the Calorimetric Test:}

The experiment was conducted as follows (Fig. 3. 11):

1. The water jacket was filled with pure water (2 litres).

2. The prepared bomb vessel may be lifted into the calorimeter vessel using the hook provided.

3. The stirrer and the temperature sensor were adjusted to gain access to the water jacket through the large hole in the cover alongside the ignition lead (red and black plug) which is connected to the two sockets in the top of the bomb vessel.

4. The offset stirrer was inserted into the larger hole in the cover. 
5. The bomb circuit indicators was checked to show a green or a closed circuit.

6. The temperature selector switch was set in the initial temperature position.

7. In order to monitor this, the switch was set to the rise temperature setting and the display will show either a +ve or -ve value to 2 decimal places. To get to the start condition, turn the rise temperature zero knob either way until the display shows a zero value.

8. The temperature rise was monitored and recorded every minute. In this case, the rise temperature is considered reaching its maximum value once it starts to progressively fall or remain constant for typically the 5 successive minutes.

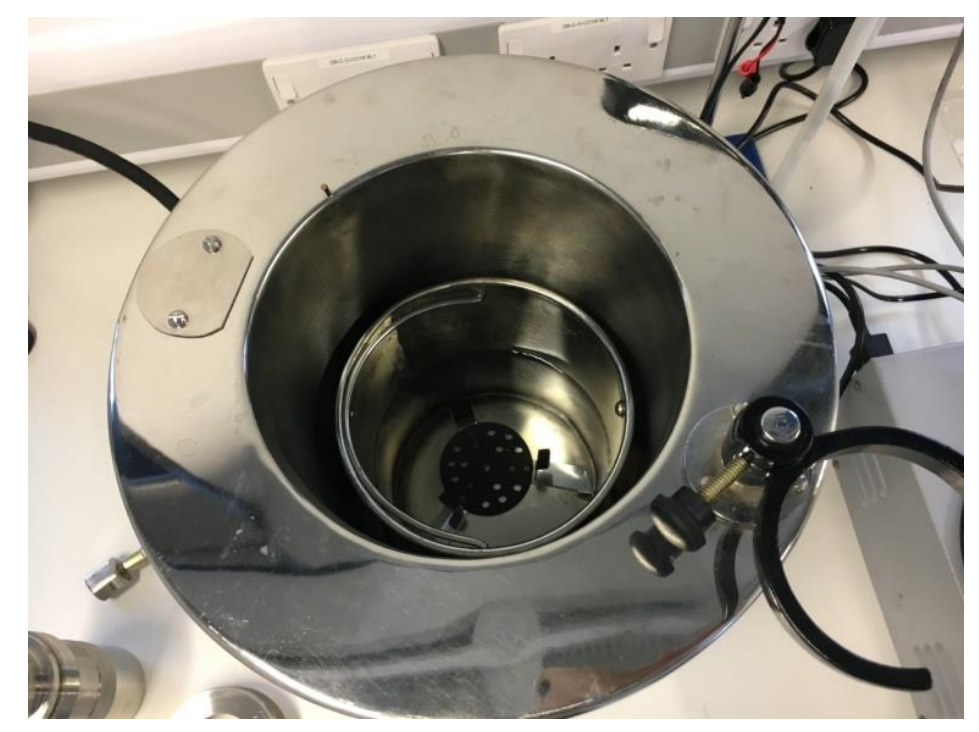

Fig. 3. 11. The procedure of set up the water jacket for the experiment.

\section{The Bomb Calibration Procedure:}

A calibrant (Benzoic Acid) is run though the equipment to calibrate the system in order to use the bomb for the actual experiment as well as to determine the effective heat capacity of the bomb. For this exercise, the following steps were carried out:

1. Prior to the experiment, approximately a $1.0 \mathrm{~g}$ sample was firstly pelletised. For samples that cannot be pelletised, approximately $1.0 \mathrm{~g}$ of the sample was weighed into the metal crucible. 
2. The bomb vessel was prepared for firing with the pellet and charge with oxygen.

3. The calorimeter test was conducted and the data was recorded.

4. The sample calculations were carried out for the cotton thread and the Nichrome wire as follows:

$$
\begin{array}{ll}
\text { The cotton thread: } & Q_{f u s e}=m_{c} q_{c} \\
\text { The Nichrome wire: } & Q_{\text {ign }}=m_{w} q_{w} \\
\text { The bomb: } & \varepsilon=\frac{m_{b a} q_{v b a}+Q_{\text {ign }} Q_{\text {fuse }}}{\theta}
\end{array}
$$

Where:

$\varepsilon:$ is the ceilometer factor,

$m_{b a}:$ is the mass of the Benzoic Acid,

$q_{v b a}:$ is the gross calorific value of the Benzoic Acid (J/g),

$Q_{f u s e}:$ is the heat contribution from the cotton thread (J),

$Q_{\text {ign }}:$ is the heat contribution from the Nichrome ignition wire (J)

$\theta$ : is the corrected temperature rise of the calorimeter vessel $(\mathrm{K})$.

\subsubsection{Thermo-gravimetric Analysis (TGA)}

Thermo-Gravimetric Analysis (TGA) investigates the relation between the mass of a sample and the applied temperature. It can be used to study the physical properties such as evaporation and the chemical behavior such as thermal degradation of materials that causes materials to lose volatile gases [195]. In TGA, a controlled atmosphere is employed to heat the sample at certain heating rate relative to time. From the obtained graph, a stability on the graph indicates a constant weight of the samples whereas a curved portion represents weight loss from the sample. The gradient of the graph indicates the rate of mass loss from the sample. It is always more convenient to plot the derivative of the TGA curve against time or temperature. This curve is known as the derivative thermogravimetric graph (DTG), which determines the exact temperature at which minimum and maximum mass loss takes place. In TGA, two processes were employed namely; TGA 
pyrolysis and TGA combustion. The former uses high temperatures (up to $900{ }^{\circ} \mathrm{C}$ ) under an inert atmosphere such as nitrogen medium whereas the latter utilises lower temperatures (up to $700{ }^{\circ} \mathrm{C}$ ) in an oxygen atmosphere [196]. The typical heating and cooling cycles of the TGA Pyrolysis and combustion utilised in the current experiment are summarised in Table 3. 1.

Table 3. 1. An overall comparison between the TGA pyrolysis and combustion.

\begin{tabular}{|c|c|}
\hline TGA Pyrolysis & TGA Combustion \\
\hline $\begin{array}{l}\text { 1. Heat from ambient to } 30^{\circ} \mathrm{C} \\
\text { and hold for } 1 \mathrm{~min} \text {. }\end{array}$ & $\begin{array}{l}\text { 1. Heat from ambient to } 30^{\circ} \mathrm{C} \text { and hold for } \\
1 \mathrm{~min} \text {. }\end{array}$ \\
\hline $\begin{array}{l}\text { 2. Heat from } 30 \text { to } 50{ }^{\circ} \mathrm{C} \\
\text { (heating rate: } 20{ }^{\circ} \mathrm{C} / \mathrm{min} \text { ). }\end{array}$ & $\begin{array}{l}\text { 2. Heat from } 30{ }^{\circ} \mathrm{C} \text { to } 50{ }^{\circ} \mathrm{C} \text { (heating rate: } \\
20^{\circ} \mathrm{C} / \mathrm{min} \text { ). }\end{array}$ \\
\hline 3. Hold at $50{ }^{\circ} \mathrm{C}$ for $5 \mathrm{~min}$ & 3. Hold at $50{ }^{\circ} \mathrm{C}$ for $5 \mathrm{~min}$. \\
\hline $\begin{array}{l}\text { 4. Heat from } 50{ }^{\circ} \mathrm{C} \text { to } 105^{\circ} \mathrm{C} \\
\text { (heating rate of } 5{ }^{\circ} \mathrm{C} / \mathrm{min} \text { ). }\end{array}$ & $\begin{array}{l}\text { 4. Heat from } 50 \text { to } 105^{\circ} \mathrm{C} \text { (heating rate: } 20 \\
{ }^{\circ} \mathrm{C} / \mathrm{min} \text { ). }\end{array}$ \\
\hline 5. Hold at $105^{\circ} \mathrm{C}$ for $5 \mathrm{~min}$. & 5. Hold at $105^{\circ} \mathrm{C}$ for $5 \mathrm{~min}$ \\
\hline $\begin{array}{l}\text { 6. Heat from } 105^{\circ} \mathrm{C} \text { to } 900{ }^{\circ} \mathrm{C} \\
\text { (heating rate of } 25^{\circ} \mathrm{C} / \mathrm{min} \text { ). }\end{array}$ & $\begin{array}{l}\text { 6. Heat from } 105{ }^{\circ} \mathrm{C} \text { to } 700{ }^{\circ} \mathrm{C} \text { (heating } \\
\text { rate of } 50{ }^{\circ} \mathrm{C} / \mathrm{min} \text { ). }\end{array}$ \\
\hline 7. Hold at $900^{\circ} \mathrm{C}$ for $15 \mathrm{~min}$. & 7. Hold at $700{ }^{\circ} \mathrm{C}$ for $15 \mathrm{~min}$. \\
\hline $\begin{array}{l}\text { 8. Cool from } 900 \text { to } 50{ }^{\circ} \mathrm{C} \\
\text { (cooling rate of } 25^{\circ} \mathrm{C} / \mathrm{min} \text { ). }\end{array}$ & $\begin{array}{l}\text { 8. Cool from } 700{ }^{\circ} \mathrm{C} \text { to } 50{ }^{\circ} \mathrm{C} \text { (cooling } \\
\text { rate: } 25^{\circ} \mathrm{C} / \mathrm{min} \text { ). }\end{array}$ \\
\hline $\begin{array}{l}\text { 9. Nitrogen flow rate: } 20 \\
\mathrm{ml} / \mathrm{min} \text {. }\end{array}$ & 9. Oxygen flow rate: $20 \mathrm{ml} / \mathrm{min}$. \\
\hline
\end{tabular}

\subsection{Characterization of bio-oil}

In order to characterize the bio-oil for any application, it is very important to know the composition, physical and chemical properties of the bio-oil extracted from the slow pyrolysis. The composition of bio-oil was specified by using gas chromatography mass spectrometry (GC-MS). The physical properties such as density, viscosity, water content 
were also measured. The $\mathrm{pH}$ of the bio-oil was measured by using JENWAY $4330 \mathrm{pH}$ meter, while, the high heating value was calculated by similar method explained in details in Ch. 2. The detailed procedure used for bio-oil characterization is presented in following sections.

\subsubsection{Bio-oil water content}

In this work, an 870 Volumetric Karl Fischer Titrator shown in Fig. 3.12 was used to specify the percentage of water content presented in the bio-oil sample according to ASTM D1744-13 analytical test method. Before starting experiment, the 870 Volumetric Karl Fischer Titrator was calibrated with known volume of water.

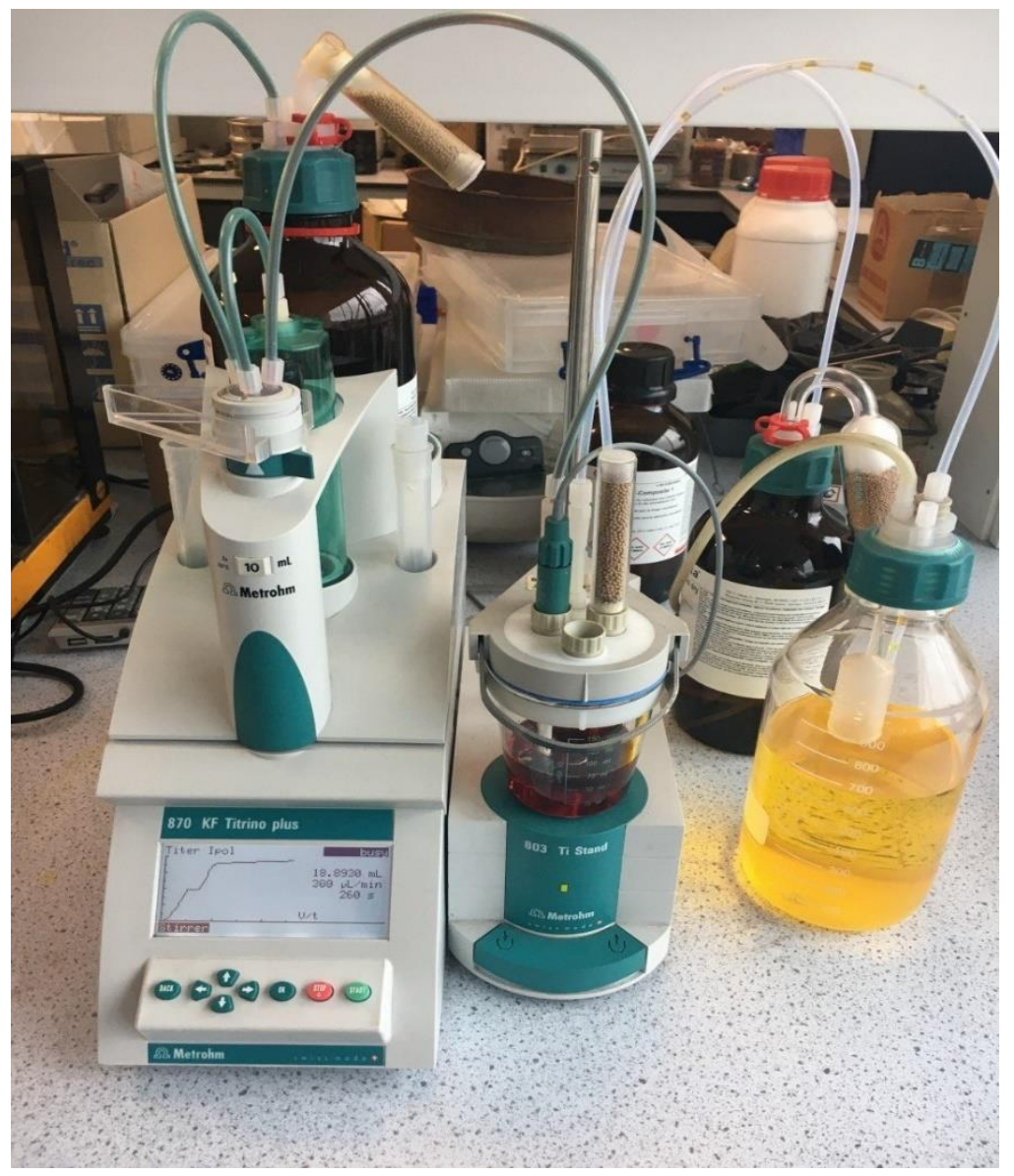

Fig. 3. 12. The 870 Volumetric Karl Fischer Titrator. 
During the titration, Iodine was added to Karl Fischer solvent containing the biooil sample. The water content of the sample was quantified based on the Karl Fischer reagent consumed [197]. The Karl Fischer titration is based on the principle of Bunsen reaction of three stages between iodine and sulphur dioxide in an aqueous solution. The Hydranal-composite 5K and 2-chloroethanol are used as titrant and solvent, respectively. The first stage of Karl Fischer titration is a reduction reaction in which the sulphur dioxide is oxidized by iodine in the presence of water [198].

$$
\mathrm{I}_{2}+\mathrm{SO}_{2}+2 \mathrm{H}_{2} \mathrm{O} \leftrightarrow 2 \mathrm{HI}+\mathrm{H}_{2} \mathrm{SO}_{4} \quad \text { [197] }
$$

The 2-chloroethanol solvent reacts with the formed acid to produce esters which neutralized with Hydranal-composite 5k titrant forming a stable complex.

$$
\begin{aligned}
& \mathrm{R}_{3} \mathrm{OH}+\mathrm{SO}_{4}+\mathrm{RN} \rightarrow[\mathrm{RNH}] \mathrm{SO}_{3} \mathrm{CH}_{3} \quad \text { [197] } \\
& \mathrm{H}_{2} \mathrm{O}+\mathrm{I}_{2}+[\mathrm{RNH}] \mathrm{SO}_{3} \mathrm{CH}_{3}+\mathrm{RN} \rightarrow\left[\mathrm{RNH}^{\mathrm{N}} \mathrm{SO}_{4} \mathrm{CH}_{3}+2[\mathrm{RNH}] \mathrm{I}\right.
\end{aligned}
$$

Before conducting the test, the used device was calibrated with a known amount of water. A known amount of bio-oil was also injected into the device. Based on the Equations 1-3, water and Iodine are consumed with ratio 1:1. The experiment ended when the water has been used up, which is detected by the indicator electrode which detects an excess of iodine in the sample. The system was programed to calculate the water content based on the concentration of the iodine in the titrating reagent as well as the volume of reagent used up using the following equation:

$$
y=\frac{V_{T} \times C_{0} \times C_{1}}{m_{s}}
$$


Where $y$ is the water content in the bio-oil (wt. \%), $V_{T}$ is the volume of titrant used (ml), $C_{0}$ is the concentration of iodine in the titrant reagent $(\mathrm{mg} / \mathrm{ml}), C_{1}$ (is a factor $)=$ $\frac{1 \mathrm{~g}}{1000 \mathrm{mg}} \times 100 \%=0.1 \mathrm{~g} \% / \mathrm{mg}$ and the $m_{s}$ is the bio-oil mass $(\mathrm{g})$.

This test was started by taking a sample of the bio-oil using a plastic syringe. Then it was weighted using a digital balance of accuracy $0.0001 \mathrm{gm}$. The volumetric Karl fisher titrator was filled with $50 \mathrm{mg}$ of titrating solvent. The system was prompted to pre-titrate the solvent in order to get rid of any water present in the system; during that 1-2 drops of bio-oil was added via the spectrum. The syringe of bio-oil was weighted again in order to figure out the amount of bio oil sample used. Finally, the water contented was recorded as it displayed in the device screen.

\subsubsection{Acidity (pH and/or acid number)}

A JENWAY $4330 \mathrm{pH}$ meter shown in Fig. 3.13 is used to measure the $\mathrm{pH}$ of the bio-oil. The $\mathrm{pH}$ meter reading based on the amount of hydronium ion $\left(\mathrm{H}_{3} \mathrm{O}^{+}\right)$presented in the bio-oil [199].

In order to ensure that the $\mathrm{pH}$ meter reading are accurately taken, the $\mathrm{pH}$ meter was calibrated using buffer solutions of $\mathrm{pH} \mathrm{4,7}$ and 10 . After the $\mathrm{pH}$ meter was calibrated, its electrode was removed from the buffer solution and well rinsed by distilled water and cleaned by cotton cloth before it was used to measure the $\mathrm{pH}$ of the bio-oil. 


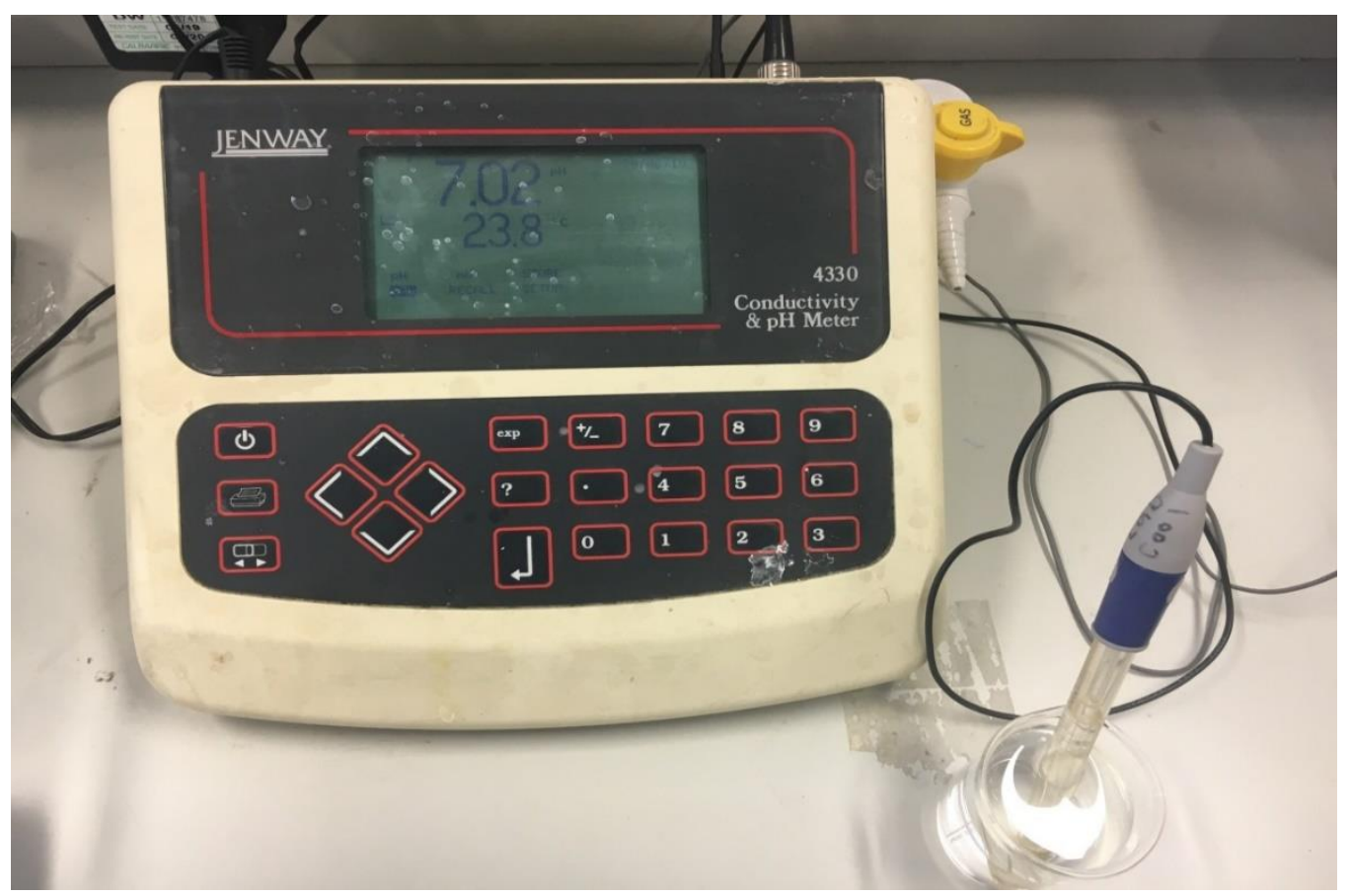

Fig. 3. 13. Photograph of $\mathrm{pH}$ meter.

\subsubsection{Viscosity and Density}

The viscosity of the bio-oil is measured at $40{ }^{\circ} \mathrm{C}$ by using Ostwald Viscometer shown in Fig. 3. 14, according to the standard test ASTM D455-88. The viscometer consists of a U-shaped glass tube vertically held in a water bath where the temperature is controlled. The first arm of the U-tube is a capillary tube with swelling at the top and the other arm also contains swelling but it located near the bottom.

An amount from 5 to $10 \mathrm{gm}$ of the bio-oil sample was directed to the upper bulge by suction then allowed to flow through the capillary tube to the lower bulge. There are two signs below and above the upper bulge indicating a known volume. The time it takes for the bio-oil to flow between the two signs is proportional to the viscosity. So, the viscometer was firstly placed in the water path at $40{ }^{\circ} \mathrm{C}$ for 5 minutes, then the bio-oil was 
sucked to past the upper sign. The time it takes for the bio-oil to flow from the upper sign and reach the down sign was recorded by a stop watch.
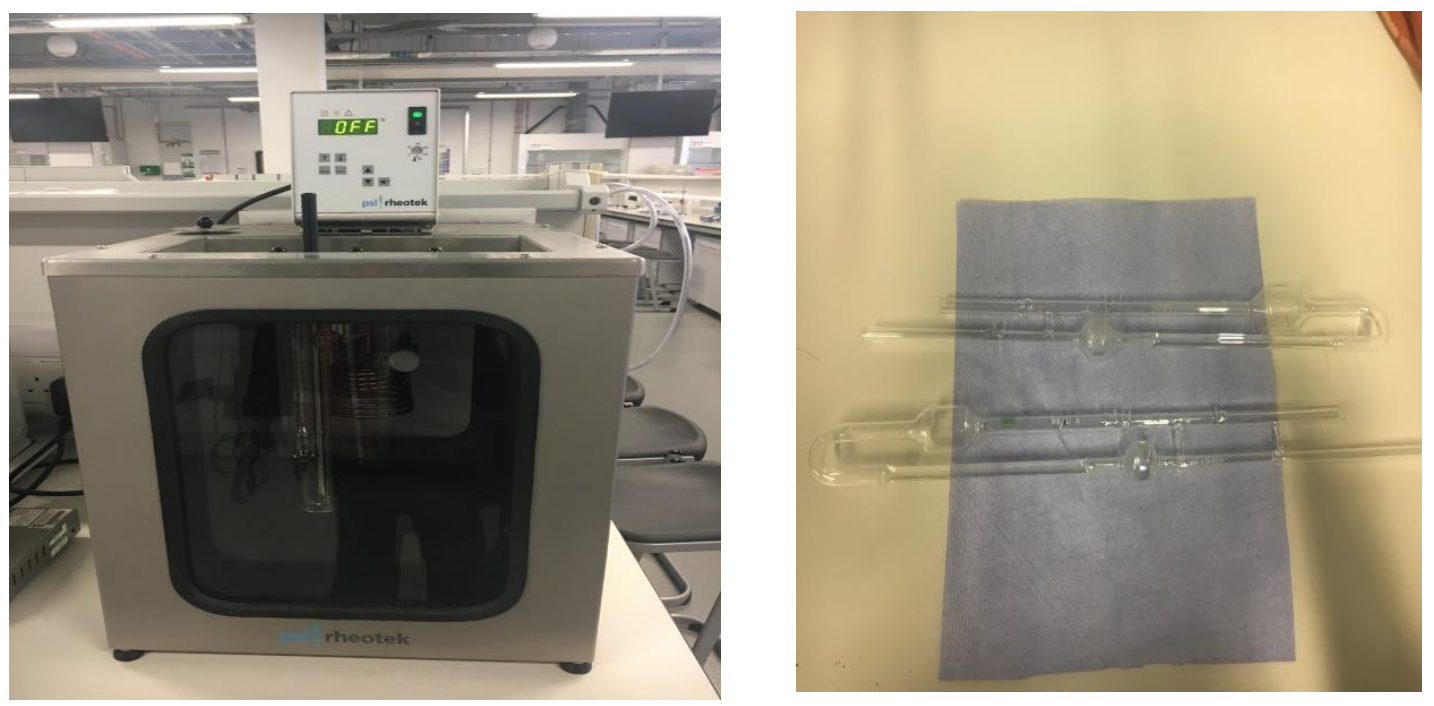

Fig. 3. 14. Photograph of the viscometer.

In order to determine the density of the bio-oil, a simple procedure was used; where the bio-oil sample was weighted using a digital balance of accuracy $0.0001 \mathrm{gm}$, and its volume was determined by using graduated cylinder then its density was simply calculated.

\subsubsection{Elemental Analysis}

The bio- oil was analyzed for its ultimate analysis by MEDAC LTD (analytical and chemical consultancy services) which provides carbon, hydrogen and nitrogen, while the oxygen content was calculated from the difference.

\subsubsection{Heating value}

Calorific value of bio-oil is acquired as higher heating values (HHV) which is the amount of heat released when the bio-oil is burnt. The calorific value was calculated according to Demirbas [194] and Singh et al. [188] as explained in section 3.2.5. 


\subsubsection{GC/MS analysis - composition}

Most researcher used the Gas Chromatography-Mass Spectrometry (GC-MS) to specify the composition of the compound present in the bio-oil sample. In this work, Clarus 680 GC connected to Clarus $600 \mathrm{~T}$ MS shown in Fig. 3. 15 is used to figure out the composition of bio-oil extracted from the slow pyrolysis experiment displayed in the previous section.

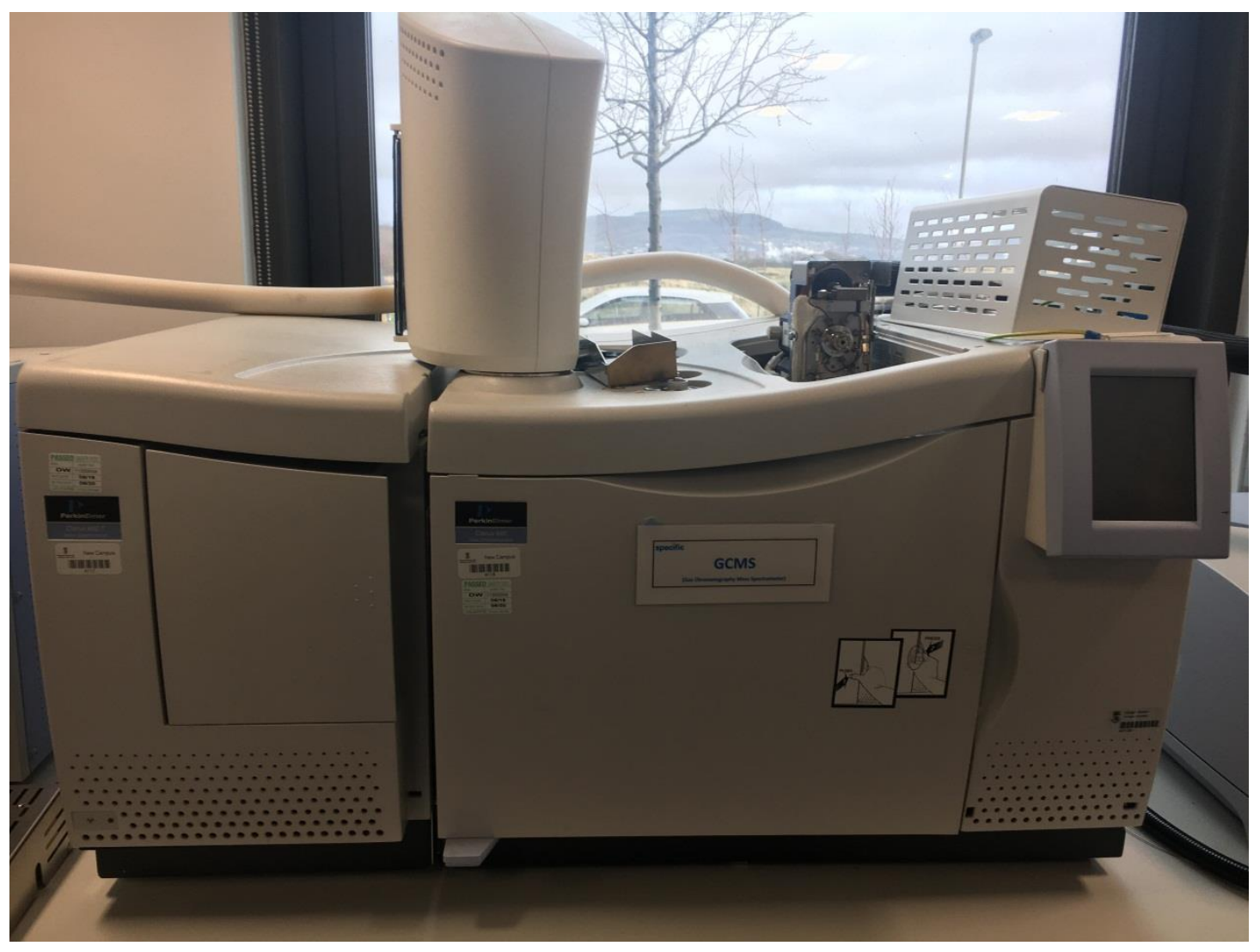

Fig. 3. 15. Clarus $680 \mathrm{GC}$ connected to Clarus $600 \mathrm{~T}$ MS.

The bio-oil samples collected from the pyrolysis experiments were prepared for GC-MS analysis by dissolving each sample in ethanol as seen in Fig. 3. 16. The ethanol and biooil were mixed with volume ratio 5:1, respectively. The mixture was shanked until the bio-oil has dissolved in the ethanol. Before starting the current test using clarus $680 \mathrm{GC}$ 
connected to clarus $600 \mathrm{~T}$ MS, the bio-oil sample was diluted also in acetone and added 5 ppm naphthalene D8 as internal standard. All bio-oil samples were filtered before placed in auto-sampler vials to protect the gas chromatography column from blockage.

The GC device is programed as follows; the initial temperature is adjusted at 40 ${ }^{\circ} \mathrm{C}$ and hold for 2 minutes then increased with constant rate of $10{ }^{\circ} \mathrm{C} / \mathrm{min}$ to reach $300{ }^{\circ} \mathrm{C}$. The bio-oil sample of volume $1 \mu \mathrm{l}$ is injected with initial temperature $280{ }^{\circ} \mathrm{C}$ [200] with Split flow ratio equal 10:1. The used column is $30 \mathrm{~m}$ DB5 equivalent, $0.25 \mu \mathrm{m}$ film thickness and $0.25 \mathrm{~m}$ internal diameter. The GC-MS were analyzed and the chemical compound components of the bio-oil peaks were identified by comparing their linear retention index (LRI) and mass spectra with the entries of mass spectra database libraries.

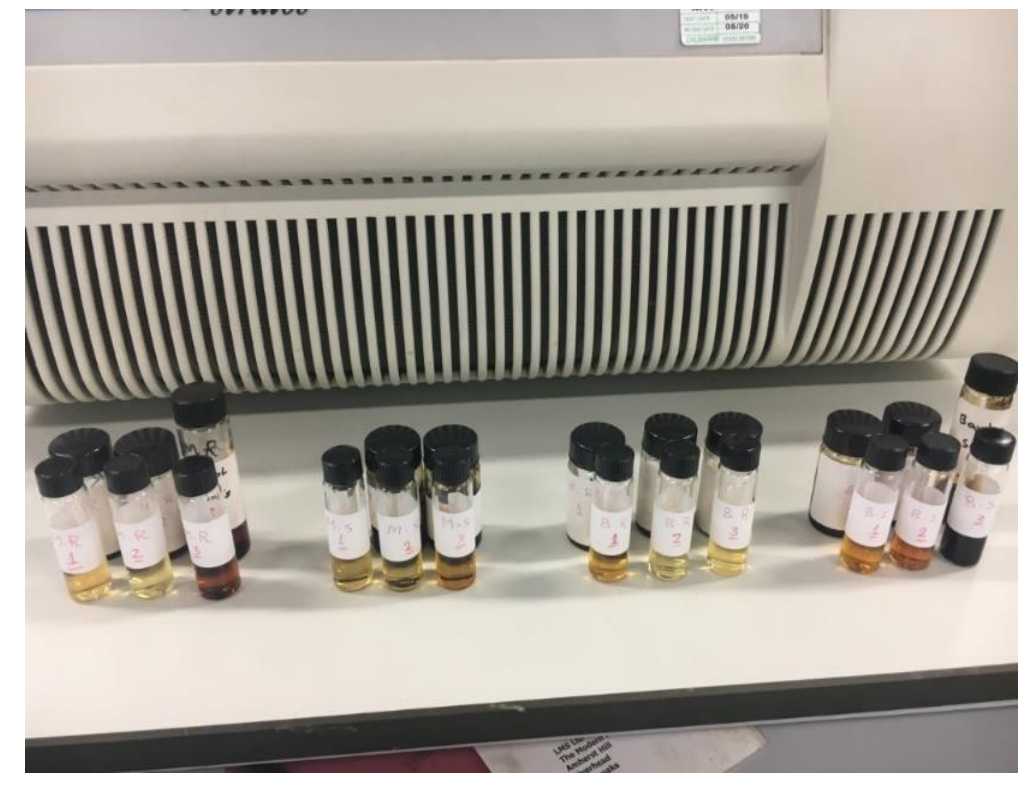

Fig. 3. 16. Bio-oil samples prepared for the GC-MS analysis. 


\section{Chapter 4}

\section{Thermochemical characterisation of Date palm fruit wastes}

\subsection{Material and method}

The literature results displayed in Chapter 2 reveal that the date stones and rachis are considered the most promising biomass feedstock for biofuel production [55, 156]. In addition to the fact that the Barhee and Medjool are the most famous and abundant date palm trees in Tabuk city, Saudi Arabia. So, in this work, Barhee and Medjool rachis and stones are characterized. The Barhee tree is characterised by a heavy trunk of a medium height of moderately curved green leaves. It has a dusty greenish colour which looks dense and spherical. The fruit itself is broadly ovate round with relatively no astringency or objectionable tannin flavour at Khalal stage. On the other hand, the Medjool tree has a medium size trunk with short to medium leaves which are arranged with little curvature. This tree has a high fruit quality with large size and attractive appearance. This type of dates outshines all the known varieties in terms of the fruit quality and size. The Medjool is of a high commercial value as evidenced from its export potentials. [56]. An illustration of the Barhee and Medjool trees is shown in Fig. 4.1.
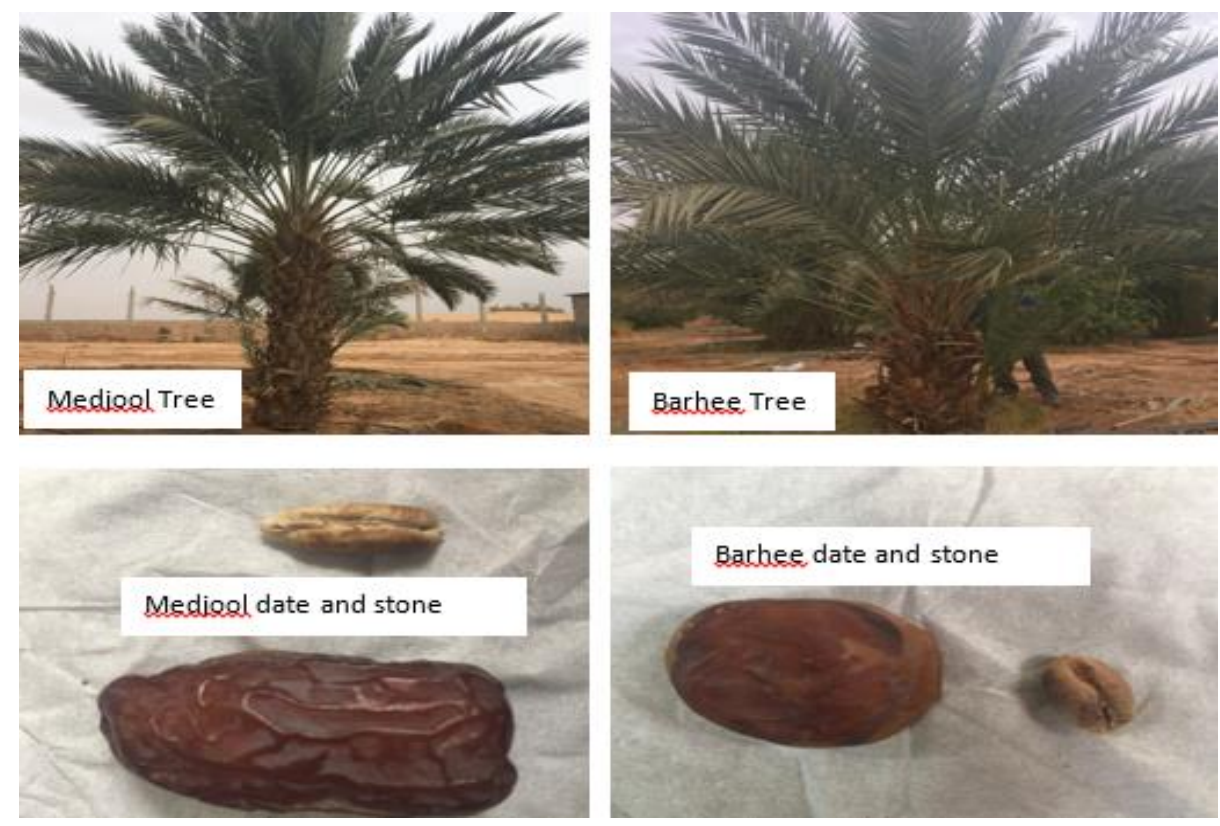

Fig. 4. 1. The Medjool tree and fruit (left) and the Barhee tree and fruit (right). 
The general distinguishing characteristics between the Barhee and Medjool are summarised in Table 4. 1. It is worthwhile mentioning that such characteristics describe the appearance of the tree as well as the nature of the stone within the date fruit itself relative to the overall size of the fruit.

Table 4. 1.The general distinguishing characteristics of the Barhee and Medjool tree and fruit [56].

\begin{tabular}{|c|c|c|c|}
\hline The name & Synonyms & Appearance & Nature of Stones \\
\hline $\begin{array}{l}\text { Medjool } \\
\text { variety }\end{array}$ & $\begin{array}{l}\text { Mejhool, } \\
\text { Medjoul, } \\
\text { Majhoul, Majul, } \\
\text { Medjhool, } \\
\text { Medjehuel, } \\
\text { Majhol and Me- } \\
\text { jool }\end{array}$ & $\begin{array}{l}\text { Medium size trunk, short to } \\
\text { medium leaves which are } \\
\text { organised with little } \\
\text { curvature. Has a high fruit } \\
\text { quality (large size and } \\
\text { attractive). It outshines all } \\
\text { other varieties with regard to } \\
\text { fruit quality and size. It is of } \\
\text { high commercial value and is } \\
\text { considered date No. } 1 \text { for } \\
\text { export market }\end{array}$ & $\begin{array}{l}\text { Walnut - Brown shiny colour } \\
\text { darker at the end, } 1.5 \text { g. } \\
\text { Seedling canal is closed } \\
\text { approximately } 50 \% \text { of the } \\
\text { seed diameter with small } \\
\text { wrinkles. On each side of the } \\
\text { seed there is a protrusion } \\
\text { forming a "wing shape" that is } \\
\text { typical of Medjool and } \\
\text { different from all other } \\
\text { varieties. }\end{array}$ \\
\hline $\begin{array}{l}\text { Barhee } \\
\text { variety }\end{array}$ & $\begin{array}{l}\text { Barhi, } \\
\text { Birhi. }\end{array}$ & $\begin{array}{l}\text { Heavy trunk of a medium } \\
\text { height, moderately curved } \\
\text { green leaves, slightly } \\
\text { drooping pinnae. The palm } \\
\text { has a dusty greenish colour } \\
\text { and looks dense and } \\
\text { spherical. The fruit is broadly } \\
\text { ovate round with relatively no } \\
\text { astringency or objectionable } \\
\text { tannin flavour at Khalal stage. }\end{array}$ & $\begin{array}{l}\text { The seed fills the whole } \\
\text { volume of the seed cavity. } \\
\text { Light brown to wood brown; } \\
\text { oblong, slightly wider above } \\
\text { middle، somewhat tapering to } \\
\text { the blunt apex. It is short and } \\
\text { wide, ( } 18 \text { to } 23 \times 8.4 \text { to } 10.5 \\
\text { mm). Germ pore central or } \\
\text { nearly so and can be clearly } \\
\text { seen at the centre of seed's } \\
\text { dorsal side. Furrow commonly } \\
\text { medium in width and depth. } \\
\text { Light seed weight } 0.88 \mathrm{~g} \text { and a } \\
\text { high pulp: seed ratio }(12.75)\end{array}$ \\
\hline
\end{tabular}

In the current study, the stones and rachis obtained from the two distinct types of dates trees were experimentally characterized on a laboratory scale and their utilization potentials as biomass feedstock were investigated.

The stones and rachis were prepared using the mixer blade grinder after which they were sieved to determine the particle sizes for each batch of date. All samples were 
obtained from Saudi Arabia, specifically from a farm of date palm in the city of Tabouk. The stones and rachis of each tree were ground and screened to 5, 10, 35 and 60 mesh size (and 120 for stones). The 60 mesh size was chosen for the analysis in the current study as will be discussed later. An illustration of the ground samples of the Barhee and the Medjool are shown in Fig. 4. 2.
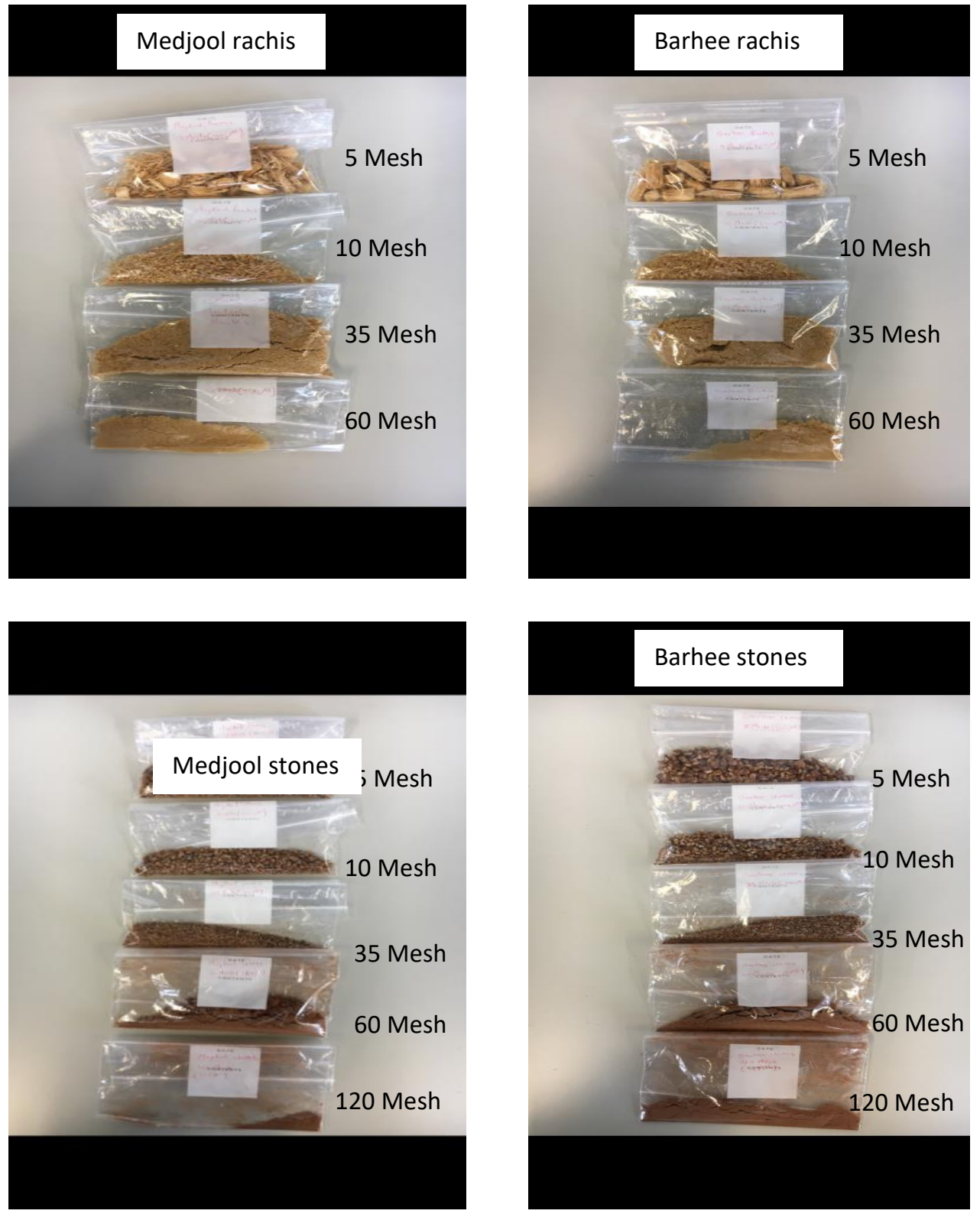

Fig. 4. 2. The ground samples of the Medjool (left) and Barhee (right) Rachis and stones. 


\subsubsection{Biomass characterisation}

The proximate, ultimate, structure/composition and thermo-gravimetric analysis experiments were conducted to characterize the selected biomass materials. The procedure of the experiments were discussed in detail in the previous chapter.

The proximate analysis is used to determine the physical characteristics of biomass. Where the moisture content, volatile matter, ash, fixed carbon, total solid, calorific value and decomposition temperature can be obtained.

The ultimate analysis provides information about the elemental components such as carbon, hydrogen, nitrogen, oxygen and sulphur contents [187, 189].

The content of cellulose, hemicellulose and lignin were also obtained by structure/composition analysis.

The heating value of each proposed biomass were calculated according the equation given by Singh et al. [188] and Demirbas [194].

Thermo-Gravimetric Analysis (TGA) was used to study the physical properties such as evaporation and the chemical behavior such as thermal degradation of materials that causes materials to lose volatile gases [195]. In TGA, two processes were employed namely; TGA pyrolysis and TGA combustion. The former uses high temperatures (up to $900{ }^{\circ} \mathrm{C}$ ) under an inert atmosphere such as nitrogen medium whereas the latter utilises lower temperatures (up to $700{ }^{\circ} \mathrm{C}$ ) in an oxygen atmosphere [196]. The typical heating and cooling cycles of the TGA Pyrolysis and combustion utilised in the current experiment are summarised in Table 3. 1 . 


\subsection{Results and discussions}

\subsubsection{The Physical Analysis Results}

The results of the proximate analysis (i.e. moisture content, ash content, volatile and fixed carbon contents) were analysed and discussed in the current section of the thesis.

\subsubsection{The Moisture Content}

The moisture contents of Barhee and Medjool stones and rachis are summarized in Table 4.2. Comparison between the Barhee and Medjool stone moisture contents is illustrated in Fig. 4.3 (a), while the moisture contents in the case of rachis obtained from Barhee and Medjool are compared in Fig. 4. 3 (b). The stones contain high amount of moisture compared to the rachis, wherever they were obtained from; Barhee or Medjool as clearly seen in Table 4.2. Accepted standard deviations are found as seen in Table 4. 2 which mean that there is no significant dependence on the mesh size as the results are almost unaffected by the mesh size for the samples. Overall, it can be seen that the moisture content of the Barhee and Medjool are almost identical in the stone samples whereas the Barhee is higher in terms of the moisture content in the rachis samples as shown in Fig.4.3 (a) and (b).

It is well known that the energy required to bring a briquette up to its pyrolytic temperature is massively dependent on the moisture content. In other words, the moisture content affects the internal temperature within the briquette due to the endothermic evaporation and this means the moisture content is one of the major parameters that influence the quality of the briquette [201].

Table 4. 2. The moisture contents of Medjool and Barhee stones and rachis.

\begin{tabular}{lllll}
\hline Size of sieve & \multicolumn{3}{c}{ Moisture content $(\%)$} \\
\cline { 2 - 5 } & \multicolumn{3}{c}{ Stones } & Rachis \\
\cline { 2 - 5 } & Medjool & Barhee & Medjool & Barhee \\
\hline Mesh 5 & 7 & 7 & 5.8 & 6.3 \\
Mesh 10 & 8 & 8 & 5.2 & 5.6 \\
Mesh 35 & 10 & 9 & 6.1 & 6.2 \\
Mesh 60 & 9 & 8 & 5.2 & 5.6 \\
Mesh 120 & 9 & 9 & - & - \\
Average & 8.6 & 8.2 & 5.575 & 5.9250 \\
Std. dev. & 1.1402 & 0.8367 & 0.45 & 0.3775 \\
\hline
\end{tabular}




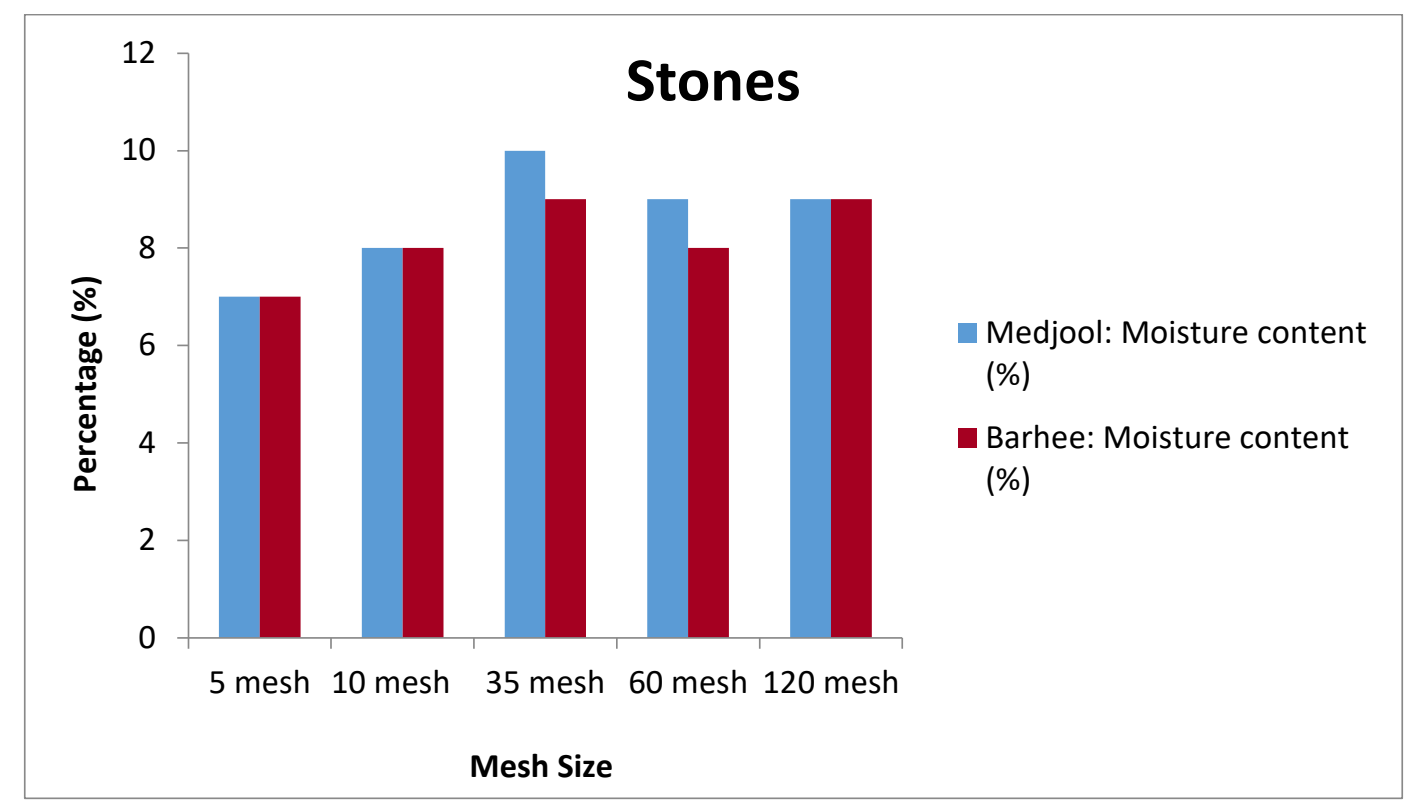

(a)

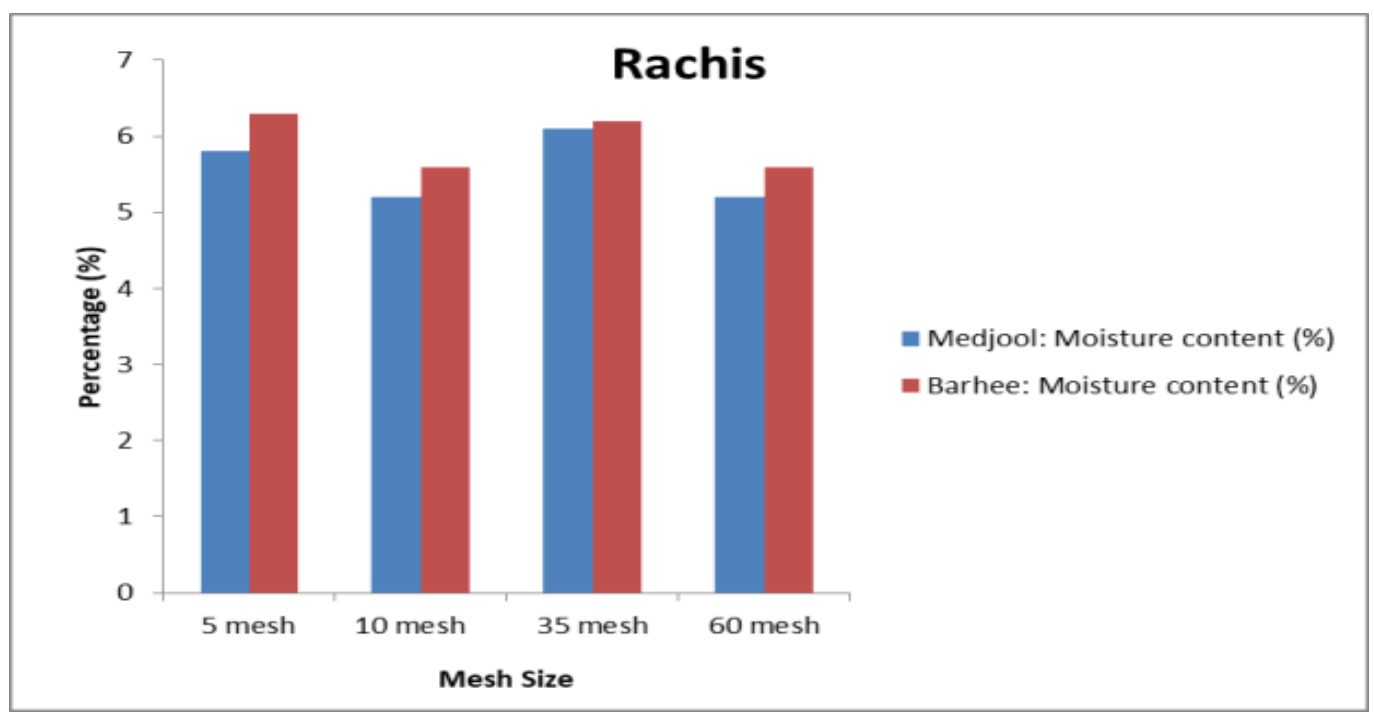

(b)

Fig. 4. 3. (a) Comparison between moisture contents of Barhee and Medjool stones, (b) comparison between moisture contents of Barhee and Medjool rachis. 


\subsubsection{The Ash Content}

The ash content is relatively high in rachis compared to stones where it reaches $15.36 \%$ and $13.5 \%$ in case of Medjool and Barhee rachis, respectively. While the ash content does not exceed $2.2 \%$ in cases of stone samples as obviously seen in Table 4. 3 . Comparisons between the ash content in Barhee and Medjool stones and rachis as vertical bar chart are displayed in Fig. 4.4 (a) and (b), respectively. Based on the results of stone and rachis samples shown in Fig. 4.4 (a) and (b), it is clearly seen that the Medjool samples has more ash content than Barhee at the various studied mesh sizes. The ash content is a non-combustible component of the biomass. So, the ash has a significant influence on the amount of heat transfer to the surface of the fuel as well as the diffusion of oxygen to the fuel surface during the combustion of char. This means that, since ash is an impurity that will not burn, fuels with less ash content are preferable in terms of thermal utilisation. Moreover, fuels with more ash content will result in higher dust emissions and will have a direct effect on the combustion volume and efficiency [201]. So, the stones have a superiority as feedstock as they have less amount of ash compared to the rachis in both date palm categories. The considerable differences in ash amount produced from Barhee rachis samples that give high standard deviation may be accepted as experimental expected errors.

Table 4. 3. Ash contents of Medjool and Barhee stones and rachis.

\begin{tabular}{lllll}
\hline Size of sieve & \multicolumn{3}{c}{ Ash content $(\%)$} \\
\cline { 2 - 5 } & \multicolumn{3}{c}{ Stones } & Rachis \\
\cline { 2 - 5 } & Medjool & Barhee & Medjool & Barhee \\
\hline Mesh 5 & 1.17 & 1.07 & 14.28 & 13.5 \\
Mesh 10 & 2.18 & 1.08 & 14.56 & 6.9 \\
Mesh 35 & 2.2 & 1.09 & 15.36 & 7.8 \\
Mesh 60 & 1.82 & 1.09 & 15.4 & 12.1 \\
Mesh 120 & 0.91 & 1.09 & - & - \\
Average & 1.656 & 1.084 & 14.9 & 10.075 \\
Std. dev. & 0.5895 & 0.0089 & 0.5662 & 3.2191 \\
\hline
\end{tabular}




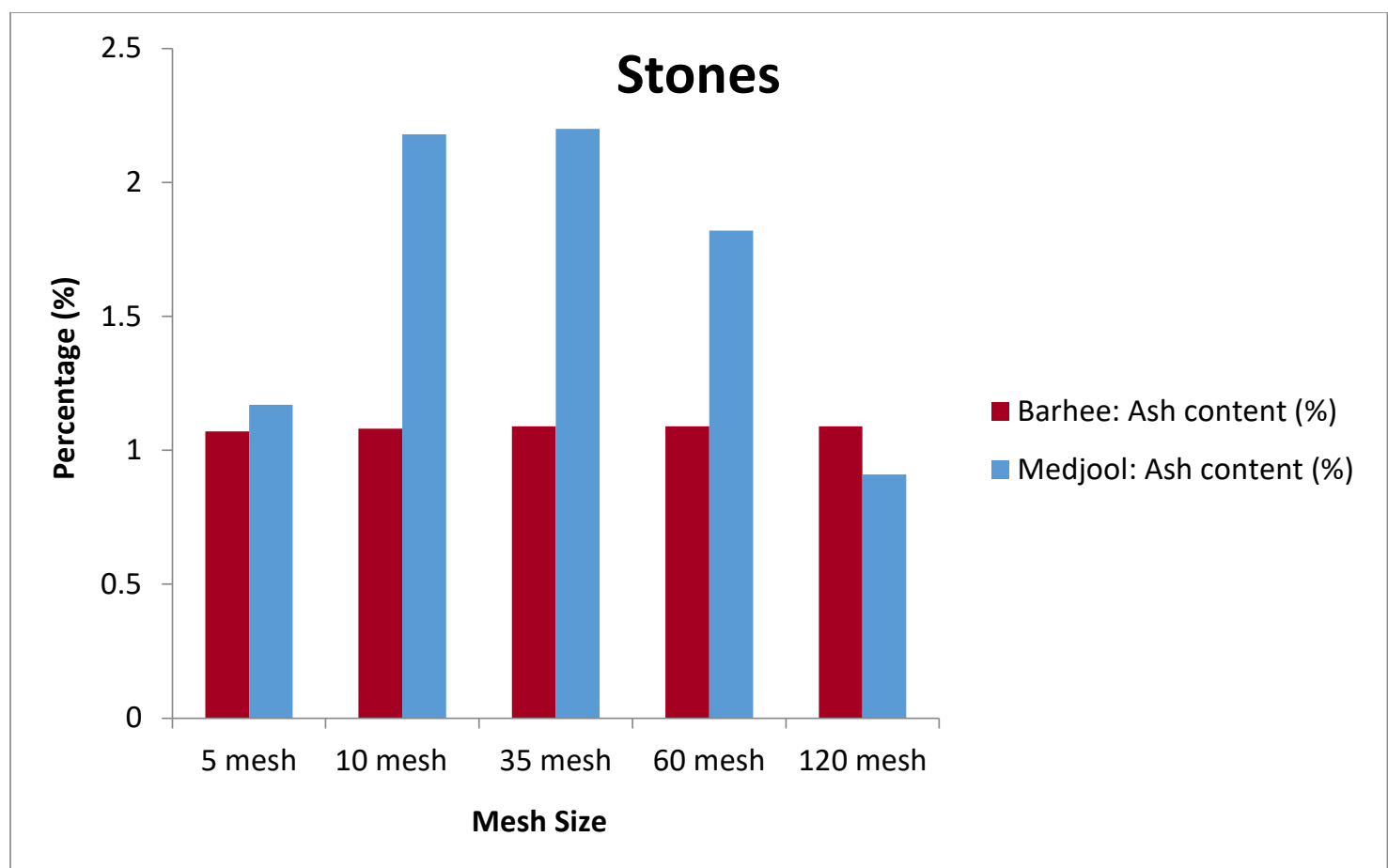

(a)

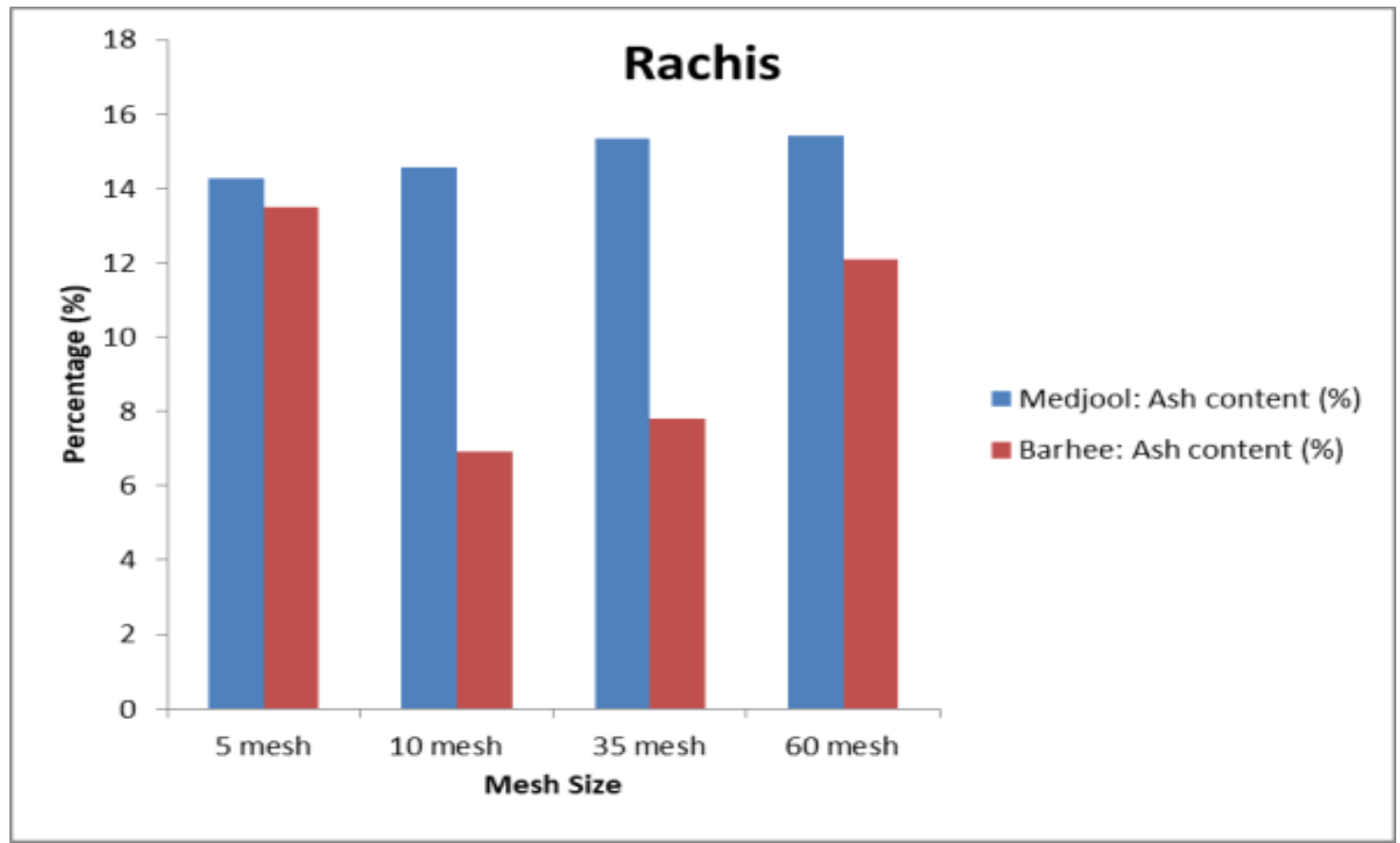

(b)

Fig. 4. 4. (a) Comparison between ash contents of Barhee and Medjool stones, (b) comparison between ash contents of Barhee and Medjool rachis. 


\subsubsection{Volatile Content}

The volatile contents of Barhee and Medjool stones and rachis are summarised in Table 4.4. The Barhee stones showed the highest values of volatile contents which reaches 89.26\%. The results reported in Table 4.4 are displayed in Fig. 4.5 (a) and (b) as vertical bar chart in order to easily compare between the volatile contents in Medjool and Barhee stone as well as their values in rachis. The volatile content of the biomass can influence the combustion efficiency of a fuel. Table 4.4 shows that the stones have more volatile content compared to the rachis samples. The increase in the volatile content means that the fuel is more reactive and therefore provides a faster combustion rate and easy ignition during the devolatisation phase [201]

Table 4. 4. Volatile contents of Medjool and Barhee stones and rachis.

\begin{tabular}{lllll}
\hline Size of sieve & \multicolumn{3}{c}{ Volatile content (\%) } \\
\cline { 2 - 5 } & \multicolumn{3}{c}{ Stones } & Rachis \\
\cline { 2 - 5 } & Medjool & Barhee & Medjool & Barhee \\
\hline Mesh 5 & 79.92 & 86.67 & 76.6 & 70.2 \\
Mesh 10 & 78.48 & 86.4 & 62.4 & 78.2 \\
Mesh 35 & 72.65 & 87.82 & 61.44 & 67.6 \\
Mesh 60 & 67.48 & 89.26 & 74.88 & 77.04 \\
Mesh 120 & 73.71 & 84.99 & - & - \\
Average & 74.448 & 87.028 & 68.83 & 73.26 \\
Std. dev. & 4.9631 & 1.6035 & 8.0194 & 5.1669 \\
\hline
\end{tabular}




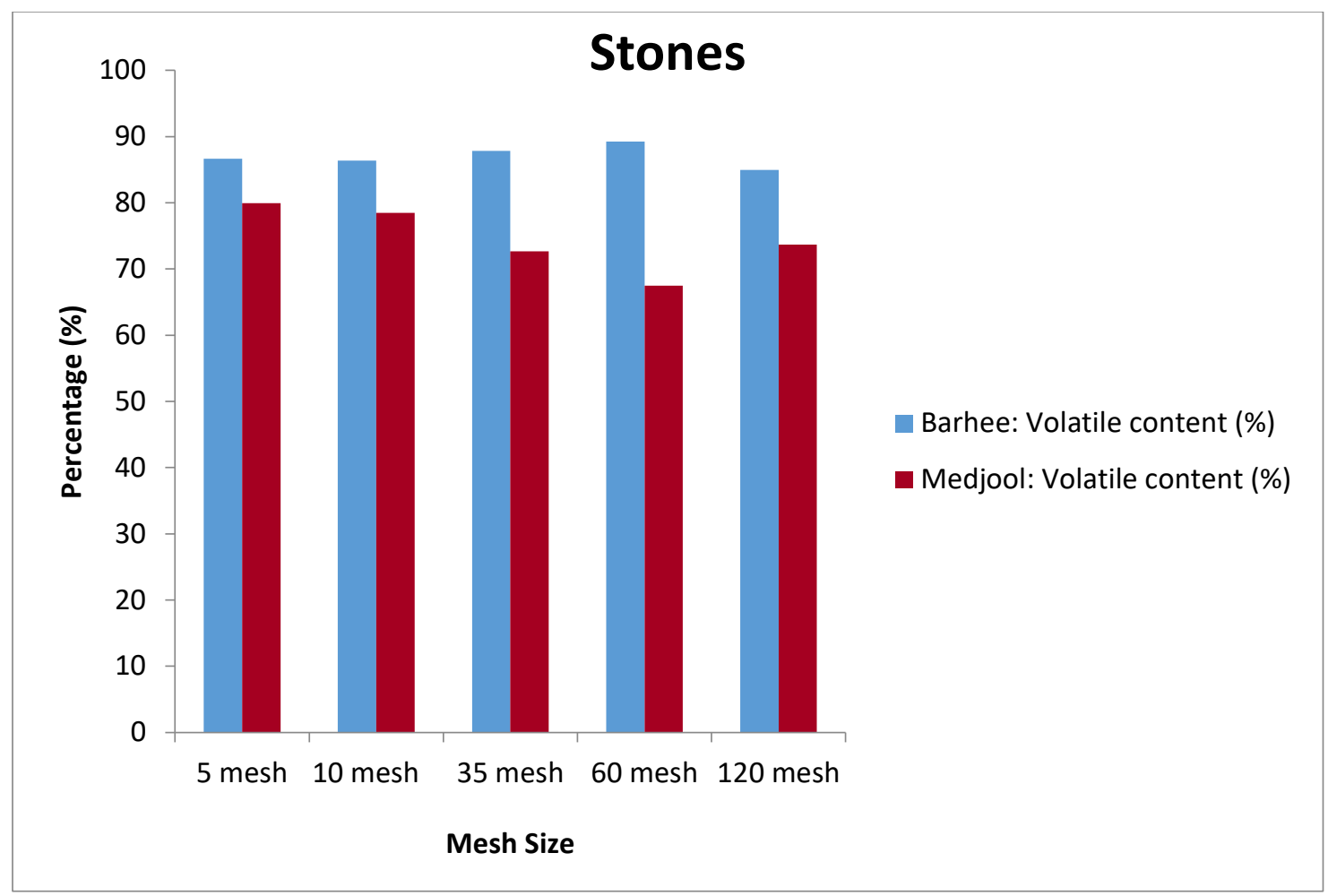

(a)

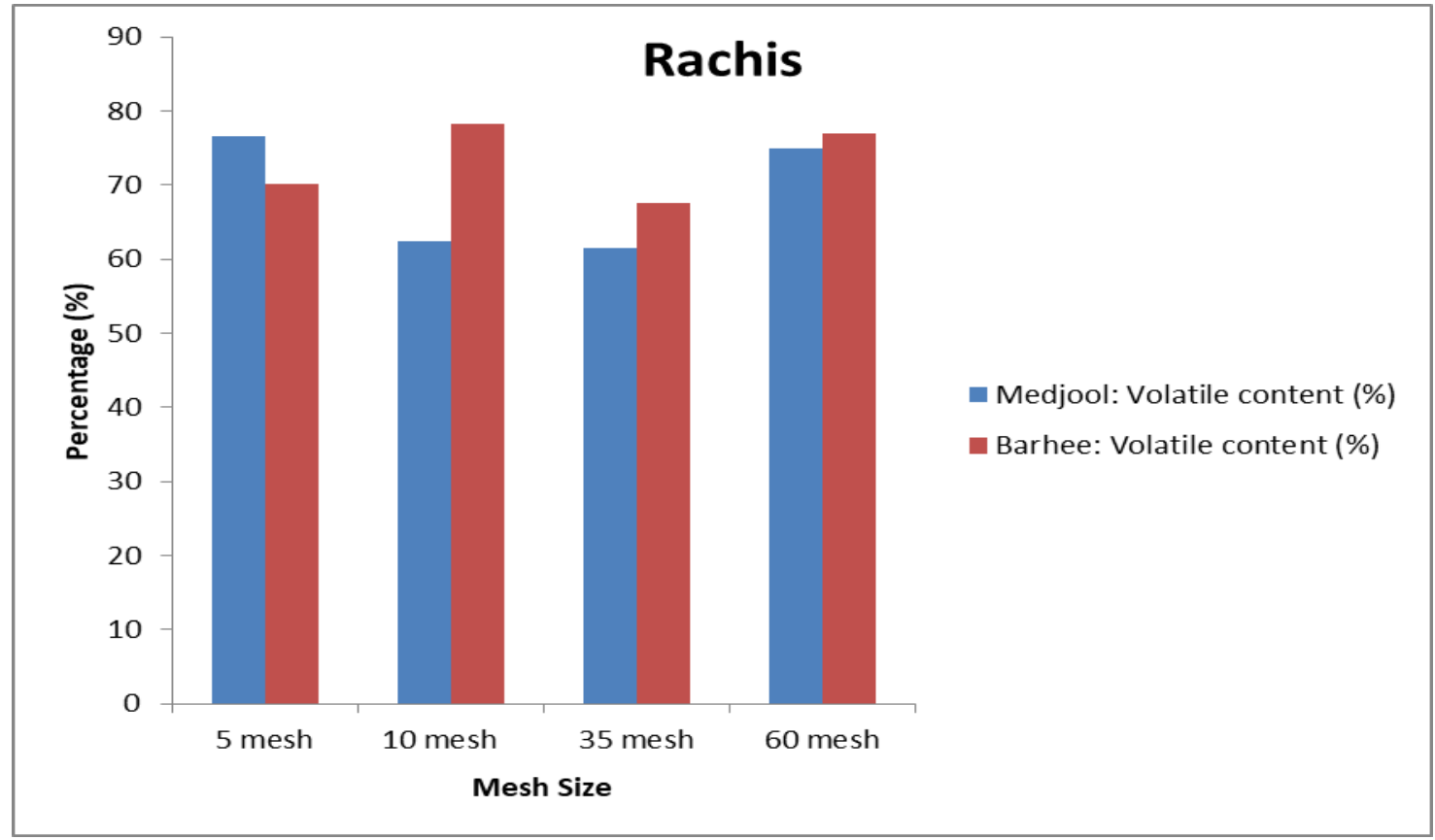

(b)

Fig. 4. 5. (a) The volatile content in Barhee and Medjool stone samples, (b) volatile content in Barhee and Medjool rachis samples. 


\subsubsection{The Fixed Carbon Content}

High fixed carbon contents were found in Medjool stones varied between 11.34-21.7 \% compared with low values found in Barhee stones ranging between 1.65-5.26\% as reported in Table 4.5. While similar contents of fixed carbon were found in the Barhee and Medjool rachis ranging between 2.896-5.26\%. The high fixed carbon content in Medjool stones is obviously seen in Fig. 4. 6 (a) compared with their values in Barhee stones at all studied mesh sizes. The fixed carbon content can also affect the combustion quality of the biomass. When comparing the results in Fig. 4. 6, the Medjool stone samples have very high amount of the fixed carbon compared to other samples of stone and rachis. In general the stone sample have more amount of fixed carbon compared to rachis samples. Generally, the fixed carbon content is the amount of carbon, i.e. solid fuel, available for char combustion after the volatile matter is used up. Also, the fixed carbon content provides an estimation of the heating value of a fuel as it is the main heat generator during combustion. This means that the stones contain more carbon resources necessary for combustion when compared to the rachis samples [201]

Table 4. 5. Fixed carbon content in Barhee and Medjool stones and rachis.

\begin{tabular}{llllc}
\hline Size of sieve & \multicolumn{4}{c}{ Fixed carbon content (\%) } \\
\cline { 2 - 5 } & \multicolumn{3}{c}{ Stones } & Rachis \\
\cline { 2 - 5 } & Medjool & Barhee & Medjool & Barhee \\
\hline Mesh 5 & 11.91 & 5.26 & 4.844 & 4.67 \\
Mesh 10 & 11.34 & 4.52 & 2.896 & 4.11 \\
Mesh 35 & 15.2 & 2.71 & 3.78 & 3.74 \\
Mesh 60 & 21.7 & 1.65 & 4.52 & 5.26 \\
Mesh 120 & 16.38 & 4.92 & - & - \\
Average & 15.306 & 3.812 & 4.01 & 4.445 \\
Std. dev. & 4.1626 & 1.5584 & 0.8659 & 0.6644 \\
\hline
\end{tabular}




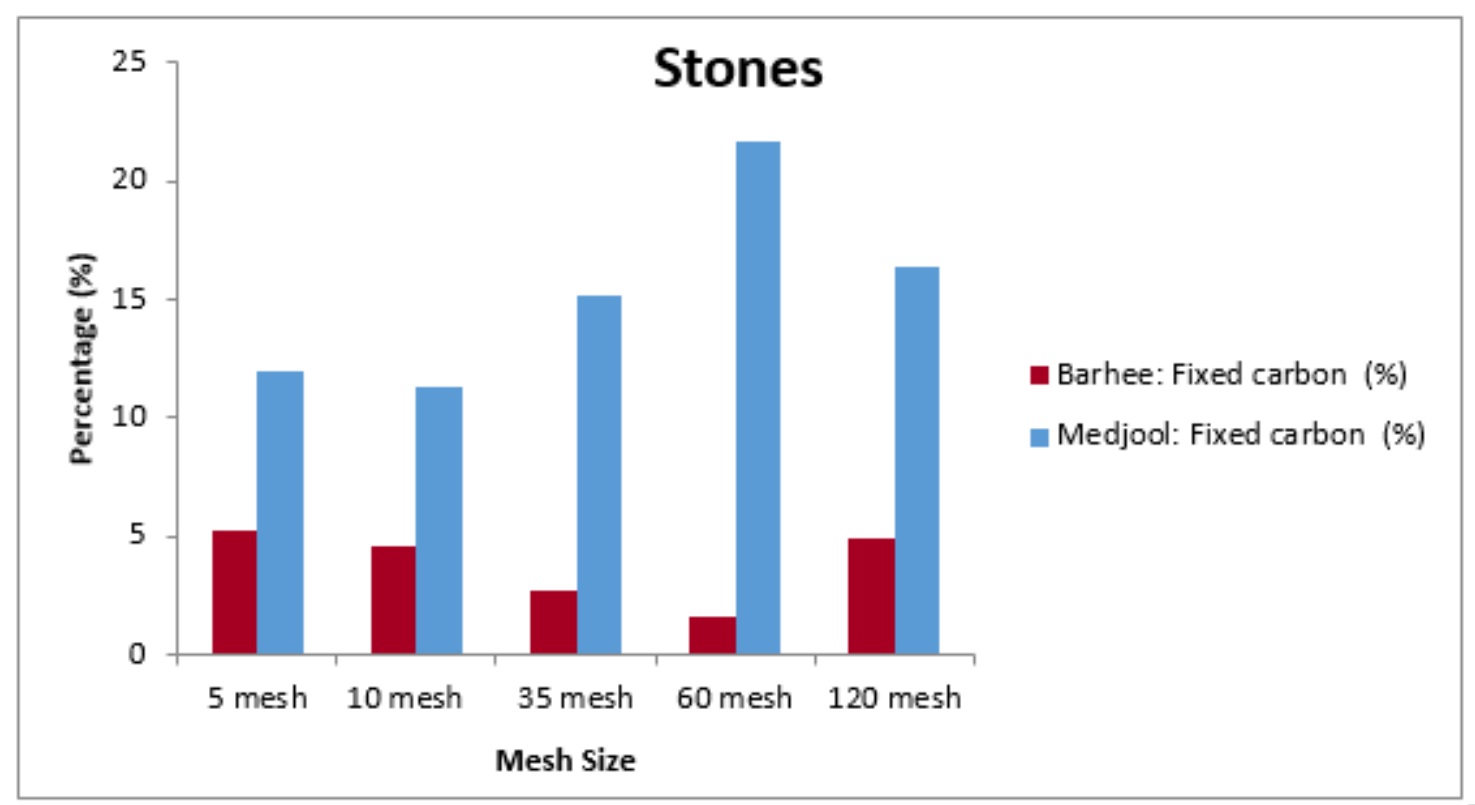

(a)

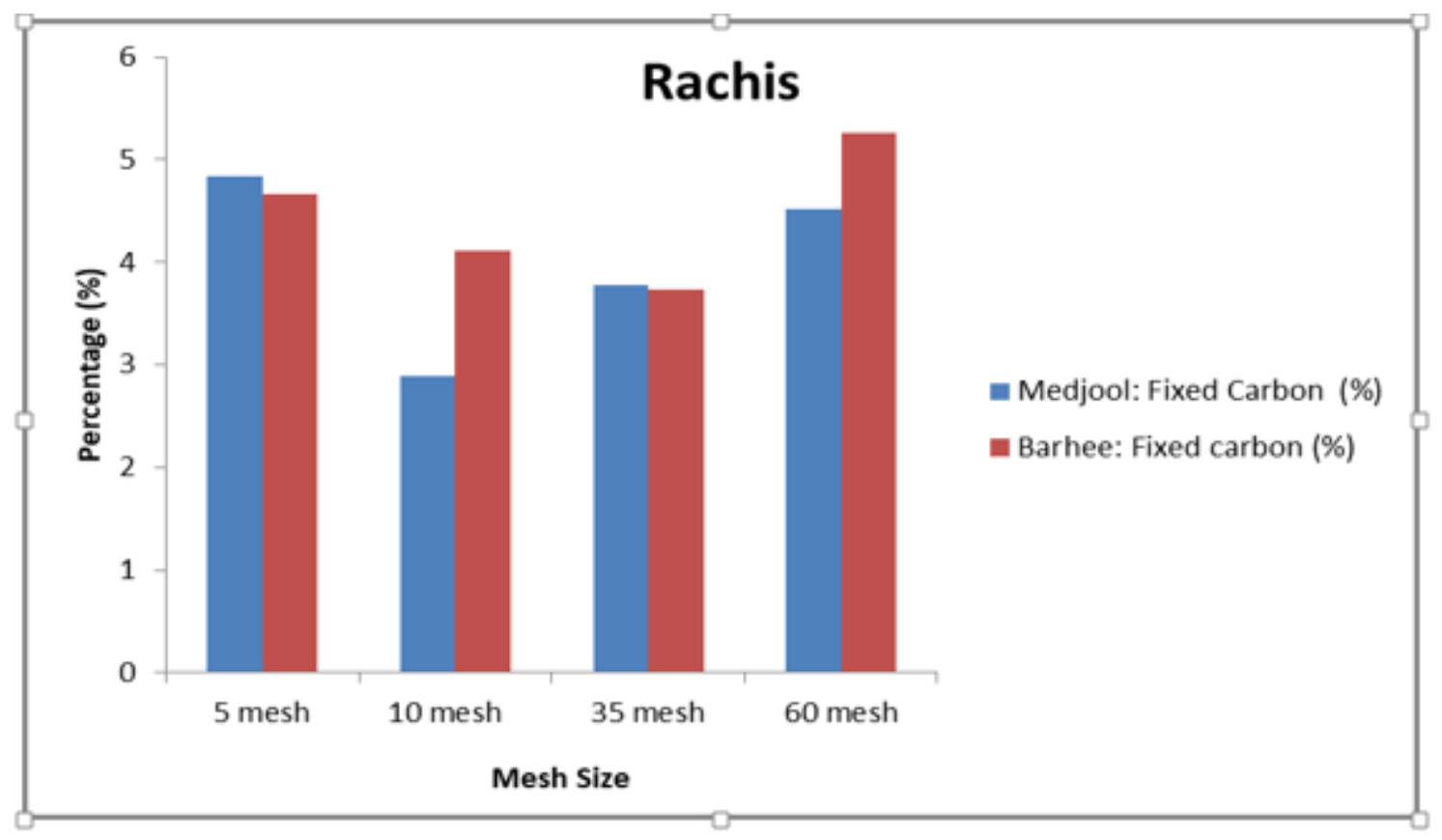

(b)

Fig. 4. 6. (a) The fixed carbon content in Barhee and Medjool stones samples, (b) The fixed carbon content in Barhee and Medjool rachis samples. 
An overall comparison is summarized in Table 4.6 (these data were extracted from Table 4.2- table 4.5). The level of judgment of the best suitable candidate biomass for biofuel production will take into consideration the various levels and amount of contents for an efficient combustion. The results of table 4. 6 show that the date stones have considerable superiority for biofuel production compared to rachis as they have high volatile and fixed carbon contents with low ash content.

Table 4. 6. An overall average comparison for all samples examined in the current study for the stones and rachis.

\begin{tabular}{|c|c|c|c|c|c|c|c|c|c|}
\hline \multirow[t]{2}{*}{$\begin{array}{l}\text { Type of } \\
\text { biomass }\end{array}$} & \multirow[t]{2}{*}{$\begin{array}{l}\text { Size } \\
\text { sieve }\end{array}$} & \multicolumn{2}{|c|}{ Moisture content } & \multicolumn{2}{|c|}{ Ash content $(\%)$} & \multicolumn{2}{|l|}{$\begin{array}{l}\text { Volatile } \\
(\%)\end{array}$} & \multicolumn{2}{|c|}{$\begin{array}{l}\text { Fixed carbon } \\
\text { content }(\%)\end{array}$} \\
\hline & & Medjool & Barhee & Medjool & Barhee & Medjool & Barhee & Medjool & Barhee \\
\hline \multirow[t]{7}{*}{ Stones } & Mesh 5 & 7 & 7 & 1.17 & 1.07 & 79.92 & 86.67 & 11.91 & 5.26 \\
\hline & Mesh 10 & 8 & 8 & 2.18 & 1.08 & 78.48 & 86.4 & 11.34 & 4.52 \\
\hline & Mesh 35 & 10 & 9 & 2.2 & 1.09 & 72.65 & 87.82 & 15.2 & 2.71 \\
\hline & Mesh 60 & 9 & 8 & 1.82 & 1.09 & 67.48 & 89.26 & 21.7 & 1.65 \\
\hline & Mesh 120 & 9 & 9 & 0.91 & 1.09 & 73.71 & 84.99 & 16.38 & 4.92 \\
\hline & average & 8.6 & 8.2 & 1.656 & 1.084 & 74.448 & 87.028 & 15.036 & 3.812 \\
\hline & Std. Dev. & 1.1402 & 0.8367 & 0.5895 & 0.00894 & 4.9631 & 1.6035 & 4.1626 & 1.5584 \\
\hline \multirow[t]{6}{*}{ Rachis } & Mesh 5 & 5.8 & 6.3 & 14.28 & 13.5 & 76.6 & 70.2 & 4.844 & 4.67 \\
\hline & Mesh 10 & 5.2 & 5.6 & 14.56 & 6.9 & 62.4 & 78.2 & 2.896 & 4.11 \\
\hline & Mesh 35 & 6.1 & 6.2 & 15.36 & 7.8 & 61.44 & 67.6 & 3.78 & 3.74 \\
\hline & Mesh 60 & 5.2 & 5.6 & 15.4 & 12.1 & 74.88 & 77.04 & 4.52 & 5.26 \\
\hline & average & 5.575 & 5.925 & 14.9 & 10.075 & 68.83 & 73.26 & 4.01 & 4.445 \\
\hline & Std. Dev. & 0.4500 & 0.3775 & 0.5662 & 3.2191 & 8.0194 & 5.1669 & 0.8659 & 0.6644 \\
\hline
\end{tabular}

When the obtained results were compared to other literature studies, a large amount of consistency was observed as shown in Table 4.7. Where the physical analysis results of Barhee and medjool stones are very close to that obtained by El may et al. [55] and Fadhil et al. [20] except for fixed carbon of Barhee stone which is considered very small. The Barhee and Medjool rachis results are approximately similar to that obtained by AlMarzouqi et al. [202], despite their relatively high ash content. This good consistency means that the analysis carried out in the current study is of high validity when compared to the widely available literature studies on the same topic. It is worthwhile mentioning that the values reported in Table 4.7 from the current work are the average values. 
Table 4. 7. The physical analysis results compared to literature studies.

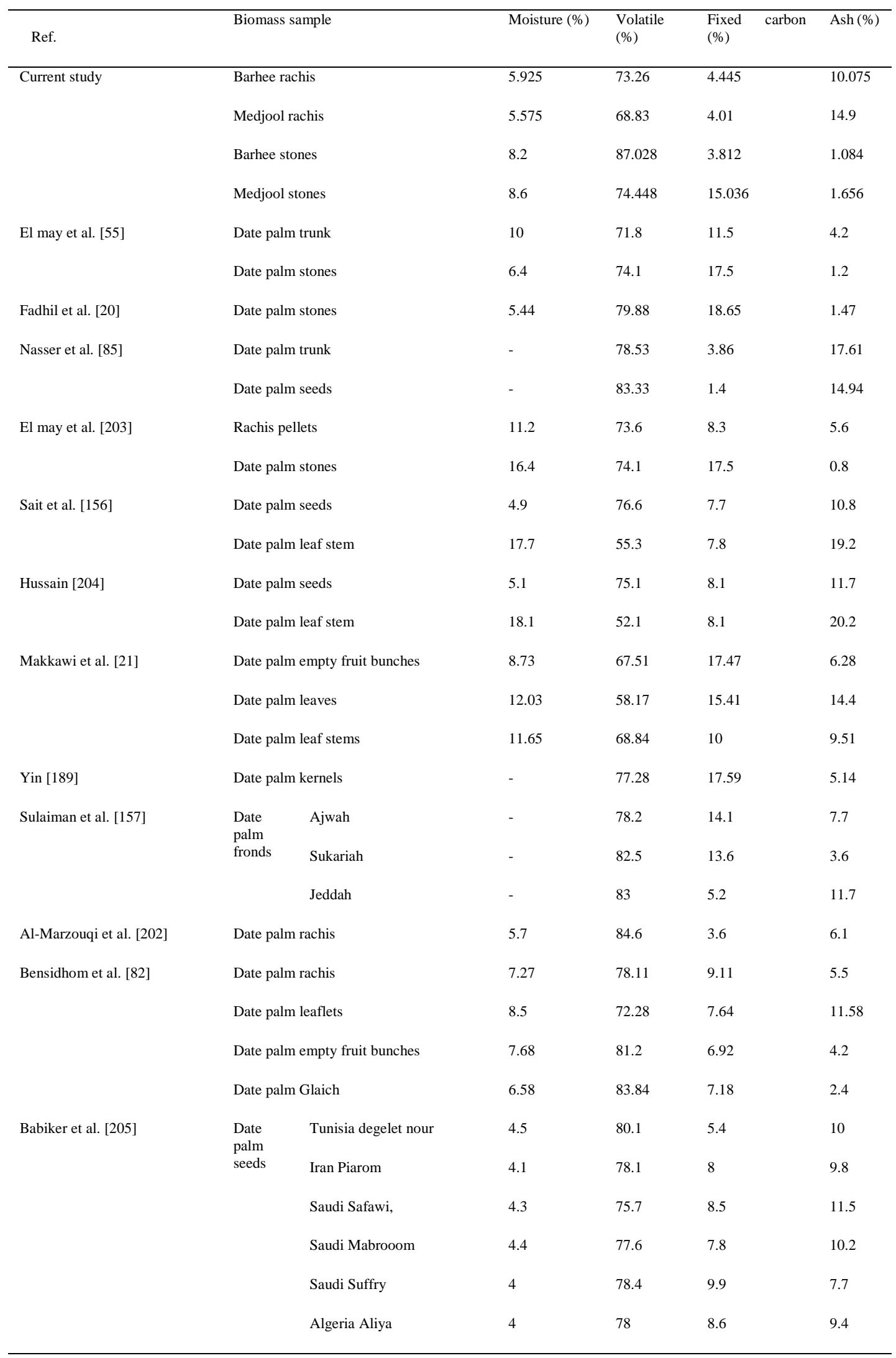




\subsubsection{Chemical analysis}

\subsubsection{The Compositional Analysis}

The results of the compositional analysis; the percentage of NDF, ADF, Hemicellulose, Cellulose and Lignin for the Medjool and Barhee stones and rachis are summarized in Table 4.8. For the purpose of comparison, the results are also presented in bar chart plots as shown in Fig. 4. 7 and Fig. 4. 8. In terms of the stone samples represented in Fig.4.7, it is clearly seen that the value of NDF, ADF, cellulose and lignin are higher for the Barhee samples when compared to the Medjool samples. However, the percentage of hemicellulose for the Barhee showed a slightly lower value when compared to that of the Medjool samples.

Table 4. 8. Compositional analysis results of Barhee and Medjool stones and rachis

\begin{tabular}{llllll}
\hline Sample & NDF (\%) & ADF (\%) & $\begin{array}{l}\text { Hemicellulose } \\
(\%)\end{array}$ & $\begin{array}{l}\text { Cellulose } \\
(\%)\end{array}$ & $\begin{array}{l}\text { Lignin } \\
(\%)\end{array}$ \\
\hline Medjool stones & 70 & 42.79 & 15.8 & 35 & 9.41 \\
Barhee stones & 91 & 74.3 & 16.6 & 66 & 21.35 \\
Medjool rachis & 66 & 65.14 & 22.73 & 43.5 & 7.57 \\
Barhee rachis & 48.88 & 36.72 & 21.8 & 16 & 20.15 \\
\hline
\end{tabular}




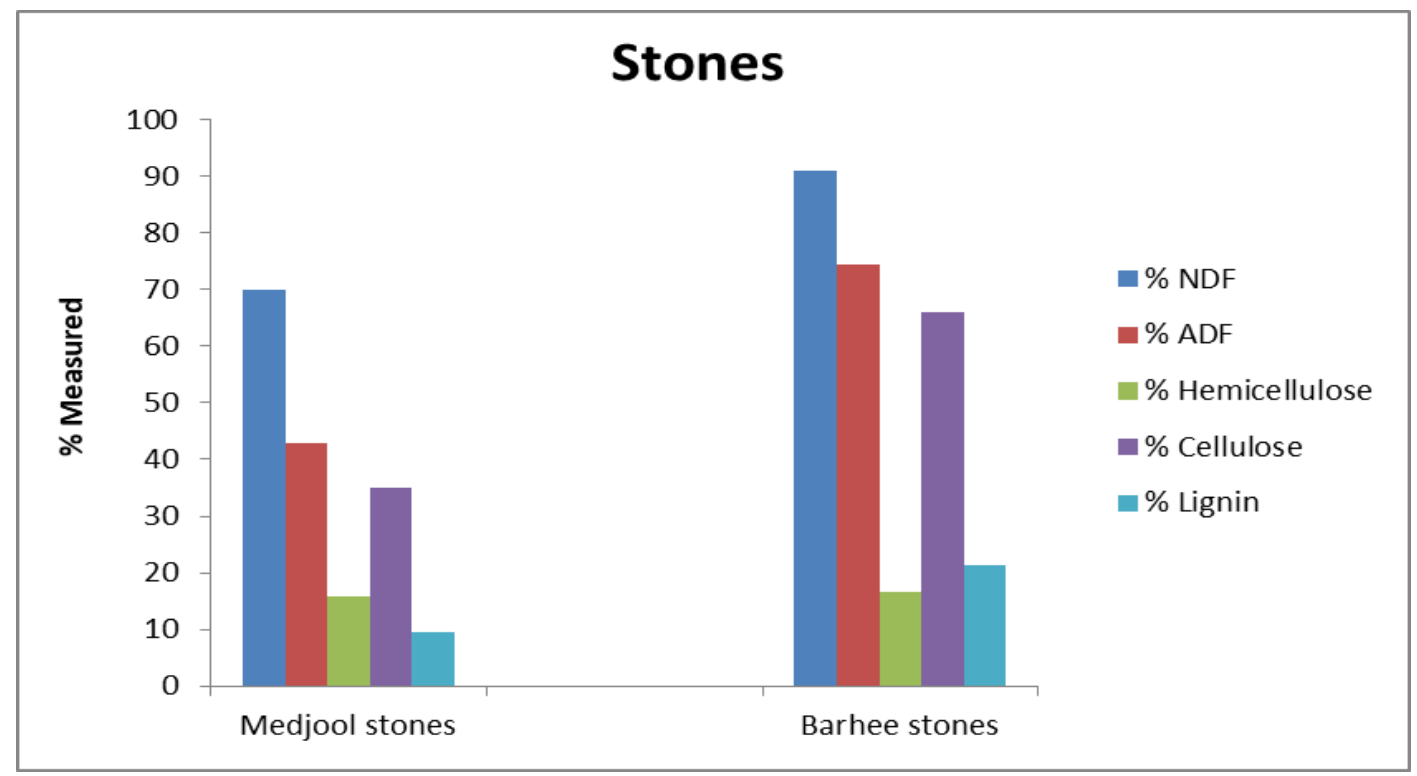

Fig. 4. 7. The compositional analysis of the Medjool and Barhee stone samples.

Regarding the compositional analysis of Barhee and Medjool rachis displayed in Fig.4. 8, it is seen that the Medjool rachis has large amounts of NDF, ADF and cellulose when compared to those of the Barhee rachis. On the contrary, the Barhee predominates when looking at the percentages of lignin. It is also noticed that approximately similar amount of hemicellulose was found in the Barhee and Medjool rachis samples.

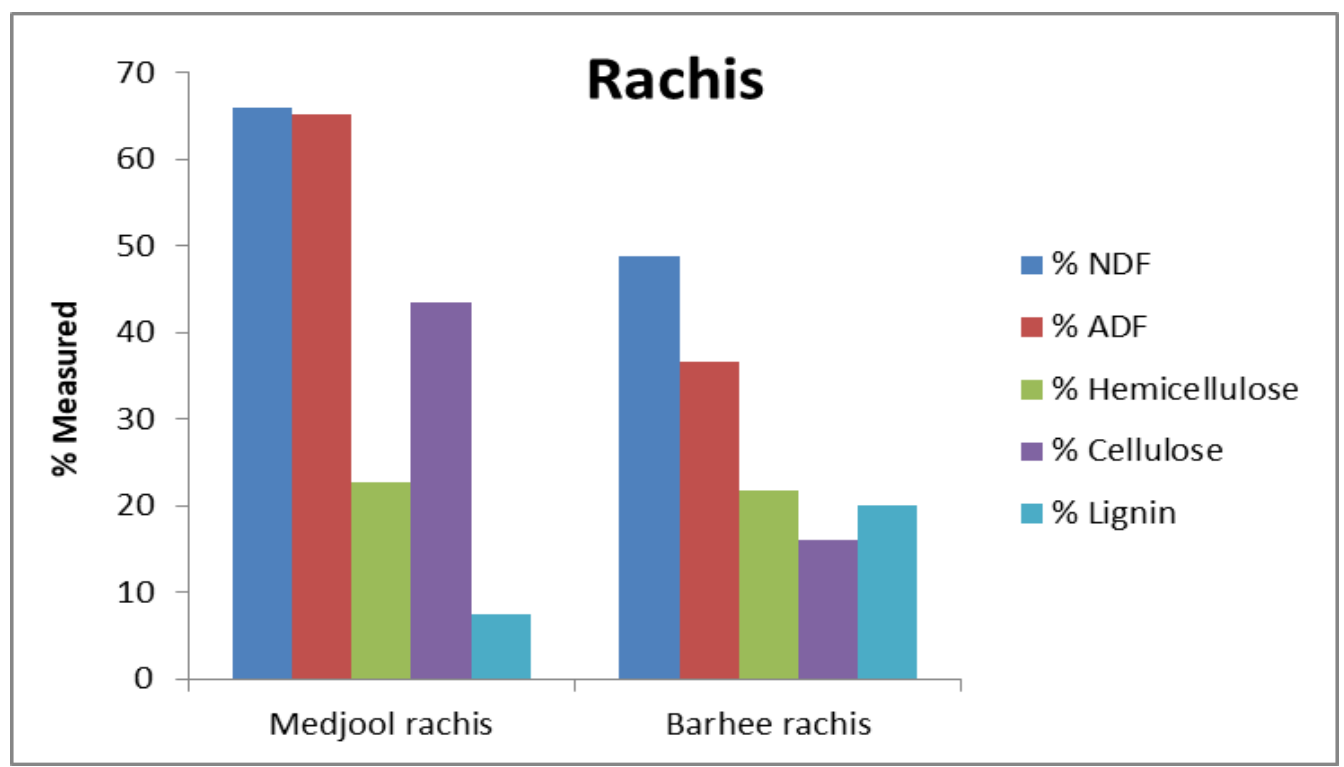

Fig.4. 8. The compositional analysis of the Medjool and Barhee rachis samples. 


\subsubsection{The Klason Measurement Results}

The Klason method has provided the results shown in Table 4.9 after carrying out two attempts for each sample then the average value was calculated. In order to make comparisons, the average values shown in Table 4.9 were plotted as illustrated in Fig. 4.9.

From the results of Fig. 4. 9, the Barhee rachis has the highest content of holocellulose followed by Medjool rachis. The Barhee and Medjool rachis also have slightly higher Acellulose compared to other samples. Approximately similar contents of lignin and lignin holocellulose are found in all samples as shown in Table 4. 9 and Fig. 4. 9.

Table 4. 9. The results obtained from Klason method for the Barhee and Medjool rachis and stones.

\begin{tabular}{|c|c|c|c|c|c|}
\hline \multicolumn{2}{|l|}{ Sample } & Lignin (\%) & Holocellulose (\%) & Lignin in holocellulose (\%) & A-cellulose (\%) \\
\hline \multirow{4}{*}{$\begin{array}{l}\text { Medjool } \\
\text { stone }\end{array}$} & Sample 1 & 12 & 5.33 & 11.73 & 10.51 \\
\hline & Sample 2 & 10.4 & 6.52 & 16.5 & 9.35 \\
\hline & Av. & 11.2 & 5.925 & 14.115 & 9.93 \\
\hline & Std. Dev. & 1.1314 & 0.8415 & 3.3729 & 0.8202 \\
\hline \multirow{4}{*}{$\begin{array}{l}\text { Barhee } \\
\text { stone }\end{array}$} & Sample 1 & 13 & 7.18 & 12.46 & 12.43 \\
\hline & Sample 2 & 16.57 & 5.79 & 14.6 & 17.1 \\
\hline & Av. & 14.785 & 6.485 & 13.53 & 14.765 \\
\hline & Std. Dev. & 2.5244 & 0.9829 & 1.5132 & 3.3022 \\
\hline \multirow{4}{*}{$\begin{array}{l}\text { Medjool } \\
\text { rachis }\end{array}$} & Sample 1 & 9.88 & 32.56 & 10.24 & 22.32 \\
\hline & Sample 2 & 15.87 & 32.42 & 16.94 & 15.45 \\
\hline & Av. & 12.875 & 32.49 & 13.59 & 18.885 \\
\hline & Std. Dev. & 4.2356 & 0.0990 & 4.7376 & 4.8578 \\
\hline \multirow{4}{*}{$\begin{array}{l}\text { Barhee } \\
\text { rachis }\end{array}$} & Sample 1 & 9.21 & 38.49 & 11.74 & 26.95 \\
\hline & Sample 2 & 8.92 & 40.96 & 7.98 & 19.34 \\
\hline & Av. & 9.065 & 39.725 & 9.86 & 23.145 \\
\hline & Std. Dev. & 0.2051 & 1.7466 & 2.6587 & 5.3811 \\
\hline
\end{tabular}




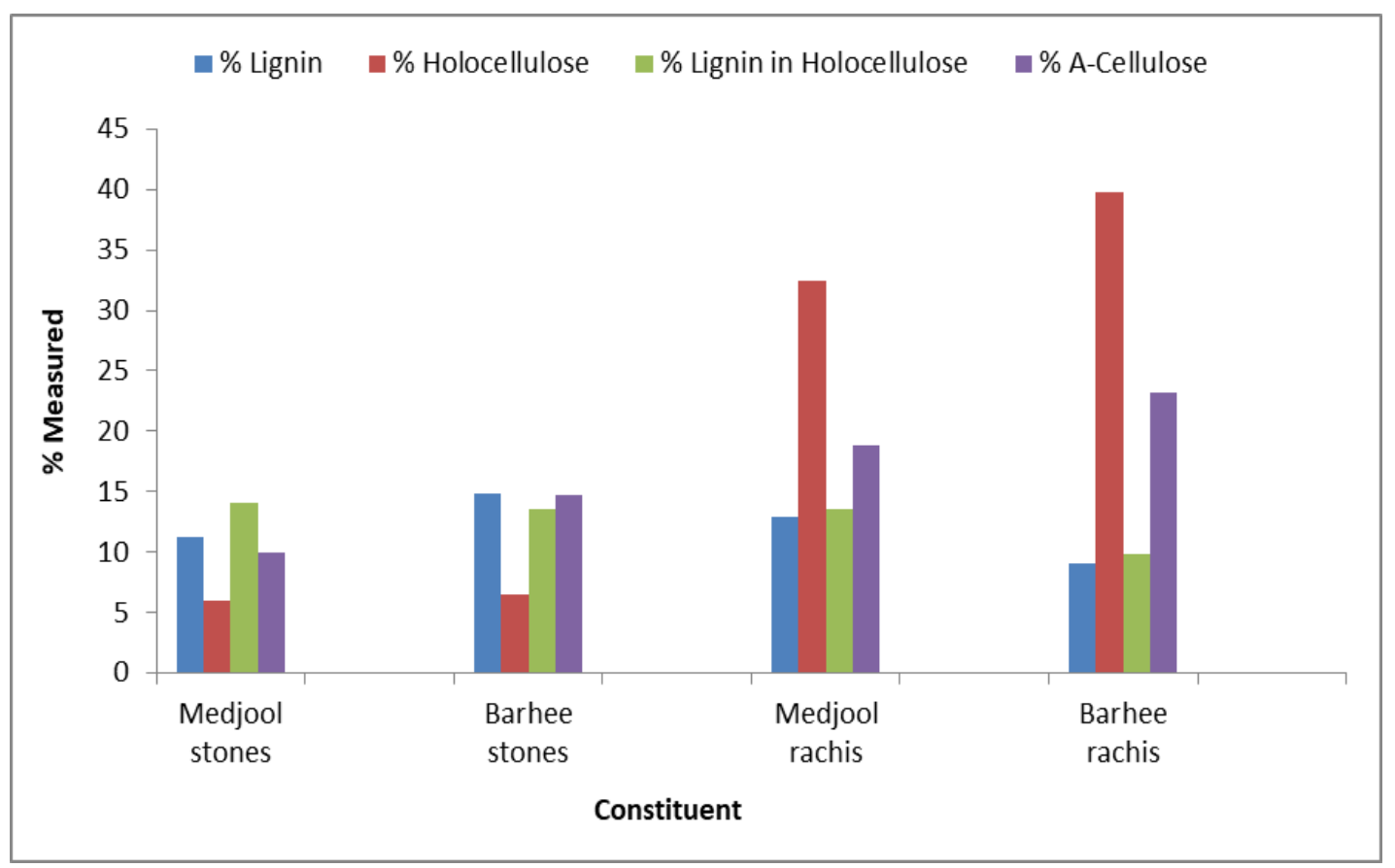

Fig. 4. 9. The results obtained from Klason method for the Barhee and Medjool stones and rachis.

\subsubsection{The Ultimate Analysis}

The ultimate analysis has provided information on the elemental content of the samples. The amount of carbon, hydrogen, nitrogen and oxygen were defined for each sample using the ultimate analysis are illustrated in Table 4. 10. It is clearly seen that the stones samples whatever they were obtained from, Barhee or Medjool trees, contain a large amount of carbon compared to the rachis samples. This means that they contain more potential in terms of the stored energy as will be discussed in the following section. The Barhee and Medjool carbon contents are found 45.24 and $45.05 \%$, respectively. Similar results of carbon content of the date palm stones were found in the literature, where the lowest value of carbon content of $44.1 \%$ is reported by Hussain [204] and its highest value of $51.2 \%$ is found by El may et al. [55] as clearly seen in Table 4.10. On the other hand, the carbon content of Barhee and Medjool rachis were found 23.75 and 20.27 \%, respectively, which are considered very small compared with that reported in the literature [82, 202]. 
Table 4. 10. The results of the ultimate analysis obtained from the current work alongside literature studies.

\begin{tabular}{|c|c|c|c|c|c|c|c|}
\hline Ref. & \multicolumn{2}{|c|}{ Biomass sample } & $\begin{array}{l}\text { Carbon } \\
(\%)\end{array}$ & $\begin{array}{l}\text { Hydrogen } \\
(\%)\end{array}$ & $\begin{array}{l}\text { Nitrogen } \\
(\%)\end{array}$ & $\begin{array}{l}\text { Oxygen } \\
(\%)\end{array}$ & $\begin{array}{l}\text { Sulphur } \\
(\%)\end{array}$ \\
\hline \multirow[t]{4}{*}{ Current study } & \multicolumn{2}{|c|}{ Barhee rachis } & 23.75 & 3.3 & 0.46 & 72.49 & $<0.1$ \\
\hline & \multicolumn{2}{|c|}{ Medjool rachis } & 20.27 & 2.74 & 0.34 & 75.87 & 0.77 \\
\hline & \multicolumn{2}{|c|}{ Barhee stones } & 45.24 & 6.63 & 0.88 & 47.25 & $<0.1$ \\
\hline & \multicolumn{2}{|c|}{ Medjool stones } & 45.05 & 6.44 & 0.89 & 47.62 & $<0.1$ \\
\hline \multirow[t]{2}{*}{ El may et al. [55] } & \multicolumn{2}{|c|}{ Date palm trunk } & 42.76 & 5.8 & 0.21 & 45.5 & 0.12 \\
\hline & \multicolumn{2}{|c|}{ Date palm stones } & 51.2 & 6.4 & 0.73 & 40.9 & $<0.2$ \\
\hline Fadhil et al. [20] & \multicolumn{2}{|c|}{ Date palm stones } & 48.43 & 6.44 & 0.670 & 42.20 & - \\
\hline \multirow[t]{2}{*}{ Nasser et al. [85] } & \multicolumn{2}{|c|}{ Date palm trunk } & 44.46 & 5.57 & 0.55 & 49.24 & - \\
\hline & \multicolumn{2}{|c|}{ Date palm seeds } & 47.14 & 6.6 & 0.9 & 45.33 & - \\
\hline \multirow[t]{3}{*}{ Sait et al. [156] } & \multicolumn{2}{|c|}{ Date palm seeds } & 45.3 & 5.6 & 1 & 47.2 & 0.8 \\
\hline & \multicolumn{2}{|c|}{ Date palm leaf } & 49.4 & 5.8 & 1.2 & 42.3 & 1.3 \\
\hline & \multicolumn{2}{|c|}{ Date palm leaf stem } & 36.1 & 5.2 & 0.7 & 57.2 & 0.7 \\
\hline \multirow[t]{2}{*}{ Hussain [204] } & \multicolumn{2}{|c|}{ Date palm seeds } & 44.1 & 6.1 & 0.9 & 48.3 & 0.6 \\
\hline & \multicolumn{2}{|c|}{ Date palm leaf stem } & 38.1 & 5.2 & 0.8 & 55.6 & 0.3 \\
\hline \multirow[t]{3}{*}{ Makkawi et al. [21] } & \multicolumn{2}{|c|}{ Date palm empty fruit bunches } & 44.07 & 5.97 & 0.74 & 49.05 & 0.18 \\
\hline & \multicolumn{2}{|c|}{ Date palm leaves } & 40.76 & 5.55 & 1.32 & 52.14 & 0.24 \\
\hline & \multicolumn{2}{|c|}{ Date palm leaf stems } & 42.67 & 5.83 & 0.58 & 50.78 & 0.15 \\
\hline Yin [189] & \multicolumn{2}{|c|}{ Date palm kernels } & 48.34 & 6.2 & 2.62 & 37.44 & 0.26 \\
\hline \multirow[t]{3}{*}{ Sulaiman et al. [157] } & $\begin{array}{l}\text { Date paln } \\
\text { fronds }\end{array}$ & Ajwah & 38.9 & 5.7 & 0.32 & - & 0.66 \\
\hline & & Sukariah & 37.9 & 5.6 & 0.47 & - & 0.66 \\
\hline & & Jeddah & 45.3 & 5.66 & 1 & 47.2 & 0.8 \\
\hline El may et al. [203] & \multicolumn{2}{|c|}{ Rachis pellets } & 39.8 & 5.7 & 0.19 & 53 & 0.26 \\
\hline $\begin{array}{l}\text { Al-Marzouqi et al. } \\
\text { [202] }\end{array}$ & \multicolumn{2}{|c|}{ Date palm rachis } & 43.6 & 6.1 & 0 & 50.3 & 0 \\
\hline \multirow[t]{4}{*}{ Bensidhom et al. [82] } & \multicolumn{2}{|c|}{ Date palm rachis } & 60.43 & 8.02 & 0.012 & 31.54 & - \\
\hline & \multicolumn{2}{|c|}{ Date palm leaflets } & 51.50 & 7.68 & 0.046 & 40.78 & - \\
\hline & Date palm & pty fruit bunches & 57.45 & 8.07 & 0.037 & 34.45 & - \\
\hline & Date palm & & 58.7 & 8.25 & 0.025 & 32.97 & - \\
\hline
\end{tabular}

* The percentage of oxygen was calculated from the differences of carbon, hydrogen and nitrogen. 


\subsubsection{Comparisons of HHV Obtained via Various Routes}

The values of the HHV obtained in the current work (both theoretically and practically) alongside those obtained from relevant literature studies are summarised in Table 4. 11. The practical measurements showed that the HHV of the stone obtained from Barhee and Medjool are 17.44 and $17.05 \mathrm{MJ} / \mathrm{kg}$, respectively with agreement with the results of date palm stones reported by Sait et al. [156] and Babiker et al. [205] as clearly seen in Table 4.11. While the HHV of Barhee and Medjool rachis are found 15.55 and $10.65 \mathrm{MJ} / \mathrm{kg}$, respectively, as clearly seen in Table 4.11. Similar results of HHV for date palm rachis are reported by Sait et al. [156], and Al-Marzouqi et al. [202]; while little bit higher values are reported by Bensidhom et al. [82] and Makkawi et al. [21] as obviously seen in Table 4.11. 
Table 4. 11. The theoretical and practical values of HHV obtained from various sources.

\begin{tabular}{|c|c|c|c|c|c|}
\hline Ref. & \multicolumn{2}{|l|}{ Sample } & $\begin{array}{l}\mathrm{HHV} \\
(\mathrm{MJ} / \mathrm{kg})\end{array}$ & $\begin{array}{l}\text { Type of } \\
\text { estimation }\end{array}$ & Country/method \\
\hline \multirow[t]{8}{*}{ Current study } & \multicolumn{2}{|c|}{ Medjool stones } & 11.18 & Calculated & Saudi Arabia/ \\
\hline & \multicolumn{2}{|c|}{ Barhee stones } & 12.25 & & \\
\hline & \multicolumn{2}{|c|}{ Medjool rachis } & 12.99 & & \\
\hline & \multicolumn{2}{|c|}{ Barhee rachis } & 12.52 & & \\
\hline & \multicolumn{2}{|c|}{ Medjool stones } & 17.05 & Practical & Saudi Arabia \\
\hline & \multicolumn{2}{|c|}{ Barhee stones } & 17.44 & & \\
\hline & \multicolumn{2}{|c|}{ Medjool rachis } & 10.65 & & \\
\hline & \multicolumn{2}{|c|}{ Barhee rachis } & 15.55 & & \\
\hline \multirow{2}{*}{ Sait et al. [156] } & \multicolumn{2}{|c|}{ Date palm stone } & 18.97 & Practical & Saudi Arabia/bomb \\
\hline & \multicolumn{2}{|c|}{ Date palm leaf stem } & 10.9 & & $\begin{array}{l}\text { calorimeter model } \\
\text { IKA2000 according to } \\
\text { DIN } 51900 \text { method }\end{array}$ \\
\hline $\begin{array}{l}\text { Al-Marzouqi et al. } \\
\text { [202] }\end{array}$ & \multicolumn{2}{|c|}{ Date palm rachis } & 15.5 & Practical & $\begin{array}{l}\text { Date palm from } \\
\text { UAE/bomb calorimeter } \\
\text { model IKA2000 } \\
\text { according to DIN } 51900 \\
\text { method }\end{array}$ \\
\hline \multirow[t]{3}{*}{ Makkawi et al. [21] } & \multicolumn{2}{|c|}{ Date palm empty fruit bunches } & 17.2 & Practical & $\begin{array}{l}\text { Date palm from Sharjah, } \\
\text { UAE/IKA-C1 static }\end{array}$ \\
\hline & \multicolumn{2}{|c|}{ Date palm leaves } & 18.9 & & jacket oxygen bomb \\
\hline & \multicolumn{2}{|c|}{ Date palm leaf stems } & 16.5 & & calorimeter \\
\hline \multirow[t]{3}{*}{$\begin{array}{l}\text { Bensidhom et al. } \\
{[82]}\end{array}$} & \multicolumn{2}{|c|}{$\begin{array}{l}\text { Date palm rachis } \\
\text { Date palm leaflets }\end{array}$} & $\begin{array}{l}17.88 \\
19.09\end{array}$ & Calculated & $\begin{array}{l}\text { Date palm from Tunisia/ } \\
\text { calculated according to } \\
\text { Shah et al. [206] }\end{array}$ \\
\hline & \multicolumn{2}{|c|}{ Date palm empty fruit bunches } & 19.21 & & \\
\hline & \multicolumn{2}{|c|}{ Date palm Glaich } & 19.32 & & \\
\hline \multirow[t]{3}{*}{ Sulaiman et al. [157] } & \multirow{3}{*}{$\begin{array}{l}\text { Date palm } \\
\text { fronds }\end{array}$} & Ajwah & 16.67 & Practical & Date palm from Madinah \\
\hline & & Sukariah & 16.81 & & Al Munawwarah and \\
\hline & & Jeddah & 16.42 & & $\begin{array}{l}\text { Jeddah in Saudi Arabia/ } \\
\text { LECO AC } 350 \text { bomb } \\
\text { Calorimeter }\end{array}$ \\
\hline \multirow[t]{6}{*}{ Babiker et al. [205] } & \multirow[t]{6}{*}{$\begin{array}{l}\text { Date palm } \\
\text { seeds }\end{array}$} & $\begin{array}{l}\text { Tunisia degelet } \\
\text { nour }\end{array}$ & 18.55 & Calculated & $\begin{array}{l}\text { Date palm from Tunisia, } \\
\text { Iran, Saudi Arabia and } \\
\text { Algeria }\end{array}$ \\
\hline & & Iran Piarom & 18.24 & & \\
\hline & & Saudi Safawi, & 18.23 & & \\
\hline & & Saudi Mabrooom & 18.36 & & \\
\hline & & Saudi Suffry & 18.44 & & \\
\hline & & Algeria Aliya & 18.29 & & \\
\hline \multirow[t]{4}{*}{ Reichel et al. [207] } & \multicolumn{2}{|c|}{ Germany Brown coals } & $\begin{array}{l}24.28- \\
25.26\end{array}$ & Practical & Germany \\
\hline & \multicolumn{2}{|c|}{ Spruce wood chips } & 20.154 & & \\
\hline & \multicolumn{2}{|c|}{ Wheat straw pellets } & 17.94 & & \\
\hline & \multicolumn{2}{|c|}{ Maize silage pellets } & 18.56 & & \\
\hline
\end{tabular}




\subsubsection{The TGA Pyrolysis ( $\mathbf{N}_{2}$ Environment)}

The TGA Pyrolysis curves of Barhee and Medjool Rachis shown in Fig. 4. 10 showed very close results in terms of weight loss and stability of the weight loss rate. It is also seen that the decomposition approximately completed below $360{ }^{\circ} \mathrm{C}$. The ignition temperature $\left(\mathrm{T}_{\mathrm{i}}\right)$ is found to be $70{ }^{\circ} \mathrm{C}$ for both Barhee and Medjool rachis, where a sudden drop in weight is observed at this temperature as seen in Fig. 4. 10.

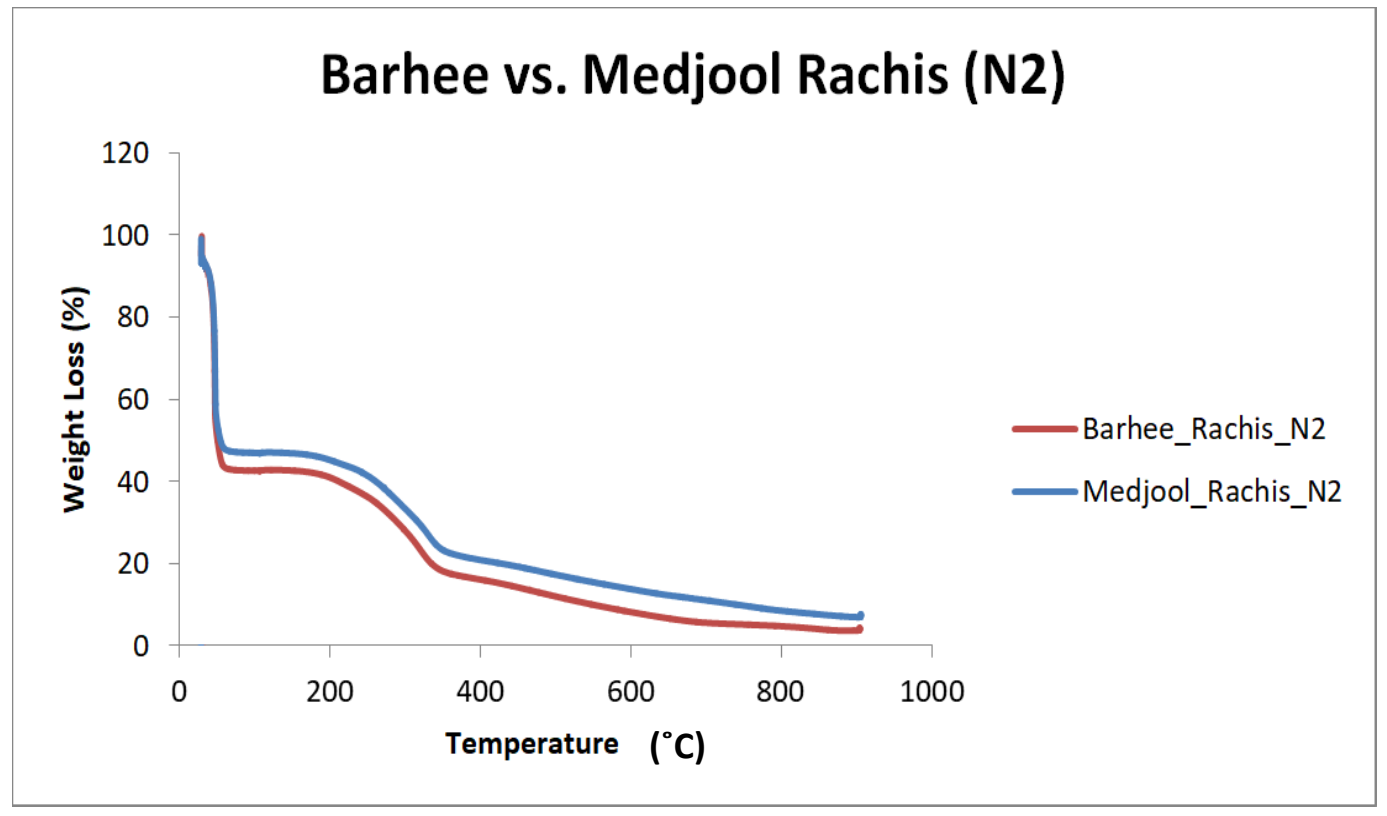

Fig. 4. 10. The TGA Pyrolysis curves for the Barhee and Medjool Rachis.

Similarly, the TGA Pyrolysis curves of the Barhee and Medjool Stones shown in Fig. 4. 11 , showed very close results in terms of weight loss and stability of the weight loss rate. It is also seen that the decomposition approximately completed below $420^{\circ} \mathrm{C}$. The ignition temperature of both Barhee and Medjool Stones is about $240^{\circ} \mathrm{C}$. 


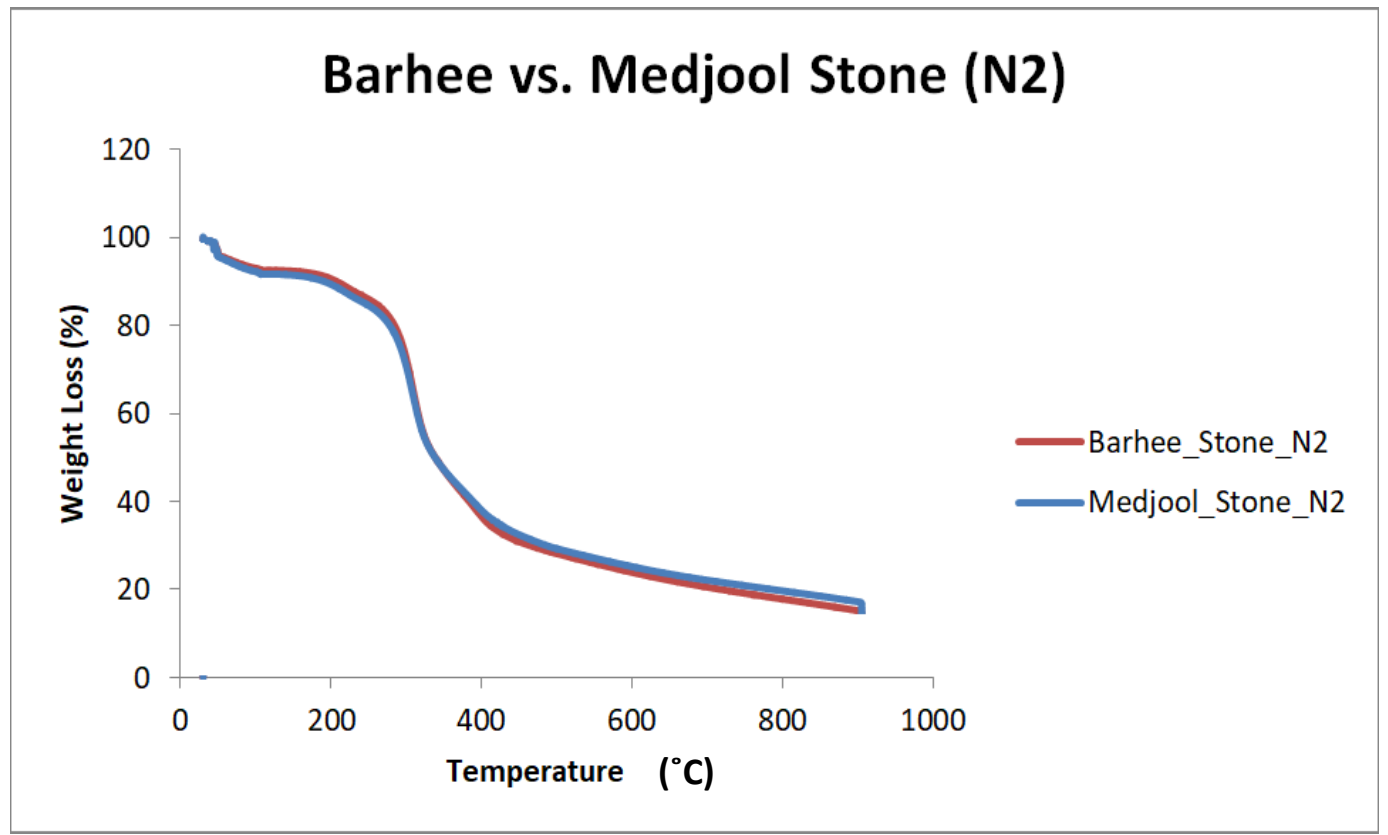

Fig. 4. 11. The TGA Pyrolysis curves for the Barhee and Medjool Stone.

\subsubsection{The TGA combustion ( $\mathrm{O}_{2}$ Environment)}

The TGA Combustion of the Barhee and Medjool Rachis, Fig. 4. 12, revealed a slight difference in terms of weight loss with temperature. This difference is observed at temperatures between $100^{\circ} \mathrm{C}$ and $300^{\circ} \mathrm{C}$ where the weight loss of the Barhee Rachis was much more significant when compared to the Medjool Rachis. After $300{ }^{\circ} \mathrm{C}$, the difference becomes less significant and the curves become almost identical beyond 600 ${ }^{\circ} \mathrm{C}$. The decomposition approximately completed at around $520{ }^{\circ} \mathrm{C}$. The ignition temperature of both is found about $50{ }^{\circ} \mathrm{C}$. 


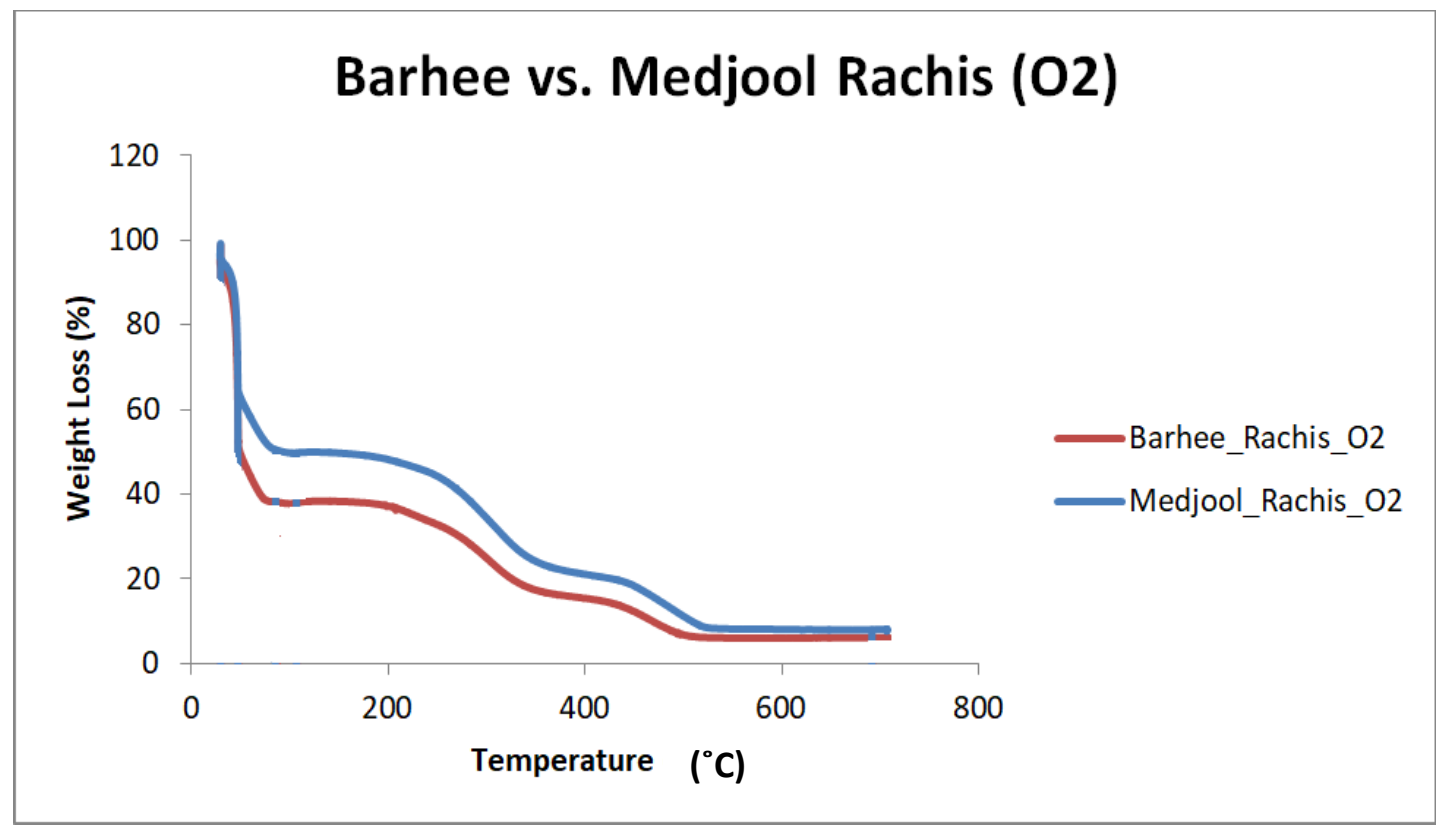

Fig. 4. 12. The TGA Combustion curves for the Barhee and Medjool Rachis.

On the other hand, the TGA Combustion of the Barhee and Medjool stone, Fig. 4. 13, showed no significant difference in the weight loss rate of the two palm tree types. The decomposition was almost complete at about $400{ }^{\circ} \mathrm{C}$. The ignition temperature of both is about $270^{\circ} \mathrm{C}$.

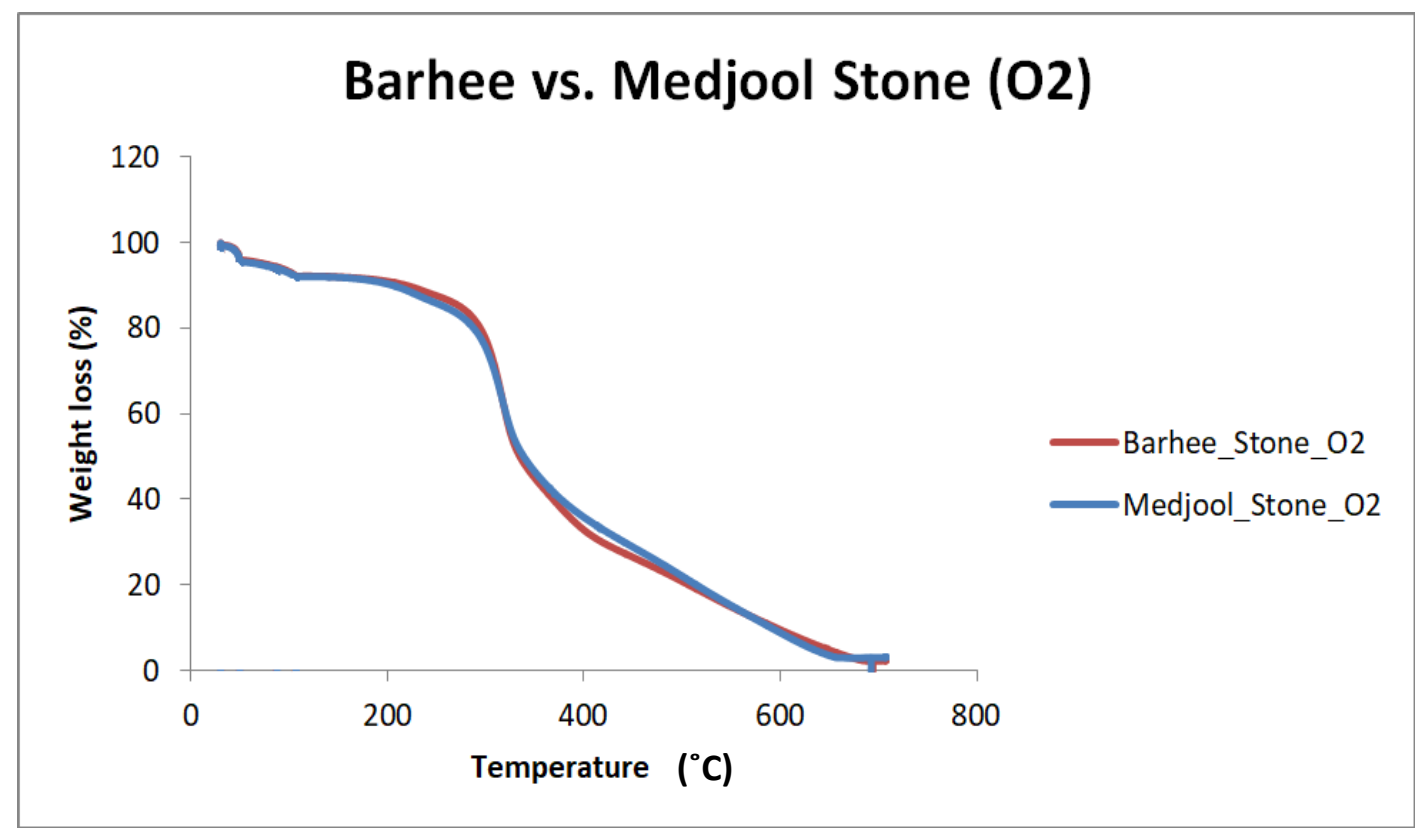

Fig. 4. 13. The TGA pyrolysis curves for the Barhee and Medjool stone. 


\subsubsection{The TGA and DTG Analysis (Overall Comparison)}

When all the TGA results (pyrolysis and combustion) for the stone and rachis of the two given palm tree types are plotted as shown in Fig. 4.14 (a) and (b), the results can be compared more clearly. It is seen that the rachis of both palm tree types under pyrolysis and combustion have shown a significant weight loss at temperatures up to $300{ }^{\circ} \mathrm{C}$ when compared to the two types of Stones. The difference in weight loss becomes less significant beyond $300{ }^{\circ} \mathrm{C}$. However, the pyrolysis results of the Medjool and Barhee stones continue to show lower weight loss beyond 500 up to $900{ }^{\circ} \mathrm{C}$. The ignition temperature of the rachis is much less than that of the stones. When the derivative of the thermo-gravimetric graph is plotted, Fig. 4.15 (a) and (b), the maximum weight loss rate at the relevant temperatures can be determined. It can be seen that the maximum weight loss rate has taken place between 200 and $500{ }^{\circ} \mathrm{C}$ depending on the palm tree type and the constituent under investigation. This confirms the results reported by Karmuddin et al. [208] as they found that the hemicelluloses and cellulose were decomposed at this range of temperature. The peak temperature $\left(\mathrm{T}_{\max }\right)$ ranged from 290 to $315^{\circ} \mathrm{C}$. It is known that the lower the $\mathrm{T}_{\max }$ of the constituent the easier it is to ignite. The rachis shows lower $\mathrm{T}_{\max }$ values when compared to Stones and this mean that they are much easier to ignite. 

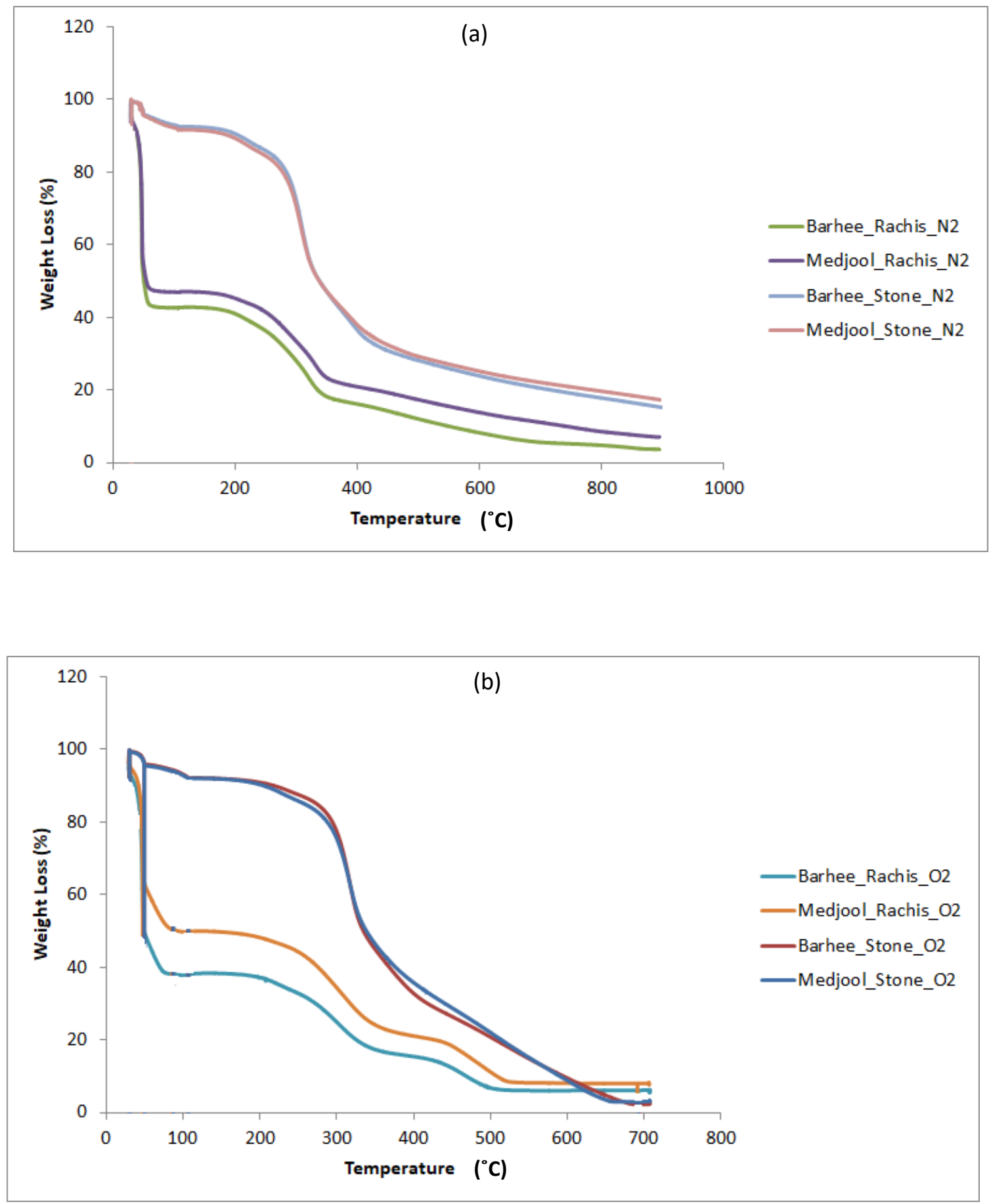

Fig. 4. 14.The TGA Pyrolysis (a) and Combustion (b) curves for all Barhee and Medjool Rachis and stones. 

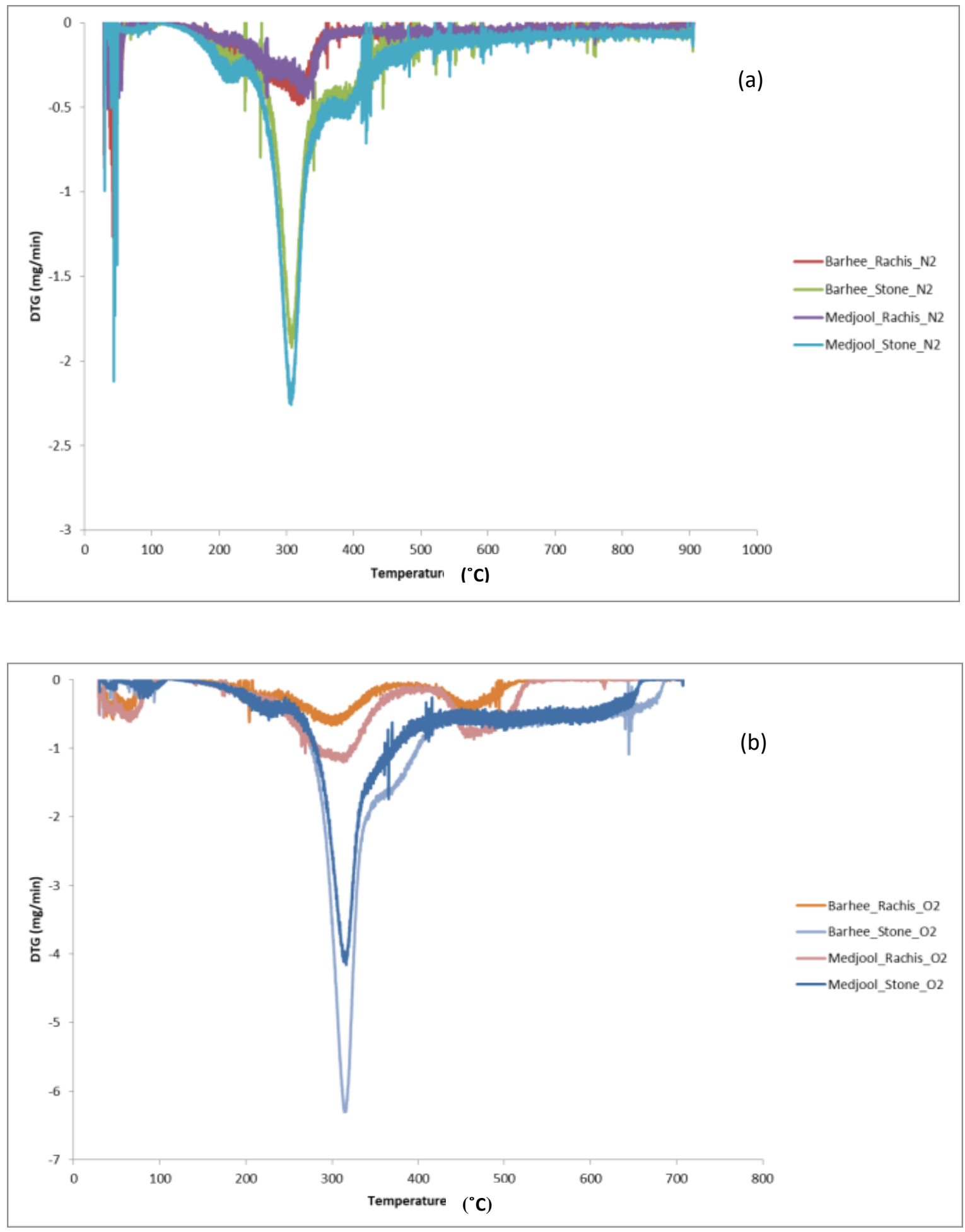

Fig. 4. 15. The DTG Pyrolysis (a) and Combustion (b) curves for the Barhee and Medjool rachis and stones. 


\subsection{Conclusions}

The experimental results presented in this chapter showed high potential of using the date palm fruit wastes as a source of feedstock for biofuel production. This can reduce the reliance on fossil fuel sources as well as save the environment. The various thermal analysis as well as chemical and physical processes can determine the potential amount of energy and constituents in palm tree waste. The obtained results are very comparable with those published in the literature which validates the various methods employed in the current work. Despite the fact that the palm tree waste contains various volatile and moisture constituents, however, the remaining part of fixed carbon are sufficient to provide an acceptable level of bio-energy that can be converted into other forms of useful energy. Based on the results introduced in this chapter the following conclusions cab be drawn:

- The Medjool and Barhee stones are a promising biomass materials as they have high volatile and fixed carbon content with low ash content. Moreover, they have also high carbon and nitrogen contents.

- The decomposition of Barhee and Medjool stones can be completed below 420 ${ }^{\circ} \mathrm{C}$; while it can be completed below $360{ }^{\circ} \mathrm{C}$ for Barhee and Medjool rachis under TGA pyrolysis analysis.

- The ignition temperature of the rachis is much less than that of the stones.

- The DTG curves peak temperature for Barhee and Medjool stones and rachis ranged from 290 to $315^{\circ} \mathrm{C}$. Keeping in mind that the rachis is found much easier to ignite as it shows lower $\mathrm{T}_{\max }$ values compared to stones. 


\section{Chapter 5}

\section{Slow pyrolysis studies of Date Palm Fruit Wastes}

\subsection{Introduction}

Nowadays, the biofuel production from several biomass feedstocks is of great research interest around the world. The selection of the thermos-chemical conversion process depends on which type of yields intended to maximize. Where the gasification is used to maximize the syngas; while, the biomass pyrolysis process is commonly used, in order to maximize the percentage of the produced bio-oil.

The pyrolysis process is a thermal decomposition of the biomass occurred in the absence of oxygen $[94,95]$. The pyrolysis process is divided into three main categories; the slow, moderate and fast pyrolysis. The slow pyrolysis is conducted at low temperature with slow heating rate and long pyrolysis time [96-99]. The moderate pyrolysis occurs at temperatures around $500{ }^{\circ} \mathrm{C}$ and residence time of 10-20 s. Whereas the fast pyrolysis needs fast heating rates, high temperatures, and residence time less than $2 \mathrm{~s}$ [95].

Many pyrolysis experiments were recently conducted to obtain bio-oil from different feedstock materials such as sweet lime empty fruit bunch [209], rice straw, cedar wood, and dalbergia wood [210], rice husk [138-140], Quercus rubra (red oak) wood chips [211], cotton wood [131], Beech wood [129], grape seeds [154], Napier grass[212], Pine [213], and date palm wastes [20, 21, 82, 156, 163, 214-217].

The slow pyrolysis is usually conducted to produce bio-char which reaches $35 \%$ [98], as the low heating rate with longer residence time further promotes the formation of solid products. Nevertheless, in some types of biomass, such as date palm stones, the biooil yield of slow pyrolysis reached 52.67-66.5\% [20, 84]. Furthermore, slow pyrolysis can handle a wider range of biomass particle size from 5 to $50 \mathrm{~mm}[100,101]$. The slow heating rate and the low temperature gives the slow pyrolysis little superiority in terms of the ease of handling; despite its low yield of bio-oil compared with other pyrolysis processes. The production of bio-char from slow pyrolysis of fronds of date palm was investigated by Jouiad et al. [162]. The proximate analysis showed that the bio-char produced from the fronds of date palm has fixed carbon $45 \mathrm{wt} \%$, volatile $43.2 \mathrm{wt} \%$ and 
ash $7.1 \mathrm{wt} \%$. In order to maximize the bio-oil yield from the slow pyrolysis of palm shell, a helical screw fluidized bed reactor was designed and installed by Qureshi et al. [161]. Their experiments were performed with heating rate of $10^{\circ} \mathrm{C} / \mathrm{min}$ to reach $500{ }^{\circ} \mathrm{C}$ without using any inert gases. The bio-oil yield was increased from 38.4 to $51.6 \mathrm{wt} \% \%$ when the helical screw rotation was increased from 0 to $50-\mathrm{rpm}$. The slow pyrolysis of date palm stones in a laboratory scale semi-batch fixed bed reactor was investigated by Fadhil et al. [20]. They studied the influence of the pyrolysis temperature, time and date stones size on the bio-oil yield. They found that the maximum bio-oil yield of $52.67 \%$ is obtained when the temperature and time of the pyrolysis process are $500{ }^{\circ} \mathrm{C}$ and $60 \mathrm{~min}$, respectively, when date stone size of $0.25 \mathrm{~mm}$ is used. The proximate and ultimate analyses were performed to obtain the physical and chemical properties of the bio-oil. Furthermore, they used also adsorption column chromatography to determine the chemical composition of the obtained bio-oil. They found that the chemical composition of the bio-oil produced from the pyrolysis of date stones showed the potential of date stones as an important source of alternative fuel and chemicals as well. The slow pyrolysis of date palm stones and date palm mixture wastes in a bench-scale fluidized bed reactor was studied also by Bharath et al. [84]. In order to optimize the production of pyrolysis bio-oil, they studied the effects of varying the different experimental parameters such as the pyrolysis time $(10-60 \mathrm{~min})$, temperature $\left(300-600{ }^{\circ} \mathrm{C}\right)$, fluidizing gas flow rate $(5-30$ $\mathrm{mL} / \mathrm{min}$ ), and biomass loading (50-350 g). Their results showed that a high quantity of bio-oil is produced from the pyrolysis of date stone and date palm mixture wastes at 500 ${ }^{\circ} \mathrm{C}$ for $30 \mathrm{~min}$ with a feedstock loading of $200 \mathrm{~g}$ and fluidizing gas flow rate of $10 \mathrm{~mL} / \mathrm{min}$. Slow pyrolysis of date palm waste (DPW) in a fixed-bed reactor was studied by Bensidhom et al. [82]. The DPW includes date palm rachis (DPR), date palm leaflets (DPL), empty fruit bunches (EFB) and date palm Glaich (DPG). The pyrolysis of the different DPW samples was conducted in fixed bed reactor at final temperature of 500 ${ }^{\circ} \mathrm{C}$, with heating rate of $15^{\circ} \mathrm{C} / \mathrm{min}$. They concluded that the maximum bio-oil is obtained from the pyrolysis of date palm empty fruits bunches which reaches $25.99 \%$ followed by rachis which produces bio-oil of $25.9 \%$.

Slow pyrolysis of various materials were also studied such as bamboo subfamily [149], crambe seeds [150], cypress [151], vegetable waste and pine cones [152], walnut 
shells [136] and live and dead vegetation native to the southern United State of America [153].

Recently, Slow pyrolysis of Seed cakes of African star apple and Silk cotton as a source of bio-oil was experimentally investigated by Sokoto et al. [135]. Their study was carried out at a temperatures range of $300-450{ }^{\circ} \mathrm{C}$ with a heating rate of $10{ }^{\circ} \mathrm{C} \mathrm{min}-1$ for 60 min residence period in a nitrogen atmosphere. Their experimental results showed that the optimum bio-oil yields for silk cotton (33.1\%) and for seed of African apple (48.3\%) were achieved at $400{ }^{\circ} \mathrm{C}$. The Bio-char yield decreases from 38 to $28 \%$ when the temperature increases from $300{ }^{\circ} \mathrm{C}$ to $450{ }^{\circ} \mathrm{C}$ for apple seed cake which could be due to greater primary decomposition of the biomass samples. A similar trend also observed for silk cotton with a lowest bio-char yield of $32 \%$ at $450{ }^{\circ} \mathrm{C}$. The GC-MS analysis showed that the seed of Apple bio-oil has an acids (25.15\%), phenolics (18.35\%), and hydrocarbons (18.58\%) as the major compounds. N-containing compounds $(38.17 \%)$, carboxylic acid (23.79\%), and phenolic (16.57\%) were the dominant compounds in Silk cotton bio-oil.

The literature results displayed in Chapter 2 reveal that the date stones and rachis are considered the most promising biomass feedstock for biofuel production $[55,156]$. In addition to the fact that the Barhee and Medjool are the most famous and abundant date palm trees in Tabuk city, Saudi Arabia. So, in this work, the slow pyrolysis of stones and rachis obtained from these two types of dates trees were experimentally studied on a laboratory scale for the first time as authors know. This chapter presents the details of the slow pyrolysis experiments and discussions of the obtained results including the characterization of the bio-oil products.

\subsection{Material and methods}

The methodology of current study is presented in this section from the material collection and preparation, followed by the details of experimental setup and procedure and ended with bio-oil products analysis and characterization. 


\subsubsection{Material preparation}

Before conducting the slow pyrolysis experiments, Barhee and Medjool stones and rachis were collected and dried at room temperature for one week to ensure that the sample reached its final moisture content. The dried samples of Barhee and the Medjool stone and rachis were milled as shown in Fig. 5. 1.

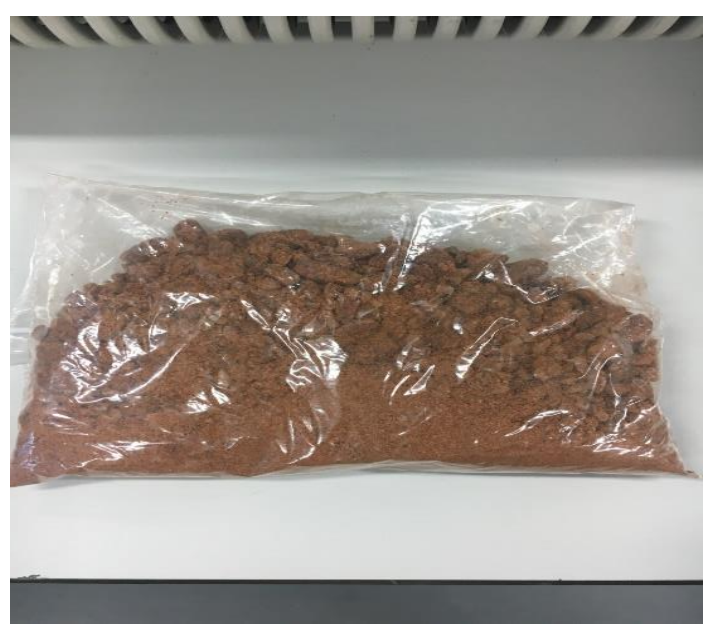

Stone sample

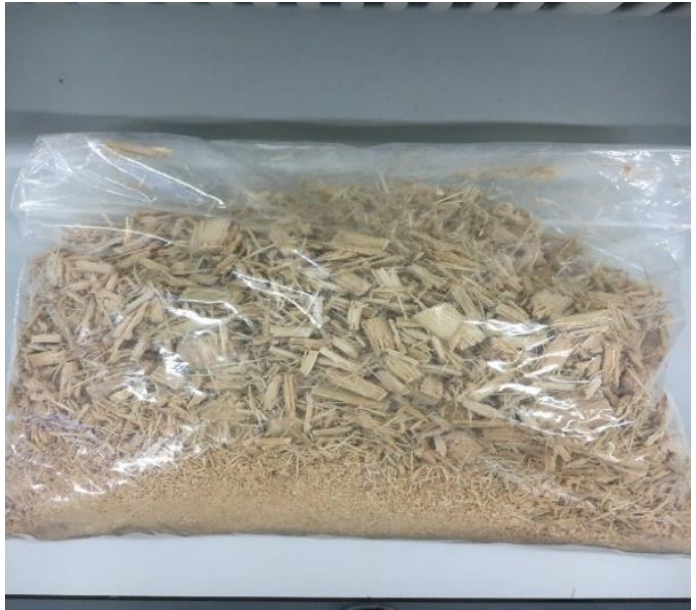

Rachis sample

Fig. 5. 1. Stone and Rachis samples

\subsubsection{Slow pyrolysis experimental setup}

The slow pyrolysis setup consists of nitrogen gas cylinder, a fixed-bed batch glass reactor, $200 \mathrm{~W}$ electric heater, and dry ice condenser as clearly seen in Fig. 5. 2 (a) and (b).

The batch reactor is a $500 \mathrm{ml}$ flask made of thermal treated glass. It has two inlets and one outlet. One inlet was used for supplying the nitrogen which serves as a purging agent and the other inlet was used for filling the biomass particles. The outlet of the flask was used for the pyrolysis vapor. In order to minimize the heat losses, the reactor and the pipe carrying the pyrolysis vapor from the reactor outlet were well insulated. An electrical heater of rated power 200 watt was used to provide the thermal energy required for heating 
up the biomass to $400{ }^{\circ} \mathrm{C}$. A cotton wool filter was also used at the outlet of the reactor to trap the impurities and solids loaded with the pyrolysis vapor.

The dry ice condenser is a double glass tube closed from the lower end forming a cylindrical cavity of volume $1 \mathrm{~L}$ with double glass jacket. This cylindrical cavity was filled with the dry ice and $300 \mathrm{ml}$ of acetone. The double glass tube of inner and outer diameter equal 14 and $20 \mathrm{~cm}$, respectively. The outer and inner tubes uppers were welded together to form a completely closed double glass jacket except the only three openings in the outer glass tube for the inlet of pyrolysis hot gasses, outlet of uncontestable gases and the outlet of bio-oil yield as shown in Fig. 5. 2. (a) and (b). This design of the dry ice condenser was chosen because it provides a suitable volume for the expansion of the condensable gas and achieves very large heat transfer area between hot gases and dry ice. Maintaining the temperature at $-70{ }^{\circ} \mathrm{C}$ by using the dry ice in this condenser is also consider another superiority of this selection that significantly maximizes the condensation.

The temperature inside the reactor was measured using a thermometer in order to continuously monitor the temperature and ensure that it constantly at the slow pyrolysis temperature. The temperature of non-condensable gases was also measured by using Ktype thermocouple. 


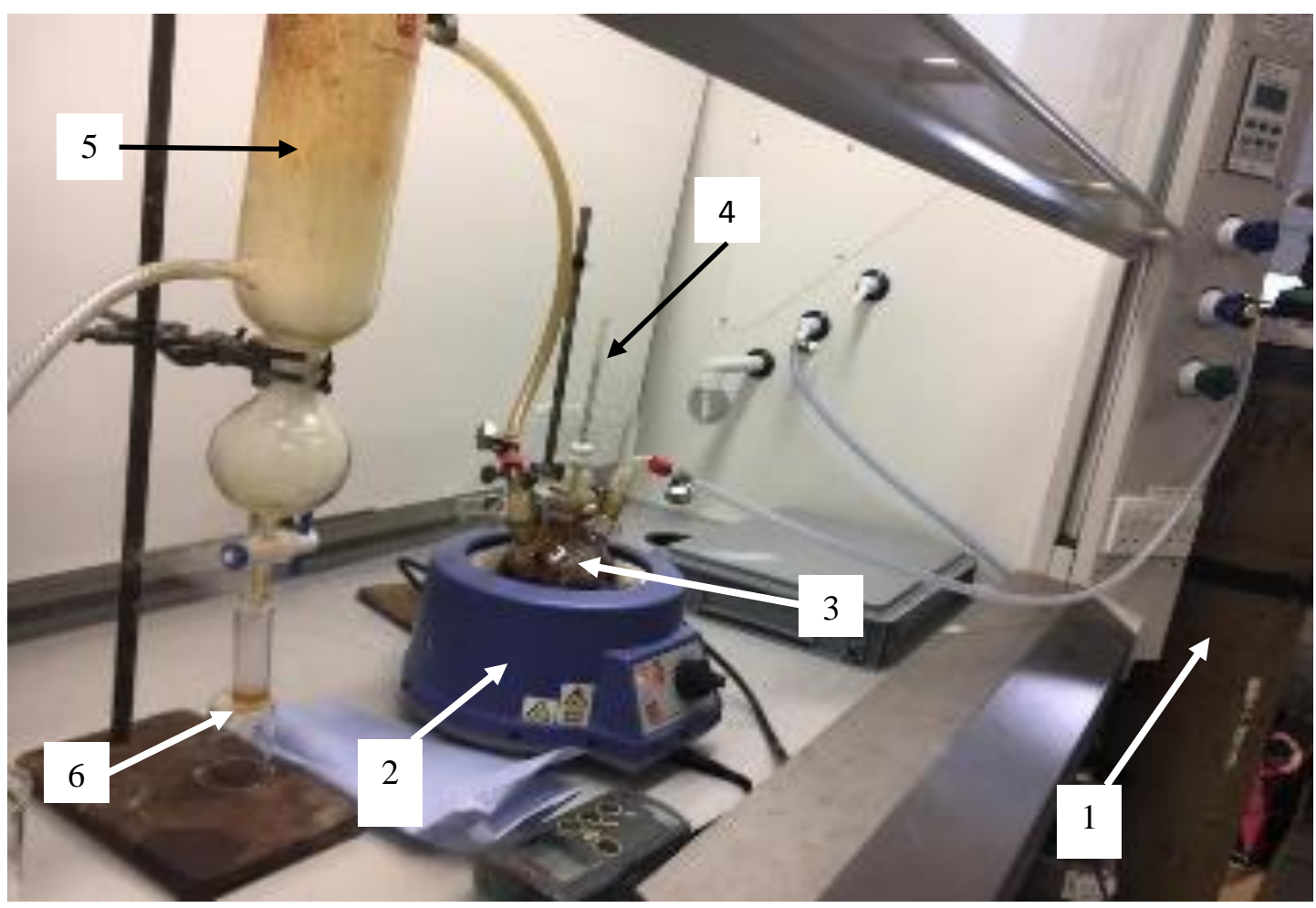

(a)

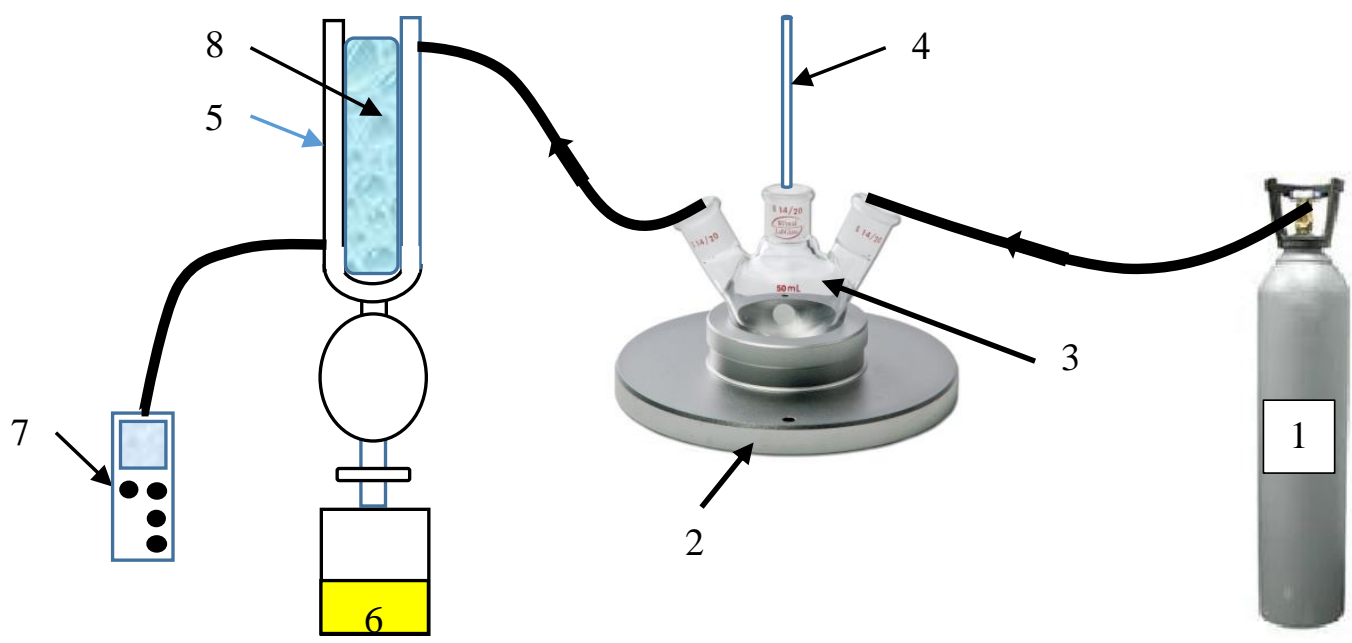

(b)

1. Nitrogen gas cylinder 2. Electric heater 3. Glass fixed bed reactor 4. Thermometer

5. Dry ice condenser 6. Bio-oil 7. K-type thermocouple 8. Dry ice and acetone.

Fig. 5. 2. Photograph of the slow pyrolysis experiment setup (a), Schematic diagram of the slow pyrolysis experiment setup (b). 


\subsubsection{Experimental procedure}

Four slow pyrolysis experiments for Barhee and Medjool date stones and rachis were conducted. Before starting the experiments, the system was checked before conducting the experiments to ensure that there is no leakage by filling the pyrolysis rig with nitrogen at $30 \mathrm{kPa}$ and left at that pressure for 5 minutes. In each slow pyrolysis experiment, firstly the sample was dried, grinded then $80 \mathrm{~g}$ of biomass was weighted and placed inside the batch reactor. In order to ensure that the weight of sample is kept at $80 \mathrm{~g}$, the reactor was weighted with and without the biomass sample.

The heat required for slow pyrolysis was provided by $200 \mathrm{~W}$ electric heater, where the temperature was increased gradually with heating rate $10{ }^{\circ} \mathrm{C} / \mathrm{min}$ until it reaches 400 ${ }^{\circ} \mathrm{C}$. During that nitrogen gas at 1 bar was forced to flow through the reactor with flow rate $100 \mathrm{ml} / \mathrm{min}$ using manual controlling valve. It was noticed that the pyrolysis gases was produced at temperature $90{ }^{\circ} \mathrm{C}$ and leaving the reactor and flow towards the condenser where the condensable gases were condensed and the bio-oil drops were collected in a container. The non-condensable gases were channeled outside via the fume chamber.

All experiments were operated until the biomass samples were completely converted to char and the yield of bio-oil tends to zero, this nearly takes one hour.

In order to obtain reliable results, the four experiments were repeated three times and the bio-oil and char produced were collected from each experiment as seen in Fig. 5. 3. The bio-oil samples were stored in a refrigerator until the GC-MS analysis. The percentage of char and bio-oil yields were calculated as follows [82]:

bio - oil yield $($ or char yield $) \%=\frac{\text { mass of bio-oil }(\text { or char })}{\text { mass of feedstock material }} \times 100$. 
The syngas yield can be calculated by applying the principle of mass balance conservation, as the following [82]:

syngas yield $\%=100 \%-[$ bio - oil yield $\%+$ char yield $\%]$.

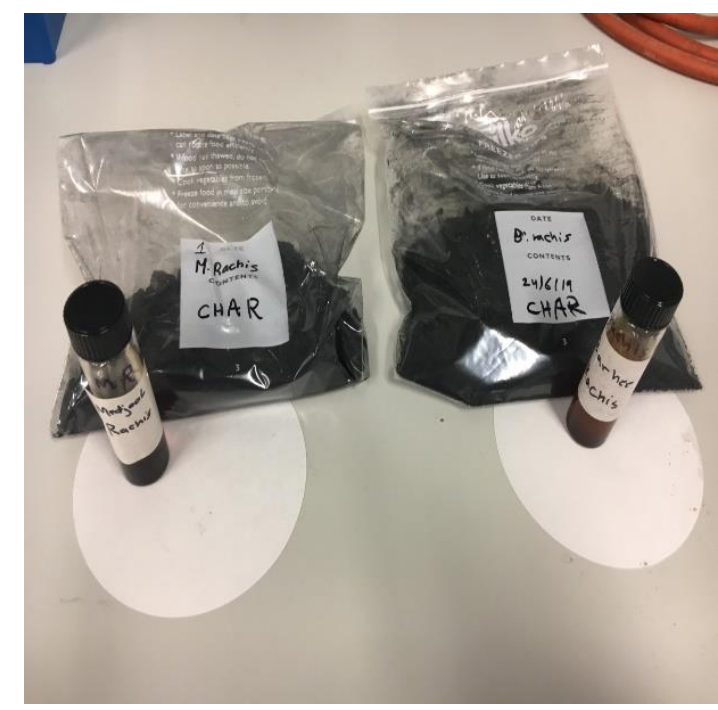

Barhee and Medjool rachis char and bio oil samples.

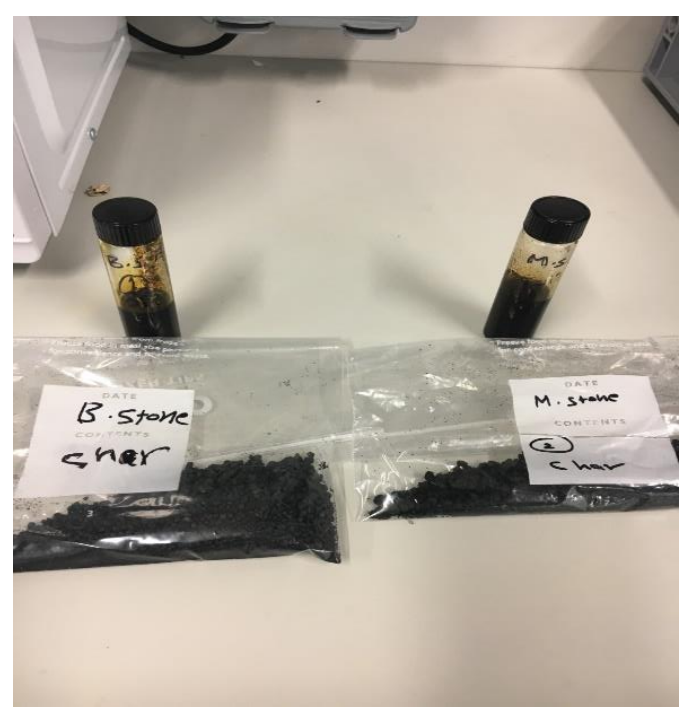

Barhee and Medjool stone bio-oil and char samples.

Fig. 5. 3. The bio-oil and char collected from the slow pyrolysis of Barhee and Medjool rachis and stone.

\subsubsection{Characterization of bio-oil}

In order to candidate the bio-oil for any application, it is very important to know the composition, physical and chemical properties of the bio-oil extracted from the slow pyrolysis. The proximate analysis is used to determine the physical characteristics of biooil. The ultimate analysis was used to obtain the elemental components of the bio-oil such as carbon, hydrogen, nitrogen, oxygen and sulphur contents $[187,189]$. The composition of bio-oil was specified by using gas chromatography mass spectrometry (GC-MS). The physical properties such as density, viscosity, water content were also measured. The $\mathrm{pH}$ 
of the bio-oil was measured by using JENWAY $4330 \mathrm{pH}$ meter. The detailed procedure used for bio-oil characterization is presented in Chapter 3.

\subsection{Results and discussions}

In order to obtain reliable results, each slow pyrolysis experiment was repeated three times with the same operating conditions. The production of bio-oil and char obtained from each experiment are reported in Table 5.1. Keeping in mind that the amount of gas yield was not measured in this work, but it was estimated by the difference between the amount of biomass and the measured yields of bio-oil and char. It is clearly seen in Table 5.1 that the largest yield of bio-oil among the four slow pyrolysis trials is obtained when the Barhee rachis is used as feedstock, where the bio-oil yield reaches $21.54 \%$. Whereas, the optimum char yield of $73.35 \%$ is obtained from the Barhee stone. The results illustrated in Table 5.1 show also that the bio-oil obtained from slow pyrolysis of Barhee stone and rachis are 12.64-17.93 and 10-21.54\%, respectively, compared with 13.04-16.71 and 6.54-14.44\% for Medjool stone and rachis, respectively. Whereas, the char yield from Barhee stone and rachis are 48.7-73.35 and 53.24-61.55\%, respectively, compared with 53.49-72.68 and 50.69-69.34 for Medjool stone and rachis, respectively. From the results summarized in Table 5.1, it is concluded that the slow pyrolysis of Barhee and Medjool stone gives high char yield at the expense of the bio-oil yield. Table 5.1 also summarizes similar results found in the literature that focus on the slow pyrolysis of different date palm wastes. For the purpose of comparison, the pyrolysis mode and temperature are also of great interest in Table 5.1. The slow pyrolysis yield results obtained from current study are close to that obtained by Bensidhum [82] especially when comparing Barhee stone and rachis bio-oil with that obtained from date palm rachis and leaflets. It is obviously 
seen in Table 5.1 that the yield of bio-oil obtained from the slow pyrolysis of date palm stones is very low compared with similar results of date stones reported by Fadhil et al [20] and Bharath et al. [84]. This is may be due the low pyrolysis temperature $\left(400{ }^{\circ} \mathrm{C}\right)$ used in the current study compared with other study reported in Table 5.1. Where, it is known that the bio-oil yield increases with increasing the pyrolysis temperature [127]. 
Table 5. 1. The yield of slow pyrolysis of Barhee and Medjool date palm stone and rachis compared with similar results in the literature.

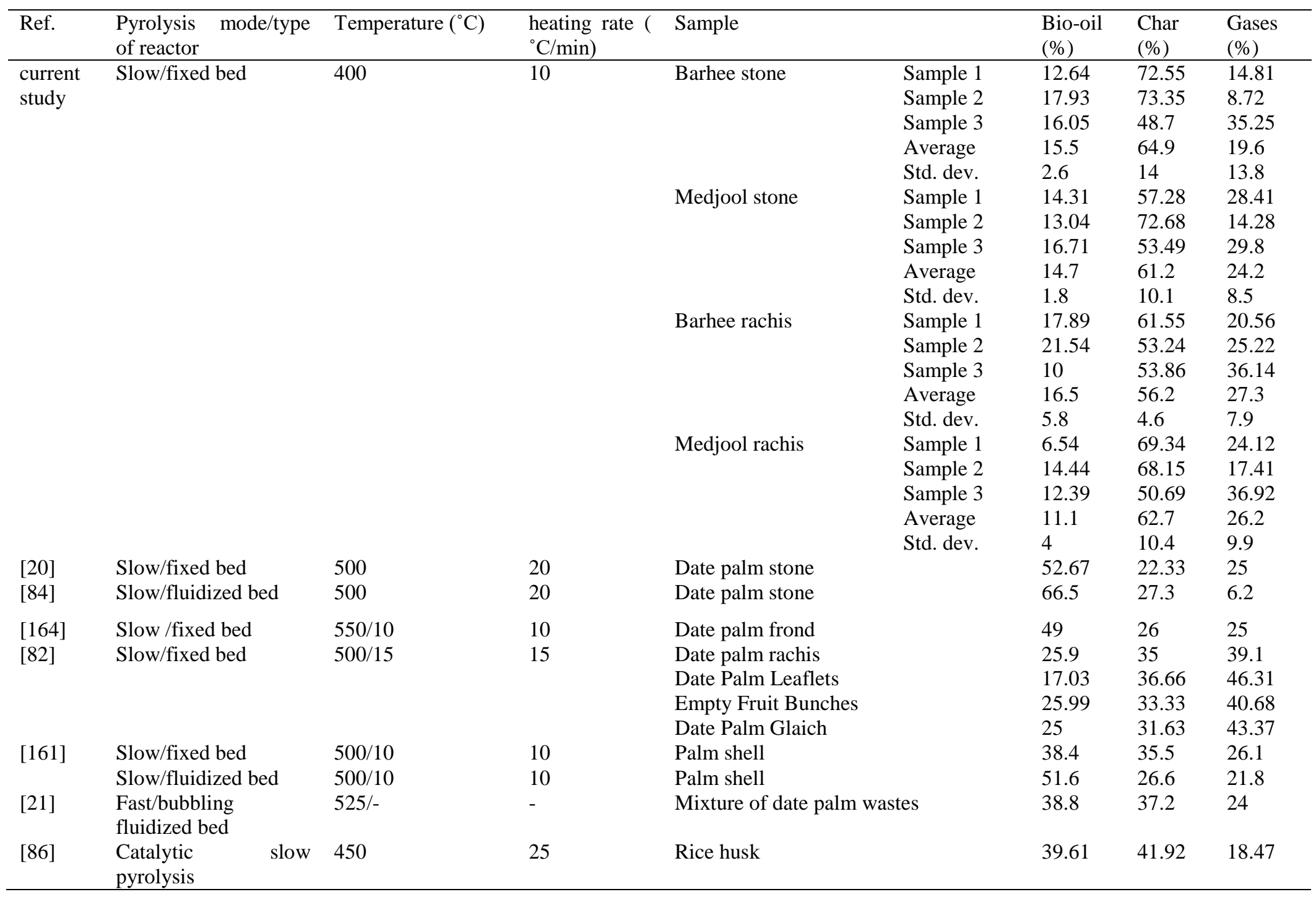




\subsubsection{Characterization of the bio-oil}

The characterization of the bio-oil is very important step in order to candidate the bio-oil for any application. Table 5.2 displays the measured results of physical and chemical properties such as density, viscosity, and $\mathrm{pH}$ of the bio-oil measured according the standard methods previously mentioned. Table 5.2 shows that the viscosity of the bio-oil obtained from Barhee rachis is little bit high compared with other samples obtained from Barhee stone and Medjool stone and rachis. Whereas, there are no significant differences in the bio-oil $\mathrm{pH}$ of different samples and density.

Table 5.2 shows also good agreement between the chemical and physical properties of the bio-oil obtained from Barhee and Medjool date palm stones and that of date palm stones reported by Fadhil et al. [20]. Table 5.2 shows also the chemical and physical properties of the bio-oil extracted by slow pyrolysis from several feedstock such as Rice husk [86], and Mahua seed [92]. No significant differences between the densities as well as $\mathrm{pH}$ of the bio-oil obtained from the different feed stocks as obviously shown in Table 5.2. 
Table 5. 2. Physical and chemical properties of bio-oil.

\begin{tabular}{|c|c|c|c|c|c|c|}
\hline Ref. & $\begin{array}{l}\text { Pyrolysis mode/type } \\
\text { of reactor }\end{array}$ & $\begin{array}{l}\text { Temperature } \quad\left({ }^{\circ} \mathrm{C}\right) / \text { heating } \\
\text { rate }\left({ }^{\circ} \mathrm{C} / \mathrm{min}\right)\end{array}$ & Sample & $\mathrm{pH}$ & $\begin{array}{l}\text { Viscosity } \\
\left(\mathrm{mm}^{2} / \mathrm{s}\right)\end{array}$ & $\begin{array}{l}\text { Density } \\
\left(\mathrm{gm} / \mathrm{cm}^{3}\right)\end{array}$ \\
\hline \multirow{4}{*}{$\begin{array}{l}\text { Current } \\
\text { study }\end{array}$} & \multirow[t]{4}{*}{ Slow/fixed bed } & \multirow[t]{4}{*}{$400 / 10$} & Barhee stone & 3.27 & 4.88 & 0.9760 \\
\hline & & & Medjool stone & 3.77 & 4.74 & 0.9499 \\
\hline & & & Barhee rachis & 3.41 & 6.66 & 0.9529 \\
\hline & & & Medjool rachis & 3.38 & 5.91 & 0.9529 \\
\hline [20] & Slow/fixed bed & $500 / 20$ & Date palm stone & 3.3 & 13.5 & 0.9572 \\
\hline [86] & $\begin{array}{l}\text { Catalytic } \\
\text { pyrolysis }\end{array}$ & $\begin{array}{l}450 / 25 \text { (the catalytic reactor } \\
\text { is kept at } 490-540{ }^{\circ} \mathrm{C} \text { ) }\end{array}$ & Rice husk & 3 & 1.68 & 1.065 \\
\hline [92] & Slow/semi-batch & $525 / 20$ & Mahua seed & 4.8 & - & 0.9213 \\
\hline
\end{tabular}


Table 5. 3 displays the percentage of water content in the bio-oil produced from the slow pyrolysis of Barhee and Medjool stone and rachis using the 870 Volumetric Karl Fischer Titrator. In order to ensure confident results, each experiment conducted 3 times as previously mentioned, and all characterizations of the bio-oil are obtained for the three 3 samples collected from each certain experiment. The results showed that high water contents are found in bio-oil produced from the slow pyrolysis of stones compared to rachis as obviously seen in Table 5.3. From the results shown in Table 5.3, the percentage of water content presented in bio-oil extracted from Medjool stone is $46.55-50.52 \%$ compared to 43.47-50.19 for Barhee stone. Whereas, it is found 14.24-16.71\% and 14.5515.66 for the Medjool rachis and Barhee rachis, respectively.

Table 5. 3. The water content of the bio-oil produced from Barhee and Medjool stone and rachis

\begin{tabular}{lcclll}
\hline Sample & Sample 1 (\%) & Sample 2 (\%) & Sample 3 (\%) & Average (\%) & Std. Dev. \\
\hline Barhee stone & 46.96 & 50.19 & 43.47 & 46.87 & 3.36 \\
Medjool stone & 50.52 & 48.48 & 46.55 & 48.52 & 1.98 \\
Barhee rachis & 15.66 & 15.65 & 14.55 & 15.29 & 0.63 \\
Medjool rachis & 14.24 & 15.74 & 16.71 & 15.56 & 1.24 \\
Mixture of date palm wastes [21] & & & 10.4 & \\
Rice husk [86] & & & 52.6 & \\
\hline
\end{tabular}

The bio- oil produced through slow pyrolysis of Barhee and Medjool date palm stones and rachises was analyzed for its ultimate analysis by MEDAC LTD (analytical and chemical consultancy services) which provides carbon, hydrogen and nitrogen, while the oxygen content was calculated from the difference. Table 5.4 summarize the ultimate analysis of the bio-oil extracted from slow pyrolysis of Barhee and Medjool date palm 
stones and rachis in comparison with literature data. The ultimate analysis of three samples of the bio-oil from the same feedstock are given in Table 5.4. High percentage content of carbon is found in bio-oil from stones whatever it is (Medjool or Barhee). This percentage reaches $73.83 \%$ in the case of Barhee stone. While, it is found from 72.94 to $73.71 \%$ in case of Medjool stone with good agreement with that value reported by Fadhil et al. [20] where they found that the percentage of carbon reaches $73.56 \%$ in the bio-oil obtained from the pyrolysis of date palm stone (Phoenix dactylifera L.) as is also clearly seen in Table 5.4. This good agreement is not only found in the carbon content in bio-oil of date palm stone (Barhee or Medjool) but also in the contents of hydrogen, and oxygen. It is also noticed that the bio-oil obtained from the slow pyrolysis of Barhee and Medjool rachis has low carbon content, where the percentage of carbon content is found 8.61-19.03 and 9.98-18.68\% in the case of Barhee and Medjool rachis, respectively. These values of carbon from Barhee and Medjool date palm rachis are considered very low compared with those reported by Bensidhom et al. [82] where the carbon content of the bio-oil obtained from Tunisian date palm rachis reaches $60.43 \%$. Whereas the percentage of hydrogen content is approximately constant (9.13-11.02\%) in all tested samples with good agreement with those reported values found in the literature [20,82].

The results showed also high superiority of the bio-oil extracted from the slow pyrolysis of Barhee and Medjool stones from the heating value point of view as obviously seen in Table 5.4. In the case of bio-oil extracted from rachis whatever it is from (Barhee or Medjool), there are significant differences between the HHV of the bio-oil obtained in current study and that reported in the literature [82]. Where, the HHV of the bio-oil from Barhee and Medjool date palm rachis are extremely low compared not only with that 
obtained from Barhee and Medjool date palm stones but also with that values of date palm rachis and stones reported in the literature $[20,82]$. There are also significant differences in the values of HHV based on the type of feed stock, where the Mahua seed bio-oil has the highest HHV of $39.02 \mathrm{MJ} / \mathrm{kg}$ flowed by date palm stones of 36-36.6 (current study), and $37.38 \mathrm{MJ} / \mathrm{kg}$ [20], whereas the Barhee rachis gives the lowest value of $4.09 \mathrm{MJ} / \mathrm{kg}$.

Table 5. 4. The ultimate analysis of the bio-oil extracted from slow pyrolysis of Barhee and Medjool date palm stones and rachis compared with similar results in the literature.

\begin{tabular}{|c|c|c|c|c|c|c|c|}
\hline Material & & C \% & H \% & $\mathbf{N} \%$ & $\mathrm{~S} \%$ & $0 \%^{a}$ & HHV (MJ/kg) \\
\hline \multirow{5}{*}{$\begin{array}{l}\text { Barhee stone } \\
\text { (current study) }\end{array}$} & Sample 1 & 72.11 & 10.52 & 0.24 & $<0.10$ & 17.03 & 36.53 \\
\hline & Sample 2 & 73.83 & 10.33 & 0.37 & $<0.10$ & 16.37 & 36.63 \\
\hline & Sample 3 & 71.62 & 10.36 & 0.44 & $<0.10$ & 17.48 & 36.10 \\
\hline & Average & 72.52 & 10.40 & 0.35 & $<0.1$ & 16.96 & 36.4200 \\
\hline & Std. dev. & 1.16 & 0.1 & 0.1 & - & 0.55 & 0.28 \\
\hline \multirow{5}{*}{$\begin{array}{l}\text { Medjool stone } \\
\text { (current study) }\end{array}$} & Sample 1 & 73.52 & 11.02 & $<0.10$ & $<0.10$ & 15.23 & 38.02 \\
\hline & Sample 2 & 72.94 & 9.92 & 0.41 & $<0.10$ & 16.63 & 36.01 \\
\hline & Sample 3 & 73.71 & 10.88 & 0.24 & $<0.10$ & 15.07 & 37.88 \\
\hline & Average & 73.39 & 10.60 & 0.25 & $<0.1$ & 15.64 & 37.30 \\
\hline & Std. dev. & 0.40 & 0.59 & 0.15 & - & 0.85 & 1.12 \\
\hline \multirow{5}{*}{$\begin{array}{l}\text { Barhee rachis } \\
\text { (current study) }\end{array}$} & Sample 1 & 19.03 & 9.61 & $<0.10$ & $<0.10$ & 71.16 & 9.12 \\
\hline & Sample 2 & 8.61 & 9.76 & $<0.10$ & $<0.10$ & 81.43 & 4.09 \\
\hline & Sample 3 & 15.14 & 10.00 & $<0.10$ & $<0.10$ & 74.57 & 7.83 \\
\hline & Average & 14.26 & 9.79 & $<0.1$ & $<0.1$ & 75.72 & 7.01 \\
\hline & Std. dev. & 5.26 & 0.19 & - & - & 5.23 & 2.61 \\
\hline
\end{tabular}




\begin{tabular}{|c|c|c|c|c|c|c|c|}
\hline \multirow{2}{*}{$\begin{array}{l}\text { Medjool rachis } \\
\text { (current study) }\end{array}$} & Sample 1 & 18.68 & 9.76 & $<0.10$ & $<0.10$ & 71.36 & 9.17 \\
\hline & Sample 2 & 16.75 & 9.13 & $<0.10$ & $<0.10$ & 73.92 & 7.23 \\
\hline & Sample 3 & 9.98 & 10.59 & $<0.10$ & $<0.10$ & 79.23 & 6.22 \\
\hline & Average & 15.13 & 9.82 & 0.1 & 0.1 & 74.83 & 7.54 \\
\hline & Std. dev. & 4.56 & 0.73 & - & - & 4.01 & 1.49 \\
\hline \multicolumn{2}{|c|}{ Date palm stone [20] } & 73.56 & 10.50 & 1.26 & - & 14.68 & 37.38 \\
\hline \multicolumn{2}{|c|}{ Date palm rachis [82] } & 60.43 & 8.02 & 0.012 & - & 31.45 & 24.21 \\
\hline \multicolumn{2}{|c|}{ Date Palm Leaflets [82] } & 51.5 & 7.68 & 0.046 & - & 40.78 & 21.46 \\
\hline \multicolumn{2}{|c|}{ Empty Fruit Bunches [82] } & 57.45 & 8.07 & 0.037 & - & 34.45 & 23.4 \\
\hline \multicolumn{2}{|c|}{ Date Palm Glaich [82] } & 58.7 & 8.25 & 0.025 & - & 32.97 & 23.89 \\
\hline \multicolumn{2}{|c|}{$\begin{array}{l}\text { Mixture of date palm } \\
\text { wastes[21] }\end{array}$} & 49.63 & 7.35 & 1.09 & 0.1 & 41.84 & 20.88 \\
\hline \multicolumn{2}{|c|}{ Rice husk [86] } & 23.38 & 10.39 & 0.51 & $<0.1$ & 65.63 & 28.71 \\
\hline \multicolumn{2}{|c|}{ Rapeseed [165] } & 73.1 & 11.5 & 4.7 & 0 & 10.7 & \\
\hline \multicolumn{2}{|c|}{ Linseed [166] } & 75.42 & 10.26 & 1.5 & 0 & 13.8 & \\
\hline \multicolumn{2}{|c|}{ Pistachio shell [89] } & 67.44 & 7.82 & 0.42 & - & 24.32 & \\
\hline \multicolumn{2}{|c|}{ Apricot shell [91] } & 64.45 & 8.24 & 0.18 & - & 26.5 & 27.19 \\
\hline \multicolumn{2}{|c|}{ Mahua seed [92] } & 69.23 & 9.12 & 2.53 & - & 18.14 & 39.02 \\
\hline Pomegranate s & eds [167] & 64.26 & 8.21 & 2.06 & - & 25.43 & 34.67 \\
\hline
\end{tabular}

\subsubsection{Chemical composition of the bio-oil}

The detected compounds from the GC-MS analysis of Barhee and Medjool rachis and stones are displayed in Fig. 5. 4 to Fig. 5. 7. The chemical composition of the bio-oil 
extracted from the slow pyrolysis of Barhee date palm rachis is summarized in Table 5.5. Twenty two chemical components were found in the first sample; whereas, few of these components were not detected in the other bio-oil samples as seen in Table 5.5. Overall, the most abundant compounds identified in the bio-oil can be classified into monosaccharides, hydrocarbons, phenols, alcohols and ketones, which are commonly reported as natural extract from plant sources [21]. It is obviously seen in this Table that, Phenol, Furfural and Benzoic acid are considered the main components of the Barhee rachis bio-oil as their average percentage are $17.55,14.97$ and $14.96 \%$, respectively. Phenol, Furfural and Benzoic acid percentage sum reaches $50.39 \%$ in one tested sample of Barhee rachis bio-oil whereas their sum is not less than $41.04 \%$ in any sample. Unfortunately, no published data of the chemical composition of date palm stone or rachis bio-oil are found in the literature. Whereas, few published work reported the chemical composition of bio-oil extracted by fast pyrolysis from date palm wastes such as a mixture of date palm wastes [21], and date palm shell [218] and by slow from date palm frond [164] and shell [161]. Phenol and furfural are also found of high percentage of the bio oil extracted from palm shell as they present $37.78-48.31 \%$ and $4.6 \%$, respectively [161].

The chemical composition of the bio-oil extracted from Barhee date palm stones by slow pyrolysis is reported in Table 5.6. The GC-MS results revealed that the Barhee stone bio-oil contains much d-allose as its percentage reaches $41.35 \%$ in one sample and $28.56 \%$ in another sample, but it is surprisingly undetected in the other two samples. But it still has the higher average percentage over the four samples of $17.48 \%$, flowed by dodecanoic acid (14.67\%) which is detected in the four samples. The 5-methyle 2furancarboxaldehyde and furfural are also detected in the four oil samples with high 
average percentage of also of 7.52 and $5.51 \%$, respectively. Little amount of phenol is found in the bio-oil of Barhee stone with an average percentage of $1.74 \%$ compared to $17.55 \%$ found in the Barhee rachis bio-oil. The d-allose is considered a monosaccharide that has the highest percentage of $11.09 \%$ of the bio-oil extracted from a mixture of date palm wastes [21].

Table 5.7 presents the chemical composition of Medjool date palm rachis bio-oil. From results summarized in Table 5.7, it is clearly seen that more than $85 \%$ of the chemical components reported in this Table are detected in each sample which reflects the accuracy in conducting the four experiments and confirms that these reported results can be relied upon. The components of bio-oil extracted from Medjool rachis are approximately similar to that found in Barhee rachis bio-oil. Phenol, Furfural and Benzoic acid are considered the main components of the Medjool rachis bio-oil as their average percentage are $18.4,19.48$, and $13.39 \%$ compared to $17.55,14.97$ and $14.96 \%$ in the case of Barhee rachis, respectively. Phenol, Furfural and Benzoic acid percentage sum reaches $63.85 \%$ in one tested sample of Medjool rachis bio-oil (MR3) whereas their sum is not less than 45.73 in any sample. The 2,6 dimethoxy phenol is also found of high content with average percentage of $7.58 \%$.

Table 5.8 illustrates the chemical composition of bio-oil obtained from the Mejool date palm stones. The GC-MS results showed that the first bio-oil sample (MS1) contains only five compounds which already found in other three samples. Whereas; $11,15,15$ compounds were found in the MS2, MS3 and MS_OLD, respectively. So, it is better to exclude the results of the first sample. d-allose, furfural, 5-methyl 2-furancarboxaldehyde, and Dodecanoic acid, are found the main components in the Mejool stone bio-oil which 
approximately represent $25.68,15.14,13.71$, and $9.25 \%$, respectively. It is clearly seen that the d-allose has the highest percentage of the composition of the bio-oil obtained from the date palm stones whatever its type was (17.48 \% in Barhee and $25.68 \%$ in Medjool). d-allose is also has the highest percentage in the results reported by Makkawi et al. [21] for the bio-oil extracted from mixture date palm wastes by fast pyrolysis. 
Table 5. 5. GC-MS of Barhee rachis bio-oil.

\begin{tabular}{|c|c|c|c|c|c|c|c|}
\hline \multirow[b]{2}{*}{ RT min-1 } & \multirow[b]{2}{*}{ Compound name } & \multirow{2}{*}{$\begin{array}{l}\text { Chemical } \\
\text { formula }\end{array}$} & \multirow[t]{2}{*}{ Chemical group } & \multicolumn{4}{|c|}{$\%$} \\
\hline & & & & S1 & $\mathrm{S} 2$ & S3 & $\mathrm{S} 4$ \\
\hline & & $\mathrm{C}_{5} \mathrm{H}_{4} \mathrm{O}_{2}$ & Furan & 17.06 & 18.27 & 13.72 & $\mathbf{1 0 . 8}$ \\
\hline 4.19 & Furfural & & & & & & 4 \\
\hline 5.35 & 2-methyl 2 cyclopenten-1-one & $\mathrm{C}_{6} \mathrm{H}_{8} \mathrm{O}$ & Ketone & 1.27 & - & - & - \\
\hline 5.43 & Acetyl furan & $\mathrm{C}_{6} \mathrm{H}_{6} \mathrm{O}_{2}$ & Furan & 0.99 & - & - & - \\
\hline 5.55 & 2(5h)Furanone & $\mathrm{C}_{4} \mathrm{H}_{4} \mathrm{O}_{2}$ & Furan & 1.95 & - & - & - \\
\hline 5.63 & 2,2 diethoxy Ethanol & $\mathrm{C}_{6} \mathrm{H}_{14} \mathrm{O}_{3}$ & Alcohol & 1.79 & 15.06 & - & 7.67 \\
\hline 5.89 & 5-methyl $2(5 \mathrm{H})$ furanone & $\mathrm{C}_{5} \mathrm{H}_{6} \mathrm{O}_{2}$ & Furan & 0.76 & - & - & - \\
\hline 6.20 & 5-methyl 2-furancarboxaldehyde & $\mathrm{C}_{6} \mathrm{H}_{6} \mathrm{O}_{2}$ & Aldehyde & 5.92 & 4.74 & 3.76 & 2.62 \\
\hline \multirow[t]{2}{*}{6.27} & 3-methyl 2 cyclopentene 1 -one & $\mathrm{C}_{6} \mathrm{H}_{8} \mathrm{O}$ & Ketone & 1.51 & 1.14 & 1.85 & 1.92 \\
\hline & & $\mathrm{C}_{6} \mathrm{H}_{6} \mathrm{O}$ & Phenol & & & & 16.1 \\
\hline 6.65 & Phenol & & & 18.32 & 16.43 & 19.33 & 2 \\
\hline 6.92 & 2,5 Diethoxytetrahydro Furan & $\mathrm{C}_{8} \mathrm{H}_{16} \mathrm{O}_{3}$ & Furan & 6.43 & 2.31 & 7.63 & 7.52 \\
\hline 7.41 & 3-methyl 1,2 cyclopentanedione & $\mathrm{C}_{6} \mathrm{H}_{8} \mathrm{O}_{2}$ & Ketone & 2.45 & 1.84 & 3.42 & 3.57 \\
\hline 7.78 & 2-methyl phenol & $\mathrm{C}_{7} \mathrm{H}_{8} \mathrm{O}$ & Phenol & 2.59 & 4.12 & 2.63 & 3.63 \\
\hline 7.82 & acetophenone & $\mathrm{C}_{8} \mathrm{H}_{8} \mathrm{O}$ & Esters & 1.39 & 1.53 & 0.87 & 1.02 \\
\hline 8.03 & 2-methyl propanoic acid anhydride & $\mathrm{C}_{8} \mathrm{H}_{14} \mathrm{O}_{3}$ & Acid & 1.15 & 3.69 & 0.89 & 2.6 \\
\hline 8.18 & 2-methoxy phenol & $\mathrm{C}_{7} \mathrm{H}_{8} \mathrm{O}_{2}$ & phenol & 2.89 & 4.52 & 4.39 & 2.88 \\
\hline 8.28 & Benzoic acid methyl ester & $\mathrm{C}_{8} \mathrm{H}_{8} \mathrm{O}_{2}$ & Ester & 1.3 & 1.63 & 2.13 & 1.62 \\
\hline \multirow[t]{2}{*}{8.72} & 3-ethyl-2-hydroxy-2-cyclopenten-1-one & $\mathrm{C}_{7} \mathrm{H}_{10} \mathrm{O}_{2}$ & Ketone & 1.8 & 1.3 & 1.96 & 2.22 \\
\hline & & $\mathrm{C}_{6} \mathrm{H}_{5} \mathrm{COOH}$ & Acid & & & & 14.0 \\
\hline 10.18 & Benzoic acid & & & 14.08 & 14.37 & 17.34 & 8 \\
\hline 10.54 & 5-hydroxymethylfurfural & $\mathrm{C}_{6} \mathrm{H}_{6} \mathrm{O}_{3}$ & Furan & 2.14 & 2.05 & 3.76 & 7.84 \\
\hline 11.94 & 2,6 dimethozy phenol & $\mathrm{C}_{11} \mathrm{H}_{14} \mathrm{O}_{3}$ & Phenol & 5.61 & 2.13 & 7.85 & 7.82 \\
\hline 13.12 & 4-methoxy-3-(methoxy methyl) phenol & $\mathrm{C}_{8} \mathrm{H}_{10} \mathrm{O}_{2}$ & Phenol & 1.49 & - & 1.91 & 1.57 \\
\hline 14.03 & 2-(methylmercapto)-benzothiazol & $\mathrm{C}_{8} \mathrm{H}_{8} \mathrm{~N}_{2} \mathrm{~S}$ & - & 0.71 & - & 0.95 & 1.12 \\
\hline 16.76 & 1-(2,4,6-trihydroxyphenyl) 2 pentanone & $\mathrm{C}_{11} \mathrm{H}_{14} \mathrm{O}_{4}$ & Ketone & - & - & 0.1 & 1.16 \\
\hline
\end{tabular}




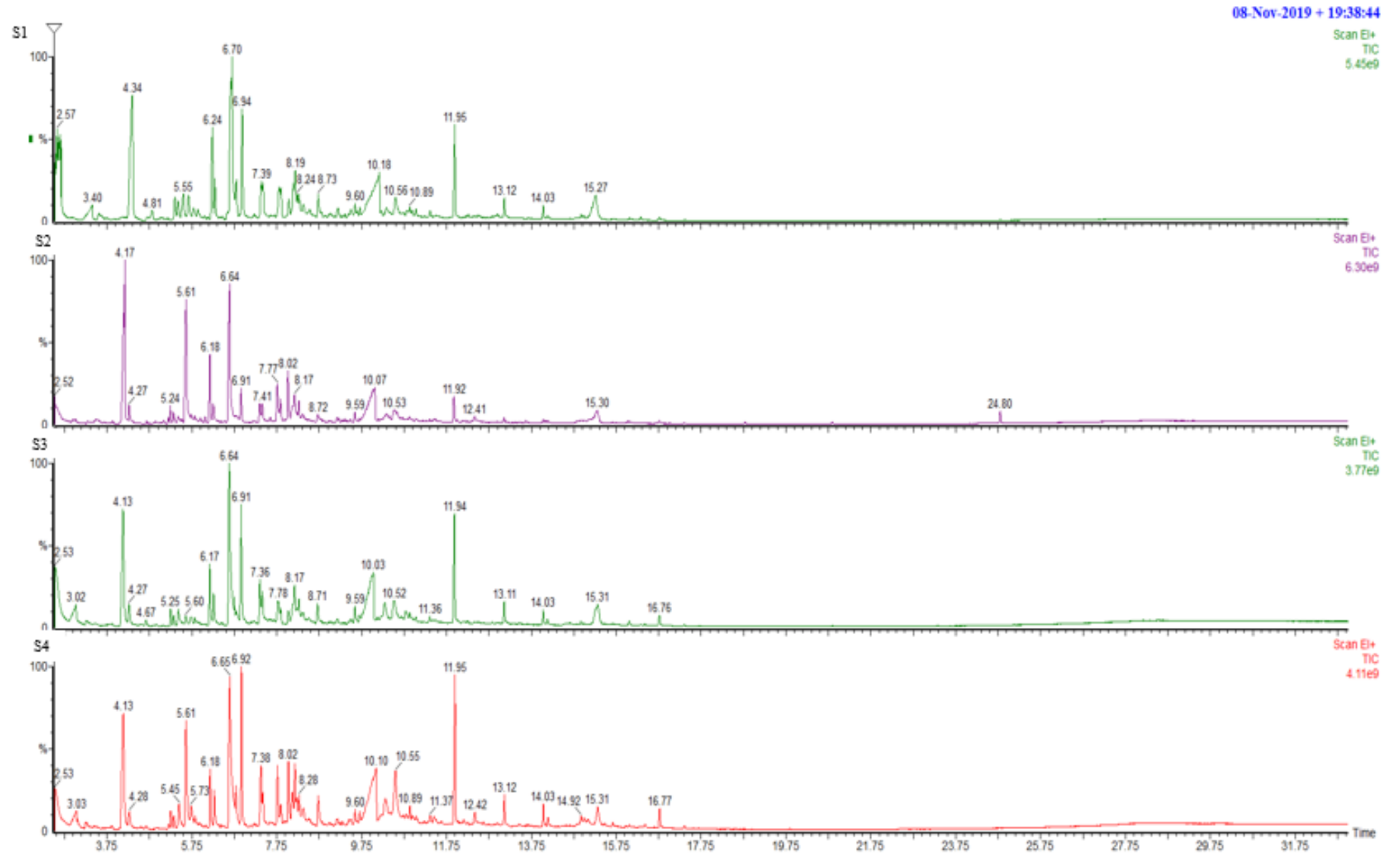

Fig. 5. 4. GC-MS of Barhee rachis bio-oil. 
Table 5. 6. GC-MS of Barhee stones bio-oil.

\begin{tabular}{|c|c|c|c|c|c|c|c|}
\hline \multirow[b]{2}{*}{ RT min-1 } & \multirow[b]{2}{*}{ Compound name } & \multirow[t]{2}{*}{ Chemical formula } & \multirow[t]{2}{*}{ Chemical group } & \multicolumn{4}{|c|}{$\%$} \\
\hline & & & & S1 & $\mathrm{S} 2$ & S3 & S4 \\
\hline 4.11 & Furfural & $\mathrm{C}_{5} \mathrm{H}_{4} \mathrm{O}_{2}$ & Furan & 2.15 & 29.75 & 5.40 & 0.736 \\
\hline 4.24 & diacetone alcohol & $\mathrm{C}_{6} \mathrm{H}_{12} \mathrm{O}_{2}$ & Ketone & 0.86 & 7.36 & 1.79 & - \\
\hline 4.51 & 2-furanmethanol & $\mathrm{C}_{5} \mathrm{H}_{6} \mathrm{O}_{2}$ & Furan & 1.94 & - & 5.45 & - \\
\hline 5.22 & 2-methyl 2 cyclopenten-1-one & $\mathrm{C}_{6} \mathrm{H}_{8} \mathrm{O}$ & - & 0.23 & - & 0.52 & - \\
\hline 5.3 & Acetyl furan & $\mathrm{C}_{6} \mathrm{H}_{6} \mathrm{O}_{2}$ & Furan & 0.44 & 3.79 & 0.92 & - \\
\hline 5.41 & 2(5h)Furanone & $\mathrm{C}_{4} \mathrm{H}_{4} \mathrm{O}_{2}$ & Furan & 1.17 & 5.32 & 3.4 & - \\
\hline 6.15 & 5-methyl 2-furancarboxaldehyde & $\mathrm{C}_{6} \mathrm{H}_{6} \mathrm{O}_{2}$ & Aldehyde & 2.96 & 21.81 & 5.69 & - \\
\hline 6.2 & 1-acetoxy-2butanone & $\mathrm{C}_{6} \mathrm{H}_{12} \mathrm{O}_{2}$ & Ester & - & - & 2.39 & - \\
\hline 6.23 & 3-methyl 2 cyclopentene 1 -one & $\mathrm{C}_{6} \mathrm{H}_{8} \mathrm{O}$ & Ketone & 1.03 & 6.7 & 2.59 & - \\
\hline 6.65 & Phenol & $\mathrm{C}_{6} \mathrm{H}_{6} \mathrm{O}$ & Phenol & 1.09 & 4.54 & 1.32 & - \\
\hline 7.32 & 3-Methylcyclopentane-1,2-dione & $\mathrm{C}_{6} \mathrm{H}_{8} \mathrm{O}_{2}$ & Ketone & 2.82 & 5.86 & 2.85 & - \\
\hline 8.66 & Maltol & $\mathrm{C}_{6} \mathrm{H}_{6} \mathrm{O}_{3}$ & - & 5.7 & 5.89 & 4.82 & - \\
\hline 9.92 & 1,4,3,6-dianhydro a-d-glucopyranose & $\mathrm{C}_{6} \mathrm{H}_{8} \mathrm{O}_{4}$ & - & 3.13 & - & 3.9 & - \\
\hline 10.17 & Catechol & $\mathrm{C}_{6} \mathrm{H}_{6} \mathrm{O}_{2}$ & - & 5.76 & - & 3.37 & - \\
\hline 10.5 & 5-hydroxymethylfurfural & $\mathrm{C}_{6} \mathrm{H}_{6} \mathrm{O}_{3}$ & Furan & 3.85 & - & 5.08 & \\
\hline 10.63 & d-melezitose & $\mathrm{C}_{18} \mathrm{H}_{32} \mathrm{O}_{16}$ & Carbohydrates & 1.58 & - & 3.51 & \\
\hline 14.38 & d-allose & $\mathrm{C}_{6} \mathrm{H}_{12} \mathrm{O}_{6}$ & Monosaccharide & 28.56 & - & 41.35 & - \\
\hline 14.63 & dodecanoic acid & $\mathrm{C}_{12} \mathrm{H}_{24} \mathrm{O}_{2}$ & Acid & 16.49 & 8.99 & 4.72 & 28.46 \\
\hline 15.56 & 8-heptadecene & $\mathrm{C}_{17} \mathrm{H}_{34}$ & - & 1.12 & - & - & 3.43 \\
\hline 15.65 & 8-heptadecene & $\mathrm{C}_{17} \mathrm{H}_{34}$ & - & 1.06 & - & - & 5.18 \\
\hline 15.85 & $2,6,10$ trimethyl tetradecane & $\mathrm{C}_{17} \mathrm{H}_{36}$ & Alkanes & 0.57 & - & - & 1.72 \\
\hline
\end{tabular}




\begin{tabular}{|c|c|c|c|c|c|c|c|}
\hline 16.7 & Tetradecanoic acid & $\mathrm{C}_{14} \mathrm{H}_{28} \mathrm{O}_{2}$ & Acid & 3.07 & - & - & 12.39 \\
\hline 18.62 & n-hexadecanoic acid & $\mathrm{C}_{16} \mathrm{H}_{32} \mathrm{O}_{2}$ & Acid & 1.89 & - & - & 6.72 \\
\hline 20.24 & Oleic acid & $\mathrm{C}_{18} \mathrm{H}_{34} \mathrm{O}_{2}$ & Acid & 4.34 & - & - & 16 \\
\hline 20.41 & Octadecanoic acid & $\mathrm{C}_{18} \mathrm{H}_{36} \mathrm{O}_{2}$ & Acid & 0.75 & - & - & 1.12 \\
\hline 21.05 & Propyl-9-octadecanoate & $\mathrm{C}_{21} \mathrm{H}_{40} \mathrm{O}_{2}$ & - & 0.19 & - & - & 1.48 \\
\hline 23.33 & Diisoctyl phthalate & $\mathrm{C}_{28} \mathrm{H}_{46} \mathrm{O}_{4}$ & Ester & 7.26 & - & 0.92 & - \\
\hline 24.84 & Dioctyl isophthalate & $\mathrm{C}_{24} \mathrm{H}_{38} \mathrm{O}_{4}$ & Ester & - & - & - & 22.79 \\
\hline
\end{tabular}




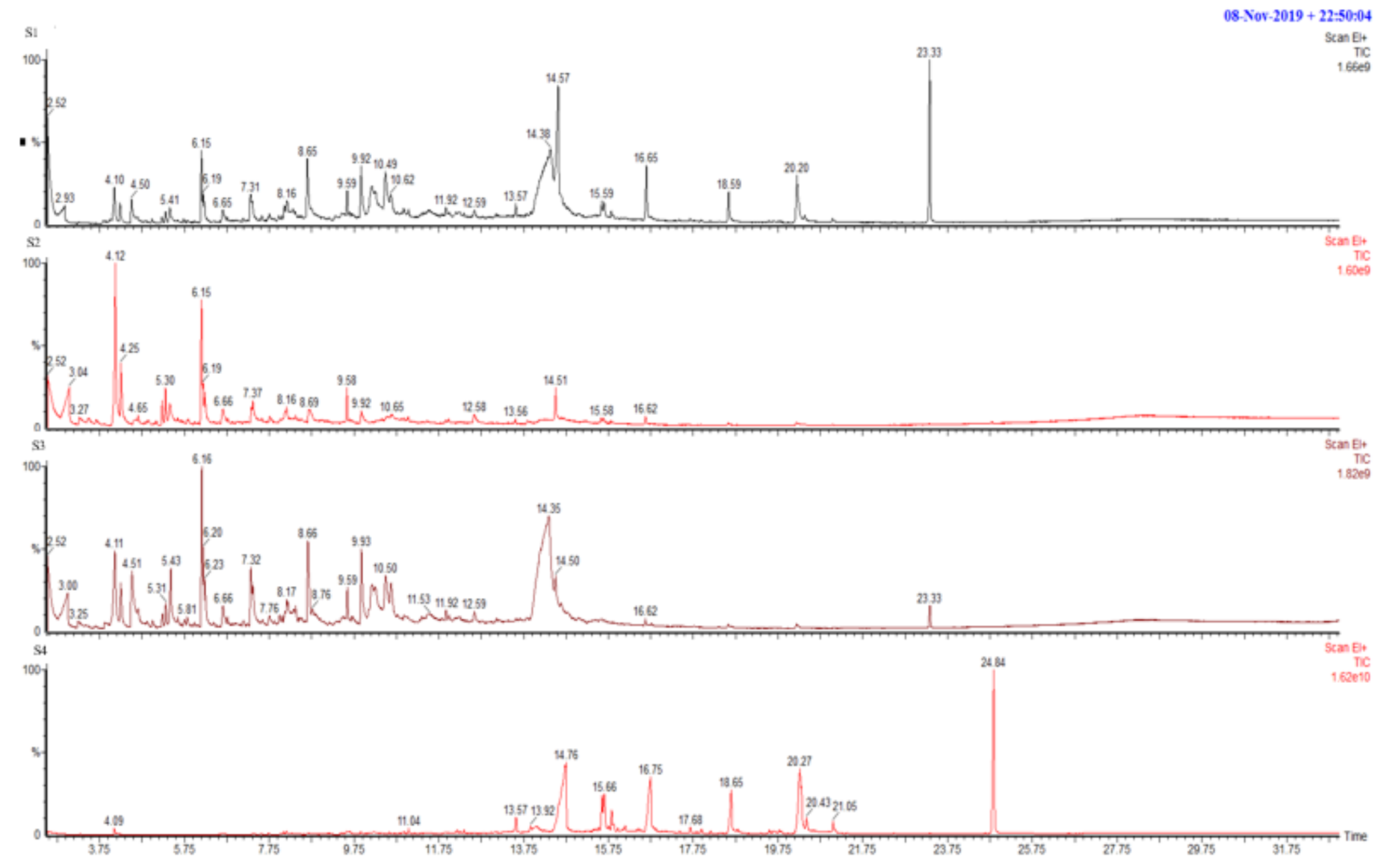

Fig. 5. 5. GC-MS of Barhee stones bio-oil. 
Table 5. 7. Medjool Rachis bio-oil chemical composition.

\begin{tabular}{|c|c|c|c|c|c|c|c|}
\hline \multirow[b]{2}{*}{ RT min-1 } & \multirow[b]{2}{*}{ Compound name } & \multirow[t]{2}{*}{ Chemical formula } & \multirow[t]{2}{*}{ Chemical group } & \multicolumn{4}{|c|}{$\%$} \\
\hline & & & & S1 & $\mathrm{S} 2$ & S3 & $\mathrm{S} 4$ \\
\hline & & $\mathrm{C}_{5} \mathrm{H}_{4} \mathrm{O}_{2}$ & Furan & & & & 28.7 \\
\hline 4.17 & Furfural & & & 8.95 & 23.18 & 17.04 & 6 \\
\hline 5.25 & 2-methyl 2 cyclopenten-1-one & $\mathrm{C}_{6} \mathrm{H}_{8} \mathrm{O}$ & - & 0.8 & 1.13 & 1.03 & 1.28 \\
\hline 5.34 & Acetyl furan & $\mathrm{C}_{6} \mathrm{H}_{6} \mathrm{O}_{2}$ & Furan & 0.63 & 0.86 & 0.85 & 1.2 \\
\hline 5.43 & 2(5h)Furanone & $\mathrm{C}_{4} \mathrm{H}_{4} \mathrm{O}_{2}$ & Furan & 1.83 & 1.36 & 1.05 & 0.55 \\
\hline 5.67 & 2,2 diethoxy Ethanol & $\mathrm{C}_{6} \mathrm{H}_{14} \mathrm{O}_{3}$ & Alcohol & - & 7.89 & 18.66 & 2.5 \\
\hline 6.19 & 5-methyl 2-furancarboxaldehyde & $\mathrm{C}_{6} \mathrm{H}_{6} \mathrm{O}_{2}$ & Aldehyde & 2.81 & 2.78 & 2.16 & 3.79 \\
\hline & & $\mathrm{C}_{6} \mathrm{H}_{6} \mathrm{O}$ & phenol & & & & $\mathbf{1 9 . 5}$ \\
\hline 6.66 & Phenol & & & 21.89 & 15.65 & 16.52 & 4 \\
\hline 6.78 & Phenol & $\mathrm{C}_{6} \mathrm{H}_{6} \mathrm{O}$ & Phenol & 6.36 & 3.63 & - & - \\
\hline 6.92 & 2,5 Diethoxytetrahydro Furan & $\mathrm{C}_{8} \mathrm{H}_{16} \mathrm{O}_{3}$ & Furan & 7.22 & 5.35 & 5.59 & 3.74 \\
\hline 7.35 & 3-methyl 1,2 cyclopentanedione & $\mathrm{C}_{6} \mathrm{H}_{8} \mathrm{O}_{2}$ & Ketone & 2.97 & 1.87 & 2.21 & 3.2 \\
\hline 7.78 & 2-methyl phenol & $\mathrm{C}_{7} \mathrm{H}_{8} \mathrm{O}$ & Phenol & 3.82 & 2.09 & 2.93 & 3.42 \\
\hline 8.02 & 2-keto-n-valenic acid & $\mathrm{C}_{8} \mathrm{H}_{15} \mathrm{~N}_{3} \mathrm{O}_{3}$ & Acid & 1.58 & 3.02 & 5.16 & 0.94 \\
\hline 8.18 & 2-methoxy phenol & $\mathrm{C}_{7} \mathrm{H}_{8} \mathrm{O}_{2}$ & Phenol & 3.07 & 3.11 & 2.65 & 3.19 \\
\hline 8.7 & 3-ethyl-2-hydroxy-2-cyclopenten-1-one & $\mathrm{C}_{7} \mathrm{H}_{10} \mathrm{O}_{2}$ & Ketone & 1.84 & 1.87 & 1.57 & 1.79 \\
\hline & & $\mathrm{C}_{6} \mathrm{H}_{5} \mathrm{COOH}$ & Acid & & & & $\mathbf{1 5 . 5}$ \\
\hline 10.06 & Benzoic acid & & & 16.21 & 9.62 & 12.17 & 5 \\
\hline 11.94 & 2,6 dimethoxy phenol & $\mathrm{C}_{8} \mathrm{H}_{10} \mathrm{O}_{3}$ & phenol & 11.86 & 6.52 & 8.86 & 3.08 \\
\hline 13.11 & $1,2,4$ trimethoxybenzene & $\mathrm{C}_{9} \mathrm{H}_{12} \mathrm{O}_{3}$ & - & 2.24 & 1.44 & 2.19 & 0.63 \\
\hline 14.02 & 2-(methylmercapto)-benzothiazol & $\mathrm{C}_{8} \mathrm{H}_{7} \mathrm{NS}_{2}$ & - & 1.91 & 0.83 & 2.59 & 0.44 \\
\hline 15.26 & 1,2 , decenylsuccinic anhydride & $\mathrm{C}_{14} \mathrm{H}_{22} \mathrm{O}_{3}$ & - & 2.64 & 6.99 & 4.88 & 5.3 \\
\hline 16.05 & Methoxyeugenol & $\mathrm{C}_{11} \mathrm{H}_{14} \mathrm{O}_{3}$ & Phenol & 0.76 & 0.82 & 6.34 & - \\
\hline 16.75 & Desaspidinol & $\mathrm{C}_{11} \mathrm{H}_{14} \mathrm{O}_{4}$ & - & 0.62 & 0.13 & 1.19 & 0.33 \\
\hline 18.79 & Hexadecanic acid ethyl ester & $\mathrm{C}_{18} \mathrm{H}_{36} \mathrm{O}_{2}$ & Ester & - & - & 1.06 & - \\
\hline
\end{tabular}



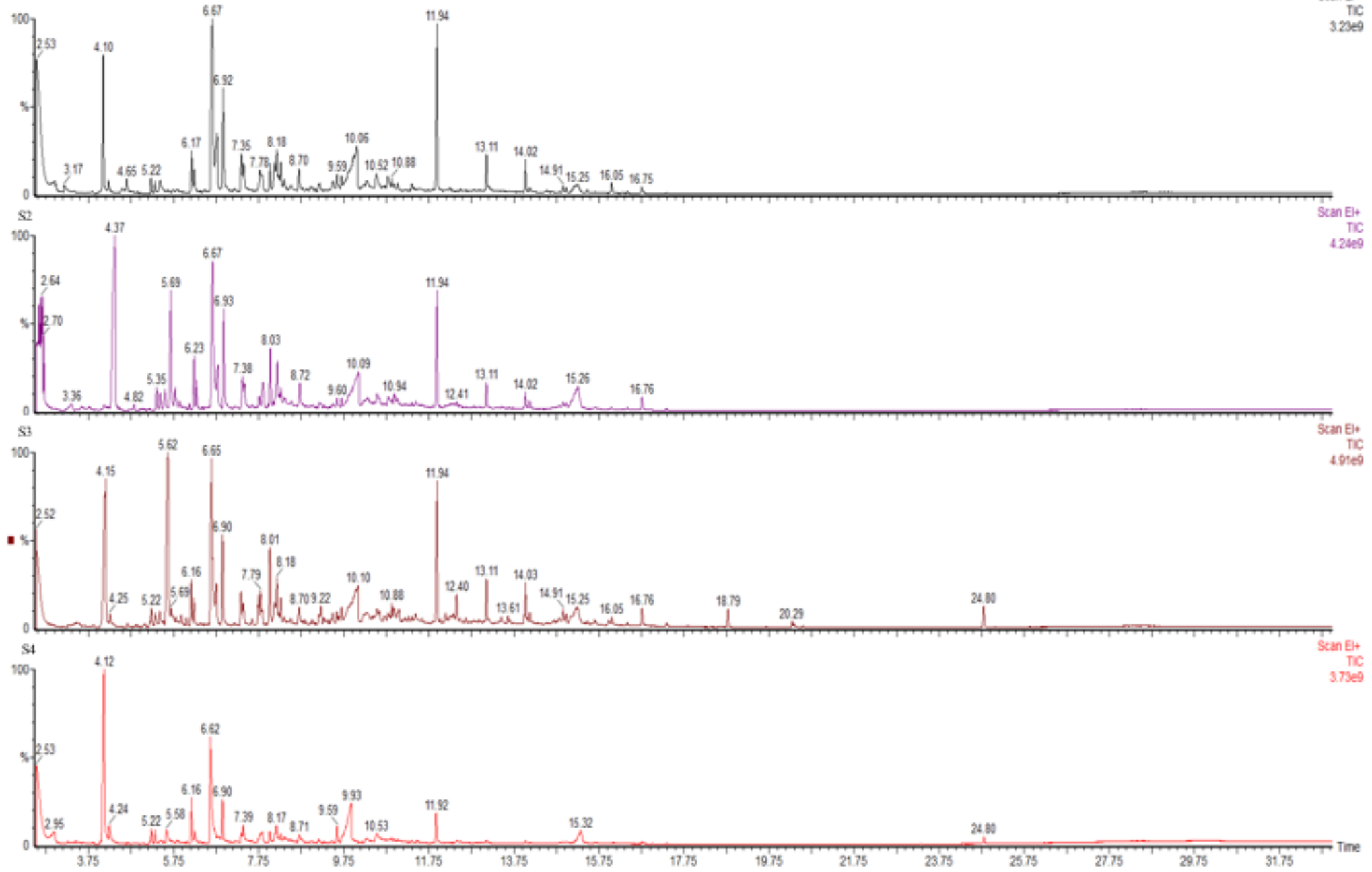

Fig. 5. 6. GC-MS of Medjool rachis bio-oil. 
Table 5. 8. Chemical composition of Medjool stones bio-oil.

\begin{tabular}{|c|c|c|c|c|c|c|c|}
\hline \multirow[b]{2}{*}{ RT min-1 } & \multirow[b]{2}{*}{ Compound name } & \multirow[t]{2}{*}{ Chemical formula } & \multirow[t]{2}{*}{ Chemical group } & \multicolumn{4}{|l|}{$\%$} \\
\hline & & & & S1 & S2 & S3 & S4 \\
\hline 4.1 & Furfural & $\mathrm{C}_{5} \mathrm{H}_{4} \mathrm{O}_{2}$ & Furan & 9.23 & 13.76 & 22.42 & 6.13 \\
\hline 5.22 & 2-methyl 2 cyclopenten-1-one & $\mathrm{C}_{6} \mathrm{H}_{8} \mathrm{O}$ & Ketone & 0.87 & 2.2 & 1.75 & - \\
\hline 5.31 & Acetyl furan & $\mathrm{C}_{6} \mathrm{H}_{6} \mathrm{O}_{2}$ & Furans & 1.44 & 5.29 & 2.72 & - \\
\hline 5.43 & $2(5 h)$ Furanone & $\mathrm{C}_{4} \mathrm{H}_{4} \mathrm{O}_{2}$ & Furan & 3.63 & 5.29 & 4.1 & 10.59 \\
\hline 6.17 & 5-methyl 2-furancarboxaldehyde & $\mathrm{C}_{6} \mathrm{H}_{6} \mathrm{O}_{2}$ & Aldehyde & 12.05 & 11.41 & 17.68 & 5.018 \\
\hline 6.66 & Phenol & $\mathrm{C}_{6} \mathrm{H}_{6} \mathrm{O}$ & Phenol & 2.63 & 2.46 & 3.78 & - \\
\hline 7.35 & 3-methyl 1,2 cyclopentanedione & $\mathrm{C}_{6} \mathrm{H}_{8} \mathrm{O}_{2}$ & Ketone & 2.34 & 2.34 & 6.97 & - \\
\hline 8.7 & Maltol & $\mathrm{C}_{6} \mathrm{H}_{6} \mathrm{O}_{3}$ & - & 7.12 & 6.44 & 8.58 & - \\
\hline 9.92 & 1,4,3,6-dianhydro a-d-glucopyranose & $\mathrm{C}_{6} \mathrm{H}_{8} \mathrm{O}_{4}$ & - & 5.42 & 4.19 & 5.77 & - \\
\hline 14.05 & d-allose & $\mathrm{C}_{6} \mathrm{H}_{12} \mathrm{O}_{6}$ & Monosaccharide & 38.22 & 18.14 & 20.69 & - \\
\hline 14.54 & Dodecanoic acid & & & 5.93 & 16.27 & 5.54 & 15.8 \\
\hline 16.64 & Tetradecanoic acid & $\mathrm{C}_{14} \mathrm{H}_{28} \mathrm{O}_{2}$ & Acid & 2.14 & 4.57 & - & - \\
\hline 18.59 & n-hexadecanoic acid & $\mathrm{C}_{16} \mathrm{H}_{32} \mathrm{O}_{2}$ & Acid & 1.42 & 2.23 & - & - \\
\hline 20.19 & Octadecanoic acid & $\mathrm{C}_{18} \mathrm{H}_{36} \mathrm{O}_{2}$ & Acid & 3.17 & 4.11 & - & - \\
\hline 24.8 & Dioctyl isophthalate & $\mathrm{C}_{24} \mathrm{H}_{38} \mathrm{O}_{4}$ & Ester & 4.38 & 17.24 & - & 62.46 \\
\hline
\end{tabular}




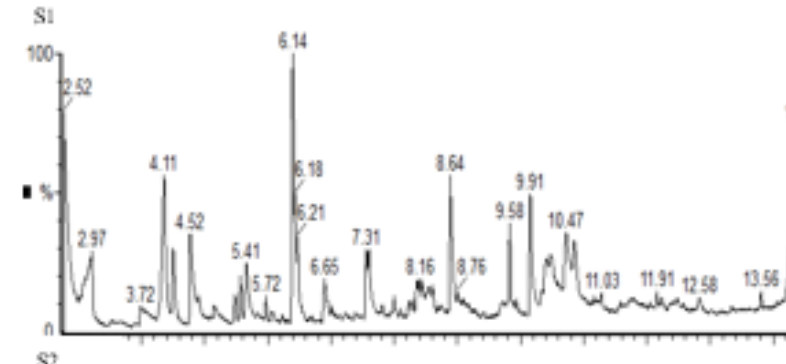

$\operatorname{scan} \theta+$

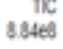
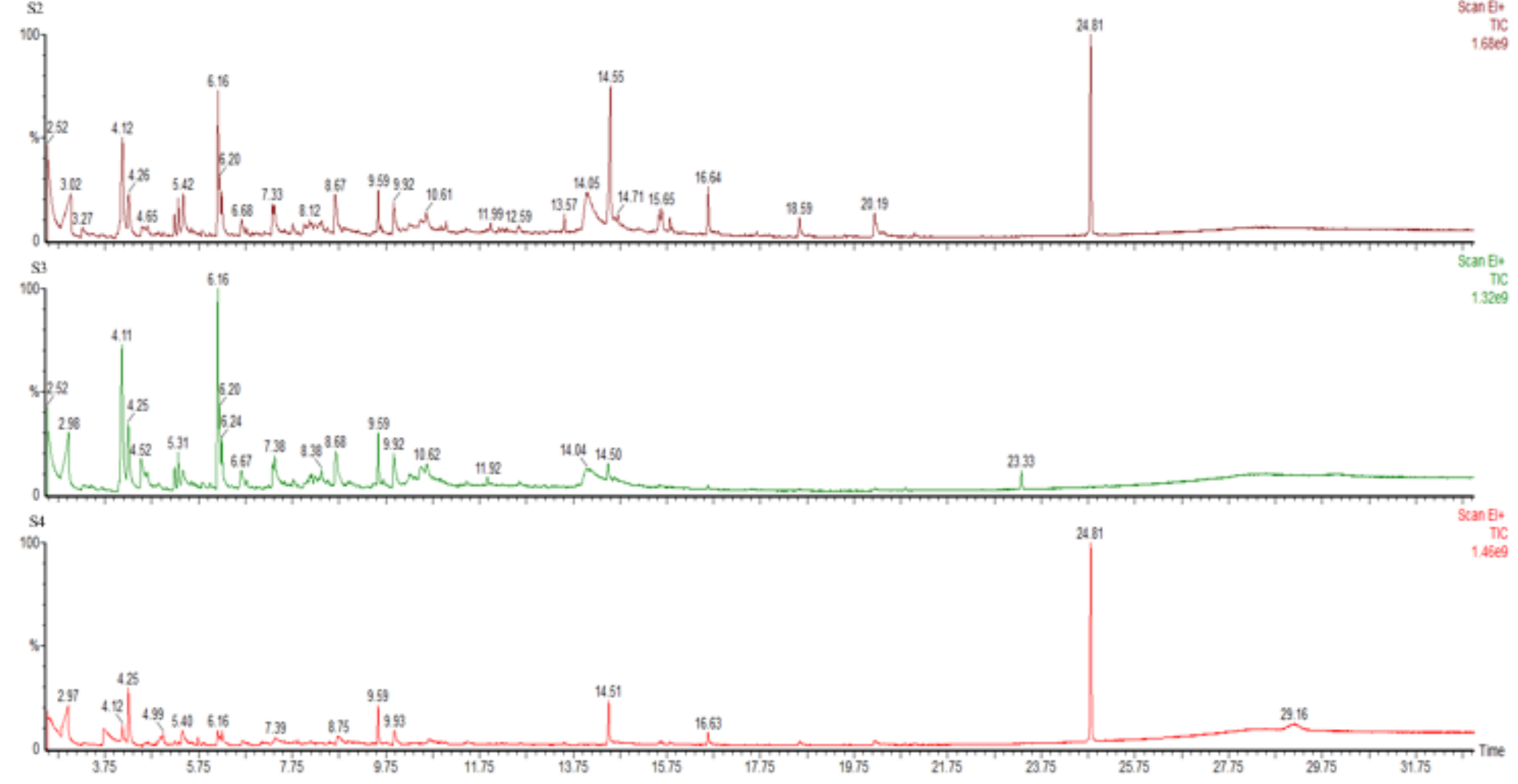

Fig. 5. 7. GC-MS of Medjool stone bio-oil. 


\subsection{Conclusions}

In this chapter, the slow pyrolysis experiments of stones and rachis obtained from Barhee and Medjool date palm trees are presented. The characterization of the bio-oil is also discussed in details in this chapter. From the experimental results illustrated in this chapter, the following conclusions can be drawn:

- The largest yield of bio-oil among the four slow pyrolysis experiments is obtained when the Barhee rachis is used as feedstock, where the bio-oil yield reaches $21.54 \%$. Whereas, the optimum char yield of $73.35 \%$ is obtained from the Barhee stone.

- It is also concluded that the slow pyrolysis of Barhee and Medjool stone gives high char yield at the expense of the bio-oil yield.

- The water content presented in bio-oil extracted from Medjool stone is found 46.55-50.52\% compared to 43.47-50.19 for Barhee stone. Whereas, it is found 14.24-16.71\% and 14.55-15.66 for the Medjool rachis and Barhee rachis, respectively.

- High percentage carbon content is found in bio-oil from stones samples; where, its percentage reaches $73.83 \%$ in the case of Barhee stone. While, it is found from 72.94 to $73.71 \%$ in case of Medjool stone.

- Low carbon contents are found in the bio-oil obtained from the slow pyrolysis of Barhee and Medjool rachis, where the percentage of carbon content is found 8.6119.03 and $9.98-18.68 \%$ in the case of Barhee and Medjool rachis, respectively.

- The results showed also high superiority of the bio-oil extracted from the slow pyrolysis of Barhee and Medjool stones from the heating value point of view. 
- The GC-MS analysis results showed that the Phenol, Furfural and Benzoic acid are considered the main components of the Medjool and Barhee rachis bio-oil; where their average percentage in the Medjool rachis bio-oil are 18.4, 19.48, and $13.39 \%$ compared to $17.55,14.97$ and $14.96 \%$ in the case of Barhee rachis, respectively.

- The GC-MS results revealed also that the Barhee and Medjool stone bio-oil mainly contents of d-allose, as its average percentage is found $17.48 \%$, in the case Barhee bio-oil and $25.68 \%$ in the case of Medjool bio-oil. 


\section{Chapter 6}

\section{Techno-economic Analysis of hybrid solar-biomass energy in the Middle East}

\subsection{Availability and current status of hybrid solar-biomass development in the Middle East}

A few studies on hybrid solar-biomass power generation have been conducted in the Middle East so far. The conventional configuration of biomass power plant operated on combined Bryton-Rankine power generation system. [219].

Two novel configurations for hybrid solar-biomass for power generation in Iran were proposed by Sarkis and Zare [219]. The first configuration is similar to the conventional biomass power plant except that the working fluid in the Rankine cycle is heat by parabolic trough collector (PTC) in addition to the heat recovered from the Bryton cycle. While in the second configuration, the PTC as direct steam generation (DSG) is used to generate additional steam in Rankine cycle. The two configurations were modeled using Engineering equation solver (EES) software. They found that the levelized cost of electricity (LCOE) for the first and second proposed configurations are 79.88 and 74.94 \$/MWh, respectively, compared to $79.34 \$$ MWh for the conventional biomass power plant system.

A combined cycle based on new configuration of hybrid biomass-solar power plant for electrical power generation in Iran was proposed by Anvari et al. [220]. The system consists of three sub-systems: biomass section (gas turbine cycle coupled to a biomass gasifier), solar section (consists of heliostats and power tower) and the steam turbine section (a conventional Rankine cycle). The biofuel produced in the gasifier firstly flows into the combustion chamber where it reacted with the compressed air from the compressor. The high temperature combustion products are expanded in the high-pressure gas turbine (HPGT) to generate main produced power. After that, it passes through the inter-mediate heat exchanger (IHE) where it is reheated by the solar energy using heliostat

field and solar tower system. The combustion products exited from the IHE pass through 
the low-pressure gas turbine (LPGT) to generate an additional power before entering the evaporator of the Rankine cycle for more power generation. The proposed system was modeled using EES software. Their results showed that, adding the solar section to the biomass-based system increases the power generation by about $25 \%$ with reduction in $\mathrm{CO}_{2}$ emission by about $31 \%$.

Micro-power optimization model is used by Ghenai and Janajreh [221] to design solar-biomass hybrid system for the electrical power generation in Sharjah, UAE. The micro grid hybrid system was designed based on solar photovoltaic (PV) and biogas generators integrated with batteries and converters. The system was simulated, optimized and economically analyzed. The results showed that the solar-biomass hybrid system can provide up to $14 \%$ of the total yearly electrical demand in the city of Sharjah with the percentage shared by PV panel of $74 \%$ and $26 \%$ by the biogas generator. The LCOE was found $0.328 \$ / \mathrm{kWh}$ which is considered relatively high and is less attractive to the users. So, it is important to search for new alternative and renewable biofuels with higher energy density for power generation in order to reduce the cost of power generation from renewable energy systems.

Although, the hybrid solar-biomass power generation systems are in their nascent stages, a number of feasibility and technology studies have been conducted for countries such as India [222], Brazil [223], Australia [224-226] and Ireland [227]. Several hybrid solar-biomass systems have been studied by Peterseim et al. [23]. The maximum energy efficiency of $33.2 \%$ is obtained for solar tower and gasification, whereas Fresnel and fluidized bed offer the lowest specific investment ( $\$ / \mathrm{MWe})$. Several challenges need to be addressed before solar-biomass hybrid plants are implemented extensively. The first challenge is the location as most of the concentrating solar power (CSP) plants around the world are located in areas with direct normal irradiation more than $20 \mathrm{MJ} / \mathrm{m}^{2} /$ day. While a few locations that simultaneously have large biomass resources suitable for hybridization. In order to construct any hybrid solar-biomass plant, a steady supply of fuel for an average plant lifespan of 25 years needs to be ensured. In spite of these challenges, the first and the only commercial CSP-biomass plant of capacity $22.5 \mathrm{MWe}$ has been installed and operated in Spain since 2012 [228]. 


\subsection{Review on Solar thermal Energy plants}

The utilization of solar energy to generate electricity is considered one of the most important points of research in the strategic plans of most universities and research centres in the Middle East. Two technologies are used to generate electricity from solar energy; the Photovoltaic (PV) technology in which the solar energy is directly converted to electricity and the solar thermal power (STP) plants in which the solar energy is firstly converted to thermal energy then converted to electricity. Most of the STP plants use the concentrating solar power (CSP) technology. Nowadays the PV is considered the most used technology around the world, because of it is still having the lower cost so far [229]. Recently, great efforts have been done by many researchers around the world to improve the performance of the CSP. It is expected that the CSP with thermal storage would develop its highest potential in arid areas located at Sun Belt (relatively low latitudes) [230], as it has two advantages over PV:

1- It uses same thermal power conversion as the conventional thermal power (fossil or nuclear) and can therefore be integrated with the existing power infrastructure easily.

2- It uses thermal energy storage which is a tenth the cost of battery storage used with PV.

The solar thermal power (STP) plant consists of three subsystem; the solar field, power cycle and the electrical generator as seen in Fig. 6. 1. The Rankine cycle is the most common and competitive power cycle in solar thermal power plants [231]; so it is presented in Fig. 6.1 as an example of the power cycle. The solar radiation is converted 
to heat by the solar field. This heat is transferred to the power cycle by using heat transfer fluid, where the working fluid (water or organic fluid) is evaporated. The turbine converted the thermal energy to mechanical energy which converted to electrical energy by using the generator. The different parts of the solar thermal power plant including the different types of solar field and power cycle are shown in Fig. 6. 2.

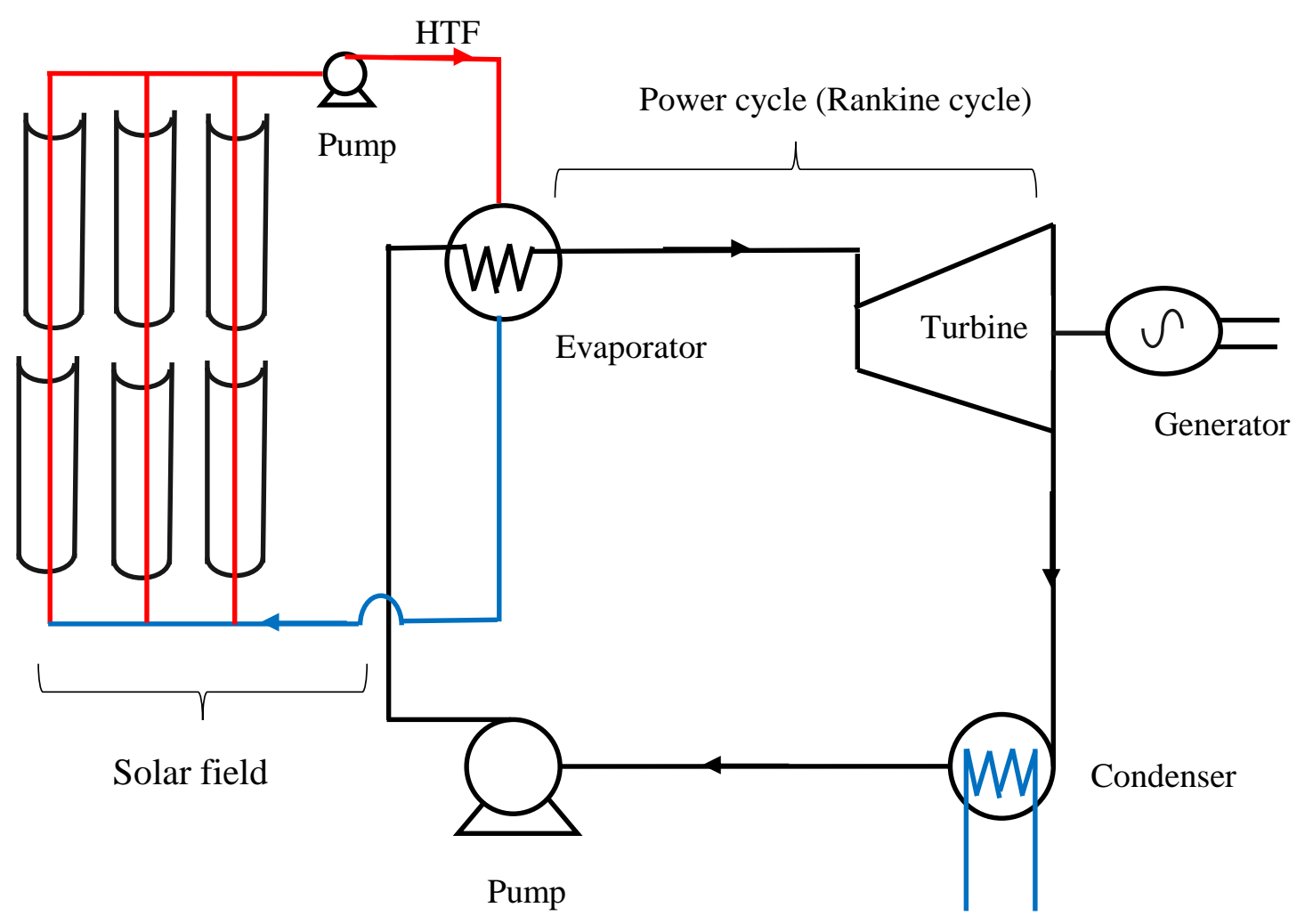

Fig. 6. 1. The solar thermal power plant $[232,233]$.

Solar collectors (flat plate or evacuated tube solar collector) can be used in low temperature solar power plant. Whereas the concentrating solar power such as solar tower, parabolic trough collector, and linear Fresnel reflector are used in a high temperature solar power plant. Two configurations of a solar field can be used: in the first, the vapor is generated inside the absorber tubes of the collector which is called direct vapor generation 
(DVG). In the second configuration, heat transfer fluid (HTF) is heated inside the absorber tube of the collector then it is used to generate the vapor inside a heat exchanger as displayed in Fig 6.1 where in this configuration, the HTF is used. The selection of heat transfer fluid is considered the key point of improving the CSP performance. 


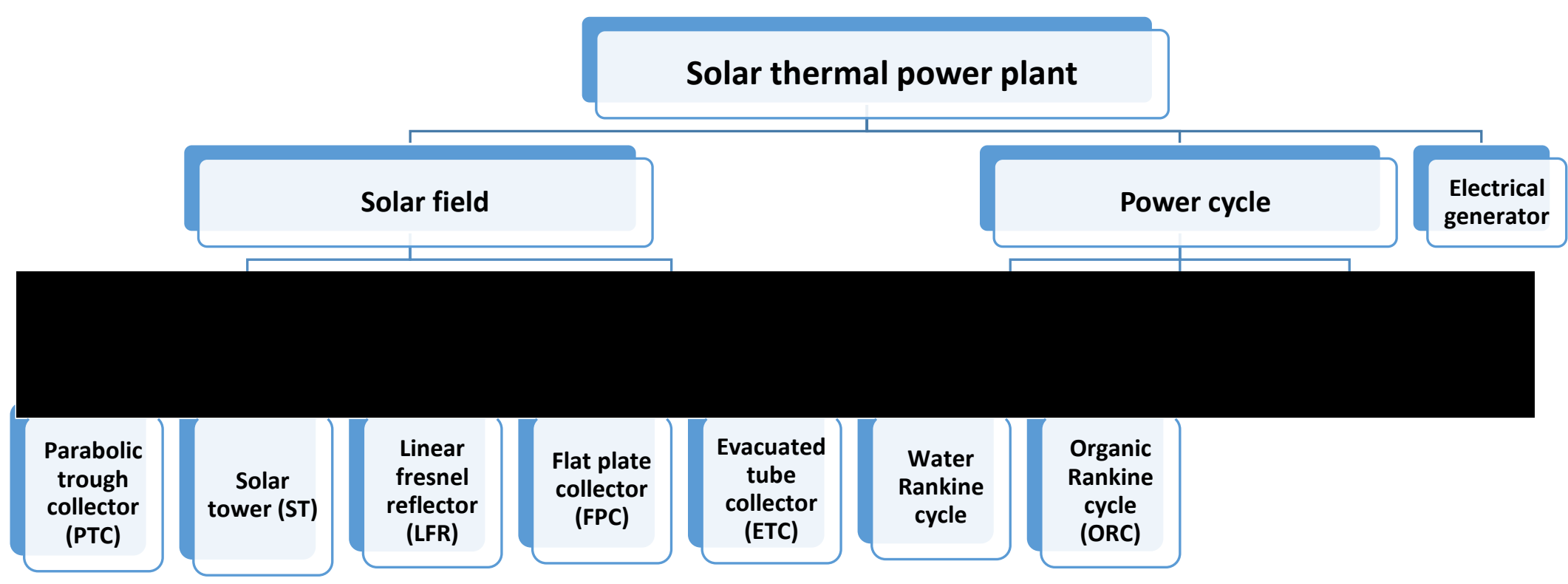

Fig. 6. 2. A schematic diagram of the different parts of the solar thermal power plant including the different strategies of solar field and power cycle [232]. 


\subsubsection{Review of developments of solar field}

The solar field circuit consists of the solar collector or CSP, heat exchanger and the heat transfer fluid which transfers the thermal energy from the solar field to the power cycle working fluid. This section focuses on the selection of the concentrating solar power and heat transfer fluid.

So far, there are four types CSP systems; the parabolic trough collector (PTC) and solar power tower (ST), parabolic solar dishes, linear Fresnel reflector (LFR). However, the PTC and solar power tower (ST) are the most dominant CSP systems [234].

The parabolic-trough system is the most widely used CSP technology as $76.57 \%$ of the CSP plants used PTC [235]. There are 77 operational PTC plants around the world so far. Most of these plants are located in United States and Spain. Five PTC plants located in the Middle East; two in Morocco, one in Algeria, one in Egypt, one in the United Arab Emirates. In addition, a PTC plant of capacity $43 \mathrm{MW}$ is under construction in Saudi Arabia. Kuwait is also planning to build PTC plant [234].

Large flat mirrors are used in the ST plants to reflect the solar radiation to a receiver located on the top of the centrally located tower [236]. The materials of the receiver are generally ceramics or metals that are stable at operating temperatures. Three ST Plants are constructed in California, USA in 2010 to generate 392 MW [234]. Fig. 6. 3 shows 10 MW ST plant installed at Seville, Spain [234]. 


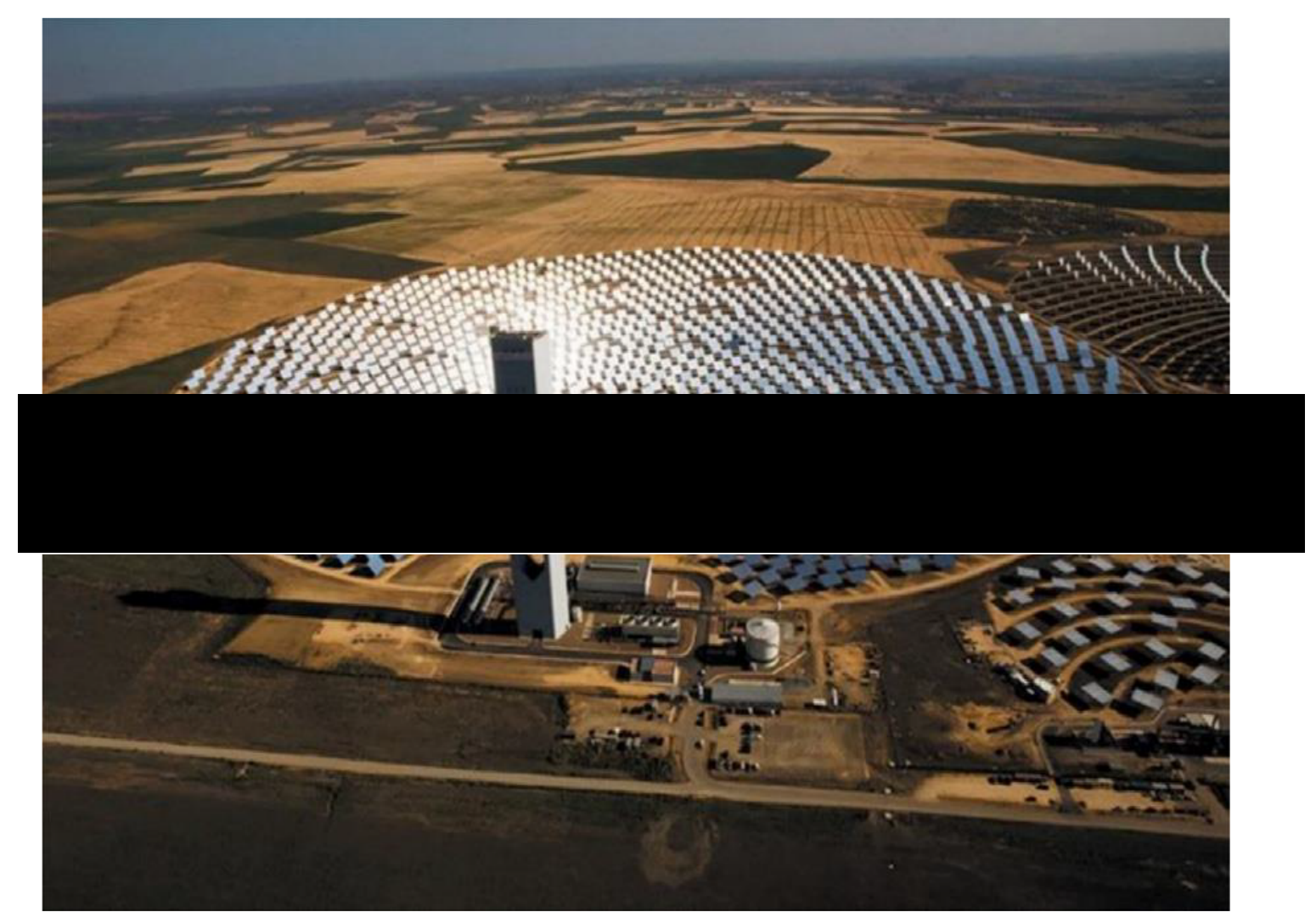

Fig. 6. 3. 10 MW ST plant located at Seville, Spain [234].

Technical and economic feasibility of integrating the main CSP technologies (PTC, SPT, LFR) with cogeneration gas turbine systems under the weather condition of Dhahran, Saudi Arabia are theoretically studied by Mokheimer et al. [237]. They used HERMOFLEX with PEACE software to simulate the performance of the proposed CSP plants. The simulation results showed that the integration of PTC and LFR are more economically and environmentally feasible.

A hybrid concentrating solar-coal power plant is theoretically studied by Zhu et al. [238]. The PTC and SPT are compared in their proposed system. They concluded that the utilization of ST is better than PTC in their proposed hybrid plant based on all key indicators (solar-to-electricity efficiency, generation efficiency, and coal consumption rate). 
In order to minimize the cost of electric power production of the CSP plant in hot arid regions, the system advisor model (SAM) software is used by Trabelsi et al. [239] to optimize the size of PTC and steam turbine. They also investigated the utilization of therminol VP-1 and molten salt as heat transfer fluid in the solar circuit. They found that the CSP plant is operated more efficient with molten salt as the HTF.

The ST plant powered by the supercritical $\mathrm{CO}_{2}$ cycle is investigated by Polimeni et al. [240] when the liquid sodium is used as heat transfer fluid. They also compare the liquid sodium with two types of HTfs; solar salt $\left(60 \% \mathrm{NaNO}_{3} / 40 \% \mathrm{KNO}_{3}\right)$ and $\mathrm{KCL}-$ $\mathrm{MgCl}_{2}$. The results showed that the best performance is obtained when the liquid sodium is used as the HTF.

\subsubsection{Techno-economic analysis for the solar power in the Middle East}

SAM (system advisor model) is used by Abbas et al. [241] in order to evaluate the solar parabolic trough collector power plant. The energetic and economic performances of the plant such as monthly and annual energy production, and Levelized cost of energy (LCOE) are investigated. They selected four typical sites in Algeria (Tamanrasset, Bechar, Ghardia and Alger) to cover the maritime in the north and semi-arid to arid in the middle and the south climate conditions. The data of the four locations are summarized in Table 6.1. 
Table 6. 1. The data of Tamanrasset, Bechar, Ghardia and Alger sites [241].

\begin{tabular}{lllll}
\hline Parameter & Tamanrasset & Bechar & Ghardia & Alger \\
\hline Latitude & $22^{\circ} 47^{\prime} \mathrm{N}$ & $31^{\circ} 37^{\prime} \mathrm{N}$ & $32^{\circ} 4^{\prime} \mathrm{N}$ & $36^{\circ} .45^{\prime} \mathrm{N}$ \\
Longitude & $5^{\circ} 31^{\prime} \mathrm{E}$ & $2^{\circ} 14^{\prime} \mathrm{W}$ & $3^{\circ} 08^{\prime} \mathrm{W}$ & $3^{\circ} 00^{\prime} \mathrm{E}$ \\
Altitude (m) & 1377 & 772 & 468 & 116 \\
Annual solar energy $\left(\mathrm{kWh} / \mathrm{m}^{2}\right)$ & 2691 & 2417 & 1800 & 1517 \\
Average ambient Temperature $\left({ }^{\circ} \mathrm{C}\right)$ & 21.7 & 20.9 & 21.3 & 17.8 \\
Average wind speed $(\mathrm{m} / \mathrm{s})$ & 3.2 & 4.4 & 3.7 & 2.5 \\
\hline
\end{tabular}

The SAM software has been used to simulate 100 MW power plant based on PTC system considered in four locations. They used PTC model LS-3 (LUZ solar collector, third generation). In their design, the PTCs are arranged in 210 rows, each row has an aperture area of $4360 \mathrm{~m}^{2}$ (the total area is $915,600 \mathrm{~m}^{2}$ ).

They found that the LCOE generated by the solar PTC plant at Tamanrasset and Bechar are $0.1193 \$ / \mathrm{kWh}$ and $0.133 \$ / \mathrm{kWh}$, respectively. These results confirm the conclusion obtained by Abbas et al. [242] that the Tamanrasset is the most promising site for solar thermal power plant.

Computer simulation code of PTC was developed by Mokheimer et al. [243] using Engineering Equations Solver (EES). In their design, the PTCs is fixed on steel structure with tracking system. They introduced also a detailed cost analysis of their proposed system. They investigated the thermal performance of the PTCs under the weather condition of Dhahran city (Latitude $26^{\circ} 267^{\prime} \mathrm{N}$ Longitude $50^{\circ} 15^{\prime} \mathrm{E}$ ), Saudi Arabia. They 
selected this city as it is located in MENA region where more than $35 \mathrm{GW}$ of CSP plants will be installed before 2040. Their simulation focuses on the solar field only which is based on the PTC. Two types of the PTC are considered in the simulation; Euro Trough solar collector (ET-100) and LS-3. They concluded that the cost rapidly decreases when the solar field size increases from 10 hectares to 60 hectares, after that the cost gradual decreases with increasing the solar field size. Therefore, they recommended that using the PTC in high capacity CSP plants.

Thermodynamic, economic and environmental analysis of solar PTC power plants with and without using thermal energy storage (TES) are introduced by Boukelia et al. [244]. Eight different configurations of solar PTC power plants with two different working fluids (Therminol VP-1 and molten solar salt), with and without using TES and/or backup fuel system are designed in order to generate $50 \mathrm{MWe}$. In the cases of using TES, two tanks of solar salt are used as latent thermal storage. The power block is assumed to be Rankine cycle using water as working fluid. SAM software is used to simulate the eight designs and evaluate their economic and environmental impacts under the weather condition of Bechar, Algeria. The PTCs are arranged in 4 rows, each row has a total length equal $100 \mathrm{~m}$ and includes 12 module of aperture width $5 \mathrm{~m}$. The plant used the molten solar salt as HTF with using TES and fossil fuel backup system (FBS) exhibits the highest overall energy efficiency $(18.48 \%)$ and the lowest LCOE $(0.0759 \$ / \mathrm{kWh})$ among the eight proposed configurations as clearly seen in Table 6.2. Based on the results presented in Table 6.2, it is not recommended that that using the TES in PTC solar thermal power plants without using FBS as this increases the LCOE whatever the used HTF is. 
Table 6. 2. The LCOE of different configurations [244].

\begin{tabular}{|c|c|c|c|c|c|c|c|c|c|c|}
\hline & \multicolumn{8}{|c|}{ Configuration } \\
\hline & & & 1 & 3 & 3 & 4 & 5 & 6 & 7 & 8 \\
\hline \multirow{4}{*}{$\begin{array}{c}\text { Technology } \\
\text { included }\end{array}$} & \multirow[t]{2}{*}{ HTF } & Therminol VP-1 & $\checkmark$ & $\begin{array}{llll} & & & \end{array}$ & $\checkmark$ & $\checkmark$ & & & & \\
\hline & & Molten salt & & & & & $\checkmark$ & 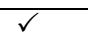 & $\checkmark$ & $\checkmark$ \\
\hline & & TES & & $\checkmark$ & & $\checkmark$ & & 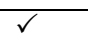 & & $\checkmark$ \\
\hline & & FBS & & & $\checkmark$ & $\checkmark$ & & & $\checkmark$ & $\checkmark$ \\
\hline & \multicolumn{2}{|c|}{$\operatorname{LCOE}(\$ / \mathrm{kWh})$} & 0.935 & 0.116 & 0.078 & 0.091 & 0.096 & 0.010 & 0.0774 & 0.075 \\
\hline
\end{tabular}

In 2013, the United Arab Emirates installed its first CSP of capacity 120 MWe (Shams-1) which is considered the largest single unit CSP in the world. Shams-1 based on PTC technology with aperture area of $627840 \mathrm{~m}^{2}$. Water is used as working fluid in the power cycle with dray cooling system. The molten salt used was HTF as well as TES. SAM software was used by Poghosyan and Hassan [245] to simulate Shams-1 and analyzing the technical and economic aspects of the plant with using TES system. They used the weather condition of Abu Dhabi city, UAE, and concluded that LCOE was 0.23 $\$ / k W h$ when booster heater and TES systems are implemented.

Mathematical model Kalina cycle power plant powered by PTC was developed by Ashouri et al. [246] using Matlab and EES software. The solar field consists of 750 PTCs using Therminol VP-1 oil as HTF. The length of each collector is $1 \mathrm{~m}$ and the aperture width is $0.7 \mathrm{~m}$. the ammonia water mixture was used as working fluid in the power cycle the cycle. The power plant includes also sensible heat storage tank using thermal oil. The LCOE of the proposed system was found to be $0.4274 \$ / \mathrm{kWh}$. 
Solar thermal power plant of capacity 50 MWe was investigated by Boukelia et al. [247] by using SAM software and artificial neural network (ANN) models. Their proposed system consists of PTCs using Therminol VP-1 as HTF, FBS, TES and Rankine cycle using water as working fluid. The solar salt was used as latent heat thermal storage in the TES. Firstly, SAM software was used to simulate their proposed system using the typical metrological year data of Bechar, Algeria. Techno-economic analysis was also performed by using SAM. Three ANN models are tested in order to select the best approach to predict and optimize the proposed system. The optimized LCOE was found to be $0.0888 \$ / \mathrm{kWh}$.

The later proposed system was also investigated by Boukelia et al. [248] when the molten salt is used as HTF. The simulation results obtained from SAM and ANN model are compared to the configuration based on Therminol VP-1 as HTF under the same weather condition. They found that the molten salt is the best choice as HTF in their study as it achieves LCOE of $0.07 \$ / \mathrm{kWh}$ compared to $0.083 \$ / \mathrm{kWh}$ when the Therminol VP-1 was used.

Techno-economic analysis for 50 MWe CSP plant using PTCs was presented by Trabelsi et al. [249]. In the solar field, they used PTCs with total aperture area of 510,120 $\mathrm{m}^{2}$ arranged in 156 row, each row includes 4 collectors. A mixture of biphenyl $\left(\mathrm{C}_{12} \mathrm{H}_{10}\right)$ and phenoxybenzene $\left(\mathrm{C}_{12} \mathrm{H}_{10} \mathrm{O}\right)$ is used as $\mathrm{HTF}$ as it can provide operating temperatures upto $400{ }^{\circ} \mathrm{C}$ while its freezes point is $12{ }^{\circ} \mathrm{C}$. They used solar salt as latent heat thermal storage. They used Rankine cycle with water as working fluid. The dry and wet cooling are also investigated. Their proposed plant is simulated by SAM software under the weather conditions of Tataouine, south region of Tunisia. The LCOE of the proposed 
system in the cases of wet and dry cooling are found to be 0.2139 and $0.1868 € / \mathrm{kWh}$, respectively.

Recently, Trabelsi et al. [239] used SAM software to simulate the CSP plant using PTC when two different types of HTF are used; Therminol VP-1 and Molten Salt. They found that the LCOE of the plant is $0.2017 \$ / \mathrm{kWh}$ and $0.1615 \$ / \mathrm{kWh}$, when the Therminol VP1 and molten salt are used as HTF, respectively. Using Molten Salt as HTF achieves also increment in overall energy efficiency of $6 \%$ compared to Therminol VP-1.

PTC solar power plant of capacity 100 MWe with TES was designed and optimized by Praveen et al. [250]. The Hitec Solar Salt was used as HTF as well as latent heat TES. They used SAM software to simulate the proposed system under the weather condition of two sites in the Middle East; Abu Dhabi, UAE and Aswan, Egypt. They found that the annual energy generation of the optimized solar plant is $392.587 \mathrm{GWh}$ and 353.69 GWh for Aswan and Abu Dhabi sites, respectively. Whereas the LCOE of the optimized solar plant was 0.06 and $0.05 \$ / \mathrm{kWh}$ for Aswan and Abu Dhabi sites, respectively.

Two configurations of solar tower power plants are simulated by Abbas et al. [251]. They used the molten salt as HTF in the first configuration while the direct steam generation technique is used in the other configuration. The energy production and economic analysis are carried out by SAM software. The design of the two ST plants are presented in Table 6.3 . 
Table 6. 3. The design parameters of the molten salt and DSG ST plants [251].

\begin{tabular}{lll}
\hline Parameter & Molten salt & Direct steam generation \\
\hline Heat transfer type & Molten salt & Steam \\
Total field reflector area $\left(\mathrm{m}^{2}\right)$ & $141,198.6$ & 137,585 \\
Total land area $\left(\mathrm{m}^{2}\right)$ & $683,905.9$ & 712,585 \\
Number of heliostat & 978 & 985 \\
Heliostat area $\left(\mathrm{m}^{2}\right)$ & 144.367 & 139.68 \\
Tower height $(\mathrm{m})$ & 180 & 150 \\
Receiver diameter $(\mathrm{m})$ & 15 & 8 \\
Cooling system & Air cooled & Air cooled \\
\hline
\end{tabular}

The results showed that the LCOE for the DSG and molten salt as HTF in ST plants are 0.1972 and $0.2863 \$ / \mathrm{kWh}$, respectively.

From the results reviewed in this work, it is found that the PTC is the most used technology for CSP plants in the Middle East as clearly seen in Table 6.4. Molten salt and Therminol VP-1 are the most HTFs used in the CSP in the Middle East as observed in Table 6.4. Little studies have been conducted to compare the different technologies of CSP at the same weather conditions in the Middle East. THERMOFLEX with PEACE simulation software has been used by Mokheimer et al. [237] in order to select the best CSP technology to be integrated with the fossil fuel gas turbine. Three CSP technologies; PTC, ST, LFR integrated individually with different gas turbine sizes (30-150 MWe) are studied under Dhahran weather conditions. In order to reach at the optimal LCOE, comparative analysis has been conducted for all possible configurations of the integrated CSP gas turbine plant. The simulation results showed that the integration of LFR with the steam side of a gas turbine cogeneration plant of capacity $50 \mathrm{MWe}$ is the best among the proposed configurations as it gives a LCOE of $0.051 \$ / \mathrm{kW}$. While both of PTC and LFR 
are recommended at high capacity $(150 \mathrm{MWe})$. According to the obtained results, the best location to install this optimal configuration in Saudi Arabia is Jazan city. A CSP-wind hybrid power plant of capacity $50 \mathrm{MWe}$ is theoretically investigated by Ayadi and Alsalhen [252]. Their proposed system consists of PTCs in the solar field, TES using solar salt, power cycle with steam turbine and wind turbine as shown in Fig. 6. 4. The hybrid plant was simulated and optimized using TRNSYS 17 energy simulation software. The LCOE of the proposed hybrid plant was found to be $0.041 \$ / \mathrm{kWh}$, compared to 0.082 $\$ / \mathrm{kWh}$ in the case of using CSP only.

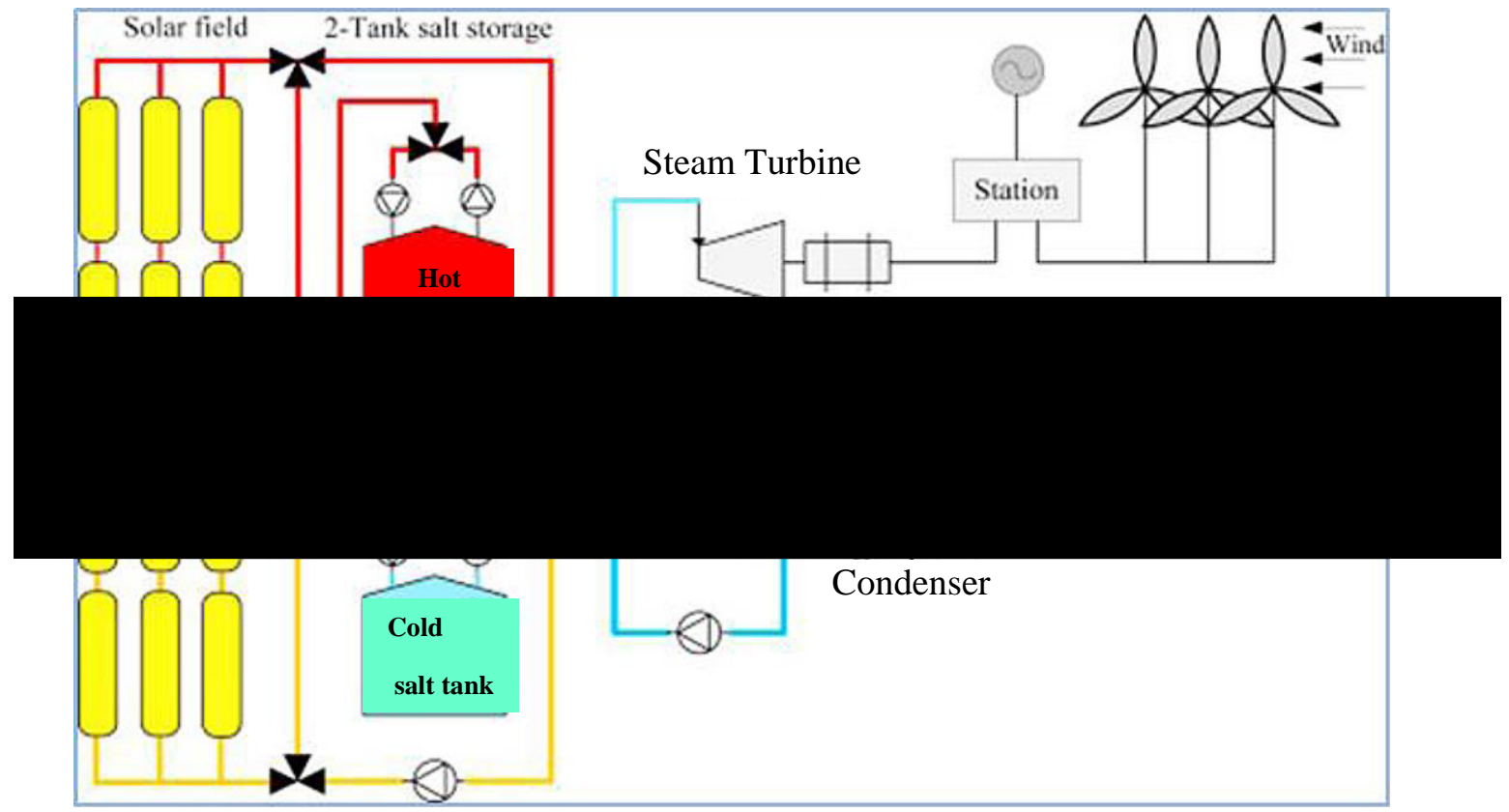

Fig. 6. 4. Hybrid CSP-Wind power plant diagram [252].

From the data presented in this work, SAM was found to be the most common software used to simulate and optimize the CSP plants in the Middle East. This software is developed by the National Renewable Energy Laboratory (NREL), Golden, Colorado, USA. The computational algorithm flow chart of the CSP on SAM software is shown Fig. 6. 5. 
Table 6. 4. The CSP plants based on PTC and ST.

\begin{tabular}{|c|c|c|c|c|c|c|c|}
\hline \multirow[t]{2}{*}{ Type of CSP } & \multirow{2}{*}{$\begin{array}{l}\text { Plant capacity } \\
(\mathrm{MWe})\end{array}$} & \multirow{2}{*}{\multicolumn{2}{|c|}{ Configuration }} & \multicolumn{2}{|c|}{ Location } & \multirow{2}{*}{$\begin{array}{l}\mathrm{LCOE} \\
(\$ / \mathrm{kWh})\end{array}$} & \multirow[t]{2}{*}{ Ref. } \\
\hline & & & & City & Country & & \\
\hline \multirow[t]{25}{*}{ PTC } & \multirow{4}{*}{100} & \multirow{4}{*}{\multicolumn{2}{|c|}{$\begin{array}{l}\text { Therminol VP-1 as HTF and solar salt as latent heat } \\
\text { thermal storage. }\end{array}$}} & Tamanrasset & \multirow{4}{*}{ Algeria } & 0.1193 & \multirow[t]{4}{*}[241]{} \\
\hline & & & & Bechar & & 0.133 & \\
\hline & & & & Ghardia & & 0.213 & \\
\hline & & & & Alger & & 0.2958 & \\
\hline & \multirow[t]{8}{*}{50} & \multicolumn{2}{|l|}{ Therminol VP-1 as HTF } & \multirow{8}{*}{ Bechar } & \multirow{8}{*}{ Algeria } & 0.0935 & \multirow[t]{8}{*}[244]{} \\
\hline & & \multicolumn{2}{|l|}{ Therminol VP-1 as HTF with TES } & & & 0.1162 & \\
\hline & & \multicolumn{2}{|l|}{ Therminol VP-1 as HTF with FBS } & & & 0.0785 & \\
\hline & & \multicolumn{2}{|c|}{ Therminol VP-1 as HTF with TES and FBS } & & & 0.0908 & \\
\hline & & \multicolumn{2}{|l|}{ Molten salt as HTF } & & & 0.0955 & \\
\hline & & \multicolumn{2}{|l|}{ Molten salt as HTF with TES } & & & 0.1029 & \\
\hline & & \multicolumn{2}{|l|}{ Molten salt as HTF with FBS } & & & 0.0774 & \\
\hline & & \multicolumn{2}{|l|}{ Molten salt as HTF with TES and FBS } & & & 0.0759 & \\
\hline & 120 & \multicolumn{2}{|c|}{ The molten salt is used as HTF as well as TES } & Abo Dhabi & UAE & 0.236 & {$[245]$} \\
\hline & - & \multicolumn{2}{|c|}{ Therminol VP-1 as HTF as well as sensible heat storage } & $\begin{array}{l}\text { Eshtehard city ( } \\
\text { latitude } 35^{\circ} 61^{\prime} \\
\mathrm{N})\end{array}$ & Iran & 0.4274 & [246] \\
\hline & 50 & \multicolumn{2}{|c|}{$\begin{array}{l}\text { Therminol VP-1 is used as HTF and solar salt as latent } \\
\text { heat thermal storage, the system includes FBS }\end{array}$} & Bechar & Algeria & 0.0888 & {$[247]$} \\
\hline & \multirow[t]{2}{*}{50} & \multicolumn{2}{|c|}{$\begin{array}{l}\text { Molten salt is used as HTF and solar salt as latent heat } \\
\text { thermal storage, the system includes FBS }\end{array}$} & & & 0.07 & \multirow[t]{2}{*}{248} \\
\hline & & \multicolumn{2}{|c|}{$\begin{array}{l}\text { Therminol VP-1 is used as HTF and solar salt as latent } \\
\text { heat thermal storage, the system includes FBS }\end{array}$} & Bechar & Algeria & 0.083 & \\
\hline & \multirow[t]{2}{*}{50} & \multirow{2}{*}{$\begin{array}{l}\text { Mixture of Biphenyl }\left(\mathrm{C}_{12} \mathrm{H}_{10}\right) \text { and } \\
\text { Phenoxybenzene }\left(\mathrm{C}_{12} \mathrm{H}_{10} \mathrm{O}\right) \text { is used } \\
\text { as HTF, solar salt as latent heat } \\
\text { thermal storage. }\end{array}$} & Dry cooling & Tataouine & Tunisia & 0.2139 & {$[249]$} \\
\hline & & & Wet cooling & & & 0.1868 & \\
\hline & 100 & $\begin{array}{l}\text { Therminol VP-1 is used as HTF an } \\
\text { heat thermal storage, the system incl }\end{array}$ & $\begin{array}{l}\text { solar salt as latent } \\
\text { des FBS }\end{array}$ & Tataouine & Tunisia & 0.2017 & {$[239]$} \\
\hline & & $\begin{array}{l}\text { Molten salt is used as HTF and sol } \\
\text { thermal storage, the system includes }\end{array}$ & $\begin{array}{l}\text { ar salt as latent heat } \\
\text { FBS }\end{array}$ & & & 0.1615 & \\
\hline & 100 & The Hitec Solar Salt is used as HTF & as well as latent heat & Aswan & Egypt & 0.06 & {$[250]$} \\
\hline & & TES & & Abu Dhabi & UAE & 0.05 & \\
\hline & 50 & Ras-Tanura conventional gas turbine & cogeneration power & Dhahran & Saudi & 0.0651 & {$[237]$} \\
\hline & 150 & plant & & & Arabia & 0.0387 & \\
\hline
\end{tabular}




\begin{tabular}{|c|c|c|c|c|c|c|}
\hline & 50 & $\begin{array}{l}\text { Molten salt is used as HTF, wet cooling technology, FBS } \\
\text { and TES are used }\end{array}$ & Hassi R'mel & Algeria & 0.2412 & {$[253]$} \\
\hline \multirow[t]{5}{*}{ ST } & \multirow[t]{2}{*}{30} & Molten salt is used as HTF & \multirow[t]{2}{*}{ Tamanrasset } & \multirow[b]{2}{*}{ Algeria } & 0.2863 & \multirow[b]{2}{*}[251]{} \\
\hline & & DSG technique is used & & & 0.1972 & \\
\hline & 50 & \multirow{2}{*}{$\begin{array}{l}\text { Ras-Tanura conventional gas turbine cogeneration power } \\
\text { plant }\end{array}$} & \multirow[t]{2}{*}{ Dhahran } & \multirow{2}{*}{$\begin{array}{l}\text { Saudi } \\
\text { Arabia }\end{array}$} & 0.0673 & \multirow[t]{2}{*}{237} \\
\hline & 150 & & & & 0.0768 & \\
\hline & 50 & $\begin{array}{l}\text { Molten salt is used as HTF, wet cooling technology, FBS } \\
\text { and TES are used }\end{array}$ & Hassi R'mel & Algeria & 0.2357 & {$[253]$} \\
\hline \multirow[t]{2}{*}{ LFR } & 50 & \multirow{2}{*}{$\begin{array}{l}\text { Ras-Tanura conventional gas turbine cogeneration power } \\
\text { plant }\end{array}$} & \multirow[t]{2}{*}{ Dhahran } & \multirow{2}{*}{$\begin{array}{l}\text { Saudi } \\
\text { Arabia }\end{array}$} & 0.0509 & \multirow[t]{2}{*}{237} \\
\hline & 70 & & & & 0.0364 & \\
\hline
\end{tabular}




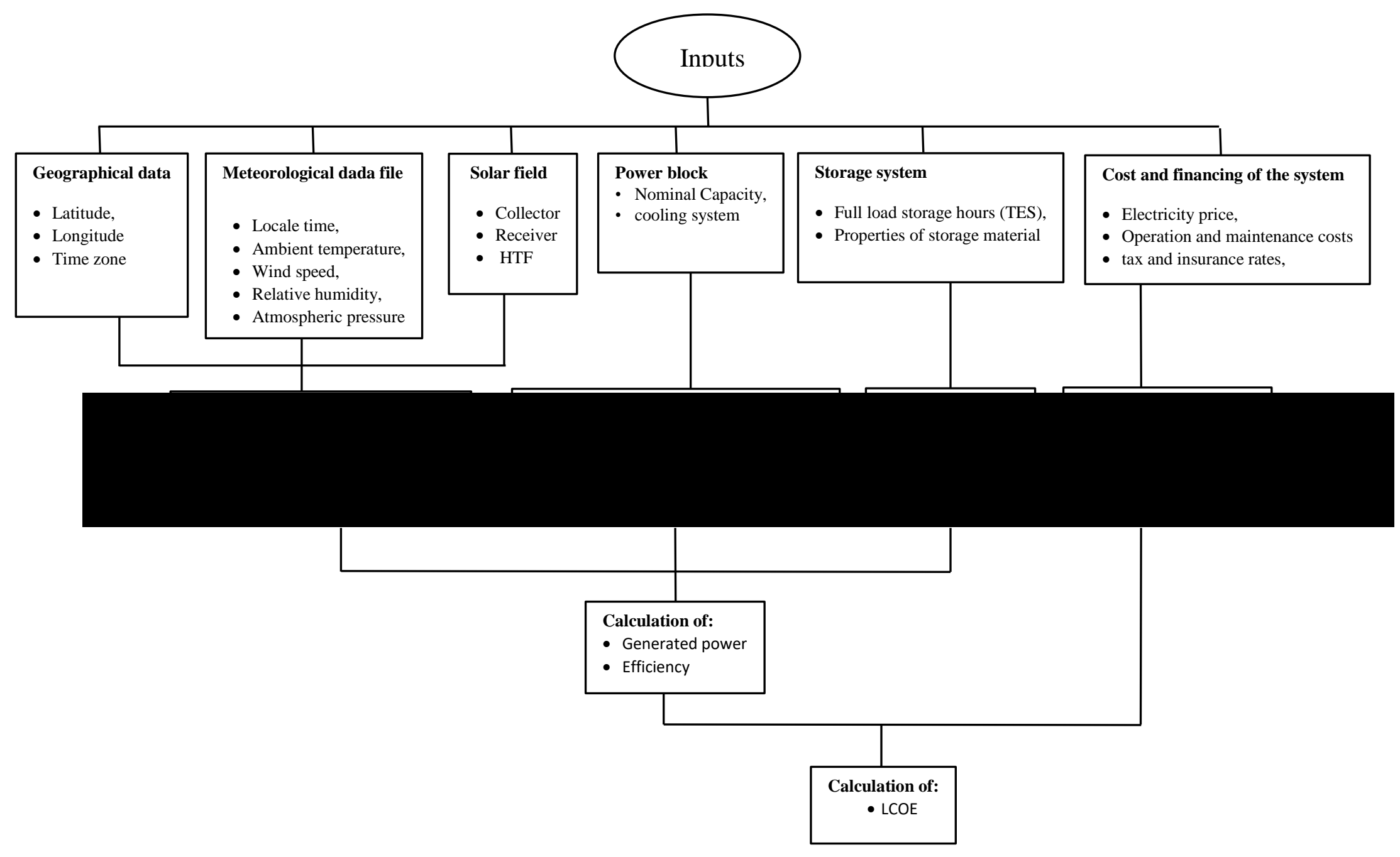

Fig. 6. 5. Flow chart of the computational algorithm of the CSP on SAM software [249]. 


\subsection{Review on Biomass energy plant}

The biomass power plants are widely used in several countries around the world; where in Italy as example, 115 biomass power plants were used in 1995 for electrical power generation [254].

There are mainly three available types of power generation from biomass; biomass combustion-turbine cycle, gas turbine, hybrid systems [255]. The direct-combustion boiler/steam turbine technology is not a good solution as it needs large-scale collection and transportation over large areas. The average size of existing bio-power plants is 10$20 \mathrm{MW}$ (the largest is nearly $75 \mathrm{MW}$ ). Many older wood-burning steam power plants produce steam at temperatures below $400{ }^{\circ} \mathrm{C}$. Those plants operate at an electric efficiency of $10-15 \%$ when backpressure turbines are used to provide both power and process steam, or of 15-20\% with condensing turbines (no process steam supply). In more modern plants, especially those of size over $50 \mathrm{MW}$, steam temperatures up to $480{ }^{\circ} \mathrm{C}$ have been used and electric efficiency around $25 \%$ can be reached [256, 257].

Gas turbine (GT) appear to be more interesting in terms of efficiency, size, cost, and fuel flexibility. Two radically different options can be found in the literature [258].

The first option, shown in Fig. 6. 6, is based on a gasifier that produces biofuel to be used in the combustion chamber of a gas turbine (BIG/GT), or in a combined cycle plant $(\mathrm{BIG} / \mathrm{CC})$. The integration of gasification and combined cycle gas turbine plants (BIG/CC) offer high efficiencies at a relatively small scale (30-50 MW). They are expected to achieve efficiencies of about $40 \%$ for wood based biomass and atmospheric gasification. Among the demonstration units that are under consideration, the largest one (for $32 \mathrm{MW}$ electrical) was built in Bahia, Brazil [13]. 


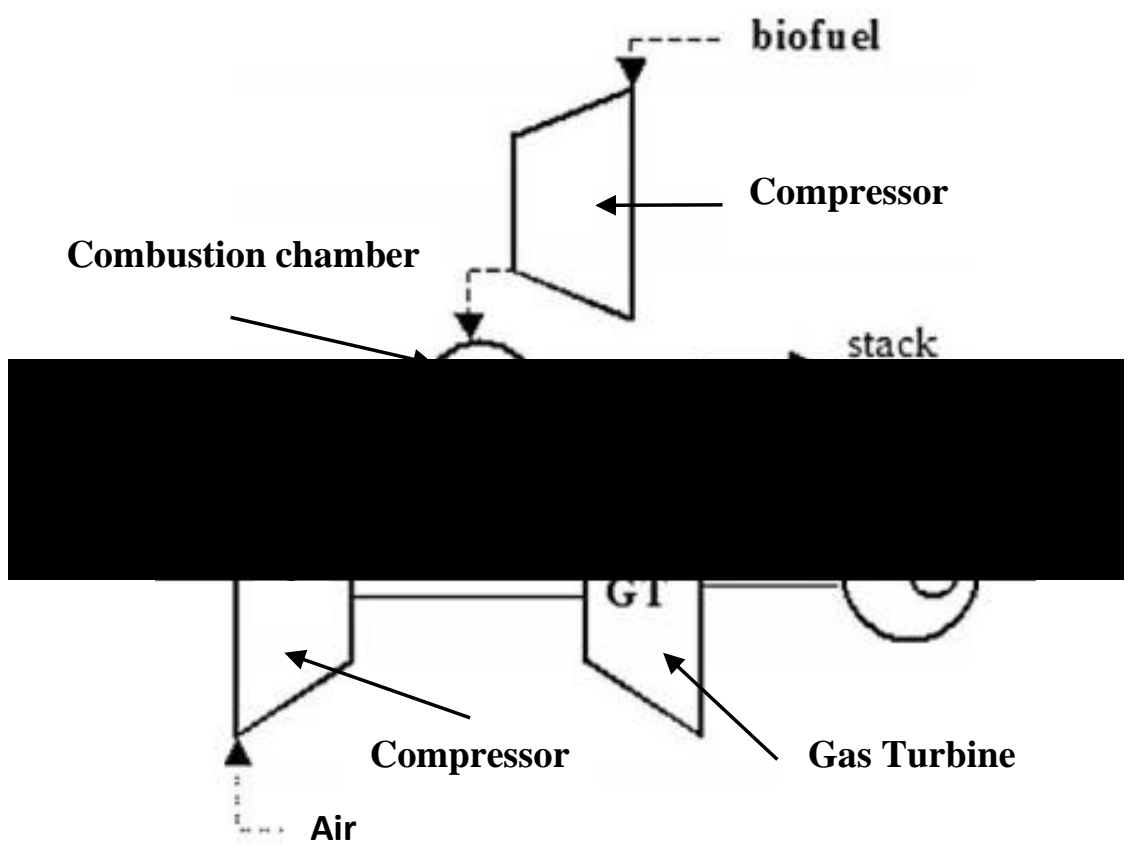

Fig. 6. 6. Schematic of the BIG/GT plant [258].

In the second option, the compressed air is heated indirectly in a heat exchanger and the biomass or the derived biofuel are directly burnt in an external combustor. Fig. 6. 7 provides a scheme of such a plant known as externally fired gas turbine combined cycle (EFGT/CC) where the hot gases pass at first through a heat exchanger, where the compressed air is heated to the turbine inlet temperature, and then through a heat recovery steam generator (HRSG), where superheated steam is produced. The topping cycle is basically a conventional gas turbine cycle and the combustion chamber, is replaced by a heat exchanger. The gas turbine cycle efficiency is up to $30 \%$; while, the EFGT/CC plant can reach an efficiency higher than $40 \%$.

Different solutions proposed in the literature suggest a combination of a gas turbine plant with a biomass burner in repowering configurations. In this case, the steam from the incineration plant is passed to the HRSG, where it is superheated and then directed to the steam turbine [259]. 


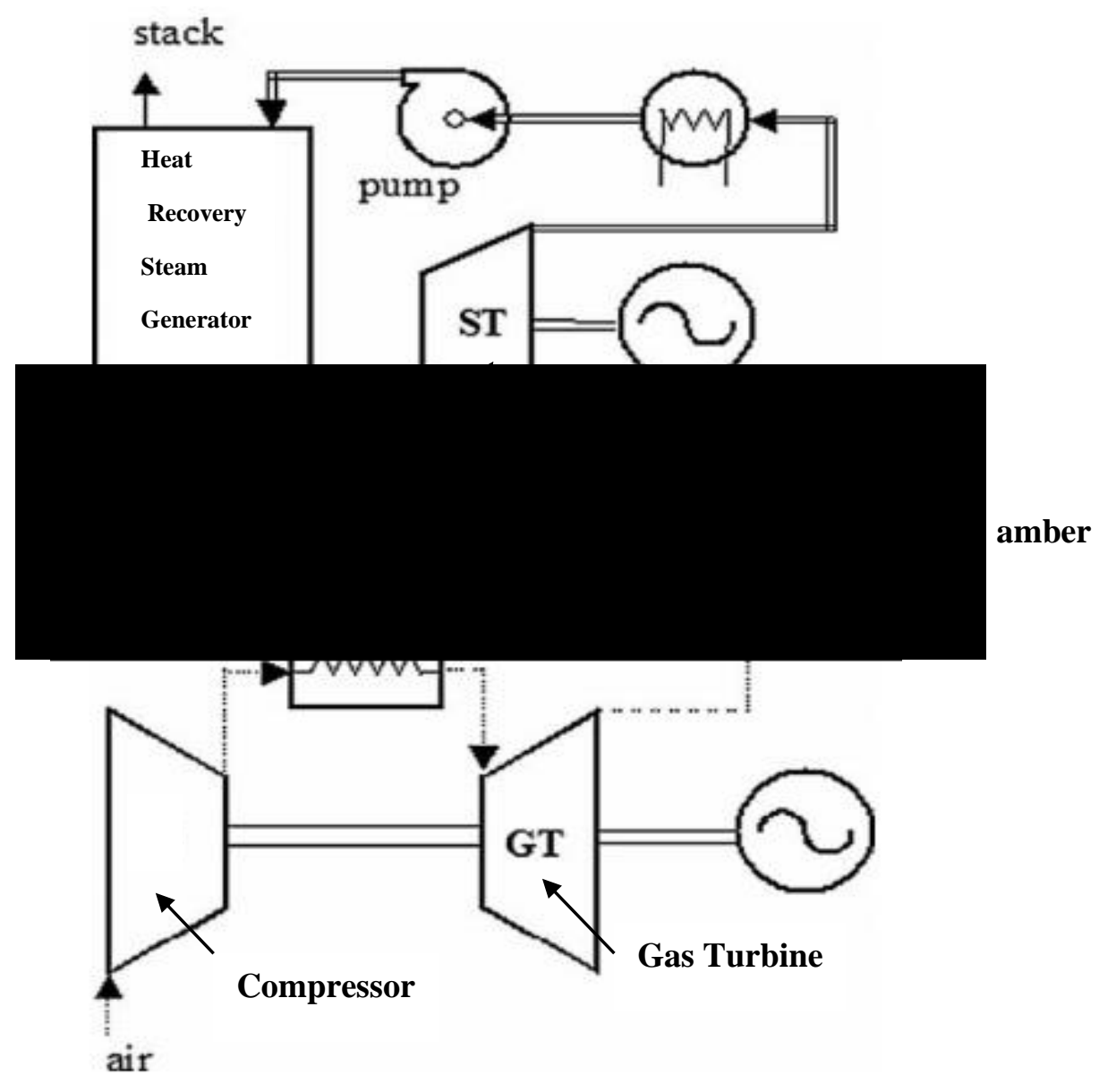

Fig. 6. 7. Schematic of the EFGT/CC plant [258].

A feasibility study of a small $(250 \mathrm{kWth})$ steam gasification fluidized bed and hot gas conditioning system (an actual employment plant situated near Rome, Italy) was presented by Villarini et al. [260]. Their study includes biomass availability and energy consumption analysis, biomass and gasification tests, power plant sizing, using experimental data and simulation. Finally, an economic analysis was carried out by varying the main economic parameters. Olive pruning are confirmed as very suitable, and in this case, able to satisfy the farm energy consumption. Global electrical efficiency of $25 \%$ can be achieved without any auxiliary fuel consumption. The investment and biomass costs were found $8000 € / \mathrm{kW}$ and $100 € / \mathrm{t}$, respectively. 
The environmental compatibility of a biomass plant constructed to produce both electricity and heat in Piedmont city, Italy are analyzed by Deborah et al. [261]. The evaluation of environmental compatibility of the biomass plant was achieved through the environmental balance, external cost evaluation and modeling of pollutant concentrations in the surrounding area. The evaluation was conducted using the tools of mass and energy balances, and an external costs methodology was also applied in order to define the social cost of the plant. In addition, the plant potential modification to local air quality was evaluated by considering the meteorological and physical characteristics of the considered area, using a pollutant dispersion model. Several different configurations for the flue gas purification line were also considered, so that the evaluation of the costs and benefits was based on the analysis of both industrial and external costs.

A life cycle assessment was carried out by Tagliaferri et al. [262] for a biomassfired CHP plant at the Heathrow Airport energy Centre. This facility burns woodchips collected from nearby forests providing $2 \mathrm{MWe}$ of electricity and 8 MWth of thermal energy. A hot spot analysis was conducted to identify the process steps with the largest environmental impact, starting from the harvesting of the forest residue to the disposal of the boiler ash. A scenario analysis is performed to compare the impacts of the biomass plant against fossil alternatives and to identify which renewable energy sources, between biomass and MSW, should be prioritized for development and investment. The results showed a reduction in GHG emissions when using biomass, with further benefits if the bottom ash is collected and reused as a soil conditioner for land-farming or forestry. The life cycle assessment approach for a sample of biomass power plants in north Italy was also presented by Paletto et al. [263].

Recently, a life cycle inventory (LCI) is presented by Branco-Vieira et al. [264], based on real pilot-scale process data, which was scaled-up to a microalgae biomass industrial plant for biofuel production. According to this model, in order to produce $1 \mathrm{~kg}$ of biodiesel, about $12 \mathrm{~kg}$ of dried algae biomass is required. This study supports the decision-making process in biofuel production to promote the development of sustainable pilot and large-scale algae-based industry, through the identification of critical factors. 
Techno-economic analysis of a biomass gasification power plant based on forestry residues blends for electricity production in Portugal central region was performed by Cardoso et al. [265]. The economic model presents a positive prospect admitting the feasibility of setting the project in the region under current market conditions.

Recently, a biomass power plant of capacity 80 MWe was studied by Blondeau et al. [266] in order to improve the dynamic control of the combustion process. They redesign the combustion control loops, and used a virtual air flow sensors in the control system. The accurate control of the local NOx production in the furnace resulted in a decrease of these emissions by $15 \%$ with an increased stability. Their study helps in increasing the cost- effectiveness of such conversions, and facilitate the development of renewable power units able to contribute to the grid stability.

\subsection{ASPEN Modelling of Biomass energy Plant}

\subsubsection{Aspen plus modeling of biomass pyrolysis energy plant}

A pine wood fast pyrolysis and bio-oil hydro-processing plant of capacity of $72 \mathrm{MT} /$ day was developed by Shemfe et al. [267] for electric power generating using Aspen Plus process simulator. The model inputs including proximate, ultimate analysis and chemical of pine wood. Multi-step reaction kinetics of biomass pyrolysis shown in Fig. 6. 8 was implemented. 


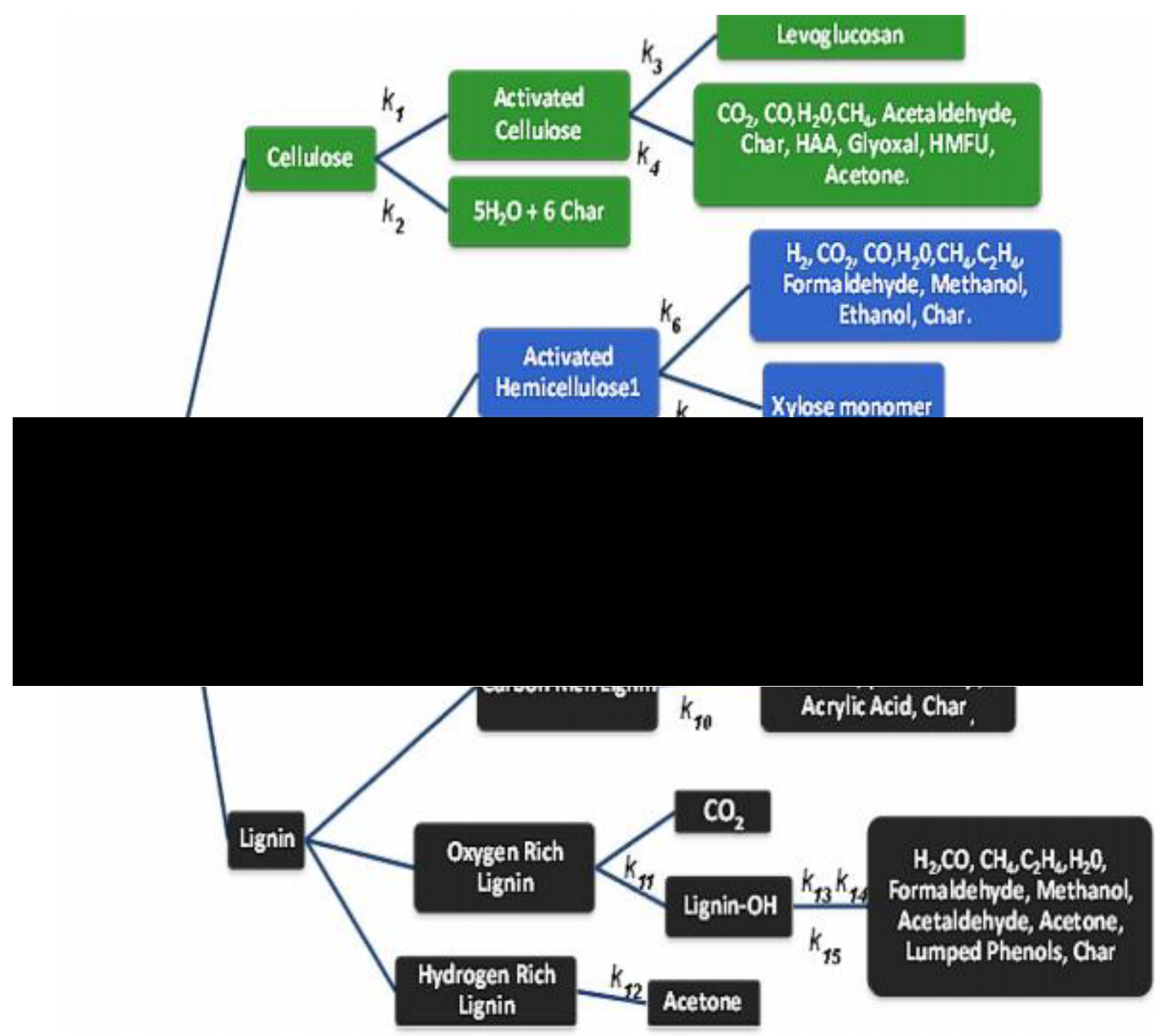

Fig. 6. 8. Multi-step reactions kinetics of biomass pyrolysis [268].

Three model blocks (PYR-DEC, PYR-FLD and PYR-RXN) were used to model a bubbling fluidized bed pyrolysis reactor. In the yield reactor (PYR-DEC), biomass decomposed into cellulose, hemicellulose and lignin. The fluidized bed (PYR-FLD) was used to model the reactor fluid dynamics with pressure drop of $150 \mathrm{mbar}$, an inert sand bed to biomass particle mass ratio of 1:1.25 and a reactor temperature of $500{ }^{\circ} \mathrm{C}$. The process heat and fluidizing gas for the fluid bed was supplied at $863{ }^{\circ} \mathrm{C}$ with a $1: 1$ mass ratio to biomass feed. The rate based chemical reactions of each biomass subcomponent were modelled by the CSTR (PYR-RXN) using multi-step reactions kinetics of biomass pyrolysis developed by Ranzi et al. [268]. The reactor products are sent into a cyclone (SP-CYC) to separate the solids particles (PYR-SD) from the mixture as seen in flow 
sheet presented in Fig. 6. 9. The combustion section is modelled by a yield reactor (CBDEC) and a Gibbs reactor (CB-BUR). Unreacted biomass separated from the cyclone is fed into the yield reactor (CB-DEC) where it is decomposed before it is fed into the Gibbs reactor (CB-BUR) along with char and non-condensable gas (NCG). The Gibbs reactor calculates the multi-phase chemical equilibrium by minimizing Gibbs free energy. A hot cyclone (ASH-SEP) was used to separate the ash from the resultant combustion gases. The resultant flue gas (FL-GAS) is fed into a splitter (GAS-SPLIT), where it is divided into two streams (PYR-FLGS) and (DRY-FLGS) which are supplying heat for both the feed nitrogen gas for pyrolysis reactor and air used for dryer. The residual flue gas heat at $800{ }^{\circ} \mathrm{C}$ is used for superheated steam generation for subsequent electric power generation. The residual heat from combustion is exchanged with water in a two-stream heat exchanger to generate superheated steam at $450{ }^{\circ} \mathrm{C}$ and 50 bar with an outlet flue gas temperature of $90{ }^{\circ} \mathrm{C}$. The superheated steam is supplied to a steam turbine (TURB), modelled at $80 \%$ isentropic efficiency and mechanical efficiency of $95 \%$ to generate electric power. The simulation results showed that $1 \mathrm{~kg} / \mathrm{s}$ of pine wood generate $0.64 \mathrm{~kg} / \mathrm{s}$ bio-oil, $0.22 \mathrm{~kg} / \mathrm{s}$ gas and $0.14 \mathrm{~kg} / \mathrm{s}$ char. It was also found that the energy required for drying and fast pyrolysis operations can be provided from the combustion of pyrolysis by-products, mainly, char and non-condensable gas with sufficient residual energy for low capacity electric power generation.

A kinetic reaction model for biomass pyrolysis processes in Aspen Plus was presented by Peters et al. [67]. The pyrolysis mechanism is divided in three phases, one decomposition phase and two pyrolysis phases. The first phase is a virtual reaction step that decomposes the biomass into cellulose, hemicellulose and lignin. The second phase represents the decomposition and volatilization of the biomass fragments, giving a high liquid yield which dominates the reaction mechanism for fast pyrolysis processes. The third phase contains the secondary cracking and charring reactions which increase gas and char yields at the expense of liquid yield, due to secondary (catalytic) cracking reactions. 


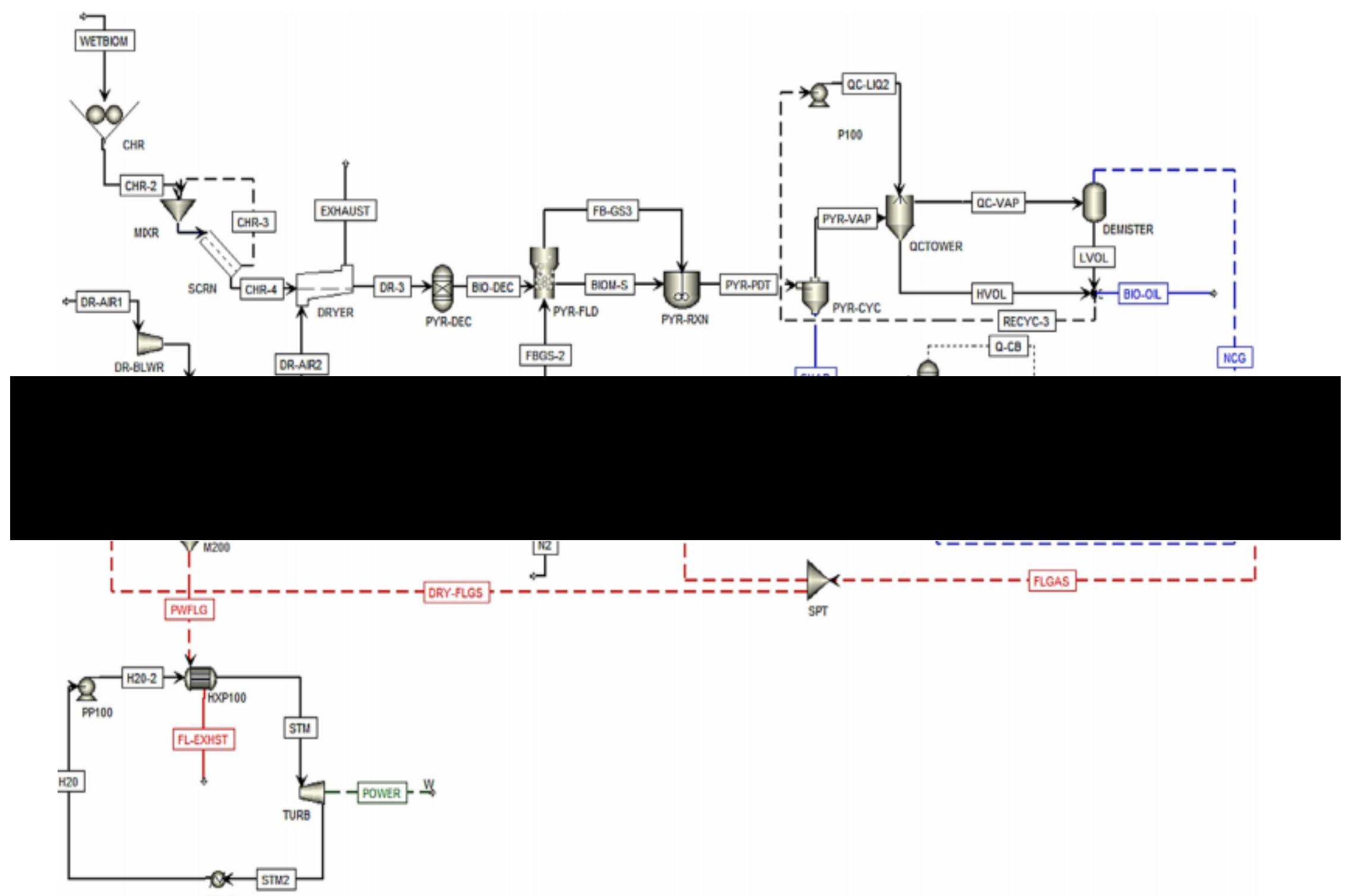

Fig. 6. 9. Aspen plus flow sheet of the biomass fast pyrolysis for electric power generation [267]. 
From the kinetic reaction modelling, the model was able to calculate the yields of the pyrolysis for a temperature range between 420 and $650{ }^{\circ} \mathrm{C}$ and for hot vapor residence times of up to $2500 \mathrm{~s}$, allowing the simulation of fast and slow pyrolysis processes for any lingo-cellulosic feedstock with known composition [38]. The inputs required by the model for calculating the pyrolysis products are the proximate and ultimate analysis and the chemical composition of the biomass. The model uses a set of 149 individual reactions that represent the volatilization, decomposition and recomposition processes of biomass pyrolysis. The bio-oil was modelled with a high level of detail, using up to 33 model compounds, which allows for a comprehensive estimation of the properties of the bio-oil and the prediction of further upgrading reactions. They also conducted a pyrolysis experiments using beech wood feedstock in order to validate the reaction model. A high agreement was found between the experimental and simulation results for the obtained fraction yields, water content and elemental composition of the pyrolysis products.

\subsection{Simulation of date palm wastes slow pyrolysis using Aspen Plus}

Indeed, serious attempts were carried out in this study in order to simulate the slow pyrolysis of the date palm wastes using Aspen Plus version 10. In these attempts, the multi-step reaction kinetics of biomass pyrolysis shown in Fig. 6.8 were used to simulate the slow pyrolysis process. Firstly, all chemical components were defined using the Aspen library as shown in Fig. 6. 10. The biomass initial temperature, pressure and charging rate were then specified as displayed in Fig. 6. 11. While the specifications of nitrogen flow are seen in Fig. 6. 12. The inputs of Aspen also include the proximate and ultimate analyses of the studied biomass material. Figure 6. 13 exhibits a photographs from Aspen Plus that show the values of proximate and ultimate analyses of Medjool stones. The slow pyrolysis in the glass fixed bed reactor was simulated by two aspen blocks where the yield reactor was used to simulate the biomass decomposition into cellulose, hemicellulose and lignin while the pyrolysis reactions were simulated using R-batch reactor. The char was separated from the pyrolysis products using the cyclone. The dry ice condenser was simulated in Aspen using the separator where the hot gasses from the cyclone was separated into bio-oil and syngas as shown in Aspen Plus simulation flow sheet displayed in Fig. 6. 14. The pyrolysis reactions performed in the R-batch were also input to Aspen as seen in Fig. 4. 15 . 


\begin{tabular}{|c|c|c|c|c|}
\hline & Component ID & Type & Component name & Alias \\
\hline > & $\mathrm{H} 2 \mathrm{O}$ & Conventional & WATER & $\mathrm{H} 2 \mathrm{O}$ \\
\hline 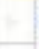 & 02 & Conventional & OXYGEN & 02 \\
\hline 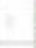 & N2 & Conventional & NITROGEN & N2 \\
\hline t & co & Conventional & CARBON-MONOXIDE & $\mathrm{CO}$ \\
\hline s & $\mathrm{CO} 2$ & Conventional & CARBON-DIOXIDE & $\mathrm{CO} 2$ \\
\hline 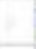 & $\mathrm{CH} 4$ & Conventional & METHANE & $\mathrm{CH}_{4}$ \\
\hline 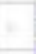 & H2 & Conventional & HYDROGEN & H2 \\
\hline 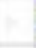 & BIOMASS & Nonconventional & & \\
\hline 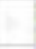 & ASH & Nonconventional & & \\
\hline 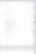 & CEuULOS & Solid & & $\mathrm{C} 6 \mathrm{H} 1005$ \\
\hline 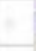 & CELU.01 & Solid & CELUULOSE-R & C6H1005-R-1 \\
\hline 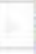 & LEVOG-01 & Conventional & LEVOGLUCOSAN & $\mathrm{C} 6 \mathrm{H} 1005-\mathrm{N} 1$ \\
\hline 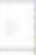 & GLYox-01 & Conventional & GIYOXAL & $\mathrm{C}_{2} \mathrm{H}_{2} \mathrm{O} 2$ \\
\hline 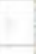 & ACETA-01 & Conventianal & ACETALDEHYDE & $\mathrm{C} 2 \mathrm{H} 4 \mathrm{O}-1$ \\
\hline 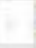 & ACETO-01 & Conventional & ACETONE & С $3 \mathrm{H} 60-1$ \\
\hline 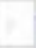 & CHAR & Nonconventional & & \\
\hline$\sqrt{2}$ & 5-HYD-01 & Conventional & 5-HYDROXYMETHYLFURFURAL & C6H603-N5 \\
\hline 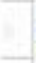 & GLYco-01 & Conventional & GIYCOL-ALDEHYDE & $\mathrm{C} 2 \mathrm{H} 402-\mathrm{D} 1$ \\
\hline 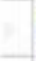 & HEMICELL & Solid & & C5H10O5 \\
\hline 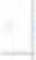 & FORMA-01 & Conventional & FORMALDEHYDE & $\mathrm{CH} 2 \mathrm{O}$ \\
\hline 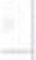 & LIGNIN & Solid & & $\mathrm{C} 8 \mathrm{H} 140$ \\
\hline$\underline{-1}$ & $\mathrm{C} 2 \mathrm{H}_{4}$ & Conventional & ETHYLENE & $\mathrm{C} 2 \mathrm{H} 4$ \\
\hline 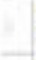 & METHANOL & Conventional & METHANOL & $\mathrm{CH} 40$ \\
\hline$\underline{-1}$ & ETHANOL & Conventional & ETHANOL & $\mathrm{C} 2 \mathrm{H} 6 \mathrm{O}-2$ \\
\hline . & PHENOL & Conventional & PHENOL & $\mathrm{C} 6 \mathrm{H} 60$ \\
\hline . & ACRYL-01 & Conventiona! & ACRYLIC-ACID & $\mathrm{C} 3 \mathrm{H} 402-1$ \\
\hline
\end{tabular}

Fig. 6. 10. Photograph from Aspen plus simulation for components setup.

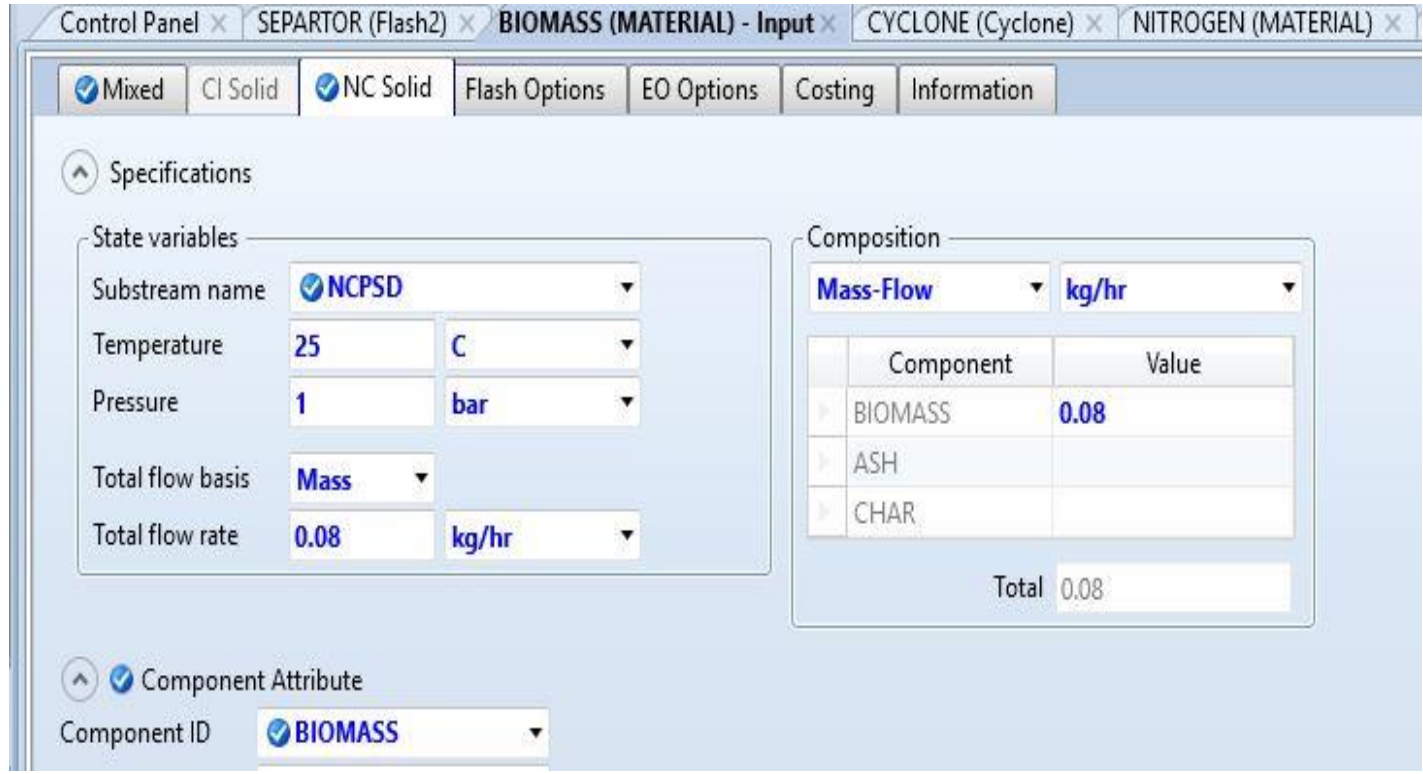

Fig. 6. 11. Photograph from Aspen simulation for biomass specifications. 


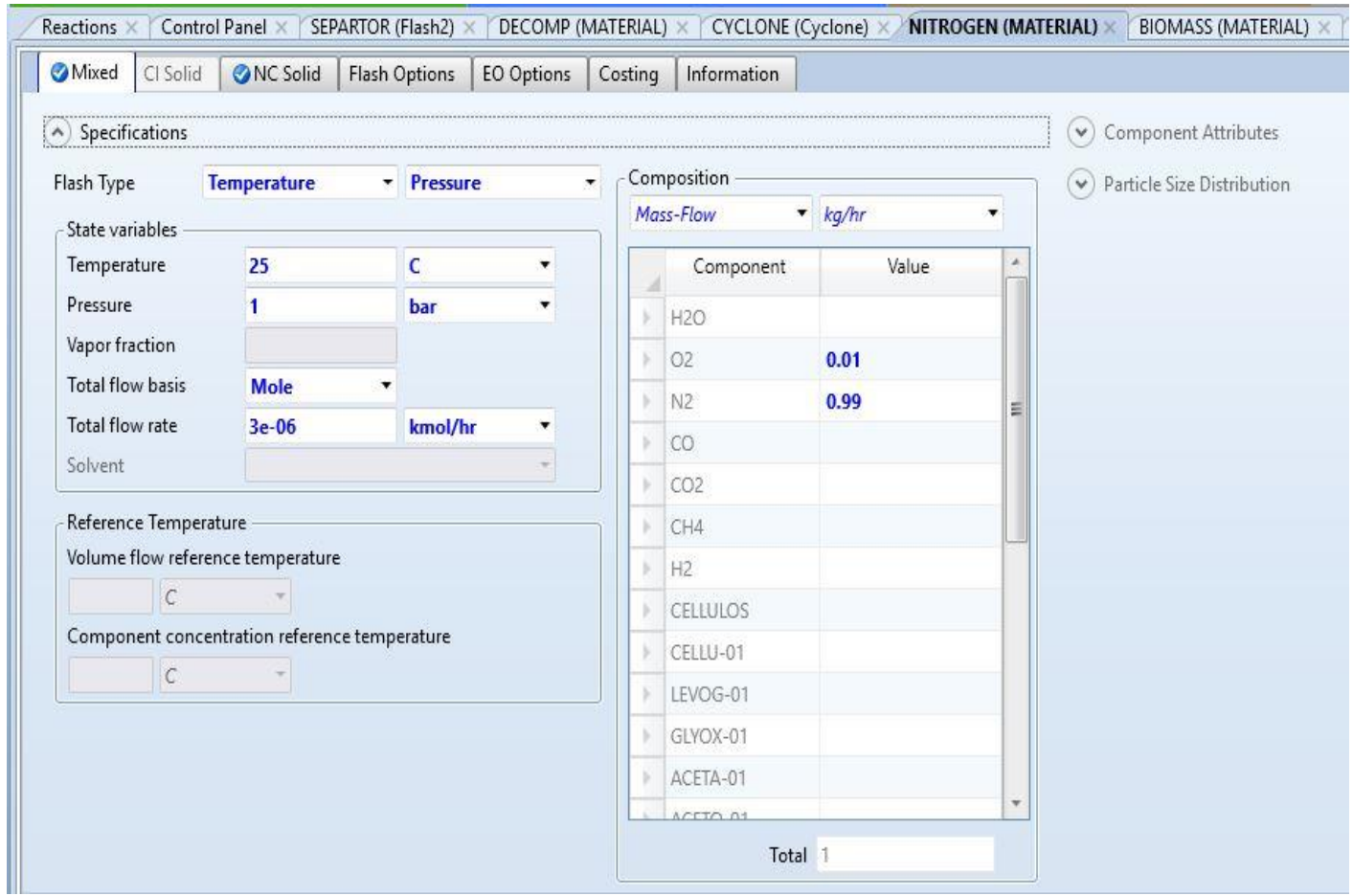

Fig. 6. 12. Photograph from Aspen simulation for nitrogen specifications.

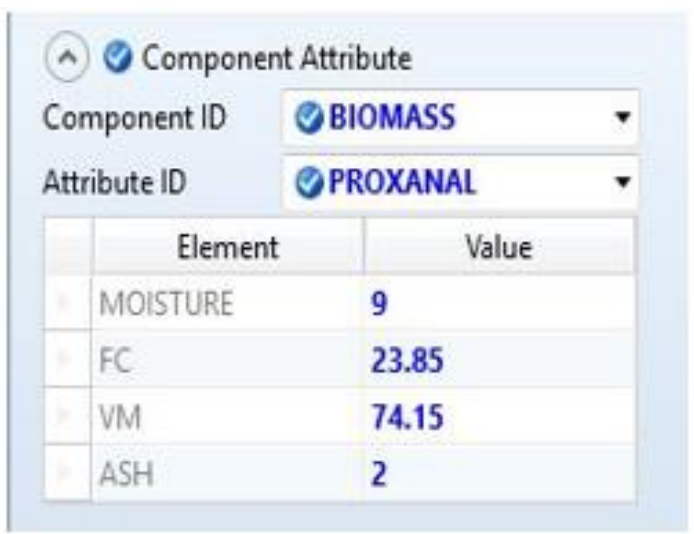

(a)

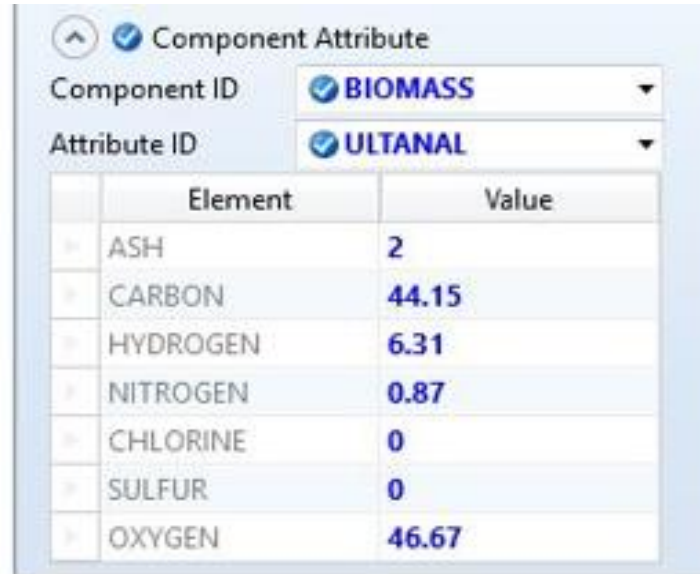

(b)

Fig. 6. 13 (a) Photograph from Aspen simulation for the proximate analysis of Medjool stones, (b) Photograph from Aspen simulation for the ultimate analysis of Medjool stones. 


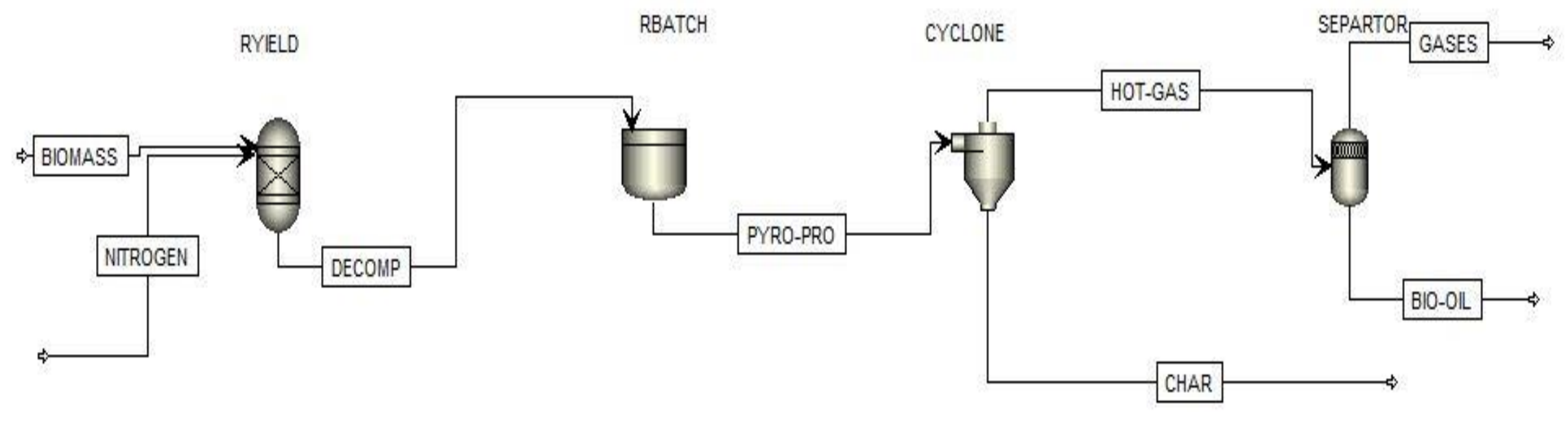

Fig. 6. 14. Photograph from Aspen for the simulation flow sheet. 


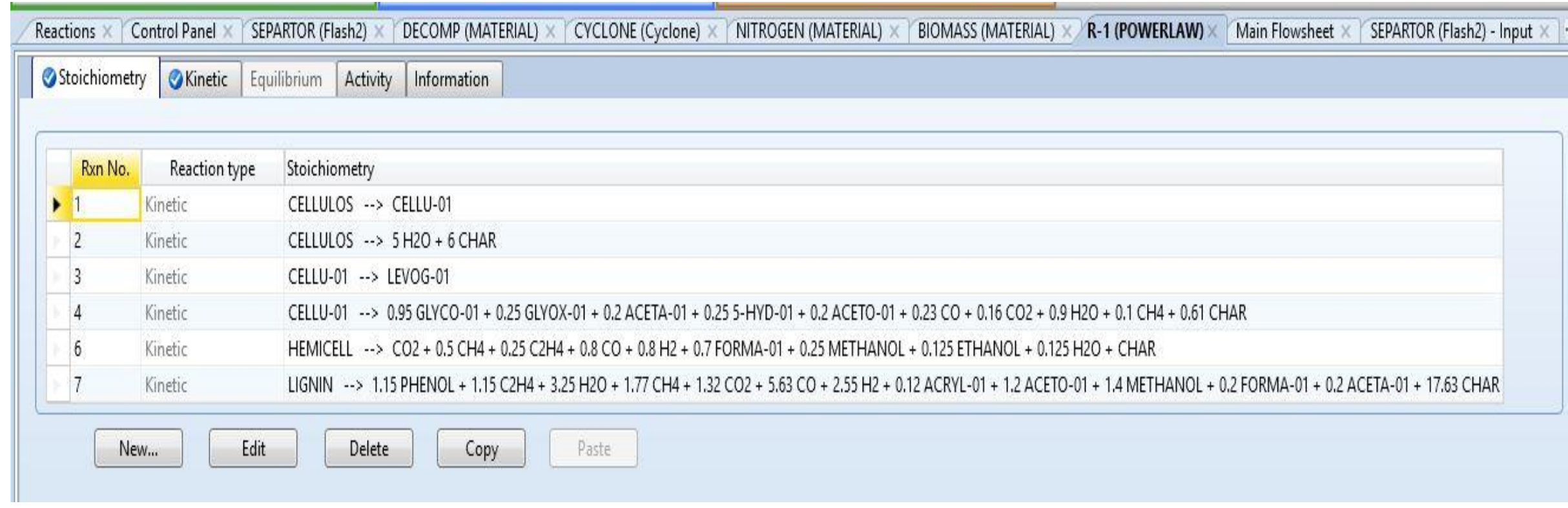

Fig. 6. 15. Photograph from Aspen simulation for chemical reactions in R-batch reactor. 
Indeed, these attempts faced some difficulties such as defining the hemicellulose and different types of lignin as Aspen Plus library is free of these complex polymers. The simulation was successfully completed only if it is assumed that the biomass includes only cellulose which is already defined in Aspen library. The results obtained from the simulation of slow pyrolysis of the Medjool date stones showed that the production rates of bio-oil, char and gases are $0.047,<0.001$ and $0.033 \mathrm{~kg} / \mathrm{s}$, respectively as shown in Table 6. 5 and Fig. 6. 16. This means that the predicted value of bio-oil, char and noncondensable gases produced from the slow pyrolysis of Medjool stones are 58.75, <1.25 and $41.25 \%$, respectively. When comparing these results with that obtained from the experiment, very large errors are found in predicted char and bio-oil yields. While, the error in predicted non-condensable gases may be accepted in this case. These errors in predicted results are expected because it is assumed that the biomass includes only cellulose.

The composition of the bio-oil obtained from the slow pyrolysis of Medjool stones is summarized in Table 6. 6 and supported with photographs from Aspen plus as shown in Fig. 6. 17. The predicted results from Aspen Plus showed that phenol is the main component of the bio-oil produced from the slow pyrolysis of Medjool stones. GlycolAldehyde and acetone are also of great amounts as seen in Table 6.6. A considerable amount of phenol was also detected during the GC-MS of the Medjool stones bio-oil.

These attempts of simulating the slow pyrolysis in Aspen gave us the main simulation structure in addition to good experience and skills of using the software tools. The previously mentioned difficulties can be solved in the future work. The validation of the simulation by comparing the simulation and experimental results will helps us to simulate high capacity biomass plant based the slow pyrolysis of the date palm wastes. 
Table 6. 5. The pyrolysis yields.

\begin{tabular}{llll}
\hline \multirow{2}{*}{ Parameter } & \multicolumn{2}{c}{ Products } \\
\cline { 2 - 4 } & Bio-oil & char & Non-condensable Gases \\
\hline Temperature C & -10 & 400 & -10 \\
Pressure bar & 1 & 1 & 1 \\
Mass Flow kg/hr & $\mathbf{0 . 0 4 7}$ & $<\mathbf{0 . 0 0 1}$ & $\mathbf{0 . 0 3 3}$ \\
Density kg/m & 1074.311 & 2274.278 & 1.09 \\
\hline
\end{tabular}

\begin{tabular}{|c|c|c|c|c|c|c|c|c|c|c|c|c|}
\hline \multicolumn{3}{|c|}{ Main Flowsheet $x$} & \multicolumn{3}{|c|}{ SEP (Flash2) - Input X } & \multicolumn{7}{|c|}{ Control Panel X RYIELD (RYield) - Stream Results $\times$} \\
\hline \multicolumn{2}{|c|}{ Material } & Heat & Load & Vol. \% C & Curves & Wt. \% Cur & ves & Petroleum & & olymers & Solids & \\
\hline \multicolumn{2}{|c|}{ Display } & Streams & $\boldsymbol{v}$ & Format & $\mathrm{t}$ SOLIDS & $\boldsymbol{v}$ & \multicolumn{2}{|r|}{ Stream Table } & & & & \\
\hline 4 & & & & \multicolumn{2}{|c|}{ BIO-OIL } & 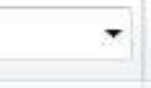 & \multicolumn{2}{|c|}{ CHAR } & \multicolumn{3}{|c|}{ GASES } & - \\
\hline r & \multicolumn{3}{|c|}{ Temperature $\mathrm{C}$} & \multicolumn{3}{|c|}{-10} & \multicolumn{2}{|l|}{400} & \multicolumn{4}{|c|}{-10} \\
\hline b & \multicolumn{3}{|c|}{ Pressure bar } & \multicolumn{3}{|l|}{1} & \multicolumn{2}{|l|}{1} & \multicolumn{4}{|c|}{1} \\
\hline b & \multicolumn{3}{|c|}{ Mass VFrac } & \multicolumn{3}{|l|}{0} & \multicolumn{2}{|l|}{0} & \multicolumn{4}{|c|}{1} \\
\hline s & \multicolumn{3}{|c|}{ Mass SFrac } & \multicolumn{3}{|c|}{$<0.001$} & \multicolumn{2}{|l|}{1} & \multicolumn{4}{|c|}{0} \\
\hline$>$ & \multicolumn{3}{|c|}{ 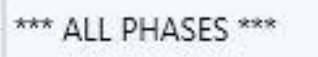 } & & & & & & & & & \\
\hline > & \multicolumn{3}{|c|}{ Mass Flow $\mathrm{kg} / \mathrm{hr}$} & \multicolumn{3}{|c|}{0.047} & \multicolumn{2}{|c|}{$<0.001$} & \multicolumn{4}{|c|}{0.033} \\
\hline , & \multicolumn{3}{|c|}{ Volume Flow cum $/ \mathrm{hr}$} & \multicolumn{3}{|c|}{$<0.001$} & $<0$. & 001 & & 0.03 & & \\
\hline p & Enth & halpy Gca & & & -0.001 & & $>-0$ & 0.001 & & $>-0.001$ & & \\
\hline b & Dens & sity $\mathrm{kg} / \mathrm{cu}$ & & & 074.31 & & 227 & 4.28 & & 1.09 & & \\
\hline
\end{tabular}

Fig. 6. 16. Photograph from Aspen simulation for the pyrolysis yields. 
Table 6. 6 The pyrolysis products components.

\begin{tabular}{|c|c|c|c|c|c|c|}
\hline \multicolumn{3}{|c|}{ Component name } & $\begin{array}{l}\text { products } \\
\text { Bio-oil }\end{array}$ & \multicolumn{3}{|c|}{$\begin{array}{l}\text { (kg/hr) } \\
\text { Non-condensable gases }\end{array}$} \\
\hline \multicolumn{2}{|l|}{ Water } & \multirow{2}{*}{$\begin{array}{l}\mathrm{H}_{2} \mathrm{O} \\
\mathrm{H}_{2}\end{array}$} & 0.012 & \multicolumn{3}{|c|}{$<0.001$} \\
\hline \multicolumn{2}{|c|}{ Hydrogen } & & trace & \multicolumn{3}{|c|}{0.001} \\
\hline \multicolumn{2}{|c|}{ Carbon monoxide } & $\mathrm{CO}$ & $<0.001$ & \multicolumn{3}{|c|}{0.015} \\
\hline \multicolumn{2}{|c|}{ Carbon dioxide } & $\mathrm{CO}_{2}$ & $<0.001$ & \multicolumn{3}{|c|}{0.009} \\
\hline \multicolumn{2}{|c|}{ Methane } & $\mathrm{CH}_{4}$ & $<0.001$ & \multicolumn{3}{|c|}{0.003} \\
\hline \multicolumn{2}{|c|}{ Ethylene } & $\mathrm{C}_{2} \mathrm{H}_{4}$ & $<0.001$ & \multicolumn{3}{|c|}{0.003} \\
\hline \multicolumn{2}{|c|}{ Levoglucosan } & $\mathrm{C}_{6} \mathrm{H}_{10} \mathrm{O}_{5}-\mathrm{N} 1$ & trace & \multicolumn{3}{|l|}{ trace } \\
\hline \multicolumn{2}{|c|}{ Glyoxal } & \multirow{2}{*}{$\begin{array}{l}\mathrm{C}_{2} \mathrm{H}_{2} \mathrm{O}_{2} \\
\mathrm{C}_{3} \mathrm{H}_{6} \mathrm{O}-1\end{array}$} & 0.002 & \multicolumn{3}{|c|}{$<0.001$} \\
\hline \multicolumn{2}{|c|}{ Acetone } & & 0.005 & \multicolumn{3}{|c|}{$<0.001$} \\
\hline \multicolumn{2}{|c|}{ Acetaldehyde } & $\mathrm{C}_{2} \mathrm{H}_{4} \mathrm{O}-1$ & 0.001 & \multicolumn{3}{|c|}{$<0.001$} \\
\hline \multicolumn{2}{|c|}{ Glycol-Aldehyde } & $\mathrm{C}_{2} \mathrm{H}_{4} \mathrm{O}_{2}-\mathrm{D} 1$ & 0.007 & trace & & \\
\hline 5-Hydr & roxymethylfurfural & $\mathrm{C}_{6} \mathrm{H}_{6} \mathrm{O}_{3}-\mathrm{N} 5$ & 0.004 & trace & & \\
\hline Formal & Idehyde & $\mathrm{CH}_{2} \mathrm{O}$ & 0.001 & 0.002 & & \\
\hline Ethano & & $\mathrm{C}_{2} \mathrm{H}_{6} \mathrm{O}-2$ & $<0.001$ & trace & & \\
\hline Phenol & & $\mathrm{C}_{6} \mathrm{H}_{6} \mathrm{O}$ & 0.011 & trace & & \\
\hline Acrylic & Acid & $\mathrm{C}_{3} \mathrm{H}_{4} \mathrm{O}_{2}-1$ & 0.001 & trace & & \\
\hline 4 & & BIO-OIL & CHAR & - & GASES & - \\
\hline$\checkmark$ & Mass Flow $\mathrm{kg} / \mathrm{hr}$ & & & & & \\
\hline$>$ & $\mathrm{H} 2 \mathrm{O}$ & 0.012 & & & $<0.001$ & \\
\hline , & $\mathrm{O2}$ & & & & & \\
\hline$>$ & N2 & & & & & \\
\hline t & $\mathrm{co}$ & $<0.001$ & & & 0.015 & \\
\hline$\geqslant$ & $\mathrm{CO} 2$ & $<0.001$ & & & 0.009 & \\
\hline ; & $\mathrm{CH} 4$ & $<0.001$ & & & 0.003 & \\
\hline t & $\mathrm{C}_{2} \mathrm{H}_{4}$ & $<0.001$ & & & 0.003 & \\
\hline , & LEVOG-01 & trace & & & trace & \\
\hline$>$ & GLYOX-01 & 0.002 & & & $<0.001$ & \\
\hline t & ACETO-01 & 0.005 & & & $<0.001$ & \\
\hline$>$ & ACETA-01 & 0.001 & & & $<0.001$ & \\
\hline t & GLYCO-01 & 0.007 & & & trace & \\
\hline 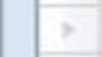 & 5-HYD-01 & 0.004 & & & trace & \\
\hline ; & $\mathrm{H} 2$ & trace & & & 0.001 & \\
\hline 7 & FORMA-01 & 0.001 & & & 0.002 & \\
\hline t & ETHANOL & $<0.001$ & & & trace & \\
\hline ; & PHENOL & 0.011 & & & trace & \\
\hline y & ACRYL-01 & 0.001 & & & trace & \\
\hline
\end{tabular}

Fig. 6. 17. Photograph from Aspen for the pyrolysis products components. 


\subsection{Conclusions and recommendations}

From the results reviewed in this chapter, the following conclusions can be drawn:

- The PTC with molten salt or Therminol VP-1 as HTF is the most technology used for CSP plants in the Middle East.

- The PTC and LFR are recommended for high capacity power plants (150 MWe or more).

- It is recommended to combine the gas turbine cycle with ORC in biomass power plant in order to improve the efficiency.

- Although, the hybrid solar-biomass power systems are still in their nascent stages, the feasibility studies of these systems showed the potential of these systems especially in the Middle East where the abundant of solar radiation and biomass availability. 


\section{Chapter 7}

\section{Conclusions and Recommendations}

In this work, the potential of date palm wastes conversion to biofuel are investigated. Firstly, the thermochemical characterisation of date palm stones and rachis wastes from two types of palm trees, Barhee and Medjool is studied. This is followed by slow pyrolysis conversion of the wastes to produce bio-oils. Indeed, the results displayed and discussed in this work showed high potential of using the date palm fruit wastes as a source of feedstock for biofuel production. The results obtained in this study are comparable with those published in the literature which validates the various methods employed in the current work. Despite the fact that the palm tree wastes contain various volatile and moisture constituents, the remaining part of fixed carbon components are sufficient to provide a useful level of bio-energy that can be converted into other forms of energy. From the thermochemical characterisation experimental results the following key conclusions and recommendations can be drawn:

- The date palm wastes, especially stones, have high volatile and fixed carbon content with low ash content. They also have very high content of cellulose reaching up to $66 \%$ in the case of Barhee stones. The results of TGA showed that the decomposition of studied date palm wastes feedstock can be completed below $420{ }^{\circ} \mathrm{C}$, while the DTG curves peak temperature ranged from $290{ }^{\circ} \mathrm{C}$ to $315^{\circ} \mathrm{C}$. The slow pyrolysis experiments of date palm stones and rachis were conducted at $400{ }^{\circ} \mathrm{C}$. Leading to a high char yield at the expense of the bio-oil yield, however, a considerable bio-oil yield up to $21.54 \%$ is achieved when Barhee rachis is used as feedstock.

- The slow pyrolysis of Barhee stones is suitable for char production as it produces the highest char yield of $73.35 \%$.

- The water content present in bio-oil obtained from the waste stones samples are considerably higher than those found in waste rachis samples.

- In general, a higher percentage of carbon contents is found in the stone samples compared to the rachis samples. 
- The results showed also that the bio-oil extracted from the slow pyrolysis of date stones samples have HHV much higher than that of rachis samples.

- The GC-MS analysis results showed that the Phenol, Furfural and Benzoic acid are considered the main components of the rachis sample bio-oil.

- The GC-MS results also revealed that the Barhee and Medjool stone bio-oil main components is d-allose with an average percentage of $17.48 \%$, and $25.68 \%$ for Barhee and Medjool respectively.

- From the results displayed in this work, and based on the abundant of date palm trees in the Middle East, it is recommended to use date palm wastes especially date stones and rachis as source of biofuel production using the slow pyrolysis process.

Finally, a techno-economic analysis of hybrid solar-biomass energy in Middle East is presented. While the CSP systems are of great interest in the Middle East several other studies are being conducted aiming to improve the system preference. These studies include selection of the solar field, HTF, and thermal energy storage system. The CSP is one of the most research point around the world and especially in the Middle East. So, it is taken a lot of interest in the techno-economic study. The results in this regard showed that:

- The PTC with molten salt or Therminol VP-1 as HTF is the most technology used for CSP plants in the Middle East.

- The PTC and LFR are recommended for high capacity power plants (150 MWe or more).

The combined Bryton- Rankine power generation system is the most used configuration of biomass power plants. Where the gas turbine of the Bryton cycle as toping cycle is operated by the syngas produced from the gasification process. While the bottoming Rankine cycle is operated by the heat recovery from the Bryton cycle. Two option may be used in hybrid solar-biomass power plant, the first option is similar to the combined Bryton-Rankine power generation system except that the working fluid in the Rankine cycle is heat by solar energy in addition to the heat recovered from the Bryton cycle. 
While in the second option, the solar energy system as direct steam generation (DSG) is used to generate additional steam in Rankine cycle.

Although, the hybrid solar-biomass power systems still in nascent stages, the feasibility studies of these systems showed the potential of these systems especially in the Middle East where there is abundant of solar radiation and biomass availability.

Based on the results displayed in this study the following research points can recommended for future work:

- Modeling the hybrid solar-biomass power plant under the Middle East weather conditions. Aspen plus software can be used for modeling the power cycle including the biomass conversion process, while SAM software can be used for modeling the solar field.

- Comparison between the pyrolysis and gasification of date palm wastes using Aspen plus simulation.

- Chemical characterization of a mixtures of agriculture residues as biomass feedstocks such as a mixture of date palm, rice, wheat, and sugar cane residues.

- Experimental and theoretical investigation of the pyrolysis and gasification of a mixture of agriculture residues available in the Middle East. 


\section{References:}

[1] M. B. Baig, K. H. Al-Zahrani, F. Schneider, G. S. Straquadine, and M. Mourad, "Food waste posing a serious threat to sustainability in the Kingdom of Saudi Arabia - A systematic review," Saudi Journal of Biological Sciences, vol. 26, no. 7, pp. 17431752, 2019/11/01/ 2019, doi: https://doi.org/10.1016/i.sjbs.2018.06.004.

[2] O. K. M. Ouda, S. A. Raza, A. S. Nizami, M. Rehan, R. Al-Waked, and N. E. Korres, "Waste to energy potential: A case study of Saudi Arabia," Renewable and Sustainable Energy Reviews, vol. 61, pp. 328-340, 2016/08/01/ 2016, doi: https://doi.org/10.1016/i.rser.2016.04.005.

[3] A. S. Nizami et al., "The potential of Saudi Arabian natural zeolites in energy recovery technologies," Energy, vol. 108, pp. 162-171, 2016/08/01/ 2016, doi: https://doi.org/10.1016/i.energy.2015.07.030.

[4] D. A.-S. Nizami et al., "An Argument for Developing Waste-to-Energy Technologies in Saudi Arabia," Chemical Engineering Transactions, vol. 45, pp. 337-342, 10/01 2015, doi: 10.3303/CET1545057.

[5] F. a. A. O. o. t. U. N. (FAO). Food and Agriculture Organization of the United Nations [Online] Available: http://www.fao.org/faostat/en/\#data/QC/visualize

[6] R. A. Nasser, S. Hiziroglu, M. A. Abdel-Aal, H. A. Al-Mefarrej, N. D. Shetta, and I. M. Aref, "Measurement of some properties of pulp and paper made from date palm midribs and wheat straw by soda-AQ pulping process," Measurement, vol. 62, pp. 179-186, 2015/02/01/ 2015, doi: https://doi.org/10.1016/j.measurement.2014.10.051.

[7] F. a. A. O. o. t. U. N. (FAO), World Food and Agriculture, Statistcal year book. Rome, 2013.

[8] S. S. Hegazy and I. M. Aref, "Suitability of Some Fast-Growing Trees and Date Palm Fronds for Particleboard Production," Forest Products Journal, vol. 60, no. 7-8, pp. 599-604, 2010, doi: 10.13073/0015-7473-60.7.599.

[9] A. Demirbaş, M. Kabli, R. Alamoudi, W. Ahmad, and A. Basahel, "Renewable energy resource facilities in the Kingdom of Saudi Arabia: Prospects, social and political challenges," Energy Sources, Part B: Economics, Planning, and Policy, vol. 12, pp. 816, 01/02 2017, doi: 10.1080/15567249.2014.996303.

[10] R. A.-S. Nasser, "An Evaluation of the Use of Midribs from Common Date Palm Cultivars Grown in Saudi Arabia for Energy Production," 2014, Date palm midrib; Energy production; Fibre saturation point; Fuel value index; Heating value vol. 9, no. 3 p. 15, 2014-06-04 2014. [Online]. Available: https://ojs.cnr.ncsu.edu/index.php/BioRes/article/view/BioRes 0934343 Nasser Midribs Date Palm.

[11] A. S. Nizami et al., "Waste biorefineries: Enabling circular economies in developing countries," Bioresource Technology, vol. 241, pp. 1101-1117, 2017/10/01/ 2017, doi: https://doi.org/10.1016/i.biortech.2017.05.097.

[12] M. Waqas, A. S. Nizami, A. S. Aburiazaiza, M. A. Barakat, I. M. I. Ismail, and M. I. Rashid, "Optimization of food waste compost with the use of biochar," Journal of Environmental Management, vol. 216, pp. 70-81, 2018/06/15/ 2018, doi: https://doi.org/10.1016/i.jenvman.2017.06.015.

[13] M. Waqas, A. S. Nizami, A. S. Aburiazaiza, M. A. Barakat, M. I. Rashid, and I. M. I. Ismail, "Optimizing the process of food waste compost and valorizing its applications: A case study of Saudi Arabia," Journal of Cleaner Production, vol. 176, pp. 426-438, 2018/03/01/ 2018, doi: https://doi.org/10.1016/i.jclepro.2017.12.165.

[14] S. Abdelhady, D. Borello, A. Shaban, and F. Rispoli, "Viability Study of Biomass Power Plant Fired with Rice Straw in Egypt," Energy Procedia, vol. 61, pp. 211-215, 2014/01/01/ 2014, doi: https://doi.org/10.1016/i.egypro.2014.11.1072. 
[15] E. M. A. Edreis, X. Li, G. Luo, S. W. Sharshir, and H. Yao, "Kinetic analyses and synergistic effects of $\mathrm{CO} 2$ co-gasification of low sulphur petroleum coke and biomass wastes," Bioresource Technology, vol. 267, pp. 54-62, 2018/11/01/ 2018, doi: https://doi.org/10.1016/j.biortech.2018.06.089.

[16] M. A. Hamad, A. M. Radwan, D. A. Heggo, and T. Moustafa, "Hydrogen rich gas production from catalytic gasification of biomass," Renewable Energy, vol. 85, pp. 1290-1300, 2016/01/01/ 2016, doi: https://doi.org/10.1016/j.renene.2015.07.082.

[17] D. A. Ali, M. A. Gadalla, O. Y. Abdelaziz, C. P. Hulteberg, and F. H. Ashour, "Cogasification of coal and biomass wastes in an entrained flow gasifier: Modelling, simulation and integration opportunities," Journal of Natural Gas Science and Engineering, vol. 37, pp. 126-137, 2017/01/01/ 2017, doi: https://doi.org/10.1016/i.jngse.2016.11.044.

[18] S. Sheweka, "Using Mud Bricks as a Temporary Solution for Gaza Reconstruction," Energy Procedia, vol. 6, pp. 236-240, 2011/01/01/ 2011, doi: https://doi.org/10.1016/i.egypro.2011.05.027.

[19] M. Bassyouni et al., "Date palm waste gasification in downdraft gasifier and simulation using ASPEN HYSYS," Energy Conversion and Management, vol. 88, pp. 693-699, 2014/12/01/2014, doi: https://doi.org/10.1016/j.enconman.2014.08.061.

[20] A. B. Fadhil, M. A. Alhayali, and L. I. Saeed, "Date (Phoenix dactylifera L.) palm stones as a potential new feedstock for liquid bio-fuels production," Fuel, vol. 210, pp. 165176, 2017/12/15/ 2017, doi: https://doi.org/10.1016/j.fuel.2017.08.059.

[21] Y. Makkawi, Y. El Sayed, M. Salih, P. Nancarrow, S. Banks, and T. Bridgwater, "Fast pyrolysis of date palm (Phoenix dactylifera) waste in a bubbling fluidized bed reactor," Renewable Energy, vol. 143, pp. 719-730, 2019/12/01/ 2019, doi: https://doi.org/10.1016/i.renene.2019.05.028.

[22] A.-M. Abdel-Rahman, "Economic Diversification in the Kingdom of Saudi Arabia ECONOMIC DIVERSIFICATION IN THE KINGDOM OF SAUDI ARABIA," 09/01 2001.

[23] F. Al-Subaiee, E. Yoder, and J. Thomson, "Extension Agents' Perceptions of Sustainable Agriculture in the Riyadh Region of Saudi Arabia," Journal of International Agricultural and Extension Education, vol. 12, 01/01 2005, doi: 10.5191/jiaee.2005.12101.

[24] S. Fiaz, M. A. Noor, and F. O. Aldosri, "Achieving food security in the Kingdom of Saudi Arabia through innovation: Potential role of agricultural extension," Journal of the Saudi Society of Agricultural Sciences, vol. 17, no. 4, pp. 365-375, 2018/10/01/ 2018, doi: https://doi.org/10.1016/i.jssas.2016.09.001.

[25] T. Nicodème, T. Berchem, N. Jacquet, and A. Richel, "Thermochemical conversion of sugar industry by-products to biofuels," Renewable and Sustainable Energy Reviews, vol. 88, pp. 151-159, 2018/05/01/ 2018, doi: https://doi.org/10.1016/j.rser.2018.02.037.

[26] R. A. Voloshin, M. V. Rodionova, S. K. Zharmukhamedov, T. Nejat Veziroglu, and S. I. Allakhverdiev, "Review: Biofuel production from plant and algal biomass," International Journal of Hydrogen Energy, vol. 41, no. 39, pp. 17257-17273, 2016/10/19/ 2016, doi: https://doi.org/10.1016/j.ijhydene.2016.07.084.

[27] F. Alam, S. Mobin, and H. Chowdhury, "Third Generation Biofuel from Algae," Procedia Engineering, vol. 105, pp. 763-768, 2015/01/01/ 2015, doi: https://doi.org/10.1016/i.proeng.2015.05.068.

[28] H. Weldekidan, V. Strezov, and G. Town, "Review of solar energy for biofuel extraction," Renewable and Sustainable Energy Reviews, vol. 88, pp. 184-192, 2018/05/01/ 2018, doi: https://doi.org/10.1016/i.rser.2018.02.027.

[29] C. Cara, E. Ruiz, J. M. Oliva, F. Sáez, and E. Castro, "Conversion of olive tree biomass into fermentable sugars by dilute acid pretreatment and enzymatic saccharification," 
Bioresource Technology, vol. 99, no. 6, pp. 1869-1876, 2008/04/01/ 2008, doi: https://doi.org/10.1016/j.biortech.2007.03.037.

[30] K. Ullah, V. Kumar Sharma, S. Dhingra, G. Braccio, M. Ahmad, and S. Sofia, "Assessing the lignocellulosic biomass resources potential in developing countries: A critical review," Renewable and Sustainable Energy Reviews, vol. 51, pp. 682-698, 2015/11/01/ 2015, doi: https://doi.org/10.1016/j.rser.2015.06.044.

[31] N. K. Mekala, R. Potumarthi, R. R. Baadhe, and V. K. Gupta, "Chapter 1 - Current Bioenergy Researches: Strengths and Future Challenges," in Bioenergy Research: Advances and Applications, V. K. Gupta, M. G. Tuohy, C. P. Kubicek, J. Saddler, and F. Xu Eds. Amsterdam: Elsevier, 2014, pp. 1-21.

[32] R. Kothari, V. V. Tyagi, and A. Pathak, "Waste-to-energy: A way from renewable energy sources to sustainable development," Renewable and Sustainable Energy Reviews, vol. 14, no. 9, pp. 3164-3170, 2010/12/01/ 2010, doi: https://doi.org/10.1016/i.rser.2010.05.005.

[33] I. A. Shah, X. Gou, Q. Zhang, J. Wu, E. Wang, and Y. Liu, "Experimental study on NOx emission characteristics of oxy-biomass combustion," Journal of Cleaner Production, vol. 199, pp. 400-410, 2018/10/20/ 2018, doi: https://doi.org/10.1016/j.jclepro.2018.07.022.

[34] Z. Gong et al., "Experimental study on combustion and pollutants emissions of oil sludge blended with microalgae residue," Journal of the Energy Institute, vol. 91, no. 6, pp. 877-886, 2018/12/01/2018, doi: https://doi.org/10.1016/j.joei.2017.10.001.

[35] L. Dong, S. Gao, W. Song, and G. Xu, "Experimental study of NO reduction over biomass char," Fuel Processing Technology, vol. 88, no. 7, pp. 707-715, 2007/07/01/ 2007, doi: https://doi.org/10.1016/i.fuproc.2007.02.005.

[36] A. AlNouss, G. McKay, and T. Al-Ansari, "A techno-economic-environmental study evaluating the potential of oxygen-steam biomass gasification for the generation of value-added products," Energy Conversion and Management, vol. 196, pp. 664-676, 2019/09/15/ 2019, doi: https://doi.org/10.1016/j.enconman.2019.06.019.

[37] A. AlNouss, G. McKay, and T. Al-Ansari, "Production of syngas via gasification using optimum blends of biomass," Journal of Cleaner Production, vol. 242, p. 118499, 2020/01/01/2020, doi: https://doi.org/10.1016/j.jclepro.2019.118499.

[38] D. N. Vienescu, J. Wang, A. Le Gresley, and J. D. Nixon, "A life cycle assessment of options for producing synthetic fuel via pyrolysis," Bioresource Technology, vol. 249, pp. 626-634, 2018/02/01/ 2018, doi: https://doi.org/10.1016/j.biortech.2017.10.069.

[39] E. G. Hertwich and X. Zhang, "Concentrating-Solar Biomass Gasification Process for a 3rd Generation Biofuel," Environmental Science \& Technology, vol. 43, no. 11, pp. 4207-4212, 2009/06/01 2009, doi: 10.1021/es802853g.

[40] M. S. Mettler, D. G. Vlachos, and P. J. Dauenhauer, "Top ten fundamental challenges of biomass pyrolysis for biofuels," Energy \& Environmental Science, 10.1039/C2EE21679E vol. 5, no. 7, pp. 7797-7809, 2012, doi: 10.1039/C2EE21679E.

[41] J. A. Melero, M. M. Clavero, G. Calleja, A. García, R. Miravalles, and T. Galindo, "Production of Biofuels via the Catalytic Cracking of Mixtures of Crude Vegetable Oils and Nonedible Animal Fats with Vacuum Gas Oil," Energy \& Fuels, vol. 24, no. 1, pp. 707-717, 2010/01/21 2010, doi: 10.1021/ef900914e.

[42] A. A. Lappas, S. Bezergianni, and I. A. Vasalos, "Production of biofuels via coprocessing in conventional refining processes," Catalysis Today, vol. 145, no. 1, pp. 55-62, 2009/07/15/ 2009, doi: https://doi.org/10.1016/i.cattod.2008.07.001.

[43] G. W. Huber and A. Corma, "Synergies between Bio- and Oil Refineries for the Production of Fuels from Biomass," Angewandte Chemie International Edition, vol. 46, no. 38, pp. 7184-7201, 2007, doi: doi:10.1002/anie.200604504. 
[44] F. Abnisa, A. Arami-Niya, W. M. A. Wan Daud, J. N. Sahu, and I. M. Noor, "Utilization of oil palm tree residues to produce bio-oil and bio-char via pyrolysis," Energy Conversion and Management, vol. 76, pp. 1073-1082, 2013/12/01/ 2013, doi: https://doi.org/10.1016/j.enconman.2013.08.038.

[45] T. X. Do, Y.-i. Lim, and H. Yeo, "Techno-economic analysis of biooil production process from palm empty fruit bunches," Energy Conversion and Management, vol. 80, pp. 525-534, 2014/04/01/ 2014, doi: https://doi.org/10.1016/i.enconman.2014.01.024.

[46] S. I. Yang, M. S. Wu, and C. Y. Wu, "Application of biomass fast pyrolysis part I: Pyrolysis characteristics and products," Energy, vol. 66, pp. 162-171, 2014/03/01/ 2014, doi: https://doi.org/10.1016/i.energy.2013.12.063.

[47] J. Fan, T. N. Kalnes, M. Alward, J. Klinger, A. Sadehvandi, and D. R. Shonnard, "Life cycle assessment of electricity generation using fast pyrolysis bio-oil," Renewable Energy, vol. 36, no. 2, pp. 632-641, 2011/02/01/ 2011, doi: https://doi.org/10.1016/j.renene.2010.06.045.

[48] A. Oasmaa, E. Kuoppala, and Y. Solantausta, "Fast Pyrolysis of Forestry Residue. 2. Physicochemical Composition of Product Liquid," Energy \& Fuels, vol. 17, no. 2, pp. 433-443, 2003/03/01 2003, doi: 10.1021/ef020206g.

[49] M. E. Boucher, A. Chaala, and C. Roy, "Bio-oils obtained by vacuum pyrolysis of softwood bark as a liquid fuel for gas turbines. Part I: Properties of bio-oil and its blends with methanol and a pyrolytic aqueous phase," Biomass and Bioenergy, vol. 19, no. 5, pp. 337-350, 2000/11/01/ 2000, doi: https://doi.org/10.1016/S09619534(00)00043-X.

[50] M. Ikura, M. Stanciulescu, and E. Hogan, "Emulsification of pyrolysis derived bio-oil in diesel fuel," Biomass and Bioenergy, vol. 24, no. 3, pp. 221-232, 2003/03/01/2003, doi: https://doi.org/10.1016/S0961-9534(02)00131-9.

[51] R. P. Anex et al., "Techno-economic comparison of biomass-to-transportation fuels via pyrolysis, gasification, and biochemical pathways," Fuel, vol. 89, pp. S29-S35, 2010/11/01/ 2010, doi: https://doi.org/10.1016/j.fuel.2010.07.015.

[52] J. S. Daystar, T. Treasure, R. Gonzalez, C. Reeb, R. Venditti, and S. Kelley, The NREL Biochemical and Thermochemical Ethanol Conversion Processes: Financial and Environmental Analysis Comparison (2015, no. 3). 2015.

[53] V. H. W. Dowson, Date Production and Protection: With Special Reference to North Africa and the Near East. Food and Agriculture Organization of the United Nations, 1982, p. 294.

[54] C. C. T. Chao and R. R. Krueger, The Date Palm (Phoenix dactylifera L.): Overview of Biology, Uses, and Cultivation. 2007.

[55] Y. El may, M. Jeguirim, S. Dorge, G. Trouvé, and R. Said, "Study on the thermal behavior of different date palm residues: Characterization and devolatilization kinetics under inert and oxidative atmospheres," Energy, vol. 44, no. 1, pp. 702-709, 2012/08/01/ 2012, doi: https://doi.org/10.1016/i.energy.2012.05.022.

[56] A. Zaid, Date Palm Cultivation. Rome, 2002.

[57] M. Shafiei, K. Karimi, and M. Taherzadeh, "Palm Date Fibers: Analysis and Enzymatic Hydrolysis," International journal of molecular sciences, vol. 11, no. 11, pp. 4285-96, 2010, doi: $10.3390 /$ ijms11114285.

[58] M. Chandrasekaran and A. H. Bahkali, "Valorization of date palm (Phoenix dactylifera) fruit processing by-products and wastes using bioprocess technology Review," Saudi Journal of Biological Sciences, vol. 20, no. 2, pp. 105-120, 2013/04/01/ 2013, doi: https://doi.org/10.1016/i.sibs.2012.12.004. 
[59] N. Haimour and S. Emeish, "Utilization of Date Stones for Production of Activated Carbon Using Phosphoric Acid," Waste management (New York, N.Y.), vol. 26, pp. 651-60, 02/01 2006, doi: 10.1016/j.wasman.2005.08.004.

[60] M. M. E. A. Manickavasagan, E. Sukumar, Dates Production, Processing, Food, and Medicinal Values. Boca Raton, Florida, USA: Taylor \& Francis Group, LLC, 2012.

[61] M. S. Rahman, S. Kasapis, N. S. Z. Al-Kharusi, I. M. Al-Marhubi, and A. J. Khan, "Composition characterisation and thermal transition of date pits powders," Journal of Food Engineering, vol. 80, no. 1, pp. 1-10, 2007/05/01/ 2007, doi: https://doi.org/10.1016/i.jfoodeng.2006.04.030.

[62] H. S. Hasan Ba Hamid and K. S. Ku Ismail, "Optimization of enzymatic hydrolysis for acid pretreated date seeds into fermentable sugars," Biocatalysis and Agricultural Biotechnology, vol. 24, p. 101530, 2020/03/01/ 2020, doi: https://doi.org/10.1016/i.bcab.2020.101530.

[63] A. Bendahou, A. Dufresne, H. Kaddami, and Y. Habibi, "Isolation and structural characterization of hemicelluloses from palm of Phoenix dactylifera L," Carbohydrate Polymers, vol. 68, no. 3, pp. 601-608, 2007/04/05/ 2007, doi: https://doi.org/10.1016/i.carbpol.2006.10.016.

[64] P. McKendry, "Energy production from biomass (part 1): overview of biomass," Bioresource Technology, vol. 83, no. 1, pp. 37-46, 2002/05/01/ 2002, doi: https://doi.org/10.1016/S0960-8524(01)00118-3.

[65] E. M. Monono, P. E. Nyren, M. T. Berti, and S. W. Pryor, "Variability in biomass yield, chemical composition, and ethanol potential of individual and mixed herbaceous biomass species grown in North Dakota," Industrial Crops and Products, vol. 41, pp. 331-339, 2013/01/01/ 2013, doi: https://doi.org/10.1016/i.indcrop.2012.04.051.

[66] T. I. M. Ragab, H. Amer, A. T. Mossa, M. Emam, A. A. Hasaballah, and W. A. Helmy, "Anticoagulation, fibrinolytic and the cytotoxic activities of sulfated hemicellulose extracted from rice straw and husk," Biocatalysis and Agricultural Biotechnology, vol. 15, pp. 86-91, 2018/07/01/ 2018, doi: https://doi.org/10.1016/j.bcab.2018.05.010.

[67] J. F. Peters, S. W. Banks, A. V. Bridgwater, and J. Dufour, "A kinetic reaction model for biomass pyrolysis processes in Aspen Plus," Applied Energy, vol. 188, pp. 595603, 2017/02/15/ 2017, doi: https://doi.org/10.1016/j.apenergy.2016.12.030.

[68] S. Wang, G. Dai, H. Yang, and Z. Luo, "Lignocellulosic biomass pyrolysis mechanism: A state-of-the-art review," Progress in Energy and Combustion Science, vol. 62, pp. 33-86, 2017/09/01/ 2017, doi: https://doi.org/10.1016/j.pecs.2017.05.004.

[69] R. M. P. Rowell, Roger; Tshabalala, Mandla A., Cell wall chemistry, Second edition ed. Boca Raton, FL, USA: CRC Press: 33-72. Chapter 3, 2013

[70] T. R. Rao and A. Sharma, "Pyrolysis rates of biomass materials," Energy, vol. 23, no. 11, pp. 973-978, 1998/11/01/ 1998, doi: https://doi.org/10.1016/S03605442(98)00037-1.

[71] F. Peng, P. Peng, F. Xu, and R.-C. Sun, "Fractional purification and bioconversion of hemicelluloses," Biotechnology Advances, vol. 30, no. 4, pp. 879-903, 2012/07/01/ 2012, doi: https://doi.org/10.1016/i.biotechadv.2012.01.018.

[72] E. McCrady, "The nature of lignin," Alkaline paper advocate, vol. 4, no. 4, pp. 33-34, 1991.

[73] D. Martin Alonso, S. Wettstein, and J. Dumesic, "Bimetallic catalysts for upgrading of biomass to fuels and chemicals," Chemical Society reviews, vol. 41, 08/08 2012, doi: 10.1039/c2cs35188a.

[74] M. Taherzadeh-Ghahfarokhi, R. Panahi, and B. Mokhtarani, "Optimizing the combination of conventional carbonaceous additives of culture media to produce lignocellulose-degrading enzymes by Trichoderma reesei in solid state fermentation 
of agricultural residues," Renewable Energy, vol. 131, pp. 946-955, 2019/02/01/ 2019, doi: https://doi.org/10.1016/i.renene.2018.07.130.

[75] S. Sohni, N. A. N. Norulaini, R. Hashim, S. B. Khan, W. Fadhullah, and A. K. Mohd Omar, "Physicochemical characterization of Malaysian crop and agro-industrial biomass residues as renewable energy resources," Industrial Crops and Products, vol. 111, pp. 642-650, 2018/01/01/ 2018, doi: https://doi.org/10.1016/j.indcrop.2017.11.031.

[76] R. Khiari, M. F. Mhenni, M. N. Belgacem, and E. Mauret, "Chemical composition and pulping of date palm rachis and Posidonia oceanica - A comparison with other wood and non-wood fibre sources," Bioresource Technology, vol. 101, no. 2, pp. 775-780, 2010/01/01/ 2010, doi: https://doi.org/10.1016/i.biortech.2009.08.079.

[77] N. Saadaoui, A. Rouilly, K. Fares, and L. Rigal, "Characterization of date palm lignocellulosic by-products and self-bonded composite materials obtained thereof," Materials \& Design, vol. 50, pp. 302-308, 2013/09/01/ 2013, doi: https://doi.org/10.1016/j.matdes.2013.03.011.

[78] S. Hamza, H. Saad, B. Charrier, N. Ayed, and F. Charrier-El Bouhtoury, "Physicochemical characterization of Tunisian plant fibers and its utilization as reinforcement for plaster based composites," Industrial Crops and Products, vol. 49, pp. 357-365, 2013/08/01/2013, doi: https://doi.org/10.1016/i.indcrop.2013.04.052.

[79] A. Sbiai, H. Kaddami, H. Sautereau, A. Maazouz, and E. Fleury, "TEMPO-mediated oxidation of lignocellulosic fibers from date palm leaves," Carbohydrate Polymers, vol. 86, no. 4, pp. 1445-1450, 2011/10/15/ 2011, doi: https://doi.org/10.1016/i.carbpol.2011.06.005.

[80] P. J. V. Soest and R. H. Wine, "Use of Detergents in the Analysis of Fibrous Feeds. IV. Determination of Plant Cell-Wall Constituents," Journal of Association of Official Analytical Chemists, vol. 50, no. 1, pp. 50-55, 2020, doi: 10.1093/jaoac/50.1.50.

[81] P. J. Van Soest and R. H. Wine, "Determination of Lignin and Cellulose in AcidDetergent Fiber with Permanganate," Journal of Association of Official Analytical Chemists, vol. 51, no. 4, pp. 780-785, 2020, doi: 10.1093/jaoac/51.4.780.

[82] G. Bensidhom, A. Ben Hassen-Trabelsi, K. Alper, M. Sghairoun, K. Zaafouri, and I. Trabelsi, "Pyrolysis of Date palm waste in a fixed-bed reactor: Characterization of pyrolytic products," Bioresource Technology, vol. 247, pp. 363-369, 2018/01/01/ 2018, doi: https://doi.org/10.1016/i.biortech.2017.09.066.

[83] C. Bouchelta, M. S. Medjram, O. Bertrand, and J.-P. Bellat, "Preparation and characterization of activated carbon from date stones by physical activation with steam," Journal of Analytical and Applied Pyrolysis, vol. 82, no. 1, pp. 70-77, 2008/05/01/ 2008, doi: https://doi.org/10.1016/j.jaap.2007.12.009.

[84] G. Bharath et al., "Systematic production and characterization of pyrolysis-oil from date tree wastes for bio-fuel applications," Biomass and Bioenergy, vol. 135, p. 105523, 2020/04/01/ 2020, doi: https://doi.org/10.1016/j.biombioe.2020.105523.

[85] R. Nasser et al., "Chemical Analysis of Different Parts of Date Palm (Phoenix dactylifera L.) Using Ultimate, Proximate and Thermo-Gravimetric Techniques for Energy Production," Energies, vol. 9, p. 374, 05/16 2016, doi: 10.3390/en9050374.

[86] M. S. Abu Bakar and J. O. Titiloye, "Catalytic pyrolysis of rice husk for bio-oil production," Journal of Analytical and Applied Pyrolysis, vol. 103, pp. 362-368, 2013/09/01/ 2013, doi: https://doi.org/10.1016/i.jaap.2012.09.005.

[87] K. Lazdovica, V. Kampars, L. Liepina, and M. Vilka, "Comparative study on thermal pyrolysis of buckwheat and wheat straws by using TGA-FTIR and Py-GC/MS methods," Journal of Analytical and Applied Pyrolysis, vol. 124, pp. 1-15, 2017/03/01/ 2017, doi: https://doi.org/10.1016/i.jaap.2017.03.010. 
[88] J. Gutiérrez, C. A. Galán, R. Suárez, A. Álvarez-Murillo, and J. F. González, "Biofuels from cardoon pyrolysis: Extraction and application of biokerosene/kerosene mixtures in a self-manufactured jet engine," Energy Conversion and Management, vol. 157, pp. 246-256, 2018/02/01/ 2018, doi: https://doi.org/10.1016/j.enconman.2017.12.006.

[89] K. Açıkalın, F. Karaca, and E. Bolat, "Pyrolysis of pistachio shell: Effects of pyrolysis conditions and analysis of products," Fuel, vol. 95, pp. 169-177, 2012/05/01/ 2012, doi: https://doi.org/10.1016/i.fuel.2011.09.037.

[90] G. Duman, C. Okutucu, S. Ucar, R. Stahl, and J. Yanik, "The slow and fast pyrolysis of cherry seed," Bioresource Technology, vol. 102, no. 2, pp. 1869-1878, 2011/01/01/ 2011, doi: https://doi.org/10.1016/i.biortech.2010.07.051.

[91] i. Demiral and Ş. Ç. Kul, "Pyrolysis of apricot kernel shell in a fixed-bed reactor: Characterization of bio-oil and char," Journal of Analytical and Applied Pyrolysis, vol. 107, pp. 17-24, 2014/05/01/ 2014, doi: https://doi.org/10.1016/i.jaap.2014.01.019.

[92] D. Pradhan, R. K. Singh, H. Bendu, and R. Mund, "Pyrolysis of Mahua seed (Madhuca indica) - Production of biofuel and its characterization," Energy Conversion and Management, vol. 108, pp. 529-538, 2016/01/15/ 2016, doi: https://doi.org/10.1016/j.enconman.2015.11.042.

[93] T. Uysal, G. Duman, Y. Onal, I. Yasa, and J. Yanik, "Production of activated carbon and fungicidal oil from peach stone by two-stage process," Journal of Analytical and Applied Pyrolysis, vol. 108, pp. 47-55, 2014/07/01/ 2014, doi: https://doi.org/10.1016/i.jaap.2014.05.017.

[94] E. Antonakou, A. Lappas, M. H. Nilsen, A. Bouzga, and M. Stöcker, "Evaluation of various types of Al-MCM-41 materials as catalysts in biomass pyrolysis for the production of bio-fuels and chemicals," Fuel, vol. 85, no. 14, pp. 2202-2212, 2006/10/01/ 2006, doi: https://doi.org/10.1016/i.fuel.2006.03.021.

[95] V. Dhyani and T. Bhaskar, "A comprehensive review on the pyrolysis of lignocellulosic biomass," Renewable Energy, vol. 129, pp. 695-716, 2018/12/01/ 2018, doi: https://doi.org/10.1016/j.renene.2017.04.035.

[96] M. Balat, M. Balat, E. Kırtay, and H. Balat, "Main routes for the thermo-conversion of biomass into fuels and chemicals. Part 1: Pyrolysis systems," Energy Conversion and Management, vol. 50, no. 12, pp. 3147-3157, 2009/12/01/ 2009, doi: https://doi.org/10.1016/i.enconman.2009.08.014.

[97] S. Kim, Y. Lee, K.-Y. Andrew Lin, E. Hong, E. E. Kwon, and J. Lee, "The valorization of food waste via pyrolysis," Journal of Cleaner Production, vol. 259, p. 120816, 2020/06/20/ 2020, doi: https://doi.org/10.1016/j.jclepro.2020.120816.

[98] M. Ahmad et al., "Biochar as a sorbent for contaminant management in soil and water: A review," Chemosphere, vol. 99, pp. 19-33, 2014/03/01/ 2014, doi: https://doi.org/10.1016/i.chemosphere.2013.10.071.

[99] X. J. Lee, H. C. Ong, Y. Y. Gan, W.-H. Chen, and T. M. I. Mahlia, "State of art review on conventional and advanced pyrolysis of macroalgae and microalgae for biochar, biooil and bio-syngas production," Energy Conversion and Management, vol. 210, p. 112707, 2020/04/15/ 2020, doi: https://doi.org/10.1016/i.enconman.2020.112707.

[100] M. Tripathi, J. N. Sahu, and P. Ganesan, "Effect of process parameters on production of biochar from biomass waste through pyrolysis: A review," Renewable and Sustainable Energy Reviews, vol. 55, pp. 467-481, 2016/03/01/ 2016, doi: https://doi.org/10.1016/i.rser.2015.10.122.

[101] X. J. Lee, L. Y. Lee, S. Gan, S. Thangalazhy-Gopakumar, and H. K. Ng, "Biochar potential evaluation of palm oil wastes through slow pyrolysis: Thermochemical characterization and pyrolytic kinetic studies," Bioresource Technology, vol. 236, pp. 155-163, 2017/07/01/2017, doi: https://doi.org/10.1016/j.biortech.2017.03.105. 
[102] D. Mohan, C. Pittman, and P. Steele, "Pyrolysis of Wood/Biomass for Bio-Oil: A Critical Review," Energy, vol. 20, p. 848, 05/01 2006, doi: 10.1021/ef0502397.

[103] A. V. Bridgwater, "Renewable fuels and chemicals by thermal processing of biomass," Chemical Engineering Journal, vol. 91, no. 2, pp. 87-102, 2003/03/15/ 2003, doi: https://doi.org/10.1016/S1385-8947(02)00142-0.

[104] P. R. Bhoi, A. S. Ouedraogo, V. Soloiu, and R. Quirino, "Recent advances on catalysts for improving hydrocarbon compounds in bio-oil of biomass catalytic pyrolysis," Renewable and Sustainable Energy Reviews, vol. 121, p. 109676, 2020/04/01/ 2020, doi: https://doi.org/10.1016/j.rser.2019.109676.

[105] J. Yanik, R. Stahl, N. Troeger, and A. Sinag, "Pyrolysis of algal biomass," Journal of Analytical and Applied Pyrolysis, vol. 103, pp. 134-141, 2013/09/01/ 2013, doi: https://doi.org/10.1016/j.jaap.2012.08.016.

[106] A. Marcilla, L. Catalá, J. C. García-Quesada, F. J. Valdés, and M. R. Hernández, "A review of thermochemical conversion of microalgae," Renewable and Sustainable Energy Reviews, vol. 27, pp. 11-19, 2013/11/01/ 2013, doi: https://doi.org/10.1016/i.rser.2013.06.032.

[107] A. Demirbaş, "Biomass resource facilities and biomass conversion processing for fuels and chemicals," Energy Conversion and Management, vol. 42, no. 11, pp. 13571378, 2001/07/01/2001, doi: https://doi.org/10.1016/S0196-8904(00)00137-0.

[108] A. Demirbas, "Progress and recent trends in biofuels," Progress in Energy and Combustion Science, vol. 33, no. 1, pp. 1-18, 2007/02/01/ 2007, doi: https://doi.org/10.1016/i.pecs.2006.06.001.

[109] A. Demirbaş and G. Arin, "An Overview of Biomass Pyrolysis," Energy Sources ENERG SOURCE, vol. 24, pp. 471-482, 05/01 2002, doi: 10.1080/00908310252889979.

[110] A. Demirbaş, "Producing Bio-oil from Olive Cake by Fast Pyrolysis," Energy Sources, vol. Part A, pp. 38-44, 01/01 2008, doi: 10.1080/00908310600626747.

[111] K. Kebelmann, A. Hornung, U. Karsten, and G. Griffiths, "Thermo-chemical behaviour and chemical product formation from Polar seaweeds during intermediate pyrolysis," Journal of Analytical and Applied Pyrolysis, vol. 104, pp. 131-138, 2013/11/01/2013, doi: https://doi.org/10.1016/j.jaap.2013.08.012.

[112] K. Kebelmann, A. Hornung, U. Karsten, and G. Griffiths, "Intermediate pyrolysis and product identification by TGA and Py-GC/MS of green microalgae and their extracted protein and lipid components," Biomass and Bioenergy, vol. 49, pp. 38-48, 2013/02/01/2013, doi: https://doi.org/10.1016/i.biombioe.2012.12.006.

[113] A. S. N. Mahmood, J. G. Brammer, A. Hornung, A. Steele, and S. Poulston, "The intermediate pyrolysis and catalytic steam reforming of Brewers spent grain," Journal of Analytical and Applied Pyrolysis, vol. 103, pp. 328-342, 2013/09/01/ 2013, doi: https://doi.org/10.1016/j.jaap.2012.09.009.

[114] Y. Yang, Y. Zhang, E. Omairey, J. Cai, F. Gu, and A. V. Bridgwater, "Intermediate pyrolysis of organic fraction of municipal solid waste and rheological study of the pyrolysis oil for potential use as bio-bitumen," Journal of Cleaner Production, vol. 187, pp. 390-399, 2018/06/20/ 2018, doi: https://doi.org/10.1016/i.jclepro.2018.03.205.

[115] Z. Al Chami et al., "Evaluation of flash and slow pyrolysis applied on heavy metal contaminated Sorghum bicolor shoots resulting from phytoremediation," Biomass and Bioenergy, vol. 63, pp. 268-279, 2014/04/01/ 2014, doi: https://doi.org/10.1016/j.biombioe.2014.02.027.

[116] M. Hervy et al., "Reactivity and deactivation mechanisms of pyrolysis chars from biowaste during catalytic cracking of tar," Applied Energy, vol. 237, pp. 487-499, 2019/03/01/ 2019, doi: https://doi.org/10.1016/j.apenergy.2019.01.021. 
[117] J. Lee, E. E. Kwon, and Y.-K. Park, "Recent advances in the catalytic pyrolysis of microalgae," Catalysis Today, 2019/03/06/ 2019, doi: https://doi.org/10.1016/i.cattod.2019.03.010.

[118] R. Miandad, M. A. Barakat, A. S. Aburiazaiza, M. Rehan, and A. S. Nizami, "Catalytic pyrolysis of plastic waste: A review," Process Safety and Environmental Protection, vol. 102, pp. 822-838, 2016/07/01/ 2016, doi: https://doi.org/10.1016/j.psep.2016.06.022.

[119] K. G. Kalogiannis et al., "First pilot scale study of basic vs acidic catalysts in biomass pyrolysis: Deoxygenation mechanisms and catalyst deactivation," Applied Catalysis B: Environmental, vol. 238, pp. 346-357, 2018/12/15/ 2018, doi: https://doi.org/10.1016/i.apcatb.2018.07.016.

[120] Z. Abu El-Rub, E. A. Bramer, and G. Brem, "Review of Catalysts for Tar Elimination in Biomass Gasification Process," Industrial \& Engineering Chemistry Research - IND ENG CHEM RES, vol. 43, 09/25 2004, doi: 10.1021/ie0498403.

[121] H. Nam, S. C. Capareda, N. Ashwath, and J. Kongkasawan, "Experimental investigation of pyrolysis of rice straw using bench-scale auger, batch and fluidized bed reactors," Energy, vol. 93, pp. 2384-2394, 2015/12/15/ 2015, doi: https://doi.org/10.1016/i.energy.2015.10.028.

[122] C. E. Greenhalf, D. J. Nowakowski, A. B. Harms, J. O. Titiloye, and A. V. Bridgwater, "Sequential pyrolysis of willow SRC at low and high heating rates - Implications for selective pyrolysis," Fuel, vol. 93, pp. 692-702, 2012/03/01/ 2012, doi: https://doi.org/10.1016/i.fuel.2011.11.050.

[123] M. Olazar, M. J. San Jose, A. T. Aguayo, J. M. Arandes, and J. Bilbao, "Stable operation conditions for gas-solid contact regimes in conical spouted beds," Industrial \& Engineering Chemistry Research, vol. 31, no. 7, pp. 1784-1792, 1992/07/01 1992, doi: 10.1021/ie00007a025.

[124] M. Olazar, M. J. San José, A. T. Aguayo, J. M. Arandes, and J. Bilbao, "Pressure drop in conical spouted beds," The Chemical Engineering Journal, vol. 51, no. 1, pp. 53-60, 1993/02/01/ 1993, doi: https://doi.org/10.1016/0300-9467(93)80008-C.

[125] M. Olazar, M. J. San José, F. J. Peñas, A. T. Aguyo, J. M. Arandes, and J. Bilbao, "A model for gas flow in jet spouted beds," The Canadian Journal of Chemical Engineering, vol. 71 , no. 2, pp. 189-194, 1993, doi: https://doi.org/10.1002/cice.5450710204.

[126] I. Hita, M. Arabiourrutia, M. Olazar, J. Bilbao, J. M. Arandes, and P. Castaño, "Opportunities and barriers for producing high quality fuels from the pyrolysis of scrap tires," Renewable and Sustainable Energy Reviews, vol. 56, pp. 745-759, 2016/04/01/2016, doi: https://doi.org/10.1016/j.rser.2015.11.081.

[127] P. T. Williams and S. Besler, "The influence of temperature and heating rate on the slow pyrolysis of biomass," Renewable Energy, vol. 7, no. 3, pp. 233-250, 1996/03/01/ 1996, doi: https://doi.org/10.1016/0960-1481(96)00006-7.

[128] T. Aysu and M. M. Küçük, "Biomass pyrolysis in a fixed-bed reactor: Effects of pyrolysis parameters on product yields and characterization of products," Energy, vol. 64, pp. 1002-1025, 2014/01/01/ 2014, doi: https://doi.org/10.1016/i.energy.2013.11.053.

[129] M. Z. Stummann et al., "Hydrogen assisted catalytic biomass pyrolysis. Effect of temperature and pressure," Biomass and Bioenergy, vol. 115, pp. 97-107, 2018/08/01/ 2018, doi: https://doi.org/10.1016/i.biombioe.2018.04.012.

[130] A. K. Varma, L. S. Thakur, R. Shankar, and P. Mondal, "Pyrolysis of wood sawdust: Effects of process parameters on products yield and characterization of products," Waste Management, vol. 89, pp. 224-235, 2019/04/15/ 2019, doi: https://doi.org/10.1016/j.wasman.2019.04.016. 
[131] D. J. Daniel et al., "An evaluative comparison of lignocellulosic pyrolysis products derived from various parts of Populus deltoides trees and Panicum virgatum grass in an inductively heated reactor," Energy Conversion and Management, vol. 171, pp. 710-720, 2018/09/01/ 2018, doi: https://doi.org/10.1016/i.enconman.2018.06.026.

[132] R. K. Singh and K. P. Shadangi, "Liquid fuel from castor seeds by pyrolysis," Fuel, vol. 90, no. 7, pp. 2538-2544, 2011/07/01/ 2011, doi: https://doi.org/10.1016/i.fuel.2011.03.015.

[133] M. A. Kader, M. R. Islam, M. Parveen, H. Haniu, and K. Takai, "Pyrolysis decomposition of tamarind seed for alternative fuel," Bioresource Technology, vol. 149, pp. 1-7, 2013/12/01/ 2013, doi: https://doi.org/10.1016/i.biortech.2013.09.032.

[134] O. Onay, "Influence of pyrolysis temperature and heating rate on the production of bio-oil and char from safflower seed by pyrolysis, using a well-swept fixed-bed reactor," Fuel Processing Technology, vol. 88, no. 5, pp. 523-531, 2007/05/01/ 2007, doi: https://doi.org/10.1016/j.fuproc.2007.01.001.

[135] M. A. Sokoto, B. Biswas, J. Kumar, and T. Bhaskar, "Slow pyrolysis of Defatted Seeds Cakes of African star apple and silk cotton for production of bio-oil," Renewable Energy, vol. 146, pp. 1710-1716, 2020/02/01/ 2020, doi: https://doi.org/10.1016/i.renene.2019.07.145.

[136] S. Gupta, G. K. Gupta, and M. K. Mondal, "Slow pyrolysis of chemically treated walnut shell for valuable products: Effect of process parameters and in-depth product analysis," Energy, vol. 181, pp. 665-676, 2019/08/15/ 2019, doi: https://doi.org/10.1016/i.energy.2019.05.214.

[137] I. A. Nehdi, H. M. Sbihi, and S. I. Al-Resayes, "Rhazya stricta Decne seed oil as an alternative, non-conventional feedstock for biodiesel production," Energy Conversion and Management, vol. 81, pp. 400-406, 2014/05/01/ 2014, doi: https://doi.org/10.1016/i.enconman.2014.02.038.

[138] W. Cai, R. Liu, Y. He, M. Chai, and J. Cai, "Bio-oil production from fast pyrolysis of rice husk in a commercial-scale plant with a downdraft circulating fluidized bed reactor," Fuel Processing Technology, vol. 171, pp. 308-317, 2018/03/01/ 2018, doi: https://doi.org/10.1016/i.fuproc.2017.12.001.

[139] W.-C. Wang and J.-J. Jan, "From laboratory to pilot: Design concept and technoeconomic analyses of the fluidized bed fast pyrolysis of biomass," Energy, vol. 155, pp. 139-151, 2018/07/15/ 2018, doi: https://doi.org/10.1016/j.energy.2018.05.012.

[140] Y. Hu et al., "Co-pyrolysis and co-hydrothermal liquefaction of seaweeds and rice husk: Comparative study towards enhanced biofuel production," Journal of Analytical and Applied Pyrolysis, vol. 129, pp. 162-170, 2018/01/01/2018, doi: https://doi.org/10.1016/i.jaap.2017.11.016.

[141] N. Gautam and A. Chaurasia, "Study on kinetics and bio-oil production from rice husk, rice straw, bamboo, sugarcane bagasse and neem bark in a fixed-bed pyrolysis process," Energy, vol. 190, p. 116434, 2020/01/01/ 2020, doi: https://doi.org/10.1016/i.energy.2019.116434.

[142] F. R. Vieira, C. M. Romero Luna, G. L. A. F. Arce, and I. Ávila, "Optimization of slow pyrolysis process parameters using a fixed bed reactor for biochar yield from rice husk," Biomass and Bioenergy, vol. 132, p. 105412, 2020/01/01/ 2020, doi: https://doi.org/10.1016/i.biombioe.2019.105412.

[143] M. Z. Farooq, M. Zeeshan, S. Iqbal, N. Ahmed, and S. A. Y. Shah, "Influence of waste tire addition on wheat straw pyrolysis yield and oil quality," Energy, vol. 144, pp. 200206, 2018/02/01/2018, doi: https://doi.org/10.1016/i.energy.2017.12.026.

[144] M. Carrier, T. Hugo, J. Gorgens, and H. Knoetze, "Comparison of slow and vacuum pyrolysis of sugar cane bagasse," Journal of Analytical and Applied Pyrolysis, vol. 90, 
no. $1, \quad$ pp. 18-26, 2011/01/01/ 2011, doi: https://doi.org/10.1016/i.jaap.2010.10.001.

[145] A. López Ortiz et al., "Low temperature sugar cane bagasse pyrolysis for the production of high purity hydrogen through steam reforming and $\mathrm{CO} 2$ capture," International Journal of Hydrogen Energy, vol. 38, no. 28, pp. 12580-12588, 2013/09/19/ 2013, doi: https://doi.org/10.1016/j.ijhydene.2013.06.059.

[146] J. M. Mesa-Perez, L. A. B. Cortez, J. D. Rocha, L. E. Brossard-Perez, and E. OlivaresGómez, "Unidimensional heat transfer analysis of elephant grass and sugar cane bagasse slow pyrolysis in a fixed bed reactor," Fuel Processing Technology, vol. 86, no. 5, pp. 565-575, 2005/02/25/ 2005, doi: https://doi.org/10.1016/i.fuproc.2004.05.014.

[147] J. M. Mesa-Pérez, J. D. Rocha, L. A. Barbosa-Cortez, M. Penedo-Medina, C. A. Luengo, and E. Cascarosa, "Fast oxidative pyrolysis of sugar cane straw in a fluidized bed reactor," Applied Thermal Engineering, vol. 56, no. 1, pp. 167-175, 2013/07/01/ 2013, doi: https://doi.org/10.1016/j.applthermaleng.2013.03.017.

[148] G. F. David, O. R. Justo, V. H. Perez, and M. Garcia-Perez, "Thermochemical conversion of sugarcane bagasse by fast pyrolysis: High yield of levoglucosan production," Journal of Analytical and Applied Pyrolysis, vol. 133, pp. 246-253, 2018/08/01/ 2018, doi: https://doi.org/10.1016/i.jaap.2018.03.004.

[149] R. Zhao, X. Wang, L. Liu, P. Li, and L. Tian, "Slow pyrolysis characteristics of bamboo subfamily evaluated through kinetics and evolved gases analysis," Bioresource Technology, vol. 289, p. 121674, 2019/10/01/ 2019, doi: https://doi.org/10.1016/j.biortech.2019.121674.

[150] R. V. S. Silva, V. B. Pereira, K. T. Stelzer, T. A. Almeida, G. A. Romeiro, and D. A. Azevedo, "Comprehensive study of the liquid products from slow pyrolysis of crambe seeds: Bio-oil and organic compounds of the aqueous phase," Biomass and Bioenergy, vol. 123, pp. 78-88, 2019/04/01/ 2019, doi: https://doi.org/10.1016/j.biombioe.2019.02.014.

[151] S. Yu, J. Park, M. Kim, C. Ryu, and J. Park, "Characterization of biochar and byproducts from slow pyrolysis of hinoki cypress," Bioresource Technology Reports, vol. 6, pp. 217-222, 2019/06/01/ 2019, doi: https://doi.org/10.1016/j.biteb.2019.03.009.

[152] X. Yang, W. Ng, B. S. E. Wong, G. H. Baeg, C.-H. Wang, and Y. S. Ok, "Characterization and ecotoxicological investigation of biochar produced via slow pyrolysis: Effect of feedstock composition and pyrolysis conditions," Journal of Hazardous Materials, vol. 365, pp. 178-185, 2019/03/05/ 2019, doi: https://doi.org/10.1016/j.jhazmat.2018.10.047.

[153] E. Amini, M.-S. Safdari, J. T. DeYoung, D. R. Weise, and T. H. Fletcher, "Characterization of pyrolysis products from slow pyrolysis of live and dead vegetation native to the southern United States," Fuel, vol. 235, pp. 1475-1491, 2019/01/01/2019, doi: https://doi.org/10.1016/i.fuel.2018.08.112.

[154] O. Sanahuja-Parejo et al., "Catalytic co-pyrolysis of grape seeds and waste tyres for the production of drop-in biofuels," Energy Conversion and Management, vol. 171, pp. 1202-1212, 2018/09/01/ 2018, doi: https://doi.org/10.1016/i.enconman.2018.06.053.

[155] A. Ben Hassen Trabelsi, K. Zaafouri, W. Baghdadi, S. Naoui, and A. Ouerghi, "Second generation biofuels production from waste cooking oil via pyrolysis process," Renewable Energy, vol. 126, pp. 888-896, 2018/10/01/ 2018, doi: https://doi.org/10.1016/j.renene.2018.04.002.

[156] H. H. Sait, A. Hussain, A. A. Salema, and F. N. Ani, "Pyrolysis and combustion kinetics of date palm biomass using thermogravimetric analysis," Bioresource Technology, 
vol. 118, pp. 382-389, 2012/08/01/ 2012, doi: https://doi.org/10.1016/i.biortech.2012.04.081.

[157] S. Sulaiman, H. Bamufleh, s. Tamili, M. Inayat, and M. Naz, "Characterization of date palm fronds as a fuel for energy production," Bulletin of the Chemical Society of Ethiopia, vol. 30, p. 465, 01/14 2017, doi: 10.4314/bcse.v30i3.15.

[158] NREL/TP-510-42618, Determination of Structural Carbohydrates and Lignin in Biomass, Colorado, U.S.A.

[159] A. M. Poulose et al., "Date palm biochar-polymer composites: An investigation of electrical, mechanical, thermal and rheological characteristics," Science of The Total Environment, vol. 619-620, pp. 311-318, 2018/04/01/ 2018, doi: https://doi.org/10.1016/i.scitotenv.2017.11.076.

[160] J. Mabrouki, K. Guedri, M. A. Abbassi, A. Omri, and M. Jeguirim, "Simulation of the fast pyrolysis of Tunisian biomass feedstocks for bio-fuel production," Comptes Rendus Chimie, vol. 19, no. 4, pp. 466-474, 2016/04/01/ 2016, doi: https://doi.org/10.1016/i.crci.2015.09.020.

[161] K. M. Qureshi, F. Abnisa, and W. M. A. Wan Daud, "Novel helical screw-fluidized bed reactor for bio-oil production in slow-pyrolysis mode: A preliminary study," Journal of Analytical and Applied Pyrolysis, vol. 142, p. 104605, 2019/09/01/ 2019, doi: https://doi.org/10.1016/i.jaap.2019.04.021.

[162] M. Jouiad, N. Al-Nofeli, N. Khalifa, F. Benyettou, and L. F. Yousef, "Characteristics of slow pyrolysis biochars produced from rhodes grass and fronds of edible date palm," Journal of Analytical and Applied Pyrolysis, vol. 111, pp. 183-190, 2015/01/01/ 2015, doi: https://doi.org/10.1016/i.jaap.2014.10.024.

[163] A. Giwa, A. Yusuf, O. Ajumobi, and P. Dzidzienyo, "Pyrolysis of date palm waste to biochar using concentrated solar thermal energy: Economic and sustainability implications," Waste Management, vol. 93, pp. 14-22, 2019/06/15/ 2019, doi: https://doi.org/10.1016/i.wasman.2019.05.022.

[164] G. Kabir, A. T. Mohd Din, and B. H. Hameed, "Pyrolysis of oil palm mesocarp fiber and palm frond in a slow-heating fixed-bed reactor: A comparative study," Bioresource Technology, vol. 241, pp. 563-572, 2017/10/01/ 2017, doi: https://doi.org/10.1016/j.biortech.2017.05.180.

[165] O. Onay and O. M. Kockar, "Slow, fast and flash pyrolysis of rapeseed," Renewable Energy, vol. 28, no. 15, pp. 2417-2433, 2003/12/01/ 2003, doi: https://doi.org/10.1016/S0960-1481(03)00137-X.

[166] C. Acıkgoz, O. Onay, and O. M. Kockar, "Fast pyrolysis of linseed: product yields and compositions," Journal of Analytical and Applied Pyrolysis, vol. 71, no. 2, pp. 417429, 2004/06/01/2004, doi: https://doi.org/10.1016/S0165-2370(03)00124-4.

[167] S. Uçar and S. Karagöz, "The slow pyrolysis of pomegranate seeds: The effect of temperature on the product yields and bio-oil properties," Journal of Analytical and Applied Pyrolysis, vol. 84, no. 2, pp. 151-156, 2009/03/01/ 2009, doi: https://doi.org/10.1016/i.jaap.2009.01.005.

[168] K. Alper, K. Tekin, and S. Karagöz, "Pyrolysis of agricultural residues for bio-oil production," Clean Technologies and Environmental Policy, vol. 17, 05/16 2014, doi: 10.1007/s10098-014-0778-8.

[169] G. Duman, C. Okutucu, S. Uçar, R. Stahl, and J. Yanik, "The slow and fast pyrolysis of cherry seed," Bioresource technology, vol. 102, pp. 1869-78, 01/31 2011, doi: 10.1016/j.biortech.2010.07.051.

[170] K. Senelwa and R. E. H. Sims, "Fuel characteristics of short rotation forest biomass," Biomass and Bioenergy, vol. 17, no. 2, pp. 127-140, 1999/08/01/ 1999, doi: https://doi.org/10.1016/S0961-9534(99)00035-5. 
[171] R. A. Nasser, and Aref, I. M., "Fuelwood characteristics of six acacia species growing wild in the southwest of Saudi Arabia as affected by geographical location," BioResource vol. 9, pp. 1212-1224, 2014.

[172] R. Kataki and D. Konwer, "Fuelwood characteristics of indigenous tree species of north-east India," Biomass and Bioenergy, vol. 22, no. 6, pp. 433-437, 2002/06/01/ 2002, doi: https://doi.org/10.1016/S0961-9534(02)00026-0.

[173] T. Yuan, A. Tahmasebi, and J. Yu, "Comparative study on pyrolysis of lignocellulosic and algal biomass using a thermogravimetric and a fixed-bed reactor," Bioresource Technology, vol. 175, pp. 333-341, 2015/01/01/ 2015, doi: https://doi.org/10.1016/i.biortech.2014.10.108.

[174] T. Aysu, H. Durak, S. Güner, A. Ş. Bengü, and N. Esim, "Bio-oil production via catalytic pyrolysis of Anchusa azurea: Effects of operating conditions on product yields and chromatographic characterization," Bioresource Technology, vol. 205, pp. 7-14, 2016/04/01/ 2016, doi: https://doi.org/10.1016/i.biortech.2016.01.015.

[175] N. Abdullah and H. Gerhauser, "Bio-oil derived from empty fruit bunches," Fuel, vol. 87 , no. 12, pp. 2606-2613, 2008/09/01/ 2008, doi: https://doi.org/10.1016/i.fuel.2008.02.011.

[176] R. Khiari, E. Mauret, N. Belgacem, and M. F. Mhenni, "Tunisian date palm rachis used as an alternative source of fibers or papermaking applications," Bioresources, vol. 6, pp. 265-281, 02/01 2011.

[177] R. Nasser, "Physical and Mechanical Properties of Three-Layer Particleboard Manufactured from the Tree Pruning of Seven Wood Species," World Applied Sciences Journal, vol. 19, pp. 741-753, 01/01 2012, doi: 10.5829/idosi.wasj.2012.19.05.2764.

[178] D. Feldman, "Wood-chemistry, ultrastructure, reactions, by D. Fengel and G. Wegener, Walter de Gruyter, Berlin and New York, 1984, 613 pp. Price: 245 DM," Journal of Polymer Science: Polymer Letters Edition, vol. 23, no. 11, pp. 601-602, 1985, doi: 10.1002/pol.1985.130231112.

[179] I. Aref, R. Nasser, I. Ali, H. Al-Mefarrej, and S. Al-Zahrani, "Effects of aqueous extraction on the performance and properties of polypropylene/wood composites from Phoenix dactylifera and Acacia tortilis wood," Journal of Reinforced Plastics and Composites, vol. 32, pp. 476-489, 04/01 2013, doi: 10.1177/0731684412454462.

[180] T. Cordero, F. Marquez, J. Rodriguez-Mirasol, and J. J. Rodriguez, "Predicting heating values of lignocellulosics and carbonaceous materials from proximate analysis," Fuel, vol. 80, no. 11, pp. 1567-1571, 2001/09/01/ 2001, doi: https://doi.org/10.1016/S0016-2361(01)00034-5.

[181] R. García, C. Pizarro, A. G. Lavín, and J. L. Bueno, "Characterization of Spanish biomass wastes for energy use," Bioresource Technology, vol. 103, no. 1, pp. 249258, 2012/01/01/ 2012, doi: https://doi.org/10.1016/j.biortech.2011.10.004.

[182] C. Telmo, J. Lousada, and N. Moreira, "Proximate analysis, backwards stepwise regression between gross calorific value, ultimate and chemical analysis of wood," Bioresource Technology, vol. 101, no. 11, pp. 3808-3815, 2010/06/01/2010, doi: https://doi.org/10.1016/i.biortech.2010.01.021.

[183] R. Briones, L. Serrano, R. B. Younes, I. Mondragon, and J. Labidi, "Polyol production by chemical modification of date seeds," Industrial Crops and Products, vol. 34, no. 1, pp. 1035-1040, 2011/07/01/ 2011, doi: https://doi.org/10.1016/j.indcrop.2011.03.012.

[184] L. Zhang, R. Liu, R. Yin, and Y. Mei, "Upgrading of bio-oil from biomass fast pyrolysis in China: A review," Renewable and Sustainable Energy Reviews, vol. 24, pp. 66-72, 2013/08/01/ 2013, doi: https://doi.org/10.1016/j.rser.2013.03.027. 
[185] B. H. A. Sluiter, D. Hyman, C. Payne,, C. S. R. Ruiz, J. Sluiter, D. Templeton,, and a. J. Wolfe, "Determination of Total Solids in Biomass and Total Dissolved Solids in Liquid Process Samples: Laboratory Analytical Procedure (LAP) " National Renewable Energy Laboratory (NREL), NREL/TP-510-42621, 31/3/2008 2008. [Online]. Available: https://www.nrel.gov/docs/gen/fy08/42621.pdf

[186] J. Pazó, E. Granada, Á. Saavedra, D. Patiño, and J. Collazo, "Heterogenic Solid Biofuel Sampling Methodology and Uncertainty Associated with Prompt Analysis," International journal of molecular sciences, vol. 11, pp. 2118-33, 05/01 2010, doi: 10.3390/ijms11052118.

[187] T. E. Odetoye, S. F. Ibarhiam, and J. O. Titiloye, "Thermochemical Characterization of Biomass Residues and Wastes for Bioenergy," in Valorization of Biomass to ValueAdded Commodities: Current Trends, Challenges, and Future Prospects, M. O. Daramola and A. O. Ayeni Eds. Cham: Springer International Publishing, 2020, pp. 93100.

[188] Y. D. Singh, P. Mahanta, and U. Bora, "Comprehensive characterization of lignocellulosic biomass through proximate, ultimate and compositional analysis for bioenergy production," Renewable Energy, vol. 103, pp. 490-500, 2017/04/01/ 2017, doi: https://doi.org/10.1016/j.renene.2016.11.039.

[189] C.-Y. Yin, "Prediction of higher heating values of biomass from proximate and ultimate analyses," Fuel, vol. 90, no. 3, pp. 1128-1132, 2011/03/01/ 2011, doi: https://doi.org/10.1016/j.fuel.2010.11.031.

[190] G. Papaspiropoulos, B. Mentes, P. Kristiansson, and B. G. Martinsson, "A high sensitivity elemental analysis methodology for upper tropospheric aerosol," Nuclear Instruments and Methods in Physics Research Section B: Beam Interactions with Materials and Atoms, vol. 150, no. 1, pp. 356-362, 1999/04/02/ 1999, doi: https://doi.org/10.1016/S0168-583X(98)01082-9.

[191] P. J. Van Soest, J. B. Robertson, and B. A. Lewis, "Methods for Dietary Fiber, Neutral Detergent Fiber, and Nonstarch Polysaccharides in Relation to Animal Nutrition," Journal of Dairy Science, vol. 74, no. 10, pp. 3583-3597, 1991/10/01/ 1991, doi: https://doi.org/10.3168/ids.S0022-0302(91)78551-2.

[192] T. Ona, T. Sonoda, M. Shibata, and K. Fukazawa, "Small-Scale Method to Determine the Content of Wood Components From Multiple Eucalyptus Samples," Tappi journal, vol. 78, pp. 121-126, 03/01 1995.

[193] P. Basu, Biomass gasification, pyrolysis and torrefaction: practical design and theory, Second Edition ed. Elsevier, 2013.

[194] A. Demirbaş, "Calculation of higher heating values of biomass fuels," Fuel, vol. 76, no. 5, pp. 431-434, 1997/04/01/ 1997, doi: https://doi.org/10.1016/S00162361(97)85520-2.

[195] D. M. Price, Hourston, D.J. and Dumont, F., "Thermogravimetry of Polymers," in Encyclopedia of Analytical Chemistry, 2006.

[196] O. Doherty, "Catalytic fast pyrolysis of biomass," Master, Aston University CE4011, 2011.

[197] D. S. Yar., Method of Analysis and Assay: Miscellaneous Methods of Analysis. Pharmaceutical Analysis. 2007, pp. 1-14.

[198] Radimeter Analytical SAS. Karl Fischer Volumeteric Titration Theory and Practice. Karl Fisher Titration. 2007, pp. 1-13.

[199] Metrohm Limited. The background of $\mathrm{pH}$ measurement and hints for your daily works. Metrohm ion analysis (no. 1). 1999.

[200] G. Guiochon and C. L. Guillemin, Quantitative Gas Chromatography for Laboratory Analyses and On-Line Process Control. Elsevier Science, 1988. 
[201] J. Akowuah, F. Kemausuor, and S. Mitchual, "Physico-chemical characteristics and market potential of sawdust charcoal briquette," International Journal of Energy and Environmental Engineering, vol. 3, 01/01 2012, doi: 10.1186/2251-6832-3-20.

[202] A. Al-Marzouqi, A. Khaleel, M. Abu-Omar, E. Galiwango, and N. Abdel Rahman, "Estimating Combustion Kinetics of UAE Date Palm tree Biomass using Thermogravimetric Analysis," Journal of Natural Sciences Research, vol. 7, 06/30 2017.

[203] Y. Elmay, G. Trouvé, M. Jeguirim, and R. Said, "Energy recovery of date palm residues in a domestic pellet boiler," Fuel Processing Technology, vol. 112, pp. 12-18, 2013/08/01/2013, doi: https://doi.org/10.1016/i.fuproc.2013.02.015.

[204] A. Hussain, "Pyrolysis Of Saudi Arabian Date Palm Waste: A Viable Option For Converting Waste Into Wealth," Life Science Journal, vol. 11, pp. 667-671, 01/01 2014.

[205] M. Babiker, A. A. R. Aziz, M. R. Heikal, and Y. Suzana, "Pyrolysis Characteristics of Phoenix Dactylifera Date Palm Seeds Using Thermo-Gravimetric Analysis (TGA)," International Journal of Environmental Science and Development, vol. 4, pp. 521-524, 10/01 2013, doi: 10.7763/IJESD.2013.V4.406.

[206] A. Shah, M. J. Darr, D. Dalluge, D. Medic, K. Webster, and R. C. Brown, "Physicochemical properties of bio-oil and biochar produced by fast pyrolysis of stored single-pass corn stover and cobs," Bioresource Technology, vol. 125, pp. 348352, 2012/12/01/ 2012, doi: https://doi.org/10.1016/j.biortech.2012.09.061.

[207] D. Reichel, M. Klinger, S. Krzack, and B. Meyer, "Effect of ash components on devolatilization behavior of coal in comparison with biomass - Product yields, composition, and heating values," Fuel, vol. 114, pp. 64-70, 2013/12/01/ 2013, doi: https://doi.org/10.1016/i.fuel.2013.01.045.

[208] M. Kamruddin, P. K. Ajikumar, S. Dash, A. Tyagi, and B. Raj, "Thermogravimetryevolved gas analysis-mass spectrometry system for materials research," Bulletin of Materials Science, vol. 26, pp. 449-460, 06/01 2003, doi: 10.1007/BF02711191.

[209] V. Sukumar, V. Manieniyan, R. Senthilkumar, and S. Sivaprakasam, "Production of bio oil from sweet lime empty fruit bunch by pyrolysis," Renewable Energy, vol. 146, pp. 309-315, 2020/02/01/ 2020, doi: https://doi.org/10.1016/j.renene.2019.06.156.

[210] W. Cai, Q. Liu, D. Shen, and J. Wang, "Py-GC/MS analysis on product distribution of two-staged biomass pyrolysis," Journal of Analytical and Applied Pyrolysis, vol. 138, pp. 62-69, 2019/03/01/2019, doi: https://doi.org/10.1016/j.jaap.2018.12.007.

[211] J. P. Polin, C. A. Peterson, L. E. Whitmer, R. G. Smith, and R. C. Brown, "Process intensification of biomass fast pyrolysis through autothermal operation of a fluidized bed reactor," Applied Energy, vol. 249, pp. 276-285, 2019/09/01/ 2019, doi: https://doi.org/10.1016/i.apenergy.2019.04.154.

[212] K. B. Ansari and V. G. Gaikar, "Investigating production of hydrocarbon rich bio-oil from grassy biomass using vacuum pyrolysis coupled with online deoxygenation of volatile products over metallic iron," Renewable Energy, vol. 130, pp. 305-318, 2019/01/01/2019, doi: https://doi.org/10.1016/j.renene.2018.06.052.

[213] A. Korshunov et al., "Pyrolysis characteristics of biomass torrefied in a quiescent mineral layer," Energy, vol. 187, p. 116015, 2019/11/15/ 2019, doi: https://doi.org/10.1016/i.energy.2019.116015.

[214] M. I. Al-Wabel, M. I. Rafique, M. Ahmad, M. Ahmad, A. Hussain, and A. R. A. Usman, "Pyrolytic and hydrothermal carbonization of date palm leaflets: Characteristics and ecotoxicological effects on seed germination of lettuce," Saudi Journal of Biological Sciences, vol. 26, no. 4, pp. 665-672, 2019/05/01/ 2019, doi: https://doi.org/10.1016/i.sjbs.2018.05.017. 
[215] A. S. Alsewaileh, A. R. Usman, and M. I. Al-Wabel, "Effects of pyrolysis temperature on nitrate-nitrogen ( $\mathrm{NO}^{--\mathrm{N}}$ ) and bromate (BrO3-) adsorption onto date palm biochar," Journal of Environmental Management, vol. 237, pp. 289-296, 2019/05/01/ 2019, doi: https://doi.org/10.1016/i.jenvman.2019.02.045.

[216] H. H. Sait and A. A. Salema, "Microwave dielectric characterization of Saudi Arabian date palm biomass during pyrolysis and at industrial frequencies," Fuel, vol. 161, pp. 239-247, 2015/12/01/ 2015, doi: https://doi.org/10.1016/j.fuel.2015.08.058.

[217] A. R. A. Usman et al., "Biochar production from date palm waste: Charring temperature induced changes in composition and surface chemistry," Journal of Analytical and Applied Pyrolysis, vol. 115, pp. 392-400, 2015/09/01/ 2015, doi: https://doi.org/10.1016/i.jaap.2015.08.016.

[218] M. Nurul Islam, R. Zailani, and F. Nasir Ani, "Pyrolytic oil from fluidised bed pyrolysis of oil palm shell and itscharacterisation," Renewable Energy, vol. 17, no. 1, pp. 7384, 1999/05/01/ 1999, doi: https://doi.org/10.1016/S0960-1481(98)00112-8.

[219] R. Bet Sarkis and V. Zare, "Proposal and analysis of two novel integrated configurations for hybrid solar-biomass power generation systems: Thermodynamic and economic evaluation," Energy Conversion and Management, vol. 160, pp. 411425, 2018/03/15/ 2018, doi: https://doi.org/10.1016/i.enconman.2018.01.061.

[220] S. Anvari, S. Khalilarya, and V. Zare, "Power generation enhancement in a biomassbased combined cycle using solar energy: Thermodynamic and environmental analysis," Applied Thermal Engineering, vol. 153, pp. 128-141, 2019/05/05/ 2019, doi: https://doi.org/10.1016/i.applthermaleng.2019.02.112.

[221] C. Ghenai and I. Janajreh, "Design of Solar-Biomass Hybrid Microgrid System in Sharjah," Energy Procedia, vol. 103, pp. 357-362, 2016/12/01/ 2016, doi: https://doi.org/10.1016/i.egypro.2016.11.299.

[222] J. D. Nixon, P. K. Dey, and P. A. Davies, "The feasibility of hybrid solar-biomass power plants in India," Energy, vol. 46, no. 1, pp. 541-554, 2012/10/01/ 2012, doi: https://doi.org/10.1016/i.energy.2012.07.058.

[223] R. Soria, J. Portugal-Pereira, A. Szklo, R. Milani, and R. Schaeffer, "Hybrid concentrated solar power (CSP)-biomass plants in a semiarid region: A strategy for CSP deployment in Brazil," Energy Policy, vol. 86, pp. 57-72, 2015/11/01/ 2015, doi: https://doi.org/10.1016/i.enpol.2015.06.028.

[224] J. H. Peterseim, S. White, A. Tadros, and U. Hellwig, "Concentrating solar power hybrid plants - Enabling cost effective synergies," Renewable Energy, vol. 67, pp. 178-185, 2014/07/01/2014, doi: https://doi.org/10.1016/j.renene.2013.11.037.

[225] J. H. Peterseim, A. Herr, S. Miller, S. White, and D. A. O'Connell, "Concentrating solar power/alternative fuel hybrid plants: Annual electricity potential and ideal areas in Australia," Energy, vol. 68, pp. 698-711, 2014/04/15/ 2014, doi: https://doi.org/10.1016/i.energy.2014.02.068.

[226] J. H. Peterseim, A. Tadros, S. White, U. Hellwig, J. Landler, and K. Galang, "Solar Tower-biomass Hybrid Plants - Maximizing Plant Performance," Energy Procedia, vol. 49, pp. 1197-1206, 2014/01/01/ 2014, doi: https://doi.org/10.1016/i.egypro.2014.03.129.

[227] C. M. I. Hussain, B. Norton, and A. Duffy, "Technological assessment of different solar-biomass systems for hybrid power generation in Europe," Renewable and Sustainable Energy Reviews, vol. 68, pp. 1115-1129, 2017/02/01/ 2017, doi: https://doi.org/10.1016/i.rser.2016.08.016.

[228] A. A. A. Cot, J. Vall-Llovera, J. Aguilo, J.M. Arque, "Termosolar borges: a thermosolar hybrid plant with biomass," presented at the Third Int. Symp. Energy from Biomass Waste, Venice, Italy, 2010. 
[229] V. V. Tyagi, N. A. A. Rahim, N. A. Rahim, and J. A. L. Selvaraj, "Progress in solar PV technology: Research and achievement," Renewable and Sustainable Energy Reviews, vol. 20, pp. 443-461, 2013/04/01/ 2013, doi: https://doi.org/10.1016/i.rser.2012.09.028.

[230] J. Hernández-Moro and J. M. Martínez-Duart, "Analytical model for solar PV and CSP electricity costs: Present LCOE values and their future evolution," Renewable and Sustainable Energy Reviews, vol. 20, pp. 119-132, 2013/04/01/ 2013, doi: https://doi.org/10.1016/i.rser.2012.11.082.

[231] C. Tzivanidis, E. Bellos, and K. A. Antonopoulos, "Energetic and financial investigation of a stand-alone solar-thermal Organic Rankine Cycle power plant," Energy Conversion and Management, vol. 126, pp. 421-433, 2016/10/15/ 2016, doi: https://doi.org/10.1016/j.enconman.2016.08.033.

[232] O. Aboelwafa, S.-E. K. Fateen, A. Soliman, and I. M. Ismail, "A review on solar Rankine cycles: Working fluids, applications, and cycle modifications," Renewable and Sustainable Energy Reviews, vol. 82, pp. 868-885, 2018/02/01/ 2018, doi: https://doi.org/10.1016/i.rser.2017.09.097.

[233] O. Behar, "Solar thermal power plants - A review of configurations and performance comparison," Renewable and Sustainable Energy Reviews, vol. 92, pp. 608-627, 2018/09/01/2018, doi: https://doi.org/10.1016/i.rser.2018.04.102.

[234] M. T. Islam, N. Huda, A. B. Abdullah, and R. Saidur, "A comprehensive review of stateof-the-art concentrating solar power (CSP) technologies: Current status and research trends," Renewable and Sustainable Energy Reviews, vol. 91, pp. 987-1018, 2018/08/01/ 2018, doi: https://doi.org/10.1016/j.rser.2018.04.097.

[235] M. Balghouthi, S. E. Trabelsi, M. B. Amara, A. B. H. Ali, and A. Guizani, "Potential of concentrating solar power (CSP) technology in Tunisia and the possibility of interconnection with Europe," Renewable and Sustainable Energy Reviews, vol. 56, pp. 1227-1248, 2016/04/01/ 2016, doi: https://doi.org/10.1016/i.rser.2015.12.052.

[236] O. Behar, A. Khellaf, and K. Mohammedi, "A review of studies on central receiver solar thermal power plants," Renewable and Sustainable Energy Reviews, vol. 23, pp. 12-39, 2013/07/01/ 2013, doi: https://doi.org/10.1016/i.rser.2013.02.017.

[237] E. M. A. Mokheimer, Y. N. Dabwan, and M. A. Habib, "Optimal integration of solar energy with fossil fuel gas turbine cogeneration plants using three different CSP technologies in Saudi Arabia," Applied Energy, vol. 185, pp. 1268-1280, 2017/01/01/ 2017, doi: https://doi.org/10.1016/j.apenergy.2015.12.029.

[238] Y. Zhu et al., "Optimization of solar aided coal-fired power plant layouts using multicriteria assessment," Applied Thermal Engineering, vol. 137, pp. 406-418, 2018/06/05/ 2018, doi: https://doi.org/10.1016/j.applthermaleng.2018.03.093.

[239] S. E. Trabelsi, L. Qoaider, and A. Guizani, "Investigation of using molten salt as heat transfer fluid for dry cooled solar parabolic trough power plants under desert conditions," Energy Conversion and Management, vol. 156, pp. 253-263, 2018/01/15/ 2018, doi: https://doi.org/10.1016/i.enconman.2017.10.101.

[240] S. Polimeni, M. Binotti, L. Moretti, and G. Manzolini, "Comparison of sodium and KCl$\mathrm{MgCl} 2$ as heat transfer fluids in CSP solar tower with sCO2 power cycles," Solar Energy, vol. 162, pp. 510-524, 2018/03/01/ 2018, doi: https://doi.org/10.1016/i.solener.2018.01.046.

[241] M. Abbas, Z. Belgroun, H. Aburidah, and N. K. Merzouk, "Assessment of a Solar Parabolic Trough Power Plant for Electricity Generation under Mediterranean and Arid Climate Conditions in Algeria," Energy Procedia, vol. 42, pp. 93-102, 2013/01/01/ 2013, doi: https://doi.org/10.1016/i.egypro.2013.11.009.

[242] M. Abbas, B. Boumeddane, N. Said, and A. Chikouche, "Dish Stirling technology: A $100 \mathrm{MW}$ solar power plant using hydrogen for Algeria," International Journal of 
Hydrogen Energy, vol. 36, no. 7, pp. 4305-4314, 2011/04/01/ 2011, doi: https://doi.org/10.1016/j.ijhydene.2010.12.114.

[243] E. M. A. Mokheimer, Y. N. Dabwan, M. A. Habib, S. A. M. Said, and F. A. Al-Sulaiman, "Techno-economic performance analysis of parabolic trough collector in Dhahran, Saudi Arabia," Energy Conversion and Management, vol. 86, pp. 622-633, 2014/10/01/ 2014, doi: https://doi.org/10.1016/i.enconman.2014.06.023.

[244] T. E. Boukelia, M. S. Mecibah, B. N. Kumar, and K. S. Reddy, "Investigation of solar parabolic trough power plants with and without integrated TES (thermal energy storage) and FBS (fuel backup system) using thermic oil and solar salt," Energy, vol. 88, pp. 292-303, 2015/08/01/ 2015, doi: https://doi.org/10.1016/i.energy.2015.05.038.

[245] V. Poghosyan and M. I. Hassan, "Techno-economic assessment of substituting natural gas based heater with thermal energy storage system in parabolic trough concentrated solar power plant," Renewable Energy, vol. 75, pp. 152-164, 2015/03/01/ 2015, doi: https://doi.org/10.1016/j.renene.2014.09.025.

[246] M. Ashouri, A. M. Khoshkar Vandani, M. Mehrpooya, M. H. Ahmadi, and A. Abdollahpour, "Techno-economic assessment of a Kalina cycle driven by a parabolic Trough solar collector," Energy Conversion and Management, vol. 105, pp. 13281339, 2015/11/15/ 2015, doi: https://doi.org/10.1016/i.enconman.2015.09.015.

[247] T. E. Boukelia, O. Arslan, and M. S. Mecibah, "ANN-based optimization of a parabolic trough solar thermal power plant," Applied Thermal Engineering, vol. 107, pp. 12101218, 2016/08/25/2016, doi: https://doi.org/10.1016/i.applthermaleng.2016.07.084.

[248] T. E. Boukelia, O. Arslan, and M. S. Mecibah, "Potential assessment of a parabolic trough solar thermal power plant considering hourly analysis: ANN-based approach," Renewable Energy, vol. 105, pp. 324-333, 2017/05/01/ 2017, doi: https://doi.org/10.1016/i.renene.2016.12.081.

[249] S. E. Trabelsi, R. Chargui, L. Qoaider, A. Liqreina, and A. Guizani, "Techno-economic performance of concentrating solar power plants under the climatic conditions of the southern region of Tunisia," Energy Conversion and Management, vol. 119, pp. 203-214, 2016/07/01/2016, doi: https://doi.org/10.1016/j.enconman.2016.04.033.

[250] P. R. P., M. Abdul Baseer, A. Awan, and M. Zubair, "Performance Analysis and Optimization of a Parabolic Trough Solar Power Plant in the Middle East Region," Energies, vol. 11, no. 4, p. 741, 2018. [Online]. Available: http://www.mdpi.com/1996-1073/11/4/741.

[251] M. Abbas, H. Aburideh, Z. Belgroun, Z. Tigrine, and N. K. Merzouk, "Comparative Study of Two Configurations of Solar Tower Power for Electricity Generation in Algeria," Energy Procedia, vol. 62, pp. 337-345, 2014/01/01/ 2014, doi: https://doi.org/10.1016/j.egypro.2014.12.395.

[252] O. Ayadi and I. Alsalhen, "Techno-Economic Assessment of Concentrating Solar Power and Wind Hybridization in Jordan," Journal of Ecological Engineering, journal article vol. 19, no. 2, pp. 16-23, 2018, doi: 10.12911/22998993/81239.

[253] S. Mihoub, A. Chermiti, and H. Beltagy, "Methodology of determining the optimum performances of future concentrating solar thermal power plants in Algeria," Energy, vol. 122, pp. 801-810, 2017/03/01/ 2017, doi: https://doi.org/10.1016/i.energy.2016.12.056.

[254] L. Pari, "Energy production from biomass: the case of Italy," Renewable Energy, vol. 22, no. 1, pp. 21-30, 2001/01/01/ 2001, doi: https://doi.org/10.1016/S09601481(00)00050-1. 
[255] A. Franco and N. Giannini, "Perspectives for the use of biomass as fuel in combined cycle power plants," International Journal of Thermal Sciences, vol. 44, no. 2, pp. 163177, 2005/02/01/2005, doi: https://doi.org/10.1016/i.ijthermalsci.2004.07.005.

[256] S. B. Ferreira and P. Pilidis, "Comparison of Externally Fired and Internal Combustion Gas Turbines Using Biomass Fuel," Journal of Energy Resources Technology, vol. 123, no. 4, pp. 291-296, 2001, doi: 10.1115/1.1413468.

[257] A. V. Bridgwater, A. J. Toft, and J. G. Brammer, "A techno-economic comparison of power production by biomass fast pyrolysis with gasification and combustion," Renewable and Sustainable Energy Reviews, vol. 6, no. 3, pp. 181-246, 2002/09/01/ 2002, doi: https://doi.org/10.1016/S1364-0321(01)00010-7.

[258] F. Evrendilek and C. Ertekin, "Assessing the potential of renewable energy sources in Turkey," Renewable Energy, vol. 28, no. 15, pp. 2303-2315, 2003/12/01/ 2003, doi: https://doi.org/10.1016/S0960-1481(03)00138-1.

[259] M. A. Korobitsyn, P. Jellema, and G. G. Hirs, "Possibilities for gas turbine and waste incinerator integration," Energy, vol. 24, no. 9, pp. 783-793, 1999/09/01/ 1999, doi: https://doi.org/10.1016/S0360-5442(99)00034-1.

[260] M. Villarini, E. Bocci, A. Di Carlo, E. Savuto, and V. Pallozzi, "The Case Study of an Innovative Small Scale Biomass Waste Gasification Heat and Power Plant Contextualized in a Farm," Energy Procedia, vol. 82, pp. 335-342, 2015/12/01/ 2015, doi: https://doi.org/10.1016/i.egypro.2015.11.790.

[261] P. Deborah, V. Francesca, and G. Giuseppe, "Analysis of the environmental impact of a biomass plant for the production of bioenergy," Renewable and Sustainable Energy Reviews, vol. 51, pp. 634-647, 2015/11/01/ 2015, doi: https://doi.org/10.1016/i.rser.2015.06.048.

[262] C. Tagliaferri, S. Evangelisti, R. Clift, and P. Lettieri, "Life cycle assessment of a biomass CHP plant in UK: The Heathrow energy centre case," Chemical Engineering Research and Design, vol. 133, pp. 210-221, 2018/05/01/ 2018, doi: https://doi.org/10.1016/j.cherd.2018.03.022.

[263] A. Paletto, S. Bernardi, E. Pieratti, F. Teston, and M. Romagnoli, "Assessment of environmental impact of biomass power plants to increase the social acceptance of renewable energy technologies," Heliyon, vol. 5, no. 7, p. e02070, 2019/07/01/ 2019, doi: https://doi.org/10.1016/i.heliyon.2019.e02070.

[264] M. Branco-Vieira, D. Costa, T. M. Mata, A. A. Martins, M. A. V. Freitas, and N. S. Caetano, "A life cycle inventory of microalgae-based biofuels production in an industrial plant concept," Energy Reports, vol. 6, pp. 397-402, 2020/02/01/ 2020, doi: https://doi.org/10.1016/j.egyr.2019.08.079.

[265] J. Cardoso, V. Silva, and D. Eusébio, "Techno-economic analysis of a biomass gasification power plant dealing with forestry residues blends for electricity production in Portugal," Journal of Cleaner Production, vol. 212, pp. 741-753, 2019/03/01/ 2019, doi: https://doi.org/10.1016/j.jclepro.2018.12.054.

[266] J. Blondeau, T. Museur, O. Demaude, P. Allard, F. Turoni, and J. Mertens, "Costeffective flexibilisation of an $80 \mathrm{MWe}$ retrofitted biomass power plants: Improved combustion control dynamics using virtual air flow sensors," Case Studies in Thermal Engineering, vol. 21, p. 100680, 2020/10/01/ 2020, doi: https://doi.org/10.1016/i.csite.2020.100680.

[267] M. B. Shemfe, S. Gu, and P. Ranganathan, "Techno-economic performance analysis of biofuel production and miniature electric power generation from biomass fast pyrolysis and bio-oil upgrading," Fuel, vol. 143, pp. 361-372, 2015/03/01/2015, doi: https://doi.org/10.1016/i.fuel.2014.11.078.

[268] E. Ranzi et al., "Chemical Kinetics of Biomass Pyrolysis," Energy \& Fuels, vol. 22, no. 6, pp. 4292-4300, 2008/11/19 2008, doi: 10.1021/ef800551t. 


\section{Appendix A: Publications}

The list below details the publications arising from this study:

1- S. F. Ibarhiam and J. O. Titiloye. Thermochemical characterisation of Date Palm fruit wastes and residues and suitability for thermal conversion via pyrolysis process. Poster presented in the 10th World Congress of Chemical Engineering held in Barcelona (Spain) from 1th to 5th October, 2017.

2- T. E. Odetoye, S. F. Ibarhiam, and J. O. Titiloye, "Thermochemical Characterization of Biomass Residues and Wastes for Bioenergy," in Valorization of Biomass to Value-Added Commodities: Current Trends, Challenges, and Future Prospects, M. O. Daramola and A. O. Ayeni Eds. Cham: Springer International Publishing, 2020, pp. 93-100.

3- S. F. Ibarhiam and J. O. Titiloye. Thermochemical Characterization of Date Palm Fruit Waste and Suitability for Biofuel Production. Prepared and will be submitted for publication in high ranked Journal.

4- S. F. Ibarhiam and J. O. Titiloye. Slow Pyrolysis of Date Palm Fruit Wastes for Bio-oil Production. Prepared and will be submitted for publication in high ranked Journal. 